\title{
Perfil de fatores de risco para doença cardiovascular em amostra de estudo epidemiológico populacional de morbidade psiquiátrica : Estudo São Paulo Megacity
}

\author{
Tese apresentada à Faculdade de Medicina \\ da Universidade de São Paulo para \\ obtenção do título de Doutor em Ciências \\ Programa de Ciências Médicas \\ Área de concentração: Educação e Saúde \\ Orientadora: Profa. Dra. Isabela Judith \\ Martins Benseñor
}

São Paulo 
Dados Internacionais de Catalogação na Publicação (CIP)

Preparada pela Biblioteca da

Faculdade de Medicina da Universidade de São Paulo

Creprodução autorizada pelo autor

Bivanco-Lima, Danielle

Perfil de fatores de risco para doença cardiovascular em amostra de estudo epidemiológico populacional de morbidade psiquiátrica : Estudo São Paulo Megacity / Danielle Bivanco de Lima. -- São Paulo, 2011.

Tese(doutorado)--Faculdade de Medicina da Universidade de São Paulo.

Programa de Ciências Médicas. Área de concentração: Educação e Saúde.

Orientadora: Isabela Judith Martins Benseñor.

Descritores: 1.Doença cardiovascular 2.Fatores de risco 3.Depressão 4.Ansiedade 5.Transtornos do humor 6.Transtornos de ansiedade

USP/FM/DBD-257/11 


\section{Dedicatória}

A Roger e Bruna, meus amores. 



\section{AGRADECIMENTOS}

Em primeiro lugar, agradeço à minha orientadora, Dra Isabela Benseñor, que, além do estímulo intelectual e do ensino contínuo, me ofereceu também todos os tipos de apoio que uma orientanda necessita. Também me proporcionou liberdade para fazer escolhas e seguir no meu ritmo, mas guiando e estimulando sempre! Não há como agradecer tudo o que me proporcionou!

Aproveito para agradecer à Laura Lotufo e Inês Lotufo pelo apoio!

Agradeço enormemente a Simone Topolski, grande amiga, que me ajudou tanto no suporte emocional, como na parte de codificação de questionários. Agradeço à Cristina Helena Ferreira Fonseca Guedes, amigona, que fez de tudo e mais um pouquinho para ajudar nesta tese.

Agradeço a algumas pessoas que me inspiraram a seguir a carreira acadêmica e foram meus maiores modelos de ciência: o meu pai João Rocha de Lima, tio José de Souza Martins, tia Heloísa Helena Martins, Profa. Dra. Rita Barradas, Prof. Dr. Manoel Ribeiro, Prof. Dr. Pedro Paulo Chieffi, Prof. Dr. Mílton de Arruda Martins, Profa. Dra. Iolanda Calvo Tibério, Prof. Dr. Fernando Marcuz Silva e Roger G.R. Guimarães.

Agradeço aos meus grandes amigos, que tornam a vida melhor e mais divertida: Teka, Brunão, Carol, Lécião, Paty, Edi Aschermann, Rubem Dario, Bruna, Bia Passarelli, Tathy Marques, Ale Gonzaga, Ju Martins.

Agradeço a Louise de Toledo Montesanti, grande amiga, médica, mãe e mulher, que me trouxe ao mundo da saúde coletiva e abriu os meus olhos a um mundo muito mais interessante!

Agradeço a Juliana Carvalho Moura, grande amiga, salvadora de corpos e almas, pelo companheirismo, inspirações, conversas estimulantes, cafés e cigarros! Corta sem apego!

Agradeço a Neide Kertzman, grande amiga, companheira, mentora e inspiração na vida diária!

Agradeço a Ana Maria Vannucchi, grande amiga, companhia nos cafés, cigarros, postos de gasolina, caronas e inspirações!

Agradeço ainda à Carla Gianna Luppi, professora do Centro de Saúde Escola Barra Funda "Dr. Alexandre Vranjac", que ouviu minhas lamentações e que me deu inúmeras orientações e bons conselhos.

Agradeço também à Sonia Regina de Almeida e Luzia Martinelli por serem grandes ombros amigos e exemplos de sabedoria e lealdade, diariamente.

Agradeço a todos funcionários e professores do Centro de Saúde Escola Barra Funda "Dr. Alexandre Vranjac" pelo apoio e inspiração, na luta pela universalidade, igualdade, 
equidade e cidadania de todos usuários (e de nós mesmos): vocês são especiais pro mundo!

Agradeço a avó Fifa, que sempre me deu um grande apoio e muito carinho (e muita comida)!

Agradeço muito aos queridos irmãos Rafa e Léo, que cuidaram da Bruna aos domingos, por meses a fio, dividiram o videogame, abraços e mordidas, e ainda por cima, tornaram nossa vida muito mais alegre!

Agradeço demais à minha mãe postiça e "boadrasta” Karlinha, exemplo de mãe, que cuidou tanto de mim e minha família! Sempre!

Agradeço demais a minha querida irmã Luciana, uma das melhores pessoas que conheço, que esteve comigo aos sábados, na coleta de dados, acordando cedo, sempre com bom humor e disposição, e que me ensina diariamente sobre a alegria de viver!

Agradeço até aquele irmão sem vergonha Gabriel, que quase não aparece.

Agradeço muito, muito, muito ao meu pai João e a minha mãe Deble, cientistas e curiosos natos, que me ensinaram quase tudo de importante que sei, que me deram condições de ser quem eu sou e que, além do amor e carinho, me ensinaram que o esforço e a atenção são ferramentas essenciais na vida.

Agradeço fundamentalmente ao meu marido e melhor amigo, Roger Guilherme Rodrigues Guimarães, a melhor pessoa e o melhor pai do mundo, que participou de todas as etapas, desde a coleta de dados aos sábados, da busca de artigos, da leitura do manuscrito e que me deu todo o suporte que alguém poderia ter, me agüentou nos meus mais insuportáveis dias, e ainda assim me inspirou e amou diariamente. Obrigada!

Agradeço a minha filhota linda, minha maior inspiração e motivo de viver: Bruninha. Obrigada por não me deixar viver só de tese!

Agradeço a todos que não estão nomeados aqui, mas que tornaram possível esta batalha e jornada tão querida. 


\section{NORMALIZAÇÃO ADOTADA}

Esta tese está de acordo com as seguintes normas, em vigor no momento desta publicação:

Referências: adaptado de International Commitee of Medical Journals Editors (Vancouver).

Universidade de São Paulo. Faculdade de Medicina. Divisão de Biblioteca e Documentação. Guia de apresentação de dissertações, teses e monografias. Elaborado por Anneliese Carneiro da Cunha, Maria Julia de A.L. Freddi, Maria F. Crestana, Marinalva de Souza Aragão, Suely Campos Cardoso, Valéria Vilhena. 3a ed. São Paulo: Divisão de Biblioteca e Documentação; 2011.

Abreviaturas dos títulos dos periódicos de acordo com List of Journals Indexed in Index Medicus. 



\section{SUMÁRIO}

Lista de abreviaturas, símbolos e siglas xi

Lista de tabelas, figuras e quadros xiii

Resumo xix

Summary xxi

\section{INTRODUÇÃO 1}

1.1 Histórico 1

1.2 Associação entre doença psiquiátrica e excesso de mortalidade cardiovascular 2

1.3 Doença psiquiátrica como fator de risco para doença cardiovascular 6

1.4 Mecanismos de associação 9

1.5 Associação entre fatores de risco cardiovascular e transtornos de humor e/ou ansiedade 11

1.5.1 Sobrepeso e obesidade $\mathbf{1 1}$

1.5.2 Diabetes mellitus $\mathbf{1 3}$

1.5.3 Hipertensão arterial 15

1.5.4 Dislipidemia 17

1.5.5 Síndrome metabólica $\mathbf{1 8}$

1.5.6 Estilo de vida $\mathbf{2 1}$

1.5.7 Escore de risco de Framingham 22

1.5.8 Proteína C reativa ultra-sensível $\mathbf{2 5}$

\section{OBJETIVOS 27}

2.1 Objetivo principal 27

2.2 Objetivos secundários 27

\section{MÉTODOS 29}

3.1 Amostra domiciliar do Inquérito de Saúde Mental São Paulo Megacity $\mathbf{3 0}$

3.2 Amostra hospitalar do Inquérito de Saúde Mental São Paulo Megacity 32

3.3 Medidas antropométricas e de pressão arterial 33

3.3.1 Aferição de peso $\mathbf{3 3}$

3.3.2 Aferição de altura $\mathbf{3 3}$

3.3.3 Cálculo do índice de massa corporal $\mathbf{3 4}$

3.3.4 Aferição da circunferência abdominal $\mathbf{3 4}$

3.3.5 Aferição da pressão arterial 35

3.4 Questionários 35

3.4.1 Questionário sobre dados gerais do participante $\mathbf{3 5}$

3.4.2 Avaliação sobre realização de atividade física 36

3.4.3 Avaliação psiquiátrica $\mathbf{3 6}$

3.5 Exames laboratoriais 37 
3.6 Definição de fatores de risco cardiovascular 39

3.6.1 Estilo de vida $\mathbf{3 9}$

3.6.2 Sobrepeso e obesidade 39

3.6.3 Diagnóstico de diabetes mellitus $\mathbf{4 0}$

3.6.4 Diagnóstico de dislipidemia $\mathbf{4 0}$

3.6.5 Proteína C reativa ultra-sensível $\mathbf{4 1}$

3.6.6 Dosagem de hormônio tireoestimulante (TSH) 41

3.6.7 Classificação de risco de eventos cardiovasculares através do escore de risco de Framingham (ERF) $\mathbf{4 2}$

3.6.8 Diagnóstico de síndrome metabólica $\mathbf{4 2}$

3.6.9 Diagnóstico de hipertensão arterial 43

3.7 Análise estatística 43

3.8 Aspectos Éticos 45

\section{RESULTADOS 47}

\section{DISCUSSÃO 107}

5.1 Panorama geral 107

5.2 Estilo de vida \& Transtorno de humor e/ou ansiedade 108

5.2.1 Tabagismo 108

5.2.2 Atividade física $\mathbf{1 1 1}$

5.3 Medidas antropométricas \& Transtornos de humor e/ou ansiedade $\mathbf{1 1 4}$

5.4 Fatores de risco para doença cardiovascular \& Transtornos de humor e/ou ansiedade 117 5.4.1 Hipertensão arterial $\mathbf{1 1 7}$

5.4.2 Diabetes mellitus $\mathbf{1 1 8}$

5.4.3 Dislipidemia 120

5.4.4 Síndrome metabólica 122

5.4.5 Proteína $C$ reativa ultra-sensível 123

5.4.6 Escore de risco de Framingham $\mathbf{1 2 5}$

5.5 Perfil sócio-demográfico \& Transtornos de humor e/ou ansiedade $\mathbf{1 2 6}$

5.6 Forças e limitações do estudo 128

5.7 Considerações finais $\mathbf{1 3 0}$

\section{CONCLUSÕES 133}

6.1 Conclusões principais 133

6.2 Conclusões secundárias 133

\section{ANEXOS 135}

Anexo A 137 Anexo B 140 Anexo C 141 Anexo D 142 Anexo E 146 Anexo F 149

REFERÊNCIAS 151 


\section{LISTA DE ABREVIATURAS, SÍMBOLOS E SIGLAS}

\section{LISTA DE ABREVIATURAS}

$\begin{aligned} \text { et al. } & \text { e outros } \\ \text { Prof. } & \text { Professor } \\ \text { Dr. } & \text { Doutor } \\ \text { ed. } & \text { edição } \\ \text { rev } & \text { revista } \\ \text { V. } & \text { volume } \\ \text { vs. } & \text { versus }\end{aligned}$

LISTA DE SÍMBOLOS

$\begin{aligned} \mathrm{kg} & \text { quilograma } \\ \mathrm{kg} / \mathrm{m}^{2} & \text { quilograma por metro quadrado } \\ \mathrm{cm} & \text { centímetros } \\ \mathrm{mm} & \text { milímetros } \\ \mathrm{Hg} & \text { mercúrio } \\ \% & \text { percentual } \\ \mathrm{N} & \text { número absoluto } \\ \mathrm{mg} & \text { miligrama } \\ \mathrm{dl} & \text { decilitro } \\ \mathrm{mcUl} & \text { microunidade } \\ \mathrm{ml} & \text { mililitro } \\ \geq & \text { maior ou igual a } \\ \leq & \text { menor ou igual a } \\ > & \text { maior que } \\ < & \text { menor que } \\ = & \text { igual }\end{aligned}$




\section{LISTA DE SIGLAS}

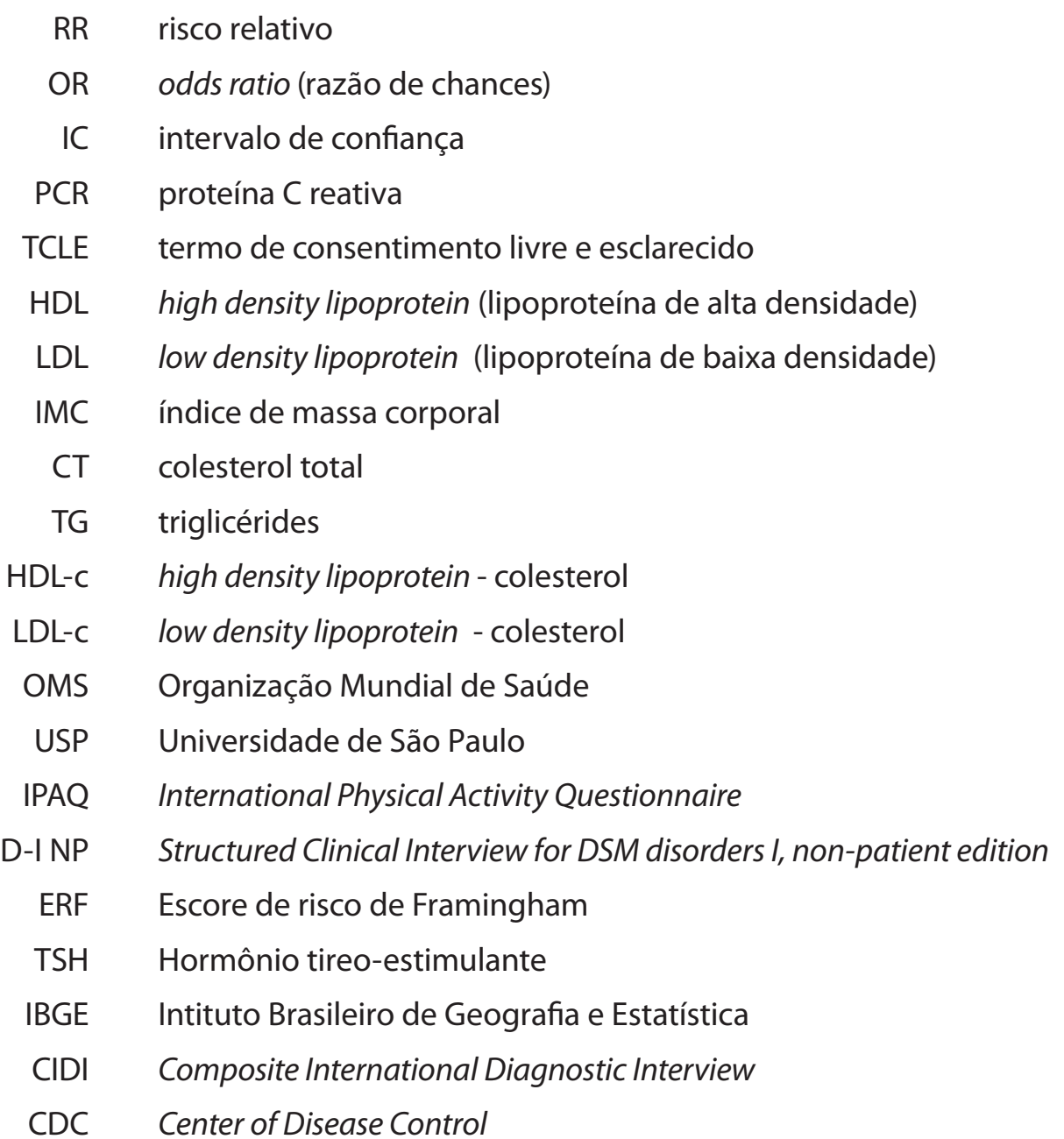

CRT DST/Aids Centro de Referência e Treinamento de Doenças Sexualmente Transmissíveis e Aids

AHA American Heart Association

SPSS Statistical Package for Social Sciences

PNAD Pesquisa Nacional por Amostra de Domicílios

EUA Estados Unidos da América 


\section{LISTA DE TABELAS, FIGURAS E QUADROS}

\section{LISTA DE FIGURAS}

: $:$ FIGURA 1 - Amostra de indivíduos que participaram da fase hospitalar do Estudo São Paulo Megacity, realizado na Grande São Paulo, 2005 a 200748

\section{LISTA DE TABELAS}

* TABELA 1 - Perfil de morbidade psiquiátrica de 772 participantes do Estudo São Paulo Megacity, realizado na Grande São Paulo - 2005 a 200750

* TABELA 2 - Número de diagnósticos psiquiátricos de 772 participantes do Estudo São Paulo Megacity, realizado na Grande São Paulo - 2005 a 200751

* TABELA 3 - Características gerais, antecedentes pessoais de doenças e hábitos de vida de acordo com gênero de 626 indivíduos com ou sem transtornos de humor e/ou de ansiedade do Estudo São Paulo Megacity, realizado na Grande São Paulo - 2005 a 200752

* TABELA 4 - Dados antropométricos e medida de pressão arterial de acordo com gênero em 626 indivíduos do Estudo São Paulo Megacity, realizado na Grande São Paulo - 2005 a 200754

* TABELA 5 - Perfil metabólico e de risco cardiovascular em 626 indivíduos do Estudo São Paulo Megacity, realizado na Grande São Paulo - 2005 a 200755

* TABELA 6 - Características gerais, antecedentes pessoais e hábitos de vida em amostra de participantes com transtorno de humor exclusivo ou sem diagnóstico psiquiátrico do Estudo São Paulo Megacity, realizado na Grande São Paulo - 2005 a 200757

* TABELA 7 - Dados antropométricos e medida de pressão arterial em 171 homens de amostra de participantes com transtorno de humor exclusivo ou sem diagnóstico psiquiátrico do Estudo São Paulo Megacity, realizado na Grande São Paulo - 2005 a 200759 
* TABELA 8 - Dados antropométricos e medida de pressão arterial em 195 mulheres de amostra de participantes com transtorno de humor exclusivo ou sem diagnóstico psiquiátrico do Estudo São Paulo Megacity, realizado na Grande São Paulo - 2005 a 200760

* TABELA 9 - Perfil metabólico e de risco cardiovascular em 171 homens de amostra de participantes com transtorno de humor exclusivo ou sem diagnóstico psiquiátrico do Estudo São Paulo Megacity, realizado na Grande São Paulo - 2005 a 200761

* TABELA 10 - Perfil metabólico e de risco cardiovascular em 195 mulheres de amostra de participantes com transtorno de humor exclusivo ou sem diagnóstico psiquiátrico do Estudo São Paulo Megacity, realizado na Grande São Paulo - 2005 a 200762

* TABELA 11 - Fatores associados à presença de transtorno de humor exclusivo no Estudo São Paulo Megacity realizado na Grande São Paulo - 2005 a 200763

* TABELA 12 - Características gerais, antecedentes pessoais e hábitos de vida em indivíduos com transtorno depressivo maior exclusivo ou sem diagnóstico psiquiátrico do Estudo São Paulo Megacity, realizado na Grande São Paulo - 2005 a 200765

* TABELA 13 - Dados antropométricos e medida de pressão arterial em 161 homens com transtorno depressivo maior exclusivo ou sem diagnóstico psiquiátrico do Estudo São Paulo Megacity, realizado na Grande São Paulo - 2005 a 200767

* TABELA 14 - Dados antropométricos e medida de pressão arterial em 183 mulheres de amostra de participantes com transtorno depressivo maior exclusivo ou sem diagnóstico psiquiátrico do Estudo São Paulo Megacity, realizado na Grande São Paulo - 2005 a 200768

* TABELA 15 - Perfil metabólico e de risco cardiovascular em 161 homens de amostra de participantes com transtorno depressivo maior exclusivo ou sem diagnóstico psiquiátrico do Estudo São Paulo Megacity, realizado na Grande São Paulo - 2005 a 200769

* TABELA 16 - Perfil metabólico e de risco cardiovascular em 183 mulheres de amostra de participantes com transtorno depressivo maior exclusivo ou sem diagnóstico psiquiátrico do Estudo São Paulo Megacity, realizado na Grande São Paulo - 2005 a 200770

* TABELA 17 - Perfil de fatores de risco cardiovascular em participantes do Estudo São Paulo Megacity de acordo com a presença de transtorno depressivo maior exclusivo, realizado na Grande São Paulo - 2005 a 200771 
* TABELA 18 - Características gerais, antecedentes pessoais de doenças e hábitos de vida em amostra de participantes com transtornos de ansiedade exclusivo ou sem diagnóstico psiquiátrico do Estudo São Paulo Megacity, realizado na Grande São Paulo - 2005 a 200773

* TABELA 19 - Dados antropométricos e medida de pressão arterial em homens de amostra de participantes com transtorno de ansiedade exclusivo ou sem diagnóstico psiquiátrico do Estudo São Paulo Megacity, realizado na Grande São Paulo - 2005 a 200775

* TABELA 20 - Dados antropométricos e medida de pressão arterial em mulheres de amostra de participantes com transtorno de ansiedade exclusivo ou sem diagnóstico psiquiátrico do Estudo São Paulo Megacity, realizado na Grande São Paulo - 2005 a 200776

* TABELA 21 - Perfil metabólico e de risco cardiovascular em homens de amostra de participantes com transtorno de ansiedade exclusivo ou sem diagnóstico psiquiátrico do Estudo São Paulo Megacity, realizado na Grande São Paulo - 2005 a 200777

* TABELA 22 - Perfil metabólico e de risco cardiovascular em mulheres de amostra de participantes com transtorno de ansiedade exclusivo ou sem diagnóstico psiquiátrico do Estudo São Paulo Megacity, realizado na Grande São Paulo - 2005 a 200778

* TABELA 23 - Perfil de fatores de risco cardiovascular em participantes do Estudo São Paulo Megacity de acordo com a presença de transtorno de ansiedade exclusivo, realizado na Grande São Paulo - 2005 a 200779

* TABELA 24 - Características gerais, antecedentes pessoais de doenças e hábitos de vida em amostra de participantes de acordo com a presença de transtorno de humor do Estudo São Paulo Megacity, realizado na Grande de São Paulo - 2005 a 200781

* TABELA 25 - Dados antropométricos e medida de pressão arterial em homens de amostra de participantes de acordo com a presença de transtorno de humor do Estudo São Paulo Megacity, realizado na Grande São Paulo - 2005 a 200783

* TABELA 26 - Dados antropométricos e medida de pressão arterial em mulheres de amostra de participantes de acordo com a presença de transtorno de humor do Estudo São Paulo Megacity, realizado na Grande São Paulo - 2005 a 200784 
* TABELA 27 - Perfil metabólico e de risco cardiovascular em homens de amostra de participantes de acordo com a presença de transtorno de humor do Estudo São Paulo Megacity, realizado na Grande São Paulo - 2005 a 200785

* TABELA 28 - Perfil metabólico e de risco cardiovascular em mulheres de amostra de participantes de acordo com a presença de transtorno de humor do Estudo São Paulo Megacity, realizado na Grande São Paulo - 2005 a 200786

* TABELA 29-Perfil de fatores de risco cardiovascular em indivíduos de amostra de participantes do Estudo São Paulo Megacity de acordo com a presença de transtorno de humor (com ou sem co-morbidade psiquiátrica), Grande São Paulo - 2005 a 200787

* TABELA 30 - Características gerais, antecedentes pessoais de doenças e hábitos de vida em amostra de participantes de acordo com a presença de transtorno depressivo maior do Estudo São Paulo Megacity, realizado na Grande São Paulo - 2005 a 200789

* TABELA 31- Dados antropométricos e medida de pressão arterial em homens de amostra de participantes de acordo com a presença de transtorno depressivo maior do Estudo São Paulo Megacity, realizado na Grande São Paulo - 2005 a 200791

* TABELA 32 - Dados antropométricos e medida de pressão arterial em mulheres de amostra de participantes de acordo com a presença de transtorno depressivo maior no Estudo São Paulo Megacity, realizado na Grande São Paulo - 2005 a 200792

* TABELA 33 - Perfil metabólico e de risco cardiovascular em homens de amostra de participantes de acordo com a presença de transtorno depressivo maior do Estudo São Paulo Megacity, realizado na Grande São Paulo - 2005 a 200793

* TABELA 34 - Perfil metabólico e de risco cardiovascular em mulheres de amostra de participantes de acordo com a presença de transtorno depressivo maior do Estudo São Paulo Megacity, realizado na Grande São Paulo - 2005 a 200794

* TABELA 35 - Perfil de fatores de risco cardiovascular em indivíduos de amostra de participantes do Estudo São Paulo Megacity de acordo com a presença de transtorno depressivo maior (com ou sem co-morbidade psiquiátrica), realizado na Grande São Paulo 2005 a 200795 
* TABELA 36 - Características gerais, antecedentes pessoais de doenças e hábitos de vida em amostra de participantes de acordo com a presença de transtorno de ansiedade do Estudo São Paulo Megacity, realizado na Grande São Paulo - 2005 a 200797

* TABELA 37 - Dados antropométricos e medida de pressão arterial em homens de amostra de participantes de acordo com a presença de transtorno de ansiedade do Estudo São Paulo Megacity, realizado na Grande São Paulo - 2005 a 200799

* TABELA 38 - Dados antropométricos e medida de pressão arterial em mulheres de amostra de participantes de acordo com a presença de transtorno de ansiedade do Estudo São Paulo Megacity, realizado na Grande São Paulo - 2005 a 2007100

* TABELA 39 - Perfil metabólico e de risco cardiovascular em homens de amostra de participantes de acordo com a presença de transtorno de ansiedade do Estudo São Paulo Megacity, realizado na Grande São Paulo - 2005 a 2007101

* TABELA 40 - Perfil metabólico e de risco cardiovascular em mulheres de amostra de participantes de acordo com a presença de transtorno de ansiedade do Estudo São Paulo Megacity, realizado na Grande São Paulo - 2005 a 2007102

* TABELA 41 - Perfil de fatores de risco cardiovascular em indivíduos de amostra de participantes do Estudo São Paulo Megacity de acordo com a presença de transtorno de ansiedade (com ou sem co-morbidade psiquiátrica), realizado na Grande São Paulo - 2005 a 2007103

* TABELA 42 - Perfil de realização de atividade física de acordo com transtorno psiquiátrico e gênero em participantes do Estudo São Paulo Megacity, realizado na Grande São Paulo 2005 a 2007105

* TABELA 43 - Características sócio-demográficas da população de estudo e da população do município 128 


\section{LISTA DE QUADROS}

䅈 QUADRO 1 - Estudos sobre mortalidade em indivíduos portadores de transtornos psiquiátricos 3

QUADRO 2 - Estudos que avaliaram a associação dos transtornos de humor e/ ou ansiedade e incidência de eventos cardiovasculares 7

* QUADRO 3 - Municípios incluídos na amostragem do Inquérito de Saúde Mental São Paulo Megacity, realizado entre 2005 e 200730

QUADRO 4 - Metodologia utilizada e valores de referência dos exames laboratoriais coletados durante a fase hospitalar do Estudo São Paulo Megacity, 2005 a 200738 


\section{RESUMO}

BIVANCO-LIMA D. Perfil de fatores de risco para doença cardiovascular em amostra de estudo epidemiológico populacional de morbidade psiquiátrica: Estudo São Paulo Megacity (tese). São Paulo: Faculdade de Medicina, Universidade de São Paulo; 2011.

INTRODUÇÃ O: Vários estudos sugerem uma possível associação entre a presença de transtornos de humor e/ou de ansiedade com doenças cardiovasculares. Há também evidências de que indivíduos portadores de transtornos de humor e/ou de ansiedade apresentem maior prevalência de sobrepeso e obesidade, diabetes mellitus e pior estilo de vida, com maior frequência de tabagismo e inatividade física. Este estudo teve por objetivo avaliar o perfil de fatores de risco cardiovascular em amostra de indivíduos com e sem transtornos de humor e/ou ansiedade da região metropolitana da cidade de São Paulo. MÉTODOS: Foram selecionados 2.820 participantes do Inquérito de Saúde Mental São Paulo Megacity, conduzido no município de São Paulo e 38 municípios adjacentes. Os indivíduos foram convidados a comparecer ao Instituto de Psiquiatria do Hospital das Clínicas da Faculdade de Medicina da Universidade de São Paulo, onde foram submetidos a avaliação psiquiátrica por meio do Structured Clinical Interview for DSM disorders (SCID$1 \mathrm{NP}$ ), a uma avaliação antropométrica incluindo peso, altura e circunferência abdominal; avaliação de fatores de risco cardiovascular e medida de pressão arterial; glicemia de jejum, perfil lipídico, de proteína C reativa ultra-sensível (PCRus), do hormônio tireoestimulante; cálculo do escore de risco de Framingham e avaliação de atividade física por meio do International Physical Activity Questionnaire (IPAQ). Os dados foram analisados por grupo de transtornos psiquiátricos (humor, ansiedade e/ou depressão maior) e por gênero. As variáveis categóricas foram comparadas usando-se o teste do qui-quadrado de Pearson e as contínuas usando-se ANOVA com teste post hoc of Bonferroni. Também foi realizada regressão logística binária expressa como a razão de chances e respectivo intervalo de confiança de 95\%. Foi utilizado o software estatístico SPSS, versão 16.0. RESULTADOS: Dos 2820 indivíduos selecionados para o estudo, foi realizado contato com 1.471 participantes $(1471 / 2820=52,2 \%)$ e, dentre eles, $780(780 / 1471=53 \%)$ aceitaram participar, sendo que 8 foram excluídos não completarem o protocolo ou por necessitarem de atendimento médico imediato, restando um total de 772 indivíduos para a análise. $\mathrm{Na}$ população estudada identificou-se 43,7\% de transtornos de ansiedade, 40,2\% de transtornos de humor e 13,9\% de transtornos por uso de substâncias. Foi observado que mulheres com transtorno de humor durante a vida apresentaram maior freqüência de tabagismo (Razão 
de chances [RC]) 2,30; Intervalo de Confiança [IC] 95\% 1,03-5,15), de diabetes (RC 2,46; IC 95\% 1,03-5,88), maiores níveis de colesterol total $(\mathrm{p}=0,035)$ e menor freqüência de PCRus elevado $(\mathrm{p}=0,04)$. Entre mulheres com depressão maior durante a vida foi observada renda familiar 30\% menor ( $\mathrm{p}=0,04)$, maior freqüência de diabetes (RC, 3,19; IC 95\% 1,33-7,66), de tabagismo (RC 1,75; IC 95\% 1,01-3,04), de LDL-colesterol elevado (RC 2,43; IC 95\% 1,01$5,87)$ e menor freqüência de PCRus elevado $(\mathrm{p}=0,005)$. Entre mulheres com transtornos de ansiedade, foram observados menores níveis de PCRus $(\mathrm{p}=0,03)$ e maior frequência de excesso de peso (RC 2,26; IC 95\% 1,15-4,44). Entre homens com depressão maior foi observada menor frequência de circunferência abdominal alterada $(p=0,01)$. Entre homens com transtornos de ansiedade, foi observado menor frequência de tabagismo (RC 0,36; IC 95\% 0,13-0,99). CONCLUSÃO: Indivíduos com transtornos de humor e/ou ansiedade apresentam um perfil diferenciado em relação ao risco cardiovascular quando comparados a indivíduos sem tais diagnósticos.

DESCRITORES: Doença cardiovascular, fatores de risco, depressão, ansiedade, transtornos do humor, transtornos de ansiedade. 


\section{SUM MARY}

BIVANCO-LIMA, D. Profile of cardiovascular risk factors in a sample of a mental health survey: Estudo São Paulo Megacity (thesis). São Paulo: Faculdade de Medicina, Universidade de São Paulo; 2011.

BACKGROUND: Several studies suggested a possible association between mood and / or anxiety disorders and cardiovascular disease. There is also evidence that individuals with mood and / or anxiety disorders have a higher prevalence of overweight and obesity, diabetes mellitus and a poor lifestyle, with increased frequency of smoking and physical inactivity. This study aimed to evaluate the profile of cardiovascular risk factors in individuals with and without mood and / or anxiety disorders in the metropolitan region of the city of São Paulo. METHODS: The study enrolled 2,820 participants of the São Paulo Megacity Mental Health Survey, conducted in São Paulo municipality and 38 municipalities around. Individuals were invited to attend an evaluation in the Instituto de Psiquiatria do Hospital das Clínicas da Faculdade de Medicina da Universidade de São Paulo, where they underwent a psychiatric evaluation using the Structured Clinical Interview for DSM disorders (SCID-1 NP), an anthropometric evaluation including weight, height and waist circumference, assessment of cardiovascular risk factors as blood pressure measurement, fasting blood glucose, lipid profile, high sensitivity C-reactive protein (hsCRP), thyroid stimulating hormone; calculation of Framingham risk score and physical activity assessment by the International Physical Activity Questionnaire (IPAQ). Data were analyzed by group of psychiatric disorders (mood, anxiety and/or major depression) and gender. Categorical variables were compared using the chi-square test and continuous variables using ANOVA with Bonferroni's post hoc test. We performed binary logistic regression expressed as odds ratios and 95\% confidence intervals. We used the statistical software SPSS, version 16.0. RESULTS: Of the 2,820 individuals selected for the study, contact was made with 1,471 participants $(1,471 / 2,820=52.2 \%)$ and among them a total of $780(780 / 1471=53 \%)$ agreed to participate, but 8 were excluded by missing data in the protocol or needing immediate medical attention, leaving a total of 772 individuals for analysis. In this population we identified $43.7 \%$ of anxiety disorders, $40.2 \%$ of mood disorders and $13.9 \%$ for substance use disorders. It was observed that women with lifetime diagnosis of mood disorder had higher rates of smoking (odds ratio [OR] 2.30, 95\% confidence interval [CI] 1.03 - 5.15 ), diabetes (OR 2,46, 95\% CI 1.03 - 5.88), higher levels of total cholesterol $(\mathrm{p}=0.035)$ and lower frequency of elevated hsCRP $(\mathrm{p}=0.04)$. Among 
women with lifetime diagnosis of major depression was observed a 30\% lower income $(\mathrm{p}=0.04)$, a higher frequency of diabetes (OR 3.19, 95\% CI 1.33 - 7.66), of smoking (OR $1.75,95 \%$ CI 1.01 - 3.04), a higher frequency of elevated LDL-cholesterol (OR 2.43, 95\% CI 1.01 to 5.87) and lower frequency of elevated hsCRP ( $p=0.005)$. Among women with lifetime diagnosis of anxiety disorders were observed lower levels of hsCRP ( $p=0.03$ ) and higher frequency of being overweight or obese (OR 2.26, 95\% CI 1.15 to 4.44). Among men with lifetime diagnosis of major depression, we found a lower frequency of altered waist circunference $(\mathrm{p}=0,01)$. And among men with anxiety disorders, we observed a lower frequency of smoking (OR 0.36, 95\% CI 0.13-0.99). CONCLUSION: Individuals with mood and / or anxiety disorders have a different cardiovascular risk profile compared to individuals without such diagnoses.

DE SCRIPTORS: Cardiovascular disease, risk factors, depression, anxiety, mood disorders, anxiety disorders. 


\section{INTRODUÇÃO}

\subsection{HISTÓRICO}

A associação entre estressores emocionais e doenças físicas é antiga no imaginário popular, haja vista o ditado "mente sã, corpo são". Hipócrates (460-377 a.C.) já descrevia a associação entre as doenças físicas e fatores psicológicos. Ele postulava que o corpo era uma unidade e que a doença resultava de desequilíbrio deste conjunto ${ }^{1}$. No entanto, a partir de Descartes (1596-1650) a dicotomia corpo e alma se aprofundou no pensamento científico, com uma visão do homem enquanto corpo-máquina ${ }^{2}$. Segundo a filosofia cartesiana, o estudo da mente seria atribuído à religião e à filosofia, enquanto que somente o estudo do corpo era objeto da medicina. Essa visão dicotômica teve importante influência sobre a prática e a ciência médica nos séculos subseqüentes, sendo vivenciada até os dias de hoje ${ }^{1}$.

A partir do final do século XIX, Pierre Janet (1859-1947) iniciou estudos sobre a psicologia e aspectos psicológicos da histeria, iniciando uso de conceitos sobre o inconsciente, que depois seriam aprofundados por Sigmund Freud (1856-1939). Esses resultaram no surgimento da psicanálise e dessa maneira houve aumento da atenção da comunidade médica à integração entre corpo e alma (ou mente), com o desenvolvimento do campo das neurociências ${ }^{1}$.

Recentemente, o fortalecimento da psiquiatria e o estabelecimento da pesquisa em neurociências, muitas associações entre fatores emocionais e doenças orgânicas vem sendo comprovadas e divulgadas para a comunidade médica, com uma nova tendência à integração entre o físico e a mente.

Extensa publicação científica divulga a associação entre estressores psicossociais e doenças cardíacas. Segundo a descrição de William Osler (1849-1919) publicada em 1892, os indivíduos que trabalham em sua capacidade máxima, em busca incessante do sucesso, são mais propensos à doença coronariana ${ }^{3}$. Apesar do tempo decorrido desde a observação de Osler, a maior parte deste conhecimento ainda se encontra restrito às publicações na área de psiquiatria e psicossomática, com menor divulgação para os médicos generalistas e clínicos.

Evidenciam-se relatos, inclusive na literatura brasileira, sobre a dificuldade do médico generalista em realizar diagnóstico e tratamento de doenças prevalentes na área de saúde mental ${ }^{4}$. Na prática clínica, ainda é pouco frequente o reconhecimento da associação entre os transtornos psiquiátricos e doenças sistêmicas ${ }^{5}$. 


\subsection{ASSOCIAÇÃO ENTRE DOENÇA PSIQUIÁTRICA E EXCESSO DE MORTALIDADE CARDIOVASCULAR}

Existem evidências sobre o excesso de mortalidade entre pacientes com doença psiquiátrica, principalmente nos indivíduos portadores de transtornos mais graves como a esquizofrenia e o transtorno afetivo bipolar ${ }^{6,7}$. Entretanto, há também publicações sobre a elevada mortalidade entre portadores de depressão maior, tanto em pacientes internados quanto ambulatoriais ${ }^{8-12}$.

O estudo mais antigo sobre a mortalidade excessiva em pacientes psiquiátricos é de 1841, realizado pelo epidemiologista britânico William Farr (1807-1883) em pacientes internados em diversas instituições na cidade de Londres. Farr relatou pela primeira vez que a mortalidade entre portadores de doença mental era de três a quatorze vezes maior que a da população geral ${ }^{6,7}$. Nessa época, Farr concluiu que a mortalidade se devia em parte à própria doença, mas que também era consequência das condições de vida nas instituições asilares, com aumento da mortalidade por infecções como pneumonia e tuberculose ${ }^{6}$.

Com a reforma psiquiátrica ocorrida nas décadas de 70 e 80 , houve uma mudança importante no perfil de morbi-mortalidade dos portadores de transtornos psiquiátricos devido a desinstitucionalização dos pacientes ${ }^{13}$. As principais causas de morte passam a ser progressivamente as doenças cardiovasculares, de maneira semelhante a população geral. No entanto, observou-se que em pacientes com transtornos psiquiátricos há uma maior proporção de mortes por causas cardiovasculares do que o esperado para indivíduos do mesmo gênero e faixa etária da população. Isso foi observado em diversos estudos (Quadro 1) que avaliaram em sua maioria a razão da taxa de mortalidade ou razão de mortalidade padronizada, em que a taxa de mortalidade nos indivíduos com transtornos psiquiátricos é comparada a taxa da população geral do mesmo sexo e mesma faixa etária. 


\section{QUADRO 1}

Estudos sobre mortalidade em indivíduos portadores de transtornos psiquiátricos.

\begin{tabular}{|c|c|c|c|c|c|}
\hline $\begin{array}{l}\text { Autor } \\
\text { principal } \\
\text { e ano de } \\
\text { publicação }\end{array}$ & $\begin{array}{l}\text { Tipo de } \\
\text { estudo }\end{array}$ & País & $\begin{array}{l}\text { Número de } \\
\text { participantes }\end{array}$ & $\begin{array}{l}\text { Transtorno } \\
\text { psiquiátrico } \\
\text { estudado }\end{array}$ & Desfecho \\
\hline $\begin{array}{l}\text { Brown S } \\
1997^{6}\end{array}$ & Metanálise & $\begin{array}{l}\text { Estados Unidos } \\
\text { da América, } \\
\text { Canadá, } \\
\text { Reino Unido, } \\
\text { Dinamarca, } \\
\text { Israel, Itália, } \\
\text { Suécia e } \\
\text { Países Baixos }\end{array}$ & $\begin{array}{l}66.161 \text { indivíduos } \\
\text { (18 estudos) }\end{array}$ & Esquizofrenia & $\begin{array}{l}\text { RMP 1,51 (IC } 95 \% \text { 1,48- } \\
\text { 1,54) para todas as causas } \\
\text { RMP 1,10 (IC } 95 \% \\
1,05-1,15) \text { para doença } \\
\text { cardiovascular }\end{array}$ \\
\hline $\begin{array}{l}\text { Brown S } \\
2000^{14}\end{array}$ & Coorte & $\begin{array}{l}\text { Inglaterra } \\
\text { (Southampton) }\end{array}$ & $\begin{array}{l}370 \text { indivíduos } \\
\text { não- } \\
\text { institucionalizados }\end{array}$ & Esquizofrenia & $\begin{array}{l}\text { RMP 1,87 (IC 95\% } \\
\text { 1,02-2,98) para doença } \\
\text { cardiovascular } \\
\text { RMP 5,34 (IC } 95 \% \\
\text { 2,56-9,82) para doença } \\
\text { cerebrovascular } \\
\text { RMP 2,98 (IC } 95 \% \text { 2,36- } \\
\text { 3,72) para todas as causas }\end{array}$ \\
\hline $\begin{array}{l}\text { Saha S } \\
2007^{15}\end{array}$ & Metanálise & 25 países & $\begin{array}{l}22.296 \text { indivíduos } \\
\text { (37 estudos) }\end{array}$ & Esquizofrenia & $\begin{array}{l}\text { RMP 2,50 (IC } 95 \% \text { 2,18- } \\
2,43 \text { ) para todas as causas, } \\
\text { RMP 1,79 (IQ10-90\% } \\
1,11 \text { - 3,60) para doenças } \\
\text { cardiovasculares }\end{array}$ \\
\hline $\begin{array}{l}\text { Osborn DPJ } \\
2007^{16}\end{array}$ & $\begin{array}{l}\text { Caso- } \\
\text { controle }\end{array}$ & $\begin{array}{l}\text { Inglaterra } \\
\text { (Londres) }\end{array}$ & $\begin{array}{l}46.136 \text { indivíduos } \\
\text { (comparados a } \\
300.246 \text { indivíduos } \\
\text { sem transtornos } \\
\text { psiquiátricos) }\end{array}$ & $\begin{array}{l}\text { Transtornos } \\
\text { psicóticos ( a } \\
\text { maioria com } \\
\text { esquizofrenia) } \\
\text { ou transtorno } \\
\text { afetivo bipolar }\end{array}$ & $\begin{array}{l}\text { RR 2,88 } \\
\text { (IC 95\% 1,77-4,70) para } \\
\text { doença coronariana entre } \\
\text { 18-49 anos } \\
\text { RR 1,76 (IC 95\% 1,54-2,01) } \\
\text { entre } 50-75 \text { anos } \\
\text { RR 1,83 (IC } 95 \% \text { 1,45-2,31) } \\
\text { entre } 50-75 \text { anos } \\
\text { RR1,33 (IC } 95 \% 1,16-1,52) \\
\text { maior ou igual a } 75 \text { anos }\end{array}$ \\
\hline $\begin{array}{l}\text { Laursen TM } \\
2009^{17}\end{array}$ & Coorte & Dinamarca & $\begin{array}{l}4.592 .803 \\
\text { indivíduos com } \\
\text { internação } \\
\text { psiquiátrica prévia }\end{array}$ & $\begin{array}{l}\text { Transtornos } \\
\text { psiquiátricos } \\
\text { com antecedente } \\
\text { de internação } \\
\text { psiquiátrica }\end{array}$ & $\begin{array}{l}\text { RMP 2,9 (IC 95\% 2,71-3,10) } \\
\text { por doença cardíaca } \\
\text { RMP 3,52 (IC 95\% 3,22- } \\
\text { 3,84) para esquizofrenia } \\
\text { RMP 2,50 (IC 95\% 2,26- } \\
\text { 2,78) para transtorno } \\
\text { afetivo bipolar }\end{array}$ \\
\hline
\end{tabular}




\begin{tabular}{|c|c|c|c|c|c|}
\hline $\begin{array}{l}\text { Autor } \\
\text { principal } \\
\text { e ano de } \\
\text { publicação }\end{array}$ & $\begin{array}{l}\text { Tipo de } \\
\text { estudo }\end{array}$ & País & $\begin{array}{l}\text { Número de } \\
\text { participantes }\end{array}$ & $\begin{array}{l}\text { Transtorno } \\
\text { psiquiátrico } \\
\text { estudado }\end{array}$ & Desfecho \\
\hline $\begin{array}{l}\text { Angst F } \\
2002^{8}\end{array}$ & Coorte & Suíça (Zurique) & $\begin{array}{l}406 \text { indivíduos } \\
\text { portadores de } \\
\text { transtornos de } \\
\text { humor internados }\end{array}$ & $\begin{array}{l}\text { Depressão } \\
\text { unipolar ( } n=186) \\
\text { e transtorno } \\
\text { afetivo bipolar } \\
(\mathrm{n}=220)\end{array}$ & $\begin{array}{l}\text { RMP 1,61 (IC } 95 \% \text { 1,43- } \\
1,80 \text { ) para todas as causas } \\
\text { RMP 1,61 (IC } 95 \% \\
1,31-1,96) \text { para doença } \\
\text { cardiovascular }\end{array}$ \\
\hline $\begin{array}{l}\text { Lawrence DM } \\
2003^{9}\end{array}$ & Coorte & Austrália & $\begin{array}{l}165.699 \text { indivíduos } \\
\text { que utilizaram } \\
\text { serviços de saúde } \\
\text { mental }\end{array}$ & $\begin{array}{l}\text { Transtornos } \\
\text { psiquiátricos }\end{array}$ & $\begin{array}{l}\text { RMP 1,81 (IC 95\% } \\
\text { 1,50-2,19) para doença } \\
\text { isquêmica miocárdica em } \\
\text { portadores de depressão } \\
\text { do sexo masculino } \\
\text { RMP 1,87 (IC95\% 1,60- } \\
\text { 2,18) para o sexo feminino }\end{array}$ \\
\hline $\begin{array}{l}\text { Zheng D } \\
1997^{10}\end{array}$ & Coorte & $\begin{array}{l}\text { Estados Unidos } \\
\text { da América }\end{array}$ & $\begin{array}{l}615 \text { indivíduos } \\
\text { de amostra } \\
\text { populacional }\end{array}$ & Depressão maior & $\begin{array}{l}\text { RR 2,4 (IC 95\% 1,4-4,2) } \\
\text { para morte por todas as } \\
\text { causas em homens e não } \\
\text { significante para mulheres } \\
\text { *Doença cardiovascular foi } \\
\text { a principal causa de morte } \\
\text { em todos os grupos }\end{array}$ \\
\hline $\begin{array}{l}\text { Menezes PR } \\
1996^{18}\end{array}$ & Coorte & $\begin{array}{l}\text { Brasil } \\
\text { (São Paulo) }\end{array}$ & $\begin{array}{l}120 \text { portadores de } \\
\text { psicoses funcionais } \\
\text { não-afetivas com } \\
\text { internação prévia }\end{array}$ & $\begin{array}{l}\text { Transtorno } \\
\text { psicótico }\end{array}$ & $\begin{array}{l}\text { RMP 8,4 (IC 95\% 4,0-15,9) } \\
\text { para todas as causas }\end{array}$ \\
\hline $\begin{array}{l}\text { Colton CW } \\
2006^{19}\end{array}$ & $\begin{array}{l}\text { Dados } \\
\text { secundários }\end{array}$ & $\begin{array}{l}\text { Estados Unidos } \\
\text { da América } \\
\text { (8 estados } \\
\text { americanos) }\end{array}$ & Não especificado & $\begin{array}{l}\text { Transtornos } \\
\text { psiquiátricos }\end{array}$ & $\begin{array}{l}\text { RMP variou de 1,2 até 4,9 } \\
\text { nos diferentes estados, } \\
\text { sendo que doença } \\
\text { cardiovascular foi a } \\
\text { primeira causa de morte } \\
\text { em todos os estados }\end{array}$ \\
\hline $\begin{array}{l}\text { Grigoletti L } \\
2009^{20}\end{array}$ & Coorte & $\begin{array}{l}\text { Itália } \\
\text { (Verona) }\end{array}$ & $\begin{array}{l}6956 \\
\text { indivíduos não- } \\
\text { institucionalizados }\end{array}$ & $\begin{array}{l}\text { Transtornos } \\
\text { psiquiátricos }\end{array}$ & $\begin{array}{l}\text { RMP 1,88 (IC 95\% 1,8-2,0) } \\
\text { para todas as doenças } \\
\text { RMP 1,55 (IC 95\% 1,4- } \\
\text { 1,7) para transtornos de } \\
\text { humor. } \\
\text { RMP 1,28 (IC 95\% 1,1- } \\
\text { 1,5) em homens para } \\
\text { causas circulatórias, mas } \\
\text { sem diferença entre as } \\
\text { mulheres }\end{array}$ \\
\hline
\end{tabular}




\begin{tabular}{|c|c|c|c|c|c|}
\hline $\begin{array}{l}\text { Autor } \\
\text { principal } \\
\text { e ano de } \\
\text { publicação }\end{array}$ & $\begin{array}{l}\text { Tipo de } \\
\text { estudo }\end{array}$ & País & $\begin{array}{l}\text { Número de } \\
\text { participantes }\end{array}$ & $\begin{array}{l}\text { Transtorno } \\
\text { psiquiátrico } \\
\text { estudado }\end{array}$ & Desfecho \\
\hline $\begin{array}{l}\text { Almeida OP } \\
2010^{21}\end{array}$ & Coorte & $\begin{array}{l}\text { Austrália } \\
\text { (Perth) }\end{array}$ & $\begin{array}{l}5276 \text { indivíduos } \\
\text { idosos do gênero } \\
\text { masculino não } \\
\text { institucionalizados }\end{array}$ & Depressão & $\begin{array}{l}\text { RMP 1,98 (IC 95\% 1,61- } \\
2,43 \text { ) para todas as causas } \\
\text { RMP 2,69 (IC } 95 \% \\
2,01-3,59 \text { ) para causas } \\
\text { cardiovasculares }\end{array}$ \\
\hline $\begin{array}{l}\text { Chang CK } \\
2010^{22}\end{array}$ & Coorte & $\begin{array}{l}\text { Inglaterra } \\
\text { (Sudeste de } \\
\text { Londres) }\end{array}$ & 31719 indivíduos & $\begin{array}{l}\text { Transtornos } \\
\text { depressivos }\end{array}$ & $\begin{array}{l}\text { RMP 1,29 (IC } 95 \% 1,19- \\
\text { 1,40) para todas as causas } \\
\text { de morte }\end{array}$ \\
\hline $\begin{array}{l}\text { Ostir GV } \\
2006^{23}\end{array}$ & Coorte & $\begin{array}{l}\text { Estados Unidos } \\
\text { da América } \\
\text { (Galveston } \\
\text { County) }\end{array}$ & $\begin{array}{l}506 \text { idosos não } \\
\text { institucionalizados }\end{array}$ & $\begin{array}{l}\text { Sintomas de } \\
\text { ansiedade }\end{array}$ & $\begin{array}{l}\text { RR 1,52 (IC } 95 \% \text { 1,02-2,28) } \\
\text { para todas as causas } \\
\text { RR 1,90 (IC } 95 \% 1,06- \\
\text { 3,36) para causas } \\
\text { cardiovasculares }\end{array}$ \\
\hline $\begin{array}{l}\text { Lin EHB } \\
2009^{24}\end{array}$ & Coorte & $\begin{array}{l}\text { Estados Unidos } \\
\text { da América } \\
\text { (0este de } \\
\text { Washington) }\end{array}$ & $\begin{array}{l}4184 \text { pacientes } \\
\text { diabéticos }\end{array}$ & $\begin{array}{l}\text { Transtorno } \\
\text { depressivo maior } \\
\text { e menor }\end{array}$ & $\begin{array}{l}\text { RR 1,52 (IC 95\% 1,19-1,95) } \\
\text { para todas as causas, sem } \\
\text { diferença significativa para } \\
\text { causa cardiovascular }\end{array}$ \\
\hline $\begin{array}{l}\text { Whooley M } \\
1998^{25}\end{array}$ & Coorte & $\begin{array}{l}\text { Estados Unidos } \\
\text { da América } \\
\text { (Baltimore, } \\
\text { Minneapolis, } \\
\text { Portland, } \\
\text { Monongahela } \\
\text { Valley) }\end{array}$ & $\begin{array}{l}7518 \text { mulheres } \\
\text { brancas de } 67 \text { anos } \\
\text { ou mais }\end{array}$ & $\begin{array}{l}\text { Sintomas } \\
\text { depressivos }\end{array}$ & $\begin{array}{l}\text { RR 2,14 (IC 95\% 1,75-2,61) } \\
\text { para morte por todas as } \\
\text { causas } \\
\text { RR 1,8 (IC 95\% 1,2- } \\
\text { 2,5) para causas } \\
\text { cardiovasculares }\end{array}$ \\
\hline $\begin{array}{l}\text { Kisely } \\
2007^{12}\end{array}$ & Coorte & $\begin{array}{l}\text { Canadá } \\
\text { (Nova Scotia) }\end{array}$ & 17665 indivíduos & $\begin{array}{l}\text { Transtornos } \\
\text { psiquiátricos }\end{array}$ & $\begin{array}{l}\text { RR 1,34 (IC 95\%1,29-1,40) } \\
\text { para morte por causa } \\
\text { cardiovascular }\end{array}$ \\
\hline $\begin{array}{l}\text { Druss } \\
2001^{11}\end{array}$ & Coorte & Estados Unidos & $\begin{array}{l}88241 \text { usuários } \\
\text { idosos do seguro } \\
\text { saúde Medicare, } \\
\text { com infarto prévio }\end{array}$ & $\begin{array}{l}\text { Transtornos } \\
\text { afetivos }\end{array}$ & $\begin{array}{l}\text { RR 1,11 (IC 95\% 1,02-1,20) } \\
\text { para morte por causa } \\
\text { cardiovascular }\end{array}$ \\
\hline
\end{tabular}

Nota: RMP- razão de mortalidade padronizada; IC95\% - intervalo de confiança a 95\%; IQ - intervalo interquartil; RR risco relativo

Em estudo de Colton et al. foram avaliadas as taxas de mortalidade entre indivíduos usuários de serviços públicos de saúde mental em oito estados americanos, entre 1997 e 2000, sendo observada uma mortalidade elevada comparada à população geral em todos os estados ${ }^{19}$. A razão de mortalidade padronizada variou de 1,2 até 4,9, com um excesso de mortes em todos os estados e em todos os anos estudados. Foram avaliados também os anos de vida perdidos, que variaram de 13,5 a 32,2 anos, sendo que os homens morreram mais precocemente que as mulheres. 
Kisely et al. avaliaram a taxa de mortalidade na cidade de Nova Scotia (Canadá), no período de 1995 a 2001 e observaram que, dentre as 17665 mortes ocorridas em indivíduos com diagnóstico de transtorno psiquiátrico, havia maior mortalidade por todas as causas com risco relativo (RR) de 1,31 [Intervalo de Confiança (IC) 95\% 1,25-1,36], por doenças isquêmicas cardíacas (RR 1,21; IC 95\% 1,14-1,28) e por acidente vascular cerebral (RR 1,59; IC $95 \%$ 1,46-1,74) $)^{12}$.

Diversos estudos evidenciam uma maior mortalidade por causas cardiovasculares entre indivíduos com transtorno de humor, no entanto, há uma possível diferença entre os gêneros. Em alguns estudos não foi relatado aumento de mortalidade em mulheres ${ }^{10,20}$ enquanto em estudos com resultados positivos em mulheres, o impacto é menor comparado aos homens ${ }^{19,22}$. Somente o estudo de Kisely et al. observou impacto semelhante em ambos os gêneros ${ }^{12}$.

Além disso, há evidências de que os transtornos de humor se associam à mortalidade precoce, sendo o excesso de mortalidade maior em faixas etárias mais jovens e menor nos mais idosos ${ }^{16,20,22}$.

As evidências são mais escassas na avaliação da possível associação entre os transtornos de ansiedade e a mortalidade cardiovascular, com somente um estudo positivo que avaliou uma população de idosos ${ }^{23}$. No entanto, diversos estudos avaliaram transtornos psiquiátricos como um todo, incluindo transtornos ansiosos, e observaram maior mortalidade por causas cardiovasculares $9,12,17,19,20$.

\subsection{DOENÇA PSIQUIÁTRICA COMO FATOR DE RISCO PARA DOENÇA CARDIOVASCULAR}

Devido às evidências sugerindo uma maior mortalidade por eventos cardiovasculares e de surgimento mais precoce entre indivíduos portadores de transtornos depressivos e ansiosos, iniciam-se questionamentos quanto a associação entre a incidência aumentada de eventos cardiovasculares entre portadores de transtornos ansiosos e/ou de humor. Logo, a partir da década de 90, diversos autores passam a investigar a associação entre transtornos psiquiátricas e incidência de eventos cardiovasculares (Quadro 2). 


\section{QUADRO 2}

Estudos que avaliaram a associação dos transtornos de humor e/ ou ansiedade e incidência de eventos cardiovasculares.

\begin{tabular}{|c|c|c|c|c|c|}
\hline $\begin{array}{l}\text { Autor } \\
\text { principal } \\
\text { e ano de } \\
\text { publicação }\end{array}$ & $\begin{array}{l}\text { Tipo de } \\
\text { estudo }\end{array}$ & País & $\begin{array}{l}\text { Número de } \\
\text { participantes }\end{array}$ & $\begin{array}{l}\text { Transtorno } \\
\text { psiquiátrico }\end{array}$ & Desfecho \\
\hline $\begin{array}{l}\text { Leon CFM } \\
1998^{26}\end{array}$ & Coorte & $\begin{array}{l}\text { Estados Unidos da } \\
\text { América } \\
\text { (New Haven) }\end{array}$ & $\begin{array}{l}2391 \text { idosos não- } \\
\text { institucionalizados, } \\
\text { com mais de } 65 \\
\text { anos }\end{array}$ & $\begin{array}{l}\text { Sintomas } \\
\text { depressivos }\end{array}$ & $\begin{array}{l}\text { RR 0,98 (IC 95\% 0,95- } \\
\text { 1,01) para IAM em } \\
\text { homens } \\
\text { RR 1,01 (IC 95\% 0,99- } \\
1,03 \text { ) em mulheres }\end{array}$ \\
\hline $\begin{array}{l}\text { Pratt LA } \\
1996^{27}\end{array}$ & Coorte & $\begin{array}{l}\text { Estados Unidos da } \\
\text { América } \\
\text { (Baltimore) }\end{array}$ & $\begin{array}{l}1551 \text { indivíduos } \\
\text { de amostra } \\
\text { populacional }\end{array}$ & Depressão & $\begin{array}{l}\text { OR 4,14 (IC 95\% 1,48- } \\
11,62 \text { ) para IAM }\end{array}$ \\
\hline $\begin{array}{l}\text { Ferketich AK } \\
2000^{28}\end{array}$ & Coorte & $\begin{array}{l}\text { Estados Unidos da } \\
\text { América }\end{array}$ & 8111 indivíduos & $\begin{array}{l}\text { Sintomas } \\
\text { depressivos }\end{array}$ & $\begin{array}{l}\text { RR 1,73 (IC 95\% 1,11- } \\
2,68 \text { ) para eventos } \\
\text { cardiovasculares não- } \\
\text { fatais em mulheres, mas } \\
\text { sem diferença nos fatais, } \\
\text { RR 1,71 (IC 95\% 1,14- } \\
\text { 2,56) para eventos não- } \\
\text { fatais em homens, } \\
\text { RR 1,69 (IC 95\% 1,35- } \\
\text { 2,11) para eventos fatais } \\
\text { em homens }\end{array}$ \\
\hline $\begin{array}{l}\text { Hippisley-Cox } \\
\text { J } 1998^{29}\end{array}$ & $\begin{array}{l}\text { Caso- } \\
\text { controle }\end{array}$ & $\begin{array}{l}\text { Inglaterra } \\
\text { (Nottinghamshire } \\
\text { e Lincolnshire) }\end{array}$ & $\begin{array}{l}327 \text { casos e } 897 \\
\text { controles entre } \\
\text { usuários de serviços } \\
\text { de saúde }\end{array}$ & $\begin{array}{l}\text { Transtornos } \\
\text { depressivos }\end{array}$ & $\begin{array}{l}\text { OR 2,75 (IC 95\% 1,13- } \\
6,69 \text { ) para doença } \\
\text { cardíaca isquêmica } \\
\text { incidente em homens } \\
\text { Entre mulheres não } \\
\text { houve diferença }\end{array}$ \\
\hline $\begin{array}{l}\text { Ariyo AA } \\
2000^{30}\end{array}$ & Coorte & $\begin{array}{l}\text { Estados Unidos da } \\
\text { América } \\
\text { (Washington, } \\
\text { Sacramento, } \\
\text { Forsyth, } \\
\text { Allegheny) }\end{array}$ & $\begin{array}{l}4493 \text { idosos com } 65 \\
\text { anos ou mais, não- } \\
\text { institucionalizados }\end{array}$ & $\begin{array}{l}\text { Transtorno } \\
\text { depressivo }\end{array}$ & $\begin{array}{l}\text { RR 1,16 (IC 95\% 1,04- } \\
1,28 \text { ) para morte } \\
\text { RR 1,15 (IC 95\% 1,04- } \\
\text { 1,27) doença coronariana } \\
\text { RR 1,20 (IC95\% 1,05- } \\
\text { 1,38) para angina, mas } \\
\text { não houve diferença } \\
\text { para IAM }\end{array}$ \\
\hline $\begin{array}{l}\text { Wulsin LR } \\
2003^{31}\end{array}$ & Metanálise & $\begin{array}{l}\text { Estados Unidos da } \\
\text { América, Finlândia } \\
\text { e Dinamarca }\end{array}$ & 28.737 indivíduos & $\begin{array}{l}\text { Transtorno } \\
\text { depressivo } \\
\text { e sintomas } \\
\text { depressivos }\end{array}$ & $\begin{array}{l}\text { RR combinado 1,64 (IC } \\
95 \% 1,41-1,90) \text { com } 3 \\
\text { estudos negativos em } \\
\text { total de } 10 .\end{array}$ \\
\hline
\end{tabular}




\begin{tabular}{|c|c|c|c|c|c|}
\hline $\begin{array}{l}\text { Autor } \\
\text { principal } \\
\text { e ano de } \\
\text { publicação }\end{array}$ & $\begin{array}{l}\text { Tipo de } \\
\text { estudo }\end{array}$ & País & $\begin{array}{l}\text { Número de } \\
\text { participantes }\end{array}$ & $\begin{array}{l}\text { Transtorno } \\
\text { psiquiátrico }\end{array}$ & Desfecho \\
\hline $\begin{array}{l}\text { Hemingway H } \\
1999^{32}\end{array}$ & $\begin{array}{l}\text { Revisão } \\
\text { sistemática }\end{array}$ & $\begin{array}{l}\text { Estados Unidos } \\
\text { da América, Reino } \\
\text { Unido, Finlândia, } \\
\text { Escócia, Lituânia e } \\
\text { Países Baixos }\end{array}$ & 63.334 indivíduos & $\begin{array}{l}\text { Transtornos } \\
\text { ansiosose } \\
\text { depressivos }\end{array}$ & $\begin{array}{l}\text { RR positivo em todos } \\
\text { estudos, variando de } \\
1,23 \text { a } 5,4 \text {. }\end{array}$ \\
\hline $\begin{array}{l}\text { Penninx BWJH } \\
2001^{33}\end{array}$ & Coorte & $\begin{array}{l}\text { Dinamarca } \\
\text { (11 municípios) }\end{array}$ & $\begin{array}{l}2847 \text { indivíduos de } \\
55 \text { a } 85 \text { anos }\end{array}$ & $\begin{array}{l}\text { Transtorno } \\
\text { depressivo }\end{array}$ & $\begin{array}{l}\text { Indivííduos sem doença } \\
\text { cardíaca RR 5,2 (IC 95\% } \\
\text { 1,5-17,7) } \\
\text { Indivíduos com doença } \\
\text { cardíaca RR 3,9 (IC 95\% } \\
\text { 1,3-11,8) }\end{array}$ \\
\hline $\begin{array}{l}\text { Surtees PG } \\
2008^{34}\end{array}$ & Coorte & $\begin{array}{l}\text { Reino Unido } \\
\text { (Norfolk) }\end{array}$ & 19649 indivíduos & $\begin{array}{l}\text { Transtorno } \\
\text { depressivo }\end{array}$ & $\begin{array}{l}\text { Homens RR 3,07 (IC 95\% } \\
\text { 1,55-6,08) } \\
\text { Mulheres RR 2,05(IC } \\
\text { 95\% 0,80-5,29) para } \\
\text { depressão no último ano }\end{array}$ \\
\hline $\begin{array}{l}\text { Wassertheil- } \\
\text { Smoller S } \\
1996^{35}\end{array}$ & Coorte & $\begin{array}{l}\text { Estados Unidos } \\
\text { da América (16 } \\
\text { centros clínicos } \\
\text { para o estudo } \\
\text { SHEP) }\end{array}$ & $\begin{array}{l}4508 \text { idosos com } \\
{ }^{3} 60 \text { anos, não- } \\
\text { institucionalizados } \\
\text { com hipertensão } \\
\text { arterial. }\end{array}$ & $\begin{array}{l}\text { Transtorno } \\
\text { depressivo }\end{array}$ & $\begin{array}{l}\text { Não houve associação } \\
\text { entre depressão na } \\
\text { primeira avaliação e } \\
\text { eventos cardiovasculares, } \\
\text { no entanto o maior } \\
\text { surgimento de sintomas } \\
\text { se associou a eventos } \\
\text { em mulheres: RR 1,29 } \\
\text { (IC95\% 1,13-1,35) }\end{array}$ \\
\hline $\begin{array}{l}\text { Aromaa A } \\
1994^{36}\end{array}$ & Coorte & Finlândia & $\begin{array}{l}5355 \text { indivíduos a } \\
\text { partir de } 40 \text { anos }\end{array}$ & $\begin{array}{l}\text { Transtorno } \\
\text { depressivo }\end{array}$ & $\begin{array}{l}\text { RR 3,52 (IC 95\% 2,44- } \\
5,08 \text { ) na faixa etária de } \\
\text { 40-64 anos } \\
\text { RR 1,63 (IC 95\% 0,89- } \\
3,01 \text { ) na faixa etária de } \\
65 \text { anos ou mais }\end{array}$ \\
\hline $\begin{array}{l}\text { Whang W } \\
2009^{37}\end{array}$ & Coorte & $\begin{array}{l}\text { Estados Unidos da } \\
\text { América }\end{array}$ & $\begin{array}{l}63.469 \text { enfermeiras } \\
\text { de } 30 \text { a } 55 \text { anos }\end{array}$ & $\begin{array}{l}\text { Transtorno } \\
\text { depressivo }\end{array}$ & $\begin{array}{l}\text { RR 1,49 (IC 95\% 1,11- } \\
\text { 2,00) para doença } \\
\text { coronariana fatal }\end{array}$ \\
\hline $\begin{array}{l}\text { Nabi H } \\
2010^{38}\end{array}$ & Coorte & Finlândia & $\begin{array}{l}24.128 \text { indivíduos } \\
\text { de } 20 \text { a } 54 \text { anos }\end{array}$ & $\begin{array}{l}\text { Transtornos } \\
\text { ansiosos }\end{array}$ & $\begin{array}{l}\text { RR 1,47 (IC 95\% 1,04- } \\
\text { 2,06) para doença } \\
\text { coronariana em } \\
\text { portadores de sintomas } \\
\text { físicos }\end{array}$ \\
\hline
\end{tabular}

Nota: RR - risco relativo; OR - Odds Ratio; IC95\% - intervalo de confiança a 95\%; SHEP - Systolic Hypertension in the Elderly Program; IAM - infarto agudo do miocárdio

Em metanálise de 2003 de Wulsin et al. foi avaliada a associação entre doença cardiovascular e presença de sintomas e/ou diagnóstico de depressão, utilizando estudos 
que realizaram seguimento de quatro anos no mínimo ${ }^{31}$. Esse estudo mostrou risco relativo combinado de 1,64 (IC 95\% 1,41-1,90) para depressão como fator de risco para doença coronariana. Também foi observado que poucos estudos controlaram para as quatro principais variáveis de confusão: presença de doença física, tabagismo, hipertensão arterial e sedentarismo. Embora haja um possível viés de publicação, segundo os autores, os mesmos afirmam que seriam necessários 572 estudos com resultados negativos para invalidar o resultado positivo dessa revisão.

Em coorte publicada em 2009 por Whang et al. foram avaliadas 63.469 enfermeiras americanas do sexo feminino, de 30 a 55 anos, com seguimento de 12 anos e foi observado que não houve um aumento de morte súbita e infarto agudo do miocárdio entre as enfermeiras com transtorno depressivo (quando comparadas às enfermeiras sem transtorno depressivo). Porém, há um aumento de doença coronariana fatal (RR 1,49 IC95\% 1,11-2,00) em portadoras de depressão ${ }^{37}$.

A associação entre transtornos ansiosos e risco de eventos cardiovasculares é controversa e ainda há poucos estudos com este enfoque. Nabi et al. publicaram os resultados de coorte de 24.128 indivíduos finlandeses de ambos os gêneros, com idade de 20 a 54 anos e seguimento de 7 anos e observaram que não houve associação entre a presença de transtornos de ansiedade e incidência de eventos cardiovasculares em homens. No entanto, em mulheres o aumento de sintomas físicos relacionados a transtornos de ansiedade aumentou o risco de doença coronariana (RR 1,47 IC95\% 1,04-2,06). Não houve associação com sintomas psíquicos de ansiedade ${ }^{38}$.

Embora diversos estudos indiquem que os transtornos de humor, entre eles os transtornos depressivos, estão associados a maior incidência de eventos cardiovasculares, persistem dúvidas sobre os mecanismos que atuariam nessa associação.

Com relação a associação entre transtornos ansiosos e incidência de eventos cardiovasculares há poucos estudos, não sendo possível afirmar se ocorre tal associação ou não.

\subsection{MECANISMOS DE ASSOCIAÇÃO}

A associação entre transtornos depressivos e a incidência de eventos cardiovasculares, como angina e infarto agudo do miocárdio, é mediada por diversos fatores. Ou seja, ter um transtorno psiquiátrico como depressão pode levar a diversos fatores que, por sua vez, podem ser associados a doença cardiovascular. Estes fatores são: a desigualdade social e pobreza ${ }^{39}$, menor acesso a serviços e cuidados à saúde, menor adesão a tratamentos de saúde, alterações neuro-humorais, efeitos colaterais de medicamentos 
de uso psiquiátrico e maior freqüência de fatores de risco para doença cardiovascular.

Há estudos demonstrando que os indivíduos portadores de transtornos psiquiátricos apresentam menor acesso efetivo aos serviços de saúde e recebem cuidados à saúde de pior qualidade ${ }^{11,12,17}$.

Kisely et al. avaliaram dados sobre usuários de seguro de saúde de Nova Scotia (Canadá) entre 1995 e 2001 e observaram que, embora a mortalidade cardiovascular destes indivíduos seja maior que a da população geral (ajustada por gênero e idade), a taxa de realização de procedimentos invasivos cardíacos é menor, como no caso do cateterismo cardíaco (RR 0,92; IC 95\% 0,86-0,98), ou igual a da população geral, como no caso da angioplastia percutânea (RR 0,97; IC 95\% 0,86-1,09) e revascularização miocárdica aberta (RR 0,92; IC 95\% 0,83-1,02). $\mathrm{O}$ autor também observou uma maior mortalidade associada a menor renda (RR 1,34; IC 95\% 1,27-1,41, quando comparado o maior e o menor quartil de renda) ${ }^{12}$.

Druss et al. avaliaram 88.241 indivíduos idosos com antecedente de infarto agudo do miocárdio que participaram do projeto Cooperative Cardiovascular Project para beneficiários do seguro de saúde Medicare e observaram que os portadores de doenças psiquiátricas (tendo sido excluído os portadores de diagnóstico de demência ou dellirium) apresentam menor chance de serem submetidos a terapia de reperfusão miocárdica (RR 0,87; IC 95\% 0,79-0,95), mesmo na ausência de qualquer contra-indicação ao procedimento "1.

$\mathrm{O}$ autor observou que há excesso de mortalidade por infarto agudo do miocárdio (RR 1,11; IC 95\% 1,02-1,20) para portadores de transtornos de humor (incluindo os transtornos depressivos). Porém, quando foi ajustado para medidas de qualidade de cuidado à saúde, esta diferença desaparece (RR 1,05; IC 95\% 0,87-1,23).

Há ainda evidências de que os portadores de transtorno depressivo apresentam alterações sistêmicas que podem causar doença cardiovascular. Os indivíduos portadores de transtorno depressivo apresentam uma hiperatividade do sistema hipotálamo-hipófiseadrenal, levando a um hipercortisolismo e a uma maior atividade simpática ${ }^{40-42}$.

O hipercortisolismo pode desencadear elevação dos níveis de pressão arterial, ganho de peso e aterosclerose precoce nos indivíduos expostos. As alterações do sistema autonômico levam a diversas alterações nos pacientes deprimidos como o aumento da freqüência cardíaca de repouso, menor variabilidade da frequência cardíaca e maior variabilidade do intervalo QT no eletrocardiograma, que são todos fatores de risco para arritmias ventriculares e morte súbita. Tais alterações podem explicar a maior frequência de taquicardia ventricular em pacientes deprimidos após infarto agudo do miocárdio e o aumento de mortalidade associado a depressão pós-infarto ${ }^{40}$.

Além disso, o aumento da atividade simpática gera vasoconstrição e maior ativação plaquetária. Há relatos sobre alterações da função plaquetária associada a quadros depressivos, com aumento da atividade e da aderência das plaquetas, podendo aumentar o risco de insuficiência coronariana aguda ${ }^{40,43}$. 
Há evidências sobre uma atividade inflamatória discretamente aumentada em portadores de transtornos depressivos, com estudos demonstrando maiores níveis de marcadores inflamatórios, como a proteína $\mathrm{C}$ reativa, interleucina - 6 e fator de necrose tumoral. Porém, esta associação é encontrada principalmente em homens, poupando as mulheres ${ }^{44}$. Existem ainda relatos sobre sinais de disfunção endotelial em indivíduos portadores de sintomas depressivos ${ }^{45}$.

Outro mecanismo de associação entre a presença de transtornos depressivos e surgimento de doença cardiovascular é a adesão a tratamentos de saúde. Os portadores de depressão apresentam pior adesão a tratamentos, gerando um maior impacto de comorbidades clínicas crônicas que possam eventualmente estar presentes. Di Matteo et al. observaram um odds ratio (OR) de 3,03 (IC 95\% 1,96-4,89) para não-adesão a recomendações de tratamento em indivíduos com depressão ${ }^{46}$.

Verifica-se ainda um componente genético que atua na associação entre o transtorno depressivo maior e a incidência de doença cardiovascular. Vaccarino et al. avaliaram 289 gêmeos monozigóticos e dizigóticos, que apresentavam discordância quanto ao diagnóstico prévio de depressão e compararam com gêmeos sem história prévia de depressão, em relação a exames sobre a função da microvasculatura coronariana ${ }^{47}$. Não foram observados sinais de isquemia miocárdica entre os gêmeos com e sem diagnóstico de depressão. No entanto, foi observado diferença entre gêmeos dizigóticos na reserva de fluxo coronariano, com pior função naqueles indivíduos com história prévia de depressão. Em gêmeos monozigóticos, não foi encontrada diferença na reserva de fluxo coronariano, sugerindo um papel de mecanismos genéticos na indução da alteração cardiovascular.

Estudos apontam para uma maior freqüência de alguns fatores de risco cardiovascular entre indivíduos portadores de transtornos depressivos e ansiosos, o que também pode mediar a associação entre estes transtornos psiquiátricos e a incidência de eventos cardiovasculares.

\subsection{ASSOCIAÇÃO ENTRE FATORES DE RISCO CARDIOVASCULAR E TRANSTORNOS PSIQUIÁTRICOS}

\subsubsection{Sobrepeso e obesidade}

O excesso de peso é definido por meio do índice de massa corporal (IMC) do indivíduo, que é calculado pela equação:

IMC $\left(\mathrm{kg} / \mathrm{m}^{2}\right)$ = peso em kilogramas / (altura em metros $\mathrm{x}$ altura em metros) 
O conceito de excesso de peso inclui indivíduos portadores de sobrepeso ou de obesidade. Os indivíduos são considerados portadores de obesidade quando o IMC se apresenta a partir de $30 \mathrm{~kg} / \mathrm{m}^{2}$. E os indivíduos são considerados portadores de sobrepeso quando o IMC se apresenta de $25 \mathrm{~kg} / \mathrm{m}^{2}$ até $29,9 \mathrm{~kg} / \mathrm{m}^{2} 48$.

Ambas condições têm apresentado uma prevalência elevada na população mundial, tanto em países desenvolvidos, quanto nos países emergentes e pobres ${ }^{48}$. Nos Estados Unidos da América, em 2004, a prevalência de obesidade era de 32,2\% da população, sendo que a prevalência de sobrepeso e obesidade associados (excesso de peso) chega a $66,3 \%$ da população ${ }^{49}$.

No Brasil, os dados nacionais são do estudo Vigitel 2009, que realiza a vigilância de fatores de risco e proteção para doenças crônicas por inquérito telefônico em 27 cidades brasileiras, e que vem sendo realizado anualmente pelo Ministério da Saúde desde 2006. Em 2009, a frequência de obesidade no Brasil foi de 13,9\% e na cidade de São Paulo de 13,1\% (IC 95\% 10,9-15,2), sendo de 13,2\% (IC 95\% 9,7-16,8) nos homens e de 12,9\% (IC 95\% 10,4-15,4) nas mulheres ${ }^{50}$.

A frequência nacional de excesso de peso foi de $46,6 \%$ da população estudada, atingindo 50,5\% (IC 95\% 46,1-54,9) dos entrevistados no município de São Paulo, com frequência de 55,9\% nos homens (IC 95\% 48,7-63,1) e 45,3\% nas mulheres (IC 95\% 40,849,8) nesta cidade.

Comparando-se os inquéritos realizados entre 2006 e 2009, observa-se que as frequências de sobrepeso e obesidade vem aumentando no país: $11,4 \%$ de obesos em 2006, comparados a 13,9\% em 2009 ( $\mathrm{p}<0,001)$. O excesso de peso, que acometia $42,7 \% \mathrm{da}$ população em 2006, chegou a 46,6\% em 2009 (p<0,001).

A associação entre excesso de peso e transtornos psiquiátricos é bastante debatida na literatura. Há evidências de que a obesidade esteja associada a transtornos de humor e de ansiedade. No entanto, a literatura demonstra possíveis diferenças de gênero nesta associação: enquanto nas mulheres a associação é direta ${ }^{51-56}$, alguns estudos demonstraram uma relação inversa entre homens ${ }^{53,57,58}$ ou ausência de associação ${ }^{55,56,59}$.

O estudo de Simon et al. avaliou amostra populacional de 48 estados americanos entre 2001 e 2002 no inquérito National Comorbity Survey Replication, com 9125 indivíduos adultos não-institucionalizados ${ }^{56}$. Observou-se que a prevalência de obesidade é maior em indivíduos com diagnóstico de transtorno de humor durante a vida (OR 1,27; IC 95\% 1,15-1,41), em indivíduos com diagnóstico de depressão maior (OR 1,21; IC 95\% 1,09-1,35) e em indivíduos com diagnóstico de transtorno de ansiedade (OR 1,28; IC 95\% 1,05-1,57). Observou-se ainda uma relação inversa em portadores de transtornos relacionados a uso de substâncias (OR 0,78; IC 95\% 0,65-0,93).

Neste estudo a associação entre obesidade e transtornos do humor foi observada em mulheres (OR, 1,29; IC 95\% 1,11-1,50), mas não em homens (OR 1,21; IC 95\% 0,99-1,46). 
A associação entre obesidade e transtornos de ansiedade também foi observada entre mulheres (OR 1,34; IC 95\% 1,09-1,64), mas não em homens (OR 1,17; IC 95\% 0,82-1,67).

Uma metanálise de Luppino et al. avaliou 15 estudos, que somam um total de 58.745 indivíduos, sobre a associação entre obesidade e depressão ${ }^{60}$. Os resultados indicam que indivíduos com obesidade apresentam maior incidência de depressão (OR 1,57; IC 95\% 1,23-2,01), assim como os portadores de sobrepeso também evoluem mais com depressão (OR, 1,08; IC 95\% 1,02-1,14). E os indivíduos com diagnóstico de depressão apresentaram maior incidência de obesidade (OR 1,40; IC 95\% 1,15-1,71), mas não foi observada esta associação com sobrepeso (OR 0,98; IC 95\% 0,83-1,16). A associação foi mais pronunciada em estudos com indivíduos americanos do que em estudos com europeus.

A suspensão do medicamento anorexígeno rimonabant (agonista de receptor endocanabinóide) do mercado europeu em 2008 devido a associação com suicídio em usuários, levou a questionamentos sobre a relação entre a perda de peso e o aumento de sintomas depressivos e tentativas de suicídio. Fabricatore et al. analisaram 31 ensaios clínicos sobre perda de peso com avaliação de sintomas depressivos antes e após a intervenção ${ }^{61}$. Houve melhora dos sintomas depressivos em todos os estudos que utilizaram estratégias não farmacológicas para redução de peso, favorecendo principalmente os que aliaram modificação do estilo de vida a prática de exercício físico. Portanto, a piora de sintomas depressivos poderia estar relacionada ao uso de medicamentos anorexígenos, não se associando especificamente à perda de peso, já que se observa melhora do humor com as estratégias não-farmacológicas.

A associação de transtornos de humor e de ansiedade com obesidade pode ser explicada, em parte, pelo uso de medicamentos psiquiátricos, já que o ganho de peso é um efeito colateral relativamente freqüente de alguns medicamentos de uso psiquiátrico ${ }^{62}$. Dentre os antidepressivos, o grupo dos tricíclicos (amitriptilina, nortriptilina, imipramina) estão associados a um maior ganho de peso e entre os antipsicóticos, a olanzapina está associada a maior ganho de peso.

\subsubsection{Diabetes mellitus}

O diabetes mellitus é uma doença crônica prevalente e se trata de um dos principais fatores de risco para aterosclerose precoce e eventos cardiovasculares. O diabetes mellitus pode ser diagnosticado em um indivíduo através de 3 maneiras, sendo recomendada confirmação laboratorial em mais de uma ocasião ${ }^{63}$ :

- medida da glicemia de jejum com valor igual ou superior a $126 \mathrm{mg} / \mathrm{dl}$.

- teste de tolerância oral a glicose alterado, com glicemia colhida após 120 minutos da ingestão de $75 \mathrm{~g}$ de glicose anidra, com valor maior ou igual a $200 \mathrm{mg} / \mathrm{dl}$. 
- glicemia casual alterada, com valor maior ou igual a $200 \mathrm{mg} / \mathrm{dl}$, caso acompanhada por sintomas de hiperglicemia, como perda de peso, polidipsia, poliúria, entre outros.

A incidência de diabetes mellitus vem aumentando nas últimas décadas, principalmente devido a sua associação com o sobrepeso e a obesidade ${ }^{64}$. No Brasil, dados do Vigitel 2009 mostram uma freqüência de diabetes de 5,8\% nos adultos entrevistados, sendo de 6,9\% (IC 95\% 5,3-8,6) no município de São Paulo, com freqüência de 6,7\% (IC95\% 4,5-8,8) em homens e de 7,2\% (IC95\% 4,7-9,6) em mulheres ${ }^{50}$. Já entre idosos com 65 anos ou mais, a prevalência chega a $22,1 \%$.

Há maior freqüência de diabetes entre os indivíduos de menor escolaridade, sendo que $7,9 \%$ dos indivíduos com de 0 a 8 anos de escolaridade apresentam o diagnóstico e 3,8\% entre indivíduos com 12 ou mais anos de escolaridade.

A frequência de diabetes mellitus vem aumentando nos últimos anos sendo de $5,2 \%$ em 2006 e passando a 5,8\% em 2009 ( $p=0,04$ ), sendo o aumento mais expressivo entre homens.

Devido aos métodos do estudo, as taxas de morbidade no Vigitel são referidas pelos entrevistados, com subestimação da prevalência real na população, já que o diabetes mellitus pode ser uma doença assintomática por anos, o que retarda o diagnóstico. Há estimativa de que $50 \%$ dos portadores de diabetes mellitus não apresentam diagnóstico da doença no município de São Paulo ${ }^{65}$. Além disso, o Vigitel foi realizado nas capitais brasileiras, não sendo fidedigno para características de população moradora de área rural.

A associação entre diabetes mellitus e transtornos de humor foi amplamente estudada. Em estudos de coorte, o diabetes mellitus aumenta a incidência de transtornos depressivos e os transtornos depressivos aumentam a incidência de diabetes mellitus, de forma que a associação é bidirecional.

Há duas metanálises publicadas sobre a associação entre diabetes e depressão: Knol et al. avaliaram nove estudos de coorte, com um total de 174.035 indivíduos, que realizaram seguimento de três a dezesseis anos, para avaliar a depressão como fator de risco para a incidência de diabetes mellitus ${ }^{66}$. Este estudo observou um risco relativo de 1,37 (IC 95\% 1,14-1,63).

Na metanálise de Mezuk et al. foi avaliada a associação entre diabetes e depressão ${ }^{67}$. Utilizando-se depressão como fator preditor para o surgimento de diabetes mellitus, foram encontrados 13 estudos, com 222.019 participantes, com RR de 1,60 (IC 95\% 1,37-1,88). Analisando-se o diabetes mellitus como fator preditor para o surgimento de depressão, foram avaliados sete estudos, com 113.271 indivíduos, resultando em um RR de 1,15 (IC 95\% 1,02-1,30).

Pan et al. avaliaram 78.282 mulheres de 54 a 79 anos no Nurses' Health Study e observaram que, após seguimento de 6 anos, a mortalidade por todas as causas em 
mulheres com depressão e diabetes mellitus foi maior (RR 2,07; IC 95\% 1,79-2,40) do que nas portadoras das mesmas doenças isoladamente (RR 1,44; IC 95\% 1,34-1,54 em portadoras de depressão somente e RR 1,35 IC 95\% 1,21-1,51 em mulheres com diabetes somente). O mesmo padrão ocorre com a mortalidade por doença cardiovascular: as portadoras de diabetes e depressão apresentam maior risco de morte (RR 2,72; IC 95\% 2,09-3,54) do que nas portadoras de depressão exclusiva (RR 1,37; IC 95\% 1,16-1,62) e diabetes exclusivo (RR 1,67 ; IC $95 \%$ 1,36-2,05) ${ }^{68}$.

\subsubsection{Hipertensão arterial}

A hipertensão arterial sistêmica é definida como a pressão arterial sistólica do indivíduo maior ou igual a $140 \mathrm{mmHg}$ e/ou a pressão arterial diastólica maior ou igual a $90 \mathrm{mmHg}$, sendo a medida realizada com o indivíduo em repouso, sentado e com confirmação da medida alterada em outra ocasião ${ }^{69}$. Também se trata de um dos mais importantes fatores de risco para desenvolvimento de doença cardiovascular.

Segundo dados do Vigitel 2009, 24,4\% dos brasileiros maiores de 18 anos relataram diagnóstico de hipertensão arterial realizado por médico ${ }^{50}$. No município de São Paulo 26,5\% (IC 95\% 23,1-29,9) dos entrevistados relataram hipertensão arterial, sendo mais freqüente entre mulheres, com frequência de 30,0\% (IC 95\% 25,4-34,5) do que entre homens, com freqüência de 22,6\% (IC 95\% 17,9-27,2).

A hipertensão arterial acomete cerca de $63,2 \%$ dos brasileiros com 65 anos ou mais e $50,4 \%$ dos brasileiros entre 55 e 64 anos de idade ${ }^{50}$. Apresenta uma relação inversa com a escolaridade, sendo mais freqüente nos indivíduos que possuem entre zero a oito anos de escolaridade quando comparados aos que possuem doze ou mais anos de educação formal.

Os dados do estudo Vigitel mostram que a prevalência de hipertensão arterial vem crescendo progressivamente, sendo de 21,5\% em 2006 e de 24,4\% em 2009 (p<0,001).

Há controvérsia na associação entre depressão, ansiedade e incidência de hipertensão arterial, pois os estudos apresentam resultados contraditórios. Yan et al. avaliaram 3.308 indivíduos adultos jovens (de dezoito a trinta anos), com seguimento de 15 anos, que participaram do estudo Coronary Artery Risk Development in Young Adults. Os indivíduos que apresentavam maior número de sintomas depressivos ou ansiosos não apresentaram maior incidência de hipertensão arterial durante o seguimento, independente de raça ou gênero ${ }^{70}$.

Um inquérito de saúde mental financiado pela Organização Mundial de Saúde entre 2002 e 2004 na África do Sul avaliou 4.351 indivíduos representativos da população nacional, não sendo observada associação entre hipertensão arterial e transtornos ansiosos, depressivos, ou ambos ${ }^{74}$. 
Resultados negativos também foram observados por Shinn et al. em estudo com 508 participantes entre 20 e 75 anos (Reno Diet Heart Study), com seguimento de 4 anos e por Meyer et al. que avaliaram 1.049 participantes do estudo sobre saúde mental Baltimore Epidemiologic Catchment Area, com seguimento de doze anos ${ }^{71,72}$.

No entanto, o estudo de corte transversal de Fiedorowicz et al. avaliou associação entre fatores de risco cardiovascular e diagnóstico psiquiátrico em amostra representativa da população americana entre 2001 e 2003 durante um inquérito de saúde mental (National Comorbity Survey Replication). Foram avaliados 5.692 participantes com 18 anos ou mais, sendo observada uma associação entre hipertensão arterial e depressão maior (OR 1,52; IC 95\% 1,01-2,29) e entre hipomania e hipertensão arterial (OR 2,22; IC 95\% 1,55-3,19) entre homens. Também foi observada entre mulheres associação entre hipertensão arterial e depressão maior (OR 1,63; IC 95\% 1,23-2,15) e entre hipertensão arterial e hipomania (OR 1,71; IC 95\% 1,05-2,77). Também foi observada associação para transtornos ansiosos e hipertensão arterial em homens (OR 1,37; IC 95\% 1,05-1,79) e em mulheres (OR 1,62; IC $95 \%$ 1,22-2,14). No entanto, por se tratar de estudo de corte transversal, não há como discutir a direção desta associação ${ }^{55}$.

Outro estudo com resultado positivo foi o de Jonas et al. que avaliou 2.992 indivíduos normotensos entre 1971 e 1975 do estudo National Health and Nutrition Examination Survey I (NHANES), com seguimento de sete a dezesseis anos ${ }^{73}$. Houve uma associação positiva entre freqüência elevada de sintomas ansiosos e depressivos com a incidência de hipertensão arterial. Entre indivíduos de raça negra, a associação aparece desde a faixa etária mais jovem, entre 25 e 64 anos (RR 2,99; IC 95\% 1,41-6,33 para sintomas depressivos e RR 2,74; IC 95\% 1,35-5,53 para sintomas ansiosos). Nos indivíduos de raça branca, a associação se torna evidente na faixa etária entre 45 e 64 anos com associação para sintomas depressivos (RR 1,80; IC 95\% 1,16-2,78) e sintomas ansiosos (RR 1,82; IC 95\% 1,302,53), mas sem uma diferença significativa na faixa etária entre 25 e 44 anos.

O estudo de Stern et al. avaliou em uma coorte de idosos entre 65 e 78 anos com dois grupos étnicos: americanos de origem mexicana e americanos de origem européia, seguidos por sete anos em média, no San Antonio Longitudinal Study of Aging ${ }^{75}$. Foi encontrada uma associação entre sintomas depressivos e a sensação de abandono como preditores de risco para incidência de hipertensão arterial (RR 4,9; IC 95\% 1,9-13,1).

Portanto, devido aos resultados contraditórios observados, não há evidência suficiente para afirmar ou rejeitar a associação entre a hipertensão arterial e os transtornos de humor e/ ou de ansiedade.

Há alguns relatos de aumento de nível pressórico devido ao uso de antidepressivos. Tal afirmação se relaciona principalmente ao uso de venlafaxina, sendo um efeito dosedependente e aos inibidores de recaptação de serotonina ${ }^{76}$. No entanto, este efeito acomete somente $4 \%$ dos pacientes em uso da medicação, sendo causa rara de hipertensão arterial. 


\subsubsection{Dislipidemia}

As dislipidemias são um grupo de alterações metabólicas relacionadas aos lípides sanguíneos, que se constituem em fatores de risco para doença aterosclerótica. Podem ser de vários tipos: por aumento de lipoproteína de baixa densidade (low density lipoprotein - LDL-colesterol), por redução de lipoproteína de alta densidade (high density lipoprotein HDL-colesterol), por aumento de triglicérides, ou ainda por alterações de outras partículas aterogênicas. Estas alterações metabólicas podem ocorrer isoladamente ou associadas entre $\mathrm{si}^{77}$.

São considerados como dislipidêmicos os indivíduos que apresentam (desde que repetidos em pelo menos mais de uma ocasião):

- Triglicérides: maior ou igual a $150 \mathrm{mg} / \mathrm{dl}$

- HDL-colesterol: menor do que $40 \mathrm{mg} / \mathrm{dl}$

- LDL-colesterol: maior do que o limite considerado para cada indivíduo, a depender do risco cardiovascular.

O valor a ser considerado normal depende de alguns fatores. Caso o indivíduo apresente doença aterosclerótica manifesta como infarto agudo do miocárdio prévio ou angina, acidente vascular cerebral, ou ainda equivalentes como doença arterial periférica, aneurisma de aorta abdominal, doença de artéria carótida sintomática, diabetes mellitus ou escore de risco de Framingham maior de 20\%, a meta de LDL-colesterol deverá ser abaixo de $100 \mathrm{mg}$ dl (com meta opcional de $<70 \mathrm{mg}$ dl). Caso o indivíduo apresente dois ou mais fatores de risco cardiovascular e ou um escore de risco de Framingham entre 10 e $20 \%$, a meta de LDL-colesterol deverá ser $<130 \mathrm{mg}$ dl (com meta opcional de $<100 \mathrm{mg}$ dl). Se o indivíduo apresentar dois ou mais fatores de risco cardiovascular e um escore de risco de Framingham $<10 \%$, a meta de LDL-colesterol deverá ser de $<130 \mathrm{mg}$ dl. E caso o indivíduo apresente um fator de risco cardiovascular e um escore de risco de Framingham $<10 \%$, a meta de LDL-colesterol é $<160 \mathrm{mg}$ dl.

O estudo Vigitel 2009 relata que 16,9\% dos entrevistados apresentam diagnóstico médico de algum tipo de dislipidemia ${ }^{50}$. No município de São Paulo, 15\% (IC 95\% 13,017,1) da população estudada referem diagnóstico de dislipidemia, sendo observado $17,4 \%$ (IC 95\% 14,9-20,0) entre mulheres e 12,3\% (IC 95\% 9,2-15,4) entre homens. Há um aumento da prevalência de dislipidemia no Brasil com o passar da idade: 36,7\% (IC 95\% 34,5-39,0) dos indivíduos com 65 anos ou mais apresentam dislipidemia, sendo que este percentual chega a 43,1\% (IC 95\% 40,3-45,8) em mulheres e 26,6\% (IC 95\% 23,0-30,2) em homens.

Há estudos que evidenciam associação entre dislipidemias e sintomas depressivos e/ ou ansiosos, porém os resultados são bastante contraditórios. Há estudos que demonstram associação entre depressão e ansiedade e dislipidemia ${ }^{78-80}$, embora haja uma dúvida 
quanto ao tipo de dislipidemia associada, sendo que alguns relacionam com níveis altos de triglicérides ou LDL - colesterol, outros com níveis baixos de HDL-colesterol. Outros estudos apontam para uma associação inversa, com relatos de que níveis reduzidos de colesterol estão associados a maior risco de suicídio, comportamento violento, agressividade e sintomas depressivos ${ }^{81-85}$. Há ainda os que não demonstram nenhuma associação ${ }^{86,87}$.

Wiltink et al. avaliaram 4753 indivíduos alemãos entre 35 e 74 anos e observaram que havia associação entre depressão e dislipidemia (OR 1,35; IC 95\% 1,02-1,79). Não houve associação entre dislipidemia e transtorno de ansiedade generalizada (OR 1,02; IC 95\% $0,69-1,51)^{78}$.

Glassy et al. avaliaram 164 indivíduos latinos em estudo transversal entre 18 e 83 anos e observou correlação positiva entre os níveis de sintomas depressivos com índice de massa corporal $(\mathrm{p}<0,05)$ e níveis de triglicérides $(\mathrm{p}<0,05)$. Não foi encontrado associação com níveis de HDL-colesterol ou LDL-colesterol ${ }^{79}$. Huang et al. avaliaram 162 pacientes em estudo transversal em Taiwan e observaram níveis de HDL - colesterol menores em homens com transtorno ansioso quando comparados a pacientes com transtorno depressivo e sem doença psiquiátrica. Não foi encontrada diferença nos níveis lipêmicos entre mulheres com transtornos depressivos ou ansiosos e sem doença psiquiátrica ${ }^{88}$.

Há metanálise publicada por Shin et al., que observaram que níveis elevados de colesterol total estão associados com menores níveis de depressão, com uma associação mais robusta entre amostras que não utilizam medicações. Não foi encontrada associação com LDL-colesterol e depressão. E foi observado que níveis altos de HDL-colesterol se correlacionaram com maiores níveis de depressão, especialmente em mulheres ${ }^{81}$.

Apesar dos resultados contraditórios, há causas mediadoras que podem ser responsáveis pela associação ou atuar como fator de confusão na associação entre dislipidemia e transtornos depressivos. Há evidência consistente sobre o pior estilo de vida adotado por estes pacientes, com maior frequência de tabagismo, menor nível de atividade física, alimentação de pior qualidade, que em conjunto podem levar a alterações nos níveis lipêmicos.

Além disso, alguns estudos sugerem que a associação entre obesidade e sintomas depressivos, principalmente entre as mulheres, pode mediar esta associação ${ }^{89}$. Faltam estudos longitudinais e com controle para variáveis de confusão para melhor avaliação dessa associação.

\subsubsection{Síndrome metabólica}

A síndrome metabólica é uma entidade clínica recente, descrita por Heaven em 1985, para descrever as condições associadas à hiperinsulinemia e obesidade abdominal, 
que resultam em aumento de mortalidade cardiovascular. Diversas entidades postulam diferentes definições para a síndrome metabólica, que geralmente associa a circunferência abdominal elevada a um aumento dos níveis pressóricos, hipertrigliceridemia, níveis de HDL-colesterol reduzidos e níveis de glicemia elevados. A definição mais aceita é a proposta pela diretriz da National Cholesterol Education Program's Adult Treatment Panel III (NCEP-ATPIII) que considera como portador de síndrome metabólica o indivíduo que apresentar três ou mais dos cinco critérios a seguir ${ }^{90}$ :

- Aumento da circunferência abdominal, considerado maior do que 102 centímetros para homens e maior do que 88 centímetros para mulheres.

- Aumento do nível de triglicérides plasmáticos (maior ou igual a $150 \mathrm{mg} / \mathrm{dl}$ ).

- Redução dos níveis de HDL-colesterol (menor do que 40 mg/dl para homens e menor do que $50 \mathrm{mg} / \mathrm{dl}$ para mulheres).

- Aumento dos níveis pressóricos (pressão arterial sistólica maior ou igual a $130 \mathrm{mmHg}$ e/ou pressão arterial diastólica maior ou igual a $85 \mathrm{mmHg}$ ).

- Aumento dos níveis de glicemia de jejum (maior ou igual a 100 mg/dl).

Ainda não há estudos populacionais sobre a prevalência nacional de síndrome metabólica no Brasil. No entanto, há uma estimativa calculada a partir dos dados do estudo Vigitel 2007 e que considerou como síndrome metabólica a presença de dois ou mais dos seguintes critérios: diabetes mellitus, dislipidemia, hipertensão arterial ou obesidade. Foi estimado que 14,2\% (IC 95\% 13.6-14,8) da população brasileira apresentava síndrome metabólica ${ }^{91}$.

Silva et al. avaliaram 214 indivíduos de 20 a 64 anos residentes na área metropolitana de São Paulo e observaram uma prevalência bruta de síndrome metabólica de 36,6\% e uma prevalência padronizada para gênero e idade de $34 \%{ }^{92}$. Silveira et al. avaliaram um total de 3.599 participantes da coorte de nascidos em 1982 em Pelotas e encontraram uma frequência de 5,9\% de portadores de síndrome metabólica ${ }^{93}$. No entanto, a frequência relativamente baixa da síndrome pode estar relacionada a faixa etária jovem desta coorte (por volta de 23 anos na época do estudo). Barbosa et al. avaliaram 1.424 indivíduos maiores de 20 anos moradores de Salvador e observaram uma frequência de síndrome metabólica de $23 \%$ nesta população ${ }^{94}$.

A associação entre transtornos psiquiátricos e síndrome metabólica tem sido bastante discutida. A depressão e os sintomas depressivos podem ser considerados fatores preditores para o surgimento de síndrome metabólica, mas esse efeito é possivelmente restrito ao gênero feminino ${ }^{95-97}$, pois a maior parte dos estudos não encontra associação em homens ${ }^{96,97}$. Há maior controvérsia na associação entre ansiedade e síndrome metabólica, pois os estudos apresentam resultados conflitantes ${ }^{95,99}$.

Raikkonen et al. avaliaram 432 mulheres na pré-menopausa da coorte Healthy Women 
Study, com seguimento por cerca de 15 anos ${ }^{95}$. Observou-se que os sintomas depressivos estavam associados à incidência de síndrome metabólica, com um RR de 1,29 (IC 95\% 1,04-1,60). Não houve associação com sintomas ansiosos (RR 1,07; IC 95\% 0,87-1,32).

Kinder et al. publicaram estudo de corte transversal com dados do National Health and Nutrition Examination Survey III (NHANES) que avaliou 6.189 indivíduos com idade entre 17 e 39 anos e observaram uma associação positiva entre a presença de síndrome metabólica e história de depressão maior durante a vida em mulheres, com OR 1,96 (IC95\% 1,03-3,73), porém sem associação em homens ${ }^{96}$.

Koponen et al. avaliaram em uma coorte de 688 indivíduos finlandeses, com seguimento de 7 anos e encontraram associação entre sintomas depressivos e incidência de síndrome metabólica em mulheres com OR de 2,2 (IC95\% 1,1-4,5), porém sem diferença estatisticamente significativa em homens ${ }^{97}$. Goldbacher et al. avaliaram 429 mulheres do período peri-menopausa, com seguimento de 7 anos, observando-se OR de 1,82 (IC 95\% 1,06-3,14) de incidência de síndrome metabólica em mulheres com história de depressão maior prévia ${ }^{98}$.

Há estudo de Carroll et al. que avaliou a associação entre depressão maior e transtornos de ansiedade generalizada e síndrome metabólica em 4.256 homens veteranos de guerra do Vietnã, observando-se ausência de associação entre depressão maior e síndrome metabólica, mas com associação positiva entre transtorno de ansiedade generalizada e síndrome metabólica (OR 1,39; IC 95\% 1,02-1,89) ${ }^{99}$.

Também foram realizados poucos estudos investigando se a síndrome metabólica poderia aumentar o risco de incidência de depressão e ansiedade. Takeuchi et al. avaliaram 956 homens trabalhadores em Tóquio, entre 20 e 66 anos, que foram reavaliados em 1 ano. Os indivíduos com síndrome metabólica evoluíram com maior incidência de depressão (OR 2,14; IC 95\% 1,10-4,17), sem aumento da incidência de ansiedade ${ }^{100}$.

Há dados brasileiros sobre a associação entre síndrome metabólica e transtornos psiquiátricos em estudos transversais. Teixeira et al. avaliaram a presença de síndrome metabólica entre 170 pacientes internados por causa psiquiátrica no Hospital Governador Israel Pinheiro em Belo Horizonte, sendo que 29,4\% (IC 95\% 22,7-36,9) apresentavam síndrome metabólica ${ }^{101}$. Houve uma diferença entre os gêneros, sendo que 43,8\% (IC 95\% 31,4-56,7) das mulheres e 20,8\% dos homens (IC 95\% 13,5-29,7) apresentavam síndrome metabólica. Houve também diferença entre a frequência de síndrome metabólica de acordo com o diagnóstico psiquiátrico, com freqüências mais elevadas entre os deprimidos (40,0\% entre homens e 52,9\% em mulheres).

Gomes et al. avaliaram em estudo transversal 65 pacientes adultos com transtorno afetivo bipolar em tratamento ambulatorial no Hospital das Clínicas de Porto Alegre, encontrando uma frequência de síndrome metabólica de 24,4\% em mulheres e de $50 \%$ em homens ${ }^{102}$. 
Há explicações fisiopatológicas para a associação entre a síndrome metabólica e os sintomas depressivos. Possivelmente, há um papel relacionado ao hipercortisolismo, que pode estar presente em parte dos quadros depressivos, o que aumentaria a resistência a insulina e o ganho de peso ${ }^{103}$. Além disso, a presença de inflamação sistêmica parece ser um substrato comum. Capuron et al. avaliaram 323 homens gêmeos e observaram associação entre síndrome metabólica, sintomas depressivos e elevações na dosagem de proteína $\mathrm{C}$ reativa e de interleucina 6, quando comparado aos irmão gêmeo livre de síndrome metabólica ${ }^{104}$.

\subsubsection{Estilo de vida}

Há um papel importante do estilo de vida do indivíduo na gênese da doença cardiovascular, incluindo o tabagismo e o sedentarismo. No Brasil, dados do estudo Vigitel 2009 demonstram que 15,5\% (IC 95\% 14,5-16,5\%) da população brasileira é fumante, sendo que no município de São Paulo 18,8\% (IC 95\% 15,5-22,1) dos entrevistados são fumantes, com diferenças entre os gêneros: 21,0\% (IC 95\% 15,3-26,7) dos homens paulistanos fumam e 16,9\% (IC 95\% 13,1-20,7) das mulheres. O tabagismo também é mais frequente na população com menor escolaridade ${ }^{50}$.

Quanto ao sedentarismo, 13,2\% (IC 95\% 12,6-13,9) da população brasileira não realiza qualquer atividade física, sendo que no município de São Paulo são 10,2\% (IC 95\% 8,7-12,0) dos indivíduos entrevistados relataram ser sedentários, com diferença entre os gêneros: 14,9\% (IC 95\% 11,6-18,3) dos homens e 6,4\% (IC 95\% 5,0-7,9) das mulheres.

Há evidências sobre o fato de que os indivíduos portadores de transtornos de humor e de ansiedade apresentam um pior estilo de vida do que a população geral. Estes indivíduos apresentam o dobro de chance de fumar e menor chance de realizar atividade física ${ }^{105,106}$.

Lasser et al. avaliaram 4.411 participantes do National Comorbidity Survey realizado entre 1990 e 1992 e observaram que portadores de transtorno mental durante a vida apresentam OR de 1,9 (IC 95\% 1,7-2,2) de serem tabagistas quando comparados aos indivíduos sem história de transtorno psiquiátrico ${ }^{106}$. A associação foi maior para aqueles indivíduos com antecedente de transtorno psiquiátrico no último mês (OR 2,7; IC 95\% 2,3-3,1).

Lawrence et al. avaliaram 8.841 adultos de inquérito australiano de saúde mental e 9.282 indivíduos de inquérito americano de saúde mental e observaram que 36\% (IC 95\% 32,9-39,6) dos australianos e 40,1\% (IC 95\% 37,6-42,7) dos americanos que apresentam transtornos psiquiátricos são tabagistas, comparados com 18,8\% (IC 95\% 17,2-20,4) dos australianos e 21,3\% (IC 95\% 20,1-22,5) dos americanos que não apresentam nenhum transtorno psiquiátrico ${ }^{105}$. Entre os participantes americanos foi observado que entre os portadores de transtornos de humor, 45,1\% (IC 95\% 41,1-49,2) eram tabagistas e entre os portadores de transtornos de ansiedade 37,6\% (IC 95\% 34,6-40,7) eram tabagistas. 
Jacka et al. avaliaram 755 mulheres australianas entre 20 e 94 anos e observaram que mulheres que apresentavam episódio de depressão prévio também apresentavam maior frequência de haverem fumado na vida $(43,5 \% \text { vs } 34,3 \%, p=0,038)^{107}$.

Bonnet et al. avaliaram 1.612 indivíduos que compareceram a uma clínica de prevenção e detecção de aterosclerose na França e avaliaram presença de sintomas depressivos e ansiosos. Tanto homens quanto mulheres com sintomas depressivos apresentaram maior frequência e intensidade de tabagismo ( $p=0,03$ entre homens e $p=0,009$ entre mulheres). Entre indivíduos com sintomas ansiosos, a frequência de tabagismo foi maior entre homens $(\mathrm{p}=0,006)$, porém não entre mulheres ${ }^{108}$.

Em relação à atividade física, indivíduos com sintomas ansiosos e/ou depressivos, apresentavam maior frequência de sedentarismo do que os indivíduos sem sintomas ( $\mathrm{p}=0,01$ para homens e $\mathrm{p}=0,02$ para mulheres com sintomas ansiosos e $\mathrm{p}=0,0005$ para homens e $\mathrm{p}<0,0001$ para mulheres com sintomas depressivos).

Strine et al. avaliaram 217.379 participantes em inquérito populacional americano realizado por telefone e observou pior estilo de vida em indivíduos portadores de ansiedade elou depressão ${ }^{109}$. Indivíduos de ambos os gêneros com episódio atual de depressão apresentavam maior frequência de tabagismo (37,9\% vs 17,6\%, OR 2,2; IC 95\% 2,0-2,3), de obesidade (35,2\% vs $23,6 \%$, OR 1,6; IC 95\% 1,5-1,7\%) e de sedentarismo ( $43,0 \%$ vs $21,2 \%$, OR 2,1; IC 95\% 1,9-2,3). Indivíduos com diagnóstico de depressão prévia também apresentavam maior frequência de tabagismo (30,8\% vs 17,3\%, OR 1,9; IC 95\% 1,8-2,1), de obesidade (32,8\% vs $23,3 \%$, OR 1,6; IC 95\% 1,5-1,7) e de sedentarismo (30,6\% vs $22,6 \%$, OR 1,3; IC 95\% 1,21,4). Indivíduos com diagnóstico de ansiedade durante a vida também apresentavam maior frequência de tabagismo (33,0\% vs $17,7 \%$, OR 2,0; IC 95\% 1,9-2,2), de obesidade (30,5\% vs 24,0\%, OR 1,3; IC 95\% 1,3-1,4) e de sedentarismo (29,0\% vs 23,2\%, OR 1,1; IC 95\% 1,1-1,2).

Mykletun et al. avaliaram 60.814 indivíduos noruegueses entre 20 e 89 anos e observaram que houve associação entre tabagismo e ansiedade (OR 1,56; IC 95\% 1,49-1,63) e entre tabagismo e depressão (OR 1,48; IC 95\% 1,40-1,57) após ajuste para idade e gênero ${ }^{110}$. Também foi observado que a associação é maior quando há co-morbidade entre depressão e ansiedade (OR 1,82; IC 95\% 1,69-1,95) do que nos portadores de ansiedade somente (OR 1,43; IC 95\% 1,35-1,52) e nos portadores de depressão (OR 1,16; IC 95\% 1,07-1,26).

\subsubsection{Escore de risco de Framingham}

A estratificação de risco é uma ferramenta útil na identificação de sujeitos de maior risco de eventos cardiovasculares e por isso é recomendada pelo Ministério da Saúde do Brasil dentro das estratégias de prevenção de doenças cardiovasculares ${ }^{111}$ e também por instituições internacionais como a American Heart Association e NCEP ATP III. 
O escore de risco de Framingham (ERF) é um sistema de pontuação baseado em modelo matemático realizado a partir das informações obtidas no Framingham Heart Study e que resulta em estimativa de risco de doença coronariana, morte súbita e infarto agudo do miocárdio em 10 anos ${ }^{112}$. Os fatores de risco considerados no ERF são: idade, níveis de pressão arterial, níveis de colesterol total e HDL-colesterol, presença de tabagismo, diagnóstico de diabetes mellitus. Devido às diferenças de gênero quanto ao impacto dos fatores de risco cardiovascular utilizados, as tabelas de estratificação de risco foram separadas para homens e mulheres.

Os resultados em percentuais do ERF são classificados da seguinte maneira ${ }^{113,}{ }^{114}$ :

- Menor do que 10\% de eventos cardiovasculares em 10 anos - baixo risco

- De 10 a 20\% de eventos cardiovasculares em 10 anos - médio risco

- Maior de 20\% de eventos cardiovasculares em 10 anos - alto risco

Há discussão sobre a aplicabilidade do ERF nas diferentes populações, uma vez que alguns estudos demonstram que o ERF resulta em superestimação do risco em populações européias, apesar de apresentar predição fidedigna em populações dos EUA, Nova Zelândia e Austráliaa ${ }^{115}$.

Nos Estados Unidos da América, Dhangana et al. avaliaram 6.292 indivíduos de 40 anos ou mais, livres de doença coronariana conhecida e observaram que $71,5 \%$ dos indivíduos apresentaram baixo risco pelo ERF, 19,7\% apresentaram risco médio e 8,8\% apresentaram risco alto ${ }^{116}$.

No Brasil não há estimativas nacionais da aplicabilidade do ERF, nem da distribuição por gênero e por faixa etária das estimativas de risco pelo ERF. No entanto, há relatos da utilização do ERF em alguns grupos.

Rodrigues e Philippi descreveram o risco cardiovascular de 329 executivos de grandes empresas, de nível sócio-econômico elevado ${ }^{117}$. A amostra era formada predominantemente por homens (89,7\%) e de faixa etária jovem (idade média 44,8 anos nos homens e 42,6 anos em mulheres). Foi observado que entre as mulheres, 100\% apresentavam baixo risco pelo ERF e dentre os homens, $84,1 \%$ eram classificados como baixo risco, $13,2 \%$ de risco médio e $2,7 \%$ de risco alto.

Barreto et al. avaliaram 1.712 indivíduos entre 30 e 74 anos residentes do município de Bambuí-MG e dividiram seus resultados em duas faixas etárias: de 30 a 59 anos e de 60 a 74 anos ${ }^{118}$. Dentre a população de 30 a 59 anos, foi observado que entre homens, $82,0 \%$ apresentavam baixo risco de eventos pelo ERF, $14 \%$ apresentavam risco médio e $4 \%$ apresentavam alto risco. Entre as mulheres, $87,8 \%$ apresentavam risco baixo de eventos estimados pelo ERF, 7,8\% apresentavam médio risco e 4,4\% apresentavam alto risco. Já a população de 60 a 74 anos, apresentava distribuição bastante diversa, sendo que entre homens somente 9,3\% apresentavam baixo risco, 34,7\% apresentavam risco médio e 56,0\% 
apresentavam alto risco. Entre as mulheres idosas, 32,3\% apresentavam baixo risco, 46,7\% apresentavam médio risco e $21,0 \%$ apresentavam alto risco.

Matos e Ladela avaliaram 126 adultos da vila de Cavunge, área rural de Ipecaetá-BA, o que representa cerca de $25,6 \%$ da população residente no local, com média de idade de 46,6 anos ${ }^{119}$. Foi observado que entre homens, $41,8 \%$ apresentavam alto risco cardiovascular, 9,1\% apresentavam médio risco e 49,1\% apresentavam baixo risco. Entre as mulheres, foi dividido o grupo entre as que já se apresentavam em menopausa e as em idade fértil. Das mulheres em idade fértil, $83,3 \%$ apresentavam baixo risco, 9,5\% alto risco e 7,2\% risco médio. Das mulheres em fase pós-menopausa, 79,3\% apresentavam alto risco, 10,3\% risco médio e $10,4 \%$ apresentavam baixo risco.

Landim e Victor avaliaram 107 motoristas de transportes coletivos de Teresina-Piauí e observaram que entre os indivíduos com faixa etária de 31 a 35 anos, 100\% dos motoristas apresentavam baixo risco ${ }^{120}$. Na faixa etária de 36 a 40 anos, 96,4\% dos indivíduos eram de baixo risco e 3,6\% de médio ou alto risco. Na faixa etária de 41 a 45 anos, 88,5\% dos participantes eram de baixo risco e $11,5 \%$ de médio ou alto risco. Na faixa etária de 46 a 50 anos, 76,9\% dos motoristas eram de baixo risco e 23,1\% de médio ou alto risco. E por fim, na faixa etária de 51 a 55 anos, $40 \%$ dos indivíduos eram de baixo risco e $60 \%$ eram de médio ou alto risco.

Estes estudos demonstram claramente o impacto da idade na determinação do risco cardiovascular, já que no ERF a idade é o fator de maior pontuação, tendo em vista a fisiopatologia da doença cardiovascular aterosclerótica. Khot et al. avaliaram resultados de 14 ensaios clínicos sobre eventos cardiovasculares agudos, incluindo infarto agudo do miocárdio (com e sem supradesnivelamento do segmento ST) e angina instável, com um total de 122.458 indivíduos e observaram que, entre homens, 15,4\% não apresentavam nenhum fator de risco cardiovascular, exceto a idade e que, entre as mulheres, $19,4 \%$ também não apresentavam nenhum fator de risco. Entre as mulheres acima de 75 anos e entre homens acima de 65 anos, este percentual excede $20 \%{ }^{121}$.

Apesar de haver vários estudos relacionando diversos fatores de risco cardiovascular em portadores de transtornos de humor e/ou de ansiedade, foi encontrado somente um estudo que utilizou o ERF como ferramenta de estratificação de risco nestes indivíduos. Koponen et al. avaliaram 923 indivíduos de meia idade em estudo de corte transversal e observaram associação entre sintomas depressivos e maior escore de risco de Framingham em homens (OR 2,2 IC 95\% 1,1-4,2), porém sem associação em mulheres (OR 1,3 IC 95\% 0,7-2,6) ${ }^{131}$. 


\subsubsection{Proteína C reativa ultra-sensível}

A dosagem de proteína $\mathrm{C}$ reativa ultra-sensível (PCR) tem sido debatida na literatura científica enquanto um fator de risco não tradicional para eventos cardiovasculares. Os indivíduos podem ser classificados a partir da dosagem de PCR em:

- Alto risco cardiovascular - PCR > 3,0 mg/l

- Médio risco cardiovascular - PCR 1,0 a 3,0 mg/l

- Baixo risco cardiovascular - PCR $<1,0 \mathrm{mg} / \mathrm{l}$

Há evidência de que a dosagem de PCR elevada (>3,0 mg/l) são preditores de um risco mais elevado quando comparados aos portadores de níveis normais de PCR $(<1,0 \mathrm{mg} / \mathrm{l}) \mathrm{com}$ um RR de 1,58 (IC 95\% 1,37-1,83), ajustado para outros fatores de risco cardiovascular ${ }^{122}$.

Dhangana et al. avaliaram 6.292 indivíduos de 40 anos ou mais, sem doença cardiovascular, participantes do National Health and Nutrition Examination Survey e observaram que, entre os indivíduos com risco baixo ou médio classificados pelo ERF, 34,3\% (IC95\% 32,7-36.0) destes apresentam um medida de PCR elevada (> 3,0 mg/l) $\left({ }^{116}\right)$.

Embora ainda não haja recomendação para estratificação de risco com o uso da dosagem sistemática de PCR na população, há algumas evidências apontando que sua utilização possa ser benéfica.

Ridker et al. avaliaram o efeito de placebo ou rosuvastatina em 17.802 indivíduos saudáveis, com níveis de LDL-colesterol menores do que $130 \mathrm{mg} / \mathrm{dl}$ e com níveis de PCR de 2,0 mg/l ou mais ${ }^{123}$. Após um seguimento mediano de 1,9 anos, os indivíduos que utilizaram rosuvastatina apresentaram menos eventos cardiovasculares (RR 0,56; IC 95\% 0,46-0,69).

Existe ausência de estudos nacionais que descrevam a frequência de portadores de níveis elevados de PCR abrangendo o território nacional. No entanto, Pitanga e Lessa avaliaram 822 indivíduos saudáveis de amostra populacional da cidade de Salvador e observaram que 22,7\% dos homens apresentavam PCR maior ou igual a 3,0 mg/l e 32,5\% das mulheres ${ }^{124}$.

Diversos estudos que demonstram um maior nível de PCR em homens portadores de depressão maior, porém o mesmo não é observado entre mulheres (125-127). Os estudos também evidenciam que esta associação ocorre quando o episódio depressivo é recente (menos de um ano), porém desaparece em indivíduos com quadro de depressão mais antigo $^{126,127}$.

Howren et al. realizaram metanálise de 49 estudos que investigaram a associação entre depressão e níveis de PCR, resultando em associação significante em homens, porém não em mulheres ${ }^{125}$. Também foi observado que o ajuste para índice de massa corporal atenua a associação, porém permanece significante. 
Alguns estudos discutem a possibilidade da associação entre níveis elevados entre PCR e transtornos depressivos ser mediado pela associação com obesidade ${ }^{128,129}$ ou ainda pela associação com maior morbidade física ${ }^{130}$. 


\section{OBJETIVOS}

\subsection{OBJETIVO PRINCIPAL}

Avaliar a associação entre a presença de fatores de risco para doença cardiovascular e diagnósticos psiquiátricos em participantes de Inquérito de Saúde Mental São Paulo Megacity, realizado na Grande São Paulo (município de São Paulo e 38 municípios adjacentes).

\subsection{OBJETIVOS SECUNDÁRIOS}

Avaliar associação de características de estilo de vida e presença de transtorno de humor e/ou transtorno de ansiedade.

Avaliar associação entre presença de alterações em medidas antropométricas e presença de transtorno de humor e/ou transtorno de ansiedade.

Avaliar associação entre presença de fatores de risco para doença cardiovascular e presença de transtorno de humor e/ou transtorno de ansiedade. 



\section{MÉTODOS}

O Inquérito de Saúde Mental São Paulo Megacity é um estudo de base populacional que avaliou a prevalência de morbidade psiquiátrica na área metropolitana de São Paulo, sendo conduzido como parte do estudo multicêntrico World Mental Health Survey realizado pela Organização Mundial de Saúde (OMS) com a participação de trinta países, e coordenado pela Harvard Medical School e pela Michigan University, ambas situadas nos Estados Unidos da América.

O Inquérito de Saúde Mental São Paulo Megacity avaliou uma amostra de indivíduos residentes na área metropolitana de São Paulo, que engloba a capital e 38 municípios adjacentes, que serão denominados ao longo deste estudo como Grande São Paulo (Quadro 3), com uma área total de $8.051 \mathrm{~km}^{2}$ e uma população estimada de 17,5 milhões de habitantes pelo Instituto Brasileiro de Geografia e Estatística (IBGE) ${ }^{132}$.

$\mathrm{O}$ estudo foi dividido em duas fases: a primeira consistiu em entrevista domiciliar utilizando o instrumento Composite International Diagnostic Interview (CIDI), aplicado por entrevistadores leigos treinados. O principal objetivo da primeira fase do Inquérito de Saúde Mental São Paulo Megacity foi avaliar as taxas de prevalência de transtornos psiquiátricos nos últimos doze meses e durante a vida.

$\mathrm{Na}$ segunda fase do estudo foi feito convite para que uma amostra dos indivíduos entrevistados na fase domiciliar comparecesse para uma avaliação no âmbito hospitalar. O objetivo da segunda fase do Inquérito de Saúde Mental São Paulo Megacity foi realizar avaliação detalhada do perfil de morbidade clínica dos indivíduos e realizar uma nova avaliação psiquiátrica, com realização de entrevista semi-estruturada por psiquiatras treinados. Os dados apresentados nesta tese se referem à avaliação realizada na segunda fase do Inquérito de Saúde Mental São Paulo Megacity. 


\section{QUADRO 3}

Municípios incluídos na amostragem do Inquérito de Saúde Mental São Paulo Megacity, realizado entre 2005 e 2007

\begin{tabular}{|l|l|l|}
\hline Arujá & Guararema & Ribeirão Pires \\
\hline Barueri & Guarulhos & Rio Grande da Serra \\
\hline Biritiba-Mirim & Itapecerica da Serra & Salesópolis \\
\hline Caieiras & Itapevi & Santa Isabel \\
\hline Cajamar & Itaquaquecetuba & Santana de Parnaíba \\
\hline Carapicuiba & Jandira & Santo André \\
\hline Cotia & Juquitiba & São Bernardo do Campo \\
\hline Diadema & Mairiporã & São Caetano do Sul \\
\hline Embu & Mauá & São Lourenço da Serra \\
\hline Embu-Guaçu & Mogi das Cruzes & São Paulo \\
\hline Ferraz de Vasconcelos & Osasco & Suzano \\
\hline Francisco Morato & Pirapora do Bom Jesus & Taboão da Serra \\
\hline Franco da Rocha & Poá & Vargem Grande Paulista \\
\hline
\end{tabular}

\subsection{AMOSTRA DOMICILIAR DO INQUÉRITO DE SAÚdE MENTAL SÃO PAULO MEGACITY}

O Inquérito de Saúde Mental São Paulo Megacity é um estudo de base populacional, de corte transversal para avaliação de morbidade psiquiátrica em indivíduos com dezoito anos completos ou mais, que falem português, não-institucionalizados, moradores da área metropolitana de São Paulo. A coleta de dados da amostra domiciliar ocorreu entre maio de 2005 e abril de 2007.

Os domicílios foram selecionados por meio de amostragem probabilística por conglomerados em estágios e estratificada. Seis estágios de seleção foram utilizados, com o objetivo de selecionar cinco mil casas de dois estratos geográficos: a cidade de São Paulo e os 38 municípios adjacentes. Em ambos os estratos, a unidade primária de amostragem foram as áreas censitárias do censo de 2000 do IBGE, definidas cartograficamente. Foi estimada taxa de não resposta de $35 \%$ e com isso, sete mil e setecentos domicílios foram selecionados.

A amostra total contou com $60 \%$ dos domicílios pertencendo à região dos 38 municípios adjacentes da cidade (4620 domicílios) e 40\% dos domicílios pertencendo à 
cidade de São Paulo (3080 domicílios), sendo que cada um dos municípios contribuiu para a amostra de acordo com sua densidade demográfica.

Os entrevistadores se apresentavam na casa selecionada, explicavam os objetivos do estudo e solicitavam uma lista dos moradores da casa com informações sobre idade, sexo, laços familiares, questionavam se os moradores se falavam ou não português e se poderiam ser entrevistados. A partir dessa lista, era sorteado o entrevistado. O indivíduo selecionado não podia ser substituído. Um total de cinco mil e trinta e sete (5.037) indivíduos foram entrevistados, com taxa de resposta de $81,3 \%$.

$\mathrm{O}$ entrevistado era apresentado ao estudo e ao termo de consentimento livre e esclarecido (TCLE), sendo que somente após a sua concordância e assinatura, era iniciada a entrevista. O questionário utilizado foi o Composite International Diagnostic Interview (CIDI) da Organização Mundial de Saúde, versão realizada para o World Mental Health Survey.

Em todos entrevistados foi utilizada a primeira parte do questionário CIDI, que consiste em rastreamento de transtornos psiquiátricos, funcionamento nos 30 dias que antecederam a entrevista, queixas físicas crônicas, sintomas inespecíficos, informação sócio-demográfica e antecedentes pessoais e familiares.

A segunda parte do questionário CIDI inclui questões sobre fatores de risco para transtornos psiquiátricos, sobre uso de serviços de saúde, uso de medicações psiquiátricas, conseqüências ocupacionais e sociais de transtornos psiquiátricos, rede de suporte social e familiar, história de relações afetivas e inclui ainda módulos de perguntas para transtornos psiquiátricos mais raros.

Foram realizados quatro tipos de entrevista:

- questionário CIDI completo (primeira e segunda parte): para todos que apresentaram algum rastreamento positivo para transtorno psiquiátrico na primeira parte da entrevista ou para aqueles que já apresentaram um plano ou tentativa de suicídio prévios;

- somente primeira parte do questionário CIDI: para indivíduos sem nenhum rastreamento positivo ou plano ou tentativa de suicídio prévios;.

- em uma amostra aleatória de 25\% de indivíduos que não apresentaram critérios para realização da segunda parte da entrevista, foram administradas as duas partes da entrevista;

- questionário CIDI com módulo de perguntas para demência aplicado aos indivíduos com 60 anos ou mais

A primeira parte do CIDI foi aplicada em 2.095 indivíduos (41,6\% da amostra total de 5.037) e o questionário completo foi aplicada em 2.942 indivíduos, divididos em dois grupos: um formado por 2.236 indivíduos $(44,4 \%)$ com transtornos psiquiátricos (identificados pela primeira parte do CIDI) e outro formado por 706 indivíduos (14,0\%) 
que foram aleatoriamente escolhidos para administração do questionário completo mesmo não apresentando critérios para diagnóstico de doenças psiquiátricas ${ }^{132}$.

\subsection{AMOSTRA HOSPITALAR DO INQUÉRITO DE SAÚDE MENTAL SÃO PAULO MEGACITY}

A coleta de dados da fase hospitalar ocorreu entre junho de 2005 e dezembro de 2007. A amostra foi selecionada da seguinte maneira: todos os indivíduos com transtorno psiquiátrico durante a vida (2.236 participantes) foram convidados a comparecer ao Instituto de Psiquiatria do Hospital das Clínicas da Faculdade de Medicina da Universidade de São Paulo para realizar avaliação complementar clínica e psiquiátrica. Além disso, foram convidados 584 indivíduos para a segunda fase do estudo, que correspondem a 35\% dos indivíduos sem nenhum transtorno psiquiátrico (2.801 indivíduos sem diagnóstico psiquiátrico, correspondendo a 55,6\% da amostra domiciliar). A seleção destes indivíduos ocorreu por sorteio simples.

Desta maneira, um total de 2.820 indivíduos foram convidados a participar da segunda fase do inquérito. Foram enviadas cartas por correio a todos indivíduos selecionados, explicando os objetivos da segunda avaliação e convidando-os a agendar por telefone o comparecimento no Instituto de Psiquiatria do Hospital das Clínicas da Faculdade de Medicina da Universidade de São Paulo. Após o envio dos convites pelo correio, uma assistente de pesquisa telefonou para todos os indivíduos escolhidos para participar da segunda fase do estudo.

Durante o contato telefônico eram explicados os objetivos do estudo, que consistiam em avaliação clínica e psiquiátrica detalhadas de cada participante. Caso o indivíduo aceitasse participar, era agendada uma data para a consulta e solicitado ao participante que comparecesse em jejum de 12 horas (devido à coleta de exames laboratoriais).

Com o objetivo de aumentar a participação na segunda fase do estudo, a avaliação da fase hospitalar era realizada aos sábados, para que não houvesse interferência no horário de trabalho da maior parte dos indivíduos.

Além disso, foi fornecido vale-transporte para os participantes e, caso este necessitasse de acompanhante, o vale-transporte era estendido também para os acompanhantes. Também foram oferecidos dois lanches aos participantes, devido a necessidade do jejum pela coleta dos exames, sendo um servido após a coleta de sangue pela manhã e o segundo lanche próximo ao horário de almoço.

Ao chegar no Instituto de Psiquiatria do Hospital das Clínicas da Faculdade de Medicina da Universidade de São Paulo, o participante recebia informações sobre o conteúdo da 
pesquisa e era apresentado ao TCLE (anexo A). Após a assinatura do termo, este participante era conduzido a sala de coleta de exames laboratoriais. Após a punção venosa, era fornecido o lanche ao participante e posteriormente eram iniciadas as avaliações clínica e psiquiátrica.

\subsection{MEDIDAS ANTROPOMÉTRICAS E DE PRESSÃO ARTERIAL}

Somente quatro pesquisadores realizaram todas as medidas antropométricas, incluindo a autora desta tese. Todos foram treinados antes do início das atividades do campo. Foram realizadas medidas de peso, altura, circunferência abdominal e pressão arterial.

As medidas realizadas foram anotadas em formulário próprio (anexo B) e em impressos que foram entregues aos participantes (com as medidas obtidas devidamente anotadas), seguidos de explicação verbal dos valores aferidos. Todos os participantes com medidas alteradas foram orientados a procurar acompanhamento médico, ressaltando-se a necessidade de confirmação dos valores em outra ocasião. Todas as dúvidas apresentadas pelo participante foram elucidadas.

Foram realizadas também orientações verbais sobre modificação de estilo de vida e entregue impresso com informações sobre alimentação saudável e importância da realização de atividade física, caso o participante assim desejasse.

\subsubsection{Aferição de peso}

Foi realizada a aferição do peso com balança antropométrica mecânica de acordo com as técnicas padronizadas pelo Center of Disease Control and Prevention (CDC) ${ }^{133}$. No início de cada dia de estudo foi realizada calibração manual da balança.

Foi solicitado que os participantes retirassem calçados, casacos, cintos e o conteúdo dos bolsos, permanecendo somente com roupas leves, antes de subir na balança. Foi solicitado que o participante se colocasse sobre a balança e permanecesse parado durante a aferição, sem se comunicar. Desta maneira, foi realizada uma aferição de peso em kg, registrada com uma casa decimal em formulário apropriado (anexo B).

\subsubsection{Aferição de altura}

Para realização da medida da altura do participante foi utilizado estadiômetro acoplado a balança antropométrica mecânica segundo as técnicas recomendadas pelo $\mathrm{CDC}^{133}$. 
Foi solicitado ao participante que retirasse o calçado e quaisquer adereços de sua cabeça (presilhas, tiara, boné, chapéu, entre outros). Foi solicitado que ele subisse na balança e ficasse em posição ereta, de costas para o estadiômetro, com os pés colocados próximos, juntos pelo calcanhar e separados na altura dos pododáctilos (formando ângulo de cerca de 60 graus), com braços pendentes ao lado do corpo, mantendo a cabeça no plano horizontal de Frankfort (plano paralelo ao chão formado pela linha que liga a órbita ao canal auricular).

Nesta posição, a extremidade superior do estadiômetro foi colocada sobre a cabeça do indivíduo, comprimindo levemente o cabelo. Foi solicitado ao participante que realizasse inspiração profunda e segurasse o fôlego para avaliação da altura. A aferição da altura foi anotada em metros com duas casas decimais, em formulário apropriado (anexo B).

\subsubsection{Cálculo do índice de massa corporal}

Com as medidas de peso e altura devidamente registradas, foi realizado cálculo do índice de massa corporal (IMC), dividindo-se o peso em kg pela medida da altura em metros elevada ao quadrado.

O IMC geralmente é classificado de acordo com a padronização da Organização Mundial de Saúde (OMS) em ${ }^{134,135}$ :

1. Baixo peso: IMC abaixo de $18,5 \mathrm{~kg} / \mathrm{m}^{2}$

2. Normal: IMC de 18,5 a $24,9 \mathrm{~kg} / \mathrm{m}^{2}$

3. Sobrepeso: IMC de 25,0 a $29,9 \mathrm{~kg} / \mathrm{m}^{2}$

4. Obesidade: IMC a partir de $30 \mathrm{~kg} / \mathrm{m}^{2}$, sendo que este pode ser dividido em:

4.1 Grau 1: IMC de 30 a $34,9 \mathrm{~kg} / \mathrm{m}^{2}$

4.2 Grau 2: IMC de 35,0 a $39,9 \mathrm{~kg} / \mathrm{m}^{2}$

4.3 Grau 3: IMC a partir de $40 \mathrm{~kg} / \mathrm{m}^{2}$

Foi utilizada neste estudo a classificação simplificada do IMC, que utiliza somente três grupos: normal (IMC até $24,9 \mathrm{~kg} / \mathrm{m}^{2}$ ), sobrepeso (IMC de 25,0 a $29,9 \mathrm{~kg} / \mathrm{m}^{2}$ ) e obesidade (IMC a partir de $30 \mathrm{~kg} / \mathrm{m}^{2}$ ).

\subsubsection{Aferição da circunferência abdominal}

Para medida da circunferência abdominal (medida da circunferência da cintura) dos indivíduos foi utilizada fita métrica flexível dividida em centímetros $(\mathrm{cm})$. Foi solicitado ao participante manter o abdome livre de roupas, elevando a camiseta ou blusa. A medida 
foi realizada durante a expiração, na altura das cristas ilíacas, em seus limites superiores e anteriores, sendo garantido que o plano formado pela fita métrica fosse paralelo ao chão ${ }^{113,133}$. Foi anotada a medida em centímetros em formulário apropriado (anexo B).

São considerados como valores normais: 102 centímetros ou menos de circunferência abdominal em homens e 88 centímetros ou menos de circunferência abdominal em mulheres ${ }^{113}$.

\subsubsection{Aferição da pressão arterial}

A pressão arterial foi medida utilizando-se esfigmomanômetro aneróide portátil calibrado, com o participante em posição sentada, com o braço livre de roupas e apoiado, na altura do precórdio. Durante o insuflar do manguito, foi palpada a artéria radial e observado o valor de desaparecimento da pulsação para realizar a estimativa da pressão arterial sistólica.

Foi desinsuflado o manguito e realizada nova insuflação, com a ausculta da artéria braquial na fossa antecubital. O valor correspondente ao surgimento dos batimentos auscultados (primeiro som de Korotkoff) foi considerado como a pressão arterial sistólica. O valor correspondente ao desaparecimento dos batimentos (quinto som de Korotkoff) foi considerado como a pressão arterial diastólica ${ }^{69}$.

Foram realizadas três medidas de pressão arterial com a técnica descrita, com intervalo de um minuto entre cada uma. Todas as medidas obtidas foram anotadas em formulário apropriado (Anexo B).

A pressão arterial final do participante foi considerada a média das duas últimas observações.

\subsection{QUESTIONÁRIOS}

\subsubsection{Questionário sobre dados gerais do participante}

O questionário sobre dados gerais foi aplicado por profissionais previamente treinados para o uso do instrumento. O questionário visava à obtenção de dados sobre a história clínica dos participantes, além de hábitos de vida e antecedentes familiares (anexo C). Todos os indivíduos foram questionados sobre: 
- Diagnóstico realizado por médico de diabetes mellitus, hipertensão arterial, acidente vascular cerebral, infarto agudo do miocárdio, doença coronariana, outras cardiopatias e doenças da tireóide.

- Antecedente familiar de primeiro grau de diabetes mellitus, hipertensão arterial, acidente vascular cerebral, infarto agudo do miocárdio, doença coronariana, outras cardiopatias, doenças da tireóide ou outras doenças crônicas.

- Informações sobre realização de atividade física regular, tabagismo, consumo regular de álcool, uso atual ou prévio de medicamentos para pressão arterial, diabetes mellitus, para cardiopatias, para doenças da tireóide, para dislipidemias ou outros medicamentos.

\subsubsection{Avaliação sobre realização de atividade física}

Foi aplicado questionário específico para avaliação de atividade física: o Questionário Internacional de Atividade Física ou International Physical Activity Questionnaire (IPAQ) - versão longa (Anexo D).

O IPAQ é um instrumento para avaliação de atividade física criado em 1998 pela Organização Mundial de Saúde, que foi validado no Brasil por Matsudo em $2000^{136,137}$. O questionário se baseia em relato do indivíduo sobre a atividade física realizada durante uma semana habitual em atividades relacionadas ao trabalho, lazer, transporte, em atividades em casa e o tempo total gasto sentado.

Segundo as informações obtidas, os participantes foram classificados em sedentários, insuficientemente ativos, ativos ou muito ativos. Foram considerados sedentários aqueles indivíduos que não realizaram pelo menos dez minutos de atividade física por dia, durante uma semana habitual. Os indivíduos foram classificados como insuficientemente ativos caso não tenham somado um total de pelo menos 150 minutos de atividade moderada durante a semana. Foram considerados como indivíduos ativos aqueles que realizaram mais de 150 minutos por semana de atividade física moderada ou mais de 90 minutos por semana de atividade física intensa. E os indivíduos foram considerados muito ativos caso realizassem mais de 150 minutos de atividade física intensa por semana.

\subsubsection{Avaliação psiquiátrica}

A avaliação psiquiátrica foi realizada por psiquiatras treinados, com uso do instrumento Structured Clinical Interview for DSM disorders I, non-patient edition (SCID I - NP). O SCID se trata de uma entrevista psiquiátrica semi-estruturada validada e com alta confiabilidade ${ }^{138}$ 
e é considerado como o padrão-ouro da avaliação psiquiátrica estruturada ${ }^{139,140}$. É um instrumento criado com objetivo de avaliar os transtornos psiquiátricos do eixo 1 e por isso, não realiza diagnóstico de transtornos de personalidade e de déficit cognitivo da infância (retardo mental). Os transtornos psiquiátricos do eixo 1 incluem ${ }^{141}$ :

1. Dellirium, demências e outros transtornos cognitivos

2. Transtornos mentais secundários a condições clínicas

3. Transtornos relacionados ao uso de substâncias

4. Transtornos psicóticos e esquizofrenia

5. Transtornos de humor

6. Transtornos de ansiedade

7. Transtornos somatoformes

8. Transtornos factícios

9. Transtornos dissociativos

10. Transtornos de identidade de gênero e sexual

11. Transtornos alimentares

12. Transtornos do sono

13. Transtornos de controle de impulsos

14. Transtornos de ajustamento

Apesar da aplicação do SCID I - NP ser possível por profissionais de saúde da área da saúde mental, foi optado pela utilização do instrumento por psiquiatras treinados, com objetivo de aprimorar sua acurácia.

Foi optado por não investigar a prevalência de transtorno de abuso ou dependência ao uso de nicotina.

\subsection{EXAMES LABORATORIAIS}

Durante o contato telefônico foi solicitado que os participantes comparecessem em jejum de 12 horas devido a possibilidade da coleta de exames laboratoriais. Antes da coleta dos exames, questionava-se novamente o participante sobre a realização do jejum. Caso o participante estivesse em jejum era realizada coleta de exames laboratoriais. Caso não estivesse em jejum, o participante era reorientado e agendada nova data para coleta dos exames. Os exames realizados estão listados no Quadro 4.

Foi realizada coleta de sangue por punção venosa periférica por auxiliar de enfermagem devidamente treinado, utilizando sistema vacutainer. Após a coleta de exames era fornecido café da manhã aos participantes. 
Após a coleta de sangue, os tubos eram centrifugados e o material era transportado para dois laboratórios. O Laboratório do Centro de Referência e Treinamento de Doenças Sexualmente Transmissíveis e Aids (CRT DST/Aids), situado a rua Santa Cruz, 81 - Vila Mariana realizava as dosagens de glicemia, perfil lipídico e dosagem de hormônios tireoideanos. O Laboratório do Hospital Universitário da Universidade de São Paulo (USP), situado a avenida Prof. Lineu Prestes, 2565 - Cidade Universitária da USP era responsável pela dosagem da proteína $\mathrm{C}$ reativa ultra-sensível.

\section{QUADRO 4}

Metodologia utilizada e valores de referência dos exames laboratoriais coletados durante a fase hospitalar do Estudo São Paulo Megacity, 2005 a 2007.

\begin{tabular}{|l|l|l|}
\hline Análise clínica & Método utilizado & Valores de referência \\
\hline Glicemia & $\begin{array}{l}\text { Equipamento konelab } 60 \mathrm{i}- \\
\text { análise fotométrica }\end{array}$ & $80 \mathrm{a} 99 \mathrm{mg} / \mathrm{dl}$ \\
\hline Colesterol total & $\begin{array}{l}\text { Equipamento konelab } 60 \mathrm{i}- \\
\text { análise fotométrica }\end{array}$ & Até $200 \mathrm{mg} / \mathrm{dl}$ \\
\hline HDL-colesterol & $\begin{array}{l}\text { Equipamento konelab } 60 \mathrm{i}- \\
\text { análise fotométrica }\end{array}$ & Maior que $40 \mathrm{mg} / \mathrm{dl}$ \\
\hline VLDL-colesterol & $\begin{array}{l}\text { Equipamento konelab } 60 \mathrm{i}- \\
\text { análise fotométrica }\end{array}$ & Até $40 \mathrm{mg} / \mathrm{dl}$ \\
\hline Triglicérides & $\begin{array}{l}\text { Equipamento konelab } 60 \mathrm{i}- \\
\text { análise fotométrica }\end{array}$ & Até $150 \mathrm{mg} / \mathrm{dl}$ \\
\hline LDL-colesterol & $\begin{array}{l}\text { Fórmula de Friedewald } \\
\text { LDL=CT - (HDL + TG/5) }\end{array}$ & Até $130 \mathrm{mg} / \mathrm{dl}$ \\
\hline Proteína C reativa ultra-sensível & Nefelometria & $\begin{array}{l}\text { Alto risco }>3,0 \mathrm{mg} / \mathrm{l} \\
\text { Médio risco } 1,0 \mathrm{a} \mathrm{3,0} \mathrm{mg/l} \\
\text { Baixo risco }<1,0 \mathrm{mg} / \mathrm{l}\end{array}$ \\
\hline $\begin{array}{l}\text { Hormônio tireoestimulante } \\
\text { (TSH) }\end{array}$ & Quimioluminescência & 0,35-5,50 mcUl/ml \\
\hline
\end{tabular}

Após duas semanas, os resultados eram enviados pelo laboratório impressos aos pesquisadores. Os resultados dos exames foram enviados aos participantes por meio de cartas com cópias dos resultados.

Para aqueles com alterações nos exames, era oferecida nova coleta de sangue e confirmação dos resultados, caso aceitassem.

Para informação adequada dos participantes, foram redigidas diversas cartas 
explicando os resultados dos exames laboratoriais com informações padronizadas, segundo as alterações presentes. Exemplos de cartas padronizadas estão no anexo E. As cartas visavam orientar os participantes sobre a necessidade de confirmação das alterações encontradas e de acompanhamento médico, além de orientar sobre modificações de estilo de vida recomendadas em cada caso.

\subsection{DEFINIÇÃO DOS FATORES DE RISCO CARDIOVASCULAR}

\subsubsection{Estilo de vida}

Os indivíduos foram avaliados quanto ao hábito de fumar por meio do questionário sobre dados gerais dos participantes (anexo C). Os indivíduos foram classificados a partir de seu relato em: fumante atual, ex-fumante ou nunca fumante.

Quanto a atividade física, os indivíduos foram submetidos a aplicação de instrumento padronizado para a mensuração de atividade física: o IPAQ (versão longa). Foram classificados em sedentários, insuficientemente ativos, ativos e muito ativos.

Posteriormente, os participantes foram re-classificados em dois grupos para as análises: inativos e ativos. Foram considerados como inativos aqueles indivíduos classificados como sedentários e insuficientemente ativos. E foram considerados ativos aqueles que foram classificados pelo IPAQ como ativos ou muito ativos.

\subsubsection{Sobrepeso e obesidade}

Os indivíduos foram classificados de acordo com o IMC calculado a partir da medida de peso e altura (aferidos no estudo). Foram considerados indivíduos normais aqueles com IMC até $24,9 \mathrm{~kg} / \mathrm{m}^{2}$. Foram considerados portadores de sobrepeso, os indivíduos com IMC de 25,0 a $29,9 \mathrm{~kg} / \mathrm{m}^{2}$ e foram considerados obesos aqueles participantes com IMC a partir de $30 \mathrm{~kg} / \mathrm{m}^{2} 134,135$. 


\subsubsection{Diagnóstico de diabetes mellitus}

Foram considerados como diabéticos os participantes com história prévia de diagnóstico médico de diabetes, uso de medicamentos para tratamento do diabetes ou glicemia de jejum maior ou igual a $126 \mathrm{mg} / \mathrm{dl}^{63}$.

\subsubsection{Diagnóstico de dislipidemia}

Todos os participantes realizaram dosagens de colesterol total (CT), HDL-colesterol, VLDL-colesterol e triglicérides (TG). O valor de LDL-colesterol foi calculado a partir da fórmula de Friedewald:

$$
L D L=C T-(H D L+T G / 5)
$$

No entanto, a fórmula de Friedewald não é acurada para indivíduos portadores de níveis séricos de triglicérides acima de $400 \mathrm{mg} \backslash \mathrm{dl}$. Nestes casos, não foi calculado o valor de LDL-colesterol e este foi considerado ausente, pela impossibilidade de realização da medida direta do LDL-colesterol no momento do estudo.

Os indivíduos foram classificados de acordo com as diretrizes da American Heart Association (AHA) ${ }^{77}$. São considerados alterados os valores abaixo:

- TRIGLICÉRIDES: maior ou igual a $150 \mathrm{mg} / \mathrm{dl}$

- hDl-Colesterol: menor do que $40 \mathrm{mg} / \mathrm{dl}$

- LDL-COlesterol: varia de acordo com a classificação de risco do indivíduo.

- ALTO RISCO: o indivíduo apresenta doença aterosclerótica manifesta como infarto agudo do miocárdio prévio ou angina, acidente vascular cerebral, ou ainda equivalentes como doença arterial periférica, aneurisma de aorta abdominal, doença de artéria carótida sintomática, diabetes mellitus ou escore de risco de Framingham maior de 20\%, a meta de LDL-colesterol deverá ser abaixo de 100 $\operatorname{mg} \mathrm{dl}$.

- Risco MOderado-Alto: presença de dois ou mais fatores de risco cardiovascular el ou um escore de risco de Framingham entre 10 e 20\% - a meta de LDL-colesterol deverá ser $<130 \mathrm{mg} \mathrm{dl}$.

- RISCO MODERADO: presença de dois ou mais fatores de risco cardiovascular e um escore de risco de Framingham $<10 \%$, a meta de LDL-colesterol deverá ser de $<130 \mathrm{mg} \mathrm{dl}$. 
- RISCO BAIXO: ausência ou presença de somente um fator de risco cardiovascular e um escore de Framingham $<10 \%$, a meta de LDL-colesterol é $<160$ mg dl.

Os participantes foram classificados como portadores de dislipidemia, caso apresentassem valores de triglicérides elevados, ou valores de HDL-colesterol reduzidos ou ainda com valores de LDL-colesterol elevados (de acordo com os limites descritos acima). Também foram considerados como portadores de dislipidemia caso relatassem diagnóstico prévio de dislipidemia realizado por médico (independente dos valores encontrados nas dosagens laboratoriais) ou ainda caso relatassem utilizar medicamentos para tratamento de dislipidemia.

\subsubsection{Proteína C reativa ultra-sensível}

Os indivíduos foram classificados de acordo com a dosagem da proteína Creativa ultrasensível (PCR) em alto risco, médio risco e baixo risco de eventos cardiovasculares. Foram considerados de alto risco cardiovascular, os indivíduos portadores de medidas acima de 3,0 mg/dl de PCR. Foram classificados como médio risco, aqueles que apresentavam níveis séricos de 1,0 a 3,0 mg/l de PCR. Foram considerados de baixo risco os participantes que apresentaram valores menores de $1,0 \mathrm{mg} / \mathrm{l}$ de $\mathrm{PCR}^{122}$.

Todos participantes que apresentaram níveis de PCR maiores ou iguais a 10,0 mg/l foram excluídos das análises devido à possibilidade de viés de confusão com doenças inflamatórias sistêmicas como doenças reumatológicas ou outras afecções auto-imunes, já que a PCR é um sensível marcador de atividade inflamatória e perde seu valor na predição de risco cardiovascular nestes casos.

\subsubsection{Dosagem de hormônio tireoestimulante (TSH)}

Os participantes tiveram sua função tireoideana avaliada através de dosagem de TSH, devido a necessidade de diagnóstico diferencial de alguns transtornos psiquiátricos com os sinais e sintomas de hipo ou hipertireoidismo. Foi oferecido aos participantes com dosagens de TSH alteradas a realização de nova coleta e novo exame de TSH, com inclusão da dosagem de tiroxina livre (T4 livre).

Foram considerados portadores de hipertireoidismo os participantes com níveis séricos de TSH menores de $0,35 \mathrm{microUI} / \mathrm{ml}$. Foram considerados portadores de hipotireoidismo, aqueles indivíduos com níveis séricos de TSH maiores de 5,5 microUI/ml. Também foram considerados como portadores de tireoidopatias, aqueles 
participantes que referiram diagnóstico prévio realizado por médico ou ainda os que utilizavam medicamentos para a tireóide.

\subsubsection{Classificação de risco de eventos cardiovasculares através do escore de risco de Framingham (ERF)}

Foi calculado o risco de morte súbita ou infarto agudo do miocárdio em 10 anos dos participantes da segunda fase do Inquérito de Saúde Mental São Paulo Megacity a partir do escore de risco de Framingham. O cálculo do ERF se baseia nos seguintes dados do participante: idade, gênero, medida de colesterol total, medida de HDL-colesterol, tabagismo, medida de pressão arterial e presença de diagnóstico de diabetes mellitus. De acordo com os dados dos participantes, estes são correspondentes a pontos, que somados correspondem ao risco de morte súbita ou infarto agudo do miocárdio em 10 anos, em percentual (Anexo F) ${ }^{112,113}$.

$\mathrm{O}$ indivíduo que apresentava risco menor de $10 \%$ de apresentar morte súbita ou infarto agudo do miocárdio em 10 anos foi considerado de baixo risco. Os participantes que apresentaram risco de 10 a 20\% foram considerados de médio risco. E aqueles que apresentavam ERF com risco maior que $20 \%$ foram considerados de alto risco ${ }^{112,113}$.

O ERF apresenta limitações em sua utilização. Os indivíduos que apresentem diabetes mellitus ou doenças ateroscleróticas devem ser considerados de alto risco, independente do risco estimado pelo ERF. Nesses casos, o ERF pode ser utilizado como marcador de controle dos fatores de risco para doença cardiovascular de cada indivíduo, porém subestima o risco real do indivíduo.

\subsubsection{Diagnóstico de síndrome metabólica}

A partir das medidas dos participantes de circunferência abdominal, medida da pressão arterial, medida da glicemia e dos níveis sanguíneos de HDL-colesterol e triglicérides foi avaliada a presença ou ausência de síndrome metabólica.

Foram utilizados os critérios preconizados pelo NCEP ATP III, que classificam como portadores da síndrome metabólica os indivíduos que apresentem três ou mais dos cinco critérios a seguir ${ }^{90}$ :

- Aumento da circunferência abdominal: maior do que 102 centímetros para homens e maior do que 88 centímetros para mulheres

- Aumento do nível de triglicérides plasmáticos: maior ou igual a 150 mg/dl 
- Redução dos níveis de HDL-coleterol: menor do que $40 \mathrm{mg} / \mathrm{dl}$ para homens e menor do que $50 \mathrm{mg} / \mathrm{dl}$ para mulheres

- Aumento dos níveis pressóricos: pressão arterial sistólica maior ou igual a $130 \mathrm{mmHg}$ e/ou pressão arterial diastólica maior ou igual a $85 \mathrm{mmHg}$

- Aumento dos níveis de glicemia de jejum: maior ou igual a 100 mg/dl

Não foi questionado aos participantes sobre diagnóstico prévio de síndrome metabólica, nem sobre uso de medicamentos para tal condição.

\subsubsection{Diagnóstico de hipertensão arterial}

Foram considerados como hipertensos os indivíduos que apresentassem o valor médio da pressão arterial sistólica $\geq 140 \mathrm{~mm} \mathrm{Hg}$ e ou o valor médio da pressão arterial diastólica $\geq 90 \mathrm{~mm} \mathrm{Hg}^{69}$. Também foram considerados como hipertensos os participantes que, durante a entrevista clínica, relatassem diagnóstico prévio de hipertensão arterial realizado por médico ou ainda tratamento para hipertensão arterial.

\subsection{ANÁLISE ESTATÍSTICA}

Todos os questionários foram submetidos à dupla digitação em planilha de software Microsoft Office Excel 2003 e posteriormente convertidos para o soft ware Statistical Package for Social Sciences (SPSS). A análise estatística foi realizada com o software estatístico SPSS versão 16.0.A segunda fase do Inquérito de Saúde Mental São Paulo Megacity obteve dados sobre diversos transtornos psiquiátricos, porém foi optado por analisar somente os dados sobre transtornos de humor (incluindo depressão maior) e transtornos de ansiedade nesta tese. Todas as análises foram divididas por gênero, devido ao grande impacto da diferença de gênero no perfil de fatores de risco para doença cardiovascular e no perfil de transtornos psiquiátricos.

Inicialmente foram comparados os fatores de risco para eventos cardiovasculares de acordo com o gênero, devido a diferenças relatadas previamente na literatura. Todas as análises foram divididas por gênero e agrupadas em três tipos de tabelas. A primeira tabela apresenta características sócio-demográficas, antecedentes pessoais de doenças e estilo de vida, detalhando dados como idade média, escolaridade (em anos), renda familiar mensal média, estado civil, emprego, tabagismo, consumo de bebidas alcoólicas, realização de atividade física, diagnóstico prévio de hipertensão arterial, diabetes mellitus 
e/ou doença cardiovascular (que inclui indivíduos com diagnóstico prévio de infarto agudo do miocárdio, acidente vascular cerebral ou coronariopatia).

O segundo grupo de tabelas apresenta os dados antropométricos dos participantes, incluindo medida do peso, altura, índice de massa corporal média e dividido por categorias, além da medida da circunferência abdominal e da média de medidas realizadas da pressão arterial sistólica e diastólica e a classificação final de hipertensão arterial.

E o terceiro grupo de tabelas inclui as dosagens laboratoriais de glicemia, colesterol total, HDL-colesterol, triglicérides, PCR ultra-sensível, hormônio tireoestimulante, além da classificação destes valores e do diagnóstico de síndrome metabólica e avaliação do escore de risco de Framingham.

Todas as variáveis de perfil de fatores de risco cardiovascular foram comparadas com diagnóstico de transtornos de humor, de transtorno depressivo maior e de transtorno de ansiedade.

As análises foram conduzidas de duas maneiras, em relação ao diagnóstico psiquiátrico: analisando os dados em portadores de diagnóstico exclusivo dos transtornos (de humor, de ansiedade ou depressão maior)e também analisando os portadores de transtornos de humor, ansiedade ou depressão maior incluindo indivíduos com ou sem co-morbidade psiquiátrica. Na primeira metade do capítulo de resultados são avaliados os indivíduos com diagnósticos psiquiátricos exclusivo, que foram comparados a indivíduos normais. E na segunda metade do capítulo de resultados, são comparados os indivíduos com transtornos psiquiátricos (com ou sem co-morbidade psiquiátrica) e comparados a indivíduos sem o transtorno analisado.

Foi optado pela realização de duas diferentes análises em relação ao diagnóstico psiquiátrico devido a frequência importante de indivíduos com mais de um transtorno psiquiátrico na amostra utilizada neste estudo.As variáveis categóricas foram expressas em proporções e comparadas pelo teste do qui-quadrado de Pearson ou teste exato de Fisher, conforme necessário. As variáveis contínuas foram expressas como média e desvio-padrão, sendo comparadas pela análise de variância (ANOVA) com teste post hoc de Bonferroni para múltiplas comparações. Foi considerado como significativo um valor de $\mathrm{P}<0,05$.

Foi realizada regressão logística binária utilizando os diagnósticos psiquiátricos como variável dependente e as variáveis relacionadas ao perfil de fatores de risco cardiovascular como variáveis independentes. Inicialmente foi realizada análise da regressão logística sem ajuste para outras variáveis e depois ajustada por idade. A idade foi utilizada como variável contínua e expressas em anos.

Para realização da regressão logística binária, as variáveis que apresentavam mais de duas categorias foram reagrupadas, como tabagismo, IMC, classificação da PCR ultrasensível e o escore de risco de Framingham. 
O tabagismo foi analisado comparando-se fumantes atuais e um grupo que incluiu indivíduos que nunca fumaram e os ex-fumantes.

O IMC foi analisado como variável categórica e os indivíduos portadores de sobrepeso foram associados aos portadores de obesidade (incluídos em grupo denominado excesso de peso) e comparados aos indivíduos com IMC normal.

A PCR ultra-sensível foi analisada como variável categórica e os indivíduos classificados como alto risco cardiovascular (com dosagem de PCR $>$ 3,0 mg/dl) foram associados aos indivíduos classificados como médio risco (dosagens de PCR de 1,0 a 3,0 $\mathrm{mg} / \mathrm{dl}$ ) e foram comparados aos indivíduos de baixo risco cardiovascular (dosagem de PCR $<1,0 \mathrm{mg} / \mathrm{dl})$.

O ERF foi analisado como variável categórica e foram analisados os indivíduos classificados como alto risco cardiovascular (> 20\% de eventos em dez anos) associados aos indivíduos classificados como de médio risco (de 10 a $20 \%$ de eventos em dez anos) e comparados aos indivíduos de baixo risco ( $<10 \%$ de eventos em dez anos).

Para análise da atividade física, foram utilizadas as mesmas categorias já descritas: os indivíduos considerados pelo IPAQ como sedentários foram agrupados com os indivíduos insuficientemente ativos. E os indivíduos considerados como ativos foram somados aos indivíduos considerados muito ativos. Os resultados da regressão logística foram apresentados como odds ratio (OR) e intervalo de confiança (IC) $95 \%$.

\subsection{ASPECTOS ÉTICOS}

Todos os participantes foram orientados verbalmente quanto aos objetivos e riscos da participação do Inquérito de Saúde Mental São Paulo Megacity. Após a orientação verbal e elucidação de dúvidas dos participantes, foi solicitado que todos analisassem o termo de consentimento livre e esclarecido (TCLE) e o assinassem, caso concordassem em participar (Anexo A).

Todos os resultados dos procedimentos realizados durante a avaliação no estudo foram informados e entregues de forma escrita aos participantes, seja através das anotações de medidas antropométricas, medidas aferidas de pressão arterial, assim como pelo envio de resultados de exames laboratoriais pelo correio (com descrição explicativa).

A primeira fase do Inquérito de Saúde Mental São Paulo Megacity foi aprovado pelo Comitê de Ética e Pesquisa da Faculdade de Medicina da Universidade de São Paulo, sob número de processo 792/03 e 696/05 (fase domiciliar).

A segunda parte do estudo (fase hospitalar), que foi objeto desta tese, foi aprovada pela Comissão de Ética para Análise de Projetos de Pesquisa da Diretoria Clínica do Hospital 
das Clínicas da Faculdade de Medicina da Universidade de São Paulo, sob protocolo de número 234/03, em 24 de abril de 2003. 


\section{RESULTADOS}

Inicialmente 2820 indivíduos foram convidados a participar da fase hospitalar do estudo por meio de carta enviada pelo correio. Para garantir o convite para todos os indivíduos, foi tentado contato telefônico por uma assistente de pesquisa, que fornecia uma explicação inicial do objetivo do estudo. No entanto, não foi possível realizar o contato telefônico em 1.349 indivíduos (47,8\% do total de 2.820 ) por diversos motivos: em 548 indivíduos, o telefone fornecido na primeira fase do estudo estava incorreto e impossibilitou o contato, em 397 indivíduos não houve resposta aos recados (pois não se encontravam em casa), em 404 indivíduos ninguém atendeu o telefone, mesmo após diversas tentativas.

Foi realizado contato com 1.471 indivíduos (52,2\% do total de 2.820), dos quais 691 se recusaram a participar $(24,5 \%$ da amostra inicial de 2.820 e $47 \%$ da total de indivíduos contatados por telefone), sendo que destes: 116 agendaram e re-agendaram o dia de avaliação, mas nunca compareceram, 54 solicitaram o agendamento de entrevista em outra data mais oportuna e nunca puderam comparecer (mesmo após novas tentativas de contato) e 521 não aceitaram o convite por motivos diversos: como impossibilidade de comparecer por motivo de trabalho, problemas de saúde, não ter com quem deixar os filhos, além de falta de interesse.

Finalmente 780 indivíduos compareceram ao Instituto de Psiquiatria do Hospital das Clínicas da Faculdade de Medicina da Universidade de São Paulo. Dentre eles, duas mulheres compareceram, porém apresentaram mal estar e não realizaram a avaliação. Seis participantes iniciaram a avaliação, porém dois apresentaram níveis de glicemia capilar elevados com sintomas, necessitando remoção para o pronto-socorro, um apresentava ascite tensa com apresentou desconforto abdominal e pediu para se retirar e três desistiram após ter chegado ao hospital. Dos 780 indivíduos que compareceram para a segunda fase do estudo, 772 completaram o protocolo. Da amostra final de 772 indivíduos, 496 participantes apresentavam algum diagnóstico psiquiátrico (64,2\%) e 276 indivíduos não apresentavam nenhum diagnóstico de transtorno mental $(35,8 \%)$. 


\section{;: FIGURA 1}

Amostra de indivíduos que participaram da fase hospitalar do Estudo São Paulo Megacity, realizado na Grande São Paulo, 2005 a 2007.

5.037 indivíduos entrevistados nos domicílios (primeira fase do estudo)

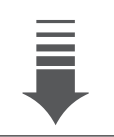

2.820 indivíduos convidados a participar da segunda fase do estudo por envio de carta pelo correio (fase hospitalar):

- Todos indivíduos com diagnóstico de transtorno psiquiátrico $(n=2.236)$

- Amostra de 35\% de indivíduos sem diagnóstico de transtorno psiquiátrico $(n=584)$

Não foi possível contato com 1.349 indivíduos:

- 548 - telefone incorreto

- 397 - não retornaram as mensagens deixadas

- 404 - ninguém atendeu o telefonema

\section{言}

1.471 indivíduos foram contatados por telefone:

- 116 marcaram a avaliação mas faltaram

- 54 solicitaram remarcação, mas nunca compareceram

- 521 se recusaram a participar por motivos pessoais

780 indivíduos compareceram a avaliação no Hospital (53\% dos contatados por telefone):

- 5 necessitavam avaliação de urgência e foram encaminhados ao pronto-socorro (não foi obtido nenhum dado)

- 3 desistiram antes da avaliação ser completada

- 772 indivíduos foram incluídos na análise 
Houve uma diferença de gênero na freqüência de diagnóstico psiquiátrico entre os gêneros: 191 (57,7\%) dos indivíduos do sexo masculino apresentaram diagnóstico de algum transtorno psiquiátrico, sendo que entre as mulheres este percentual foi maior (305 mulheres, perfazendo 69,2\% das pessoas de sexo feminino) (tabela 1).

Em ambos os sexos, os transtornos de ansiedade foram o diagnóstico psiquiátrico mais frequente $(34,1 \%$ dos homens e $50,8 \%$ das mulheres) e, em segundo lugar, os transtornos de humor (28,1\% dos homens e $49,2 \%$ das mulheres).

Entre os portadores de transtornos de ansiedade, os diagnósticos mais frequentes variam de acordo com o gênero. Entre as mulheres, a fobia específica é o diagnóstico mais frequente (26,8\%), seguido pela fobia social $(17,0 \%)$ e transtorno de ansiedade generalizada (15,6\%). Já entre os homens, a fobia social é o diagnóstico mais frequente (17,8\%), seguido pela fobia específica (11,8\%) e pelo transtorno de ansiedade generalizada (6,9\%).

Entre os portadores de transtornos de humor, o transtorno depressivo maior é o diagnóstico psiquiátrico mais frequente em ambos os gêneros (23,6\% do sexo masculino e $43,8 \%$ do sexo feminino). No entanto, o segundo e o terceiro lugar variam conforme o sexo: nas mulheres o transtorno distímico $(4,8 \%)$ e o transtorno depressivo menor $(4,3 \%)$ são mais frequentes e, entre os homens, o transtorno depressivo menor $(3,6 \%)$ e o transtorno afetivo bipolar tipo $2(2,4 \%)$ são mais frequentes.

Cabe ainda ressaltar que o transtorno de uso de substâncias (que engloba abuso e/ou dependência de álcool ou drogas ilícitas) foi mais frequente em homens $(24,2 \%)$ do que em mulheres $(6,1 \%)$, sendo que não foi incluído o uso de nicotina neste grupo.

Foi observada uma frequência alta de co-morbidades psiquiátricas nesta amostra, pois apenas 38,7\% do total de 496 indivíduos com transtorno psiquiátrico apresentam somente um diagnóstico psiquiátrico. Do total de portadores de transtornos psiquiátricos, 304 (61,3\%) indivíduos apresentavam dois ou mais diagnósticos (tabela 2). 
TABELA 1

Perfil de morbidade psiquiátrica de 772 participantes do Estudo São Paulo Megacity, realizado na Grande São Paulo - 2005 a 2007

\begin{tabular}{|c|c|c|c|c|}
\hline \multirow[t]{3}{*}{ TRANSTORNO PSIQUIÁTRICO } & \multicolumn{2}{|c|}{ GÊNERO } & \multirow[t]{2}{*}{ TOTAL } & \multirow[t]{2}{*}{$\mathbf{P}$} \\
\hline & Masculino (\%) & Feminino (\%) & & \\
\hline & $N=331$ & $\mathrm{~N}=441$ & $\mathrm{~N}=772$ & \\
\hline Sem diagnóstico psiquiátrico & $140(42,3)$ & $136(30,8)$ & $276(35,8)$ & 0,001 \\
\hline $\begin{array}{l}\text { Um ou mais transtornos } \\
\text { psiquiátricos }\end{array}$ & $191(57,7)$ & $305(69,2)$ & $496(64,2)$ & 0,001 \\
\hline Transtornos de humor & $93(28,1)$ & $217(49,2)$ & $310(40,2)$ & 0,0001 \\
\hline Transtorno depressivo maior & $78(23,6)$ & $193(43,8)$ & $271(35,1)$ & 0,0001 \\
\hline Transtorno depressivo menor & $12(3,6)$ & $19(4,3)$ & $31(4,0)$ & 0,71 \\
\hline Transtorno distímico & $4(1,2)$ & $21(4,8)$ & $25(3,2)$ & 0,007 \\
\hline Transtorno afetivo bipolar tipo1 & $5(1,5)$ & $10(2,3)$ & $15(1,9)$ & 0,60 \\
\hline Transtorno afetivo bipolar tipo 2 & $8(2,4)$ & $12(2,7)$ & $20(2,6)$ & 0,82 \\
\hline Transtornos de ansiedade & $113(34,1)$ & $224(50,8)$ & $337(43,7)$ & 0,0001 \\
\hline Fobia específica & $39(11,8)$ & $118(26,8)$ & $157(20,3)$ & 0,0001 \\
\hline Fobia social & $59(17,8)$ & $75(17,0)$ & $134(17,4)$ & 0,77 \\
\hline $\begin{array}{l}\text { Transtorno de ansiedade } \\
\text { generalizada }\end{array}$ & $23(6,9)$ & $69(15,6)$ & $92(11,9)$ & 0,0001 \\
\hline $\begin{array}{l}\text { Transtorno de estresse pós- } \\
\text { traumático }\end{array}$ & $15(4,5)$ & $29(6,6)$ & $44(5,7)$ & 0,27 \\
\hline Agorafobia & $22(6,6)$ & $46(10,4)$ & $68(8,8)$ & 0,07 \\
\hline Transtorno de pânico & $13(3,9)$ & $39(8,8)$ & $52(6,7)$ & 0,008 \\
\hline $\begin{array}{l}\text { Transtorno obsessivo- } \\
\text { compulsivo }\end{array}$ & $10(3,0)$ & $24(5,4)$ & $34(4,4)$ & 0,11 \\
\hline $\begin{array}{l}\text { Transtornos de uso de } \\
\text { substâncias }\end{array}$ & $80(24,2)$ & $27(6,1)$ & $107(13,9)$ & 0,0001 \\
\hline Transtornos alimentares & $8(2,4)$ & $23(5,2)$ & $31(4,0)$ & 0,06 \\
\hline Transtorno de ajustamento & $6(1,8)$ & $13(2,9)$ & $19(2,5)$ & 0,36 \\
\hline
\end{tabular}


* TABELA 2

Número de diagnósticos psiquiátricos de 772 participantes do Estudo São Paulo Megacity, realizado na Grande São Paulo - 2005 a 2007

\begin{tabular}{|c|c|c|c|c|}
\hline \multirow{3}{*}{$\begin{array}{l}\text { NÚMERO DE DIAGNÓSTICOS } \\
\text { PSIQUIÁTRICOS }\end{array}$} & \multicolumn{2}{|c|}{ GÊNERO } & \multirow[t]{2}{*}{ TOTAL } & \multirow[t]{2}{*}{$\mathbf{P}$} \\
\hline & Masculino (\%) & Feminino (\%) & & \\
\hline & $N=331$ & $N=441$ & $\mathrm{~N}=772$ & 0,009 \\
\hline 0 & $140(42,3)$ & $136(30,8)$ & $276(35,8)$ & \\
\hline 1 & $77(23,3)$ & $115(26,1)$ & $192(24,9)$ & \\
\hline 2 & $46(13,9)$ & $85(19,3)$ & $131(17,0)$ & \\
\hline 3 ou mais & $68(20,5)$ & $105(23,8)$ & $173(22,4)$ & \\
\hline
\end{tabular}

Os indivíduos portadores de transtornos de uso de substâncias, transtornos alimentares e transtorno de ajustamento foram excluídos das análises, pois poderia haver interferência de características próprias dos indivíduos portadores de tais diagnósticos no perfil de pessoas com transtornos de humor e/ou de ansiedade. Desta maneira, nos restou um total de 626 indivíduos com diagnóstico de transtornos de humor e/ou de ansiedade, sem outras co-morbidades psiquiátricas.

Os indivíduos participantes são jovens, com média de idade de cerca de 41 anos, sendo que aproximadamente $60 \%$ dos participantes de encontram abaixo dos 45 anos, com baixa representação de pessoas idosas (com 60 anos ou mais). Quanto a escolaridade, $46 \%$ dos indivíduos apresentam primeiro grau e 17,6\% dos indivíduos possuem terceiro grau, sem diferença entre os gêneros (tabela 3).

Há mais homens casados ou com parceria estável $(76,3 \%)$ do que as mulheres $(55,8 \%)$ e há mais homens com emprego (86,7\%) do que as mulheres $(58,5 \%)$ em nossa amostra $(\mathrm{p}<0,0001)$. Os homens referem consumir bebidas alcoólicas com regularidade $(27,0 \%)$ mais frequentemente do que as mulheres (11,0\%). Não há diferenças de gênero quanto ao uso do tabaco $(\mathrm{p}=0,79)$, sendo que a maioria das pessoas nunca fumou $(59,3 \%$ dos homens e $60,1 \%$ das mulheres) ou já abandonou o uso (26,0\% dos homens e $24,0 \%$ das mulheres).

Também foi observado que há uma elevada frequência de indivíduos ativos fisicamente entre os participantes do estudo e sem diferença entre os gêneros, pois $85,9 \%$ dos homens e $84,0 \%$ das mulheres são considerados ativos ou muito ativos pelo instrumento utilizado $(\mathrm{p}=0,58)$.

Por se tratar de uma amostra relativamente jovem, apenas 14 (5,7\%) indivíduos do sexo masculino e 18 (4,7\%) indivíduos de sexo feminino apresentaram algum evento cardiovascular prévio (relato de diagnóstico prévio de acidente vascular cerebral, infarto agudo do miocárdio e/ou coronariopatias), sem diferença entre os gêneros $(\mathrm{p}=1,0)$. Também 
não foram encontradas freqüências diferentes entre os gêneros para os diagnósticos prévios de hipertensão arterial (30,2\% dos homens e 27,7\% das mulheres, $\mathrm{p}=0,53)$ e diabetes mellitus (7,4\% dos homens e 6,0\% das mulheres, $\mathrm{p}=0,51)$.

\section{* TABELA 3}

Características gerais, antecedentes pessoais de doenças e hábitos de vida de acordo com gênero de 626 indivíduos com ou sem transtornos de humor e/ou de ansiedade do Estudo São Paulo Megacity, realizado na Grande São Paulo - 2005 a 2007

\begin{tabular}{|c|c|c|c|c|}
\hline & \multicolumn{2}{|c|}{ GÊNERO } & \multirow[t]{2}{*}{ TOTAL } & \multirow[t]{2}{*}{$\mathbf{P}$} \\
\hline & Masculino (\%) & Feminino (\%) & & \\
\hline & $N=243$ & $\mathrm{~N}=\mathbf{3 8 3}$ & $N=626$ & \\
\hline Idade (anos) ${ }^{1}$ & $41,1(10,6)$ & $40,6(11,1)$ & $40,8(10,9)$ & 0,64 \\
\hline Faixa etária (anos) & & & & 0,95 \\
\hline $18-24$ & $20(8,2)$ & $39(10,2)$ & $59(9,4)$ & \\
\hline $25-34$ & $50(20,6)$ & $76(19,8)$ & $126(20,1)$ & \\
\hline $35-44$ & $71(29,2)$ & $110(28,7)$ & $181(28,9)$ & \\
\hline $45-54$ & $75(30,9)$ & $114(29,8)$ & $189(30,2)$ & \\
\hline $55-64$ & $27(11,1)$ & $44(11,5)$ & $71(11,3)$ & \\
\hline 65 ou mais & - & - & & \\
\hline Escolaridade (anos) $^{1}$ & $9,2(3,9)$ & $9,0(4,2)$ & $9,1(4,1)$ & 0,66 \\
\hline Nível educacional (anos) & & & & 0,38 \\
\hline $0-8$ - Primeiro grau & $108(44,8)$ & $177(46,8)$ & $285(46,0)$ & \\
\hline 9-11 - Segundo grau & $95(39,4)$ & $130(34,4)$ & $225(36,3)$ & \\
\hline 12 ou mais - Terceiro grau & $38(15,8)$ & $71(18,8)$ & $109(17,6)$ & \\
\hline Renda mensal familiar (reais) ${ }^{1}$ & $1.435(1.355)$ & $1.294(1.464)$ & $1.349(1.424)$ & 0,23 \\
\hline Estado civil (\%) & & & & 0,0001 \\
\hline Casado & $184(76,3)$ & $211(55,8)$ & $395(63,8)$ & \\
\hline Viúvo/Separado/ Divorciado & $18(7,5)$ & $78(20,6)$ & $96(15,5)$ & \\
\hline Solteiro & $39(16,2)$ & $89(23,5)$ & $128(20,7)$ & \\
\hline Emprego (\%) & & & & 0,0001 \\
\hline Trabalhador & $209(86,7)$ & $221(58,5)$ & $430(69,5)$ & \\
\hline Estudante & $2(0,8)$ & $5(1,3)$ & $7(1,1)$ & \\
\hline Do lar & $2(0,8)$ & $90(23,8)$ & $92(14,9)$ & \\
\hline Aposentado & $12(5,0)$ & $15(4,0)$ & $27(4,4)$ & \\
\hline Outros & $16(6,6)$ & $47(12,4)$ & $63(10,2)$ & \\
\hline Tabagismo (\%) & & & & 0,79 \\
\hline
\end{tabular}




\begin{tabular}{|c|c|c|c|c|}
\hline & \multicolumn{2}{|c|}{ GÊNERO } & \multirow[t]{2}{*}{ TOTAL } & \multirow[t]{2}{*}{$\mathbf{P}$} \\
\hline & Masculino (\%) & Feminino (\%) & & \\
\hline & $N=243$ & $N=383$ & $N=626$ & \\
\hline Nunca fumante & $143(59,3)$ & $230(60,1)$ & $373(59,8)$ & \\
\hline Ex-fumante & $63(26,0)$ & $92(24,0)$ & $155(24,8)$ & \\
\hline Fumante ativo & $35(14,5)$ & $61(15,9)$ & $96(15,4)$ & \\
\hline Consumo de álcool (\%) ${ }^{2}$ & $65(27,0)$ & $42(11,0)$ & $107(17,1)$ & 0,0001 \\
\hline Atividade física regular (\%) ${ }^{3}$ & $237(85,9)$ & $294(84,0)$ & $531(84,8)$ & 0,58 \\
\hline $\begin{array}{l}\text { Diagnóstico prévio de } \\
\text { hipertensão arterial (\%) }\end{array}$ & $73(30,2)$ & $106(27,7)$ & $179(28,6)$ & 0,53 \\
\hline $\begin{array}{l}\text { Diagnóstico prévio de } \\
\text { diabetes mellitus (\%) }\end{array}$ & $18(7,4)$ & $23(6,0)$ & $41(6,5)$ & 0,51 \\
\hline $\begin{array}{l}\text { Diagnóstico prévio de } \\
\text { doença cardiovascular }{ }^{4}\end{array}$ & $14(5,7)$ & $18(4,7)$ & $32(5,1)$ & 1,0 \\
\hline \multicolumn{5}{|l|}{${ }^{1}$ Média (desvio-padrão). } \\
\hline \multicolumn{5}{|c|}{${ }^{2}$ Definido como consumo regular de bebidas alcoólicas pelo menos uma vez por semana. } \\
\hline \multicolumn{5}{|c|}{${ }^{3}$ Definido por meio do IPAQ, somando indivíduos ativos e muito ativos. } \\
\hline
\end{tabular}

Quanto aos dados antropométricos (índice de massa corporal, diagnóstico de sobrepeso ou obesidade e circunferência abdominal) foi observado que não há diferenças entre os homens e mulheres, com exceção da circunferência abdominal (tabela 4). $\mathrm{O}$ índice de massa corporal (IMC) médio observado foi de $26,8 \mathrm{~kg} / \mathrm{m}^{2}$ nos homens e 27,0 $\mathrm{kg} / \mathrm{m}^{2}$ entre as mulheres $(\mathrm{p}=0,63)$, com uma predominância de indivíduos com sobrepeso $(\mathrm{p}=0,10)$.

Houve diferença na média das circunferências abdominais (93,3 cm em homens e 90,4 $\mathrm{cm}$ nas mulheres, $\mathrm{p}=0,005)$ e, embora os limites aceitáveis de circunferência abdominal variem em cada gênero, também foi observada discrepância na frequência de indivíduos considerados com valores de circunferência abdominal acima do normal (21,5\% dos homens e 54,7\% das mulheres, $\mathrm{p}=0,0001$ ).

A medida da pressão arterial foi maior em homens, tanto nos valores sistólicos, quanto nos diastólicos ( $\mathrm{p}=0,0001 \mathrm{em}$ ambos), no entanto não houve maior frequência de hipertensos entre os homens ( $41,6 \%$ dos homens e $34,5 \%$ das mulheres, $\mathrm{p}=0,08)$ (tabela 4 ). 


\section{TABELA 4}

Dados antropométricos e medida de pressão arterial de acordo com gênero em 626 indivíduos do Estudo São Paulo Megacity, realizado na Grande São Paulo - 2005 a 2007

\begin{tabular}{|c|c|c|c|c|}
\hline & \multicolumn{2}{|c|}{ GÊNERO } & \multirow[t]{2}{*}{ TOTAL } & \multirow[t]{2}{*}{$\mathbf{P}$} \\
\hline & Masculino (\%) & Feminino (\%) & & \\
\hline & $N=244$ & $\mathrm{~N}=383$ & $N=626$ & \\
\hline Índice de massa corporal $\left(\mathrm{kg} / \mathrm{m}^{2}\right)^{1}$ & $26,8(4,3)$ & $27,0(5,3)$ & $26,9(4,9)$ & 0,63 \\
\hline Estado nutricional (\%) ${ }^{2}$ & & & & 0,10 \\
\hline Normal & $83(34,2)$ & $149(38,9)$ & $232(37,1)$ & \\
\hline Sobrepeso & $110(45,1)$ & $140(36,6)$ & $250(39,9)$ & \\
\hline Obesidade & $50(20,5)$ & $94(24,5)$ & $144(23,0)$ & \\
\hline Circunferência abdominal (cm) (\%) & $93,3(11,8)$ & $90,4(12,8)$ & $91,5(12,5)$ & 0,005 \\
\hline $\begin{array}{l}\text { Circunferência abdominal } \\
\text { elevada }(\%)^{3}\end{array}$ & $52(21,5)$ & $209(54,7)$ & $261(41,9)$ & 0,0001 \\
\hline $\begin{array}{l}\text { Pressão arterial sistólica } \\
(\mathrm{mm} \mathrm{Hg})^{1}\end{array}$ & $126,6(20,3)$ & $118,0(20,2)$ & $121,3(20,7)$ & 0,0001 \\
\hline $\begin{array}{l}\text { Pressão arterial diastólica } \\
(\mathrm{mm} \mathrm{Hg})^{1}\end{array}$ & $84,5(13,5)$ & $77,6(12,7)$ & $80,3(13,5)$ & 0,0001 \\
\hline Hipertensão arterial (\%) ${ }^{4}$ & $101(41,6)$ & $132(34,5)$ & $233(37,3)$ & 0,08 \\
\hline \multicolumn{5}{|l|}{${ }^{1}$ Média (desvio padrão) } \\
\hline \multicolumn{5}{|c|}{$\begin{array}{l}2 \text { Estado nutricional definido por índice de massa corporal (IMC): normal - IMC }<25 \mathrm{~kg} / \mathrm{m}^{2} \text {, sobrepeso - IMC } \\
25 \text { a } 29,9 \mathrm{~kg} / \mathrm{m}^{2} \text { e obesos - IMC } \geq 30 \mathrm{~kg} / \mathrm{m}^{2} \text {. } \\
{ }^{3} \text { Definido como circunferência abdominal acima de } 102 \mathrm{~cm} \text { em homens e acima de } 88 \mathrm{~cm} \text { em mulheres. } \\
{ }^{4} \text { Hipertensão arterial definida como história médica de hipertensão arterial, ou uso de medicamentos } \\
\text { para hipertensão arterial ou pressão arterial sistólica } \geq 140 \mathrm{~mm} \mathrm{Hg} \text { ou pressão arterial diastólica } \geq 90 \\
\mathrm{~mm} \text { Hg. }\end{array}$} \\
\hline
\end{tabular}

Os homens também apresentaram níveis médios maiores de glicemia do que as mulheres ( $95,5 \mathrm{mg} / \mathrm{dl}$ vs $89,2 \mathrm{mg} / \mathrm{dl}$, respectivamente, $\mathrm{p}=0,003)$, porém não foi observada maior frequência de diagnóstico de diabetes mellitus (8,2\% dos homens e 6,5\% das mulheres, $\mathrm{p}=0,43)$.

Quanto aos níveis de lípides plasmáticos, houve diferenças importantes entre os gêneros, pois os homens apresentaram mais frequentemente os níveis de LDL-colesterol elevados ( $p=0,01)$, HDL-colesterol reduzido ( $p=0,0001)$ e triglicérides elevados ( $p=0,0001)$. Os homens também apresentaram pior perfil de risco pelo escore de Framingham $(\mathrm{p}=0,0001)$. Já as mulheres apresentaram maiores níveis médios de PCR ultra-sensível $(0,0001)$ e PCR classificado como de alto risco $(\mathrm{p}=0,0001)$ (tabela 5$)$.

Portanto, como o perfil de fatores de risco para doenças cardiovasculares difere de forma importante entre homens e mulheres em vários aspectos (tabelas 3, 4 e 5), foi optado por realizar todas as análises subsequentes separadas por gênero. 
TABELA 5

Perfil metabólico e de risco cardiovascular em 626 indivíduos do Estudo São Paulo Megacity, realizado na Grande São Paulo - 2005 a 2007

\begin{tabular}{|c|c|c|c|c|}
\hline & \multicolumn{2}{|c|}{ GÊNERO } & \multirow[t]{2}{*}{ TOTAL } & \multirow[t]{2}{*}{$\mathbf{P}$} \\
\hline & Masculino (\%) & Feminino (\%) & & \\
\hline & $\mathrm{N}=244$ & $\mathrm{~N}=\mathbf{3 8 3}$ & $N=626$ & \\
\hline Glicemia (mg/dl) ${ }^{1}$ & $95,5(25,8)$ & $89,2(21,6)$ & $91,6(23,5)$ & 0,003 \\
\hline Diabetes mellitus (\%) ${ }^{2}$ & $20(8,2)$ & $25(6,5)$ & $45(7,2)$ & 0,43 \\
\hline Colesterol total (mg/dl) ${ }^{1}$ & $193,5(51,2)$ & $193,3(42,7)$ & $193,3(46,1)$ & 0,97 \\
\hline 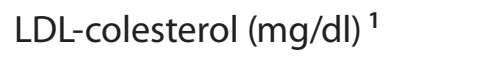 & $123,4(33,8)$ & $122,5(35,8)$ & $122,7(34,9)$ & 0,78 \\
\hline HDL-colesterol $(\mathrm{mg} / \mathrm{dl})^{1}$ & $42,6(10,2)$ & $49,5(12,1)$ & $46,9(11,9)$ & 0,0001 \\
\hline Triglicérides $(\mathrm{mg} / \mathrm{dl})^{1}$ & $153,3(294,0)$ & $105,7(64,9)$ & $124,2(191,8)$ & 0,002 \\
\hline LDL-colesterol elevado (\%) ${ }^{3}$ & $64(27,1)$ & $71(18,6)$ & $135(21,8)$ & 0,02 \\
\hline HDL-colesterol < 40 mg/dl (\%) & $102(43,0)$ & $75(19,6)$ & $177(28,6)$ & 0,0001 \\
\hline Triglicérides >150 mg/dl (\%) & $74(30,5)$ & $66(17,3)$ & $140(22,4)$ & 0,0001 \\
\hline Dislipidemia (\%) & $154(63,4)$ & $159(41,5)$ & $313(50,0)$ & 0,0001 \\
\hline $\begin{array}{l}\text { Proteína C reativa } \\
\text { ultra-sensível }(\mathrm{mg} / \mathrm{dl})^{1}\end{array}$ & $2,0(1,9)$ & $2,7(2,6)$ & $2,5(2,4)$ & 0,0001 \\
\hline $\begin{array}{l}\text { Proteína C reativa > } \\
3,0 \mathrm{mg} / \mathrm{dl}(\%)\end{array}$ & $45(19,8)$ & $123(35,1)$ & $168(29,1)$ & 0,0001 \\
\hline $\begin{array}{l}\text { Hormônio tireoestimulante } \\
\text { (TSH) }(\mathrm{mcUl} / \mathrm{ml})^{1}\end{array}$ & $2,5(3,2)$ & $2,4(1,8)$ & $2,4(2,4)$ & 0,55 \\
\hline Síndrome metabólica (\%) & $71(29,2)$ & $117(30,5)$ & $188(30,0)$ & 0,79 \\
\hline $\begin{array}{l}\text { Escore de risco de } \\
\text { Framingham (\%) }\end{array}$ & & & & 0,0001 \\
\hline Menor de $10 \%$ & $180(74,1)$ & $372(97,1)$ & $552(88,2)$ & \\
\hline $10-20 \%$ & $58(23,9)$ & $11(2,9)$ & $69(11,0)$ & \\
\hline Maior de $20 \%$ & $5(2,0)$ & - & $5(0,8)$ & \\
\hline \multicolumn{5}{|l|}{1 Média (desvio padrão) } \\
\hline \multicolumn{5}{|c|}{$\begin{array}{l}2 \text { Diabetes mellitus definido como história médica de diabetes, uso de medicamentos para tratamento de } \\
\text { diabetes mellitus ou glicemia de jejum } \geq 126 \mathrm{mg} / \mathrm{dl}\end{array}$} \\
\hline \multicolumn{5}{|c|}{$\begin{array}{l}{ }^{3} \text { Para indivíduos com doença cardiovascular aterosclerótica estabelecida ou diabetes mellitus ou Escore de } \\
\text { Risco de Framingham (ERF) }>20 \% \text { a meta de LDL-c é }<100 \mathrm{mg} / \text { dl. Para indivíduos com ERF de } 10 \text { a 20\%, a } \\
\text { meta de LDL-c é }<130 \mathrm{mg} / \mathrm{dl} \text { e para aqueles com ERF }<10 \% \text {, a meta é de LDL-c é }<160 \mathrm{mg} / \mathrm{dl} \text {. }\end{array}$} \\
\hline
\end{tabular}

Os indivíduos portadores de transtornos de humor exclusivo (incluindo transtornos depressivos, transtornos bipolares e transtorno distímico, porém sem nenhum transtorno de ansiedade associado) foram comparados a indivíduos sem nenhum transtorno 
psiquiátrico e foi observado que não há diferenças entre os dois grupos quanto as características sócio-demográficas, aos antecedentes pessoais de doenças e aos hábitos de vida dos participantes, tanto entre homens, quanto entre as mulheres (tabela 6).

Não foi encontrada diferença nas freqüências de sobrepeso, obesidade, circunferência abdominal elevada e diagnóstico de hipertensão arterial entre indivíduos portadores de transtornos de humor, quando comparados aos participantes sem diagnóstico psiquiátrico, em ambos os gêneros (tabelas 7 e 8).

Entre homens com transtornos de humor exclusivo há menos portadores de hipertrigliceridemia do que entre homens sem diagnóstico psiquiátrico $(p=0,046)$. Não há diferenças entre os grupos quanto as demais variáveis de perfil metabólico e de risco cardiovascular dos participantes do sexo masculino (tabela 9).

Foi observado entre as mulheres com transtornos de humor maiores níveis de colesterol total $(p=0,035)$, com uma diferença limítrofe nos níveis de LDL-colesterol $(p=0,057)$. Também foi observado que as mulheres portadoras de transtornos afetivos apresentam menores níveis de PCR ultra-sensível $(\mathrm{p}=0,038)$ e menor chance de apresentar PCR elevado $(\mathrm{p}=0,007)$. Não foram encontradas outras diferenças nas demais características de perfil metabólico e de risco cardiovascular nestes grupos (tabela 10). 
* TABELA 6

Características gerais, antecedentes pessoais e hábitos de vida em amostra de participantes com transtorno de humor exclusivo ou sem diagnóstico psiquiátrico do Estudo São Paulo Megacity, realizado na Grande São Paulo - 2005 a 2007

\begin{tabular}{|c|c|c|c|}
\hline & \multicolumn{2}{|c|}{ TRANSTORNO PSIQUIÁTRICO } & \multirow[t]{2}{*}{$\mathbf{P}$} \\
\hline & Transtorno de humor & Ausente & \\
\hline Homens & $\mathbf{N}=\mathbf{3 1}$ & $N=140$ & \\
\hline Idade (anos) ${ }^{1}$ & $39,4(11,0)$ & $41,6(10,6)$ & 0,29 \\
\hline Escolaridade (anos) ${ }^{1}$ & $10,1(3,8)$ & $8,9(4,0)$ & 0,14 \\
\hline Renda mensal domiciliar (reais) $^{1}$ & $1.753(1.454)$ & $1.394(1.395)$ & 0,21 \\
\hline Estado civil (\%) & & & 0,51 \\
\hline Casado & $21(75,0)$ & $104(77,0)$ & \\
\hline Viúvo/Separado/ Divorciado & $3(10,7)$ & $7(5,2)$ & \\
\hline Solteiro & $4(14,3)$ & $24(17,8)$ & \\
\hline Emprego (\%) & & & 0,46 \\
\hline Trabalhador & $21(75,0)$ & $115(85,2)$ & \\
\hline Estudante & - & $2(1,5)$ & \\
\hline Do lar & $1(3,6)$ & $1(0,7)$ & \\
\hline Aposentado & $2(7,1)$ & $7(5,2)$ & \\
\hline Outros & $4(14,3)$ & $10(7,4)$ & \\
\hline Tabagismo (\%) & & & 0,40 \\
\hline Nunca fumante & $17(54,8)$ & $84(60,0)$ & \\
\hline Ex-fumante & $6(19,4)$ & $34(24,3)$ & \\
\hline Fumante ativo & $8(25,8)$ & $22(15,7)$ & \\
\hline Consumo de álcool (\%) ${ }^{2}$ & $8(25,8)$ & $37(26,4)$ & 0,40 \\
\hline Atividade física regular (\%) ${ }^{3}$ & $28(90,3)$ & $122(87,1)$ & 0,77 \\
\hline $\begin{array}{l}\text { Diagnóstico prévio de } \\
\text { hipertensão arterial (\%) }\end{array}$ & $10(32,3)$ & $38(27,1)$ & 0,66 \\
\hline $\begin{array}{l}\text { Diagnóstico prévio de diabetes } \\
\text { mellitus (\%) }\end{array}$ & $3(9,7)$ & $8(5,7)$ & 0,42 \\
\hline $\begin{array}{l}\text { Diagnóstico prévio de } \\
\text { doença cardiovascular }{ }^{4}\end{array}$ & $2(6,5)$ & $4(2,9)$ & 0,30 \\
\hline Mulheres & $\mathrm{N}=59$ & $N=136$ & \\
\hline Idade (anos) ${ }^{1}$ & $41,9(10,9)$ & $41,0(10,6)$ & 0,60 \\
\hline Escolaridade (anos) ${ }^{1}$ & $8,4(3,8)$ & $9,2(4,2)$ & 0,24 \\
\hline Renda mensal domiciliar (reais) $^{1}$ & $1.075(1.091)$ & $1.391(1.278)$ & 0,10 \\
\hline Estado civil (\%) & & & 0,85 \\
\hline
\end{tabular}




\begin{tabular}{|c|c|c|c|}
\hline & \multicolumn{2}{|c|}{ TRANSTORNO PSIQUIÁTRICO } & \multirow[t]{2}{*}{$\mathbf{P}$} \\
\hline & Transtorno de humor & Ausente & \\
\hline Mulheres & $\mathbf{N}=\mathbf{5 9}$ & $N=136$ & \\
\hline Casado & $29(50,0)$ & $73(54,5)$ & \\
\hline Viúvo/ Separado/ Divorciado & $14(24,1)$ & $30(22,4)$ & \\
\hline Solteiro & $15(25,9)$ & $31(23,1)$ & \\
\hline Emprego (\%) & & & 0,46 \\
\hline Trabalhador & $34(58,6)$ & $79(59,0)$ & \\
\hline Estudante & $2(3,4)$ & $2(1,5)$ & \\
\hline Do lar & $12(20,7)$ & $30(22,4)$ & \\
\hline Aposentado & $1(1,7)$ & $9(6,7)$ & \\
\hline Outros & $9(15,5)$ & $14(10,4)$ & \\
\hline Tabagismo (\%) & & & 0,10 \\
\hline Nunca fumante & $32(54,2)$ & $84(61,8)$ & \\
\hline Ex-fumante & $13(22,0)$ & $36(26,5)$ & \\
\hline Fumante ativo & $14(23,7)$ & $16(11,8)$ & \\
\hline Consumo de álcool (\%) ${ }^{2}$ & $5(8,5)$ & $13(9,6)$ & 0,25 \\
\hline Atividade física regular (\%) ${ }^{3}$ & $49(83,1)$ & $115(84,6)$ & 0,83 \\
\hline $\begin{array}{l}\text { Diagnóstico prévio de } \\
\text { hipertensão arterial (\%) }\end{array}$ & $17(28,8)$ & $30(22,1)$ & 0,36 \\
\hline $\begin{array}{l}\text { Diagnóstico prévio de diabetes } \\
\text { mellitus (\%) }\end{array}$ & $5(8,5)$ & $5(3,7)$ & 0,17 \\
\hline $\begin{array}{l}\text { Diagnóstico prévio de } \\
\text { doença cardiovascular }{ }^{4}\end{array}$ & $3(5,1)$ & $5(3,7)$ & 0,70 \\
\hline
\end{tabular}

${ }^{1}$ Média (desvio-padrão)

2 Definido como consumo regular de bebidas alcoólicas pelo menos uma vez por semana

${ }^{3}$ Definido por meio do IPAQ, somando indivíduos ativos e muito ativos.

${ }^{4}$ Definido como diagnóstico prévio de acidente vascular cerebral, infarto agudo do miocárdio ou coronariopatias. 
* TABELA 7

Dados antropométricos e medida de pressão arterial em 171 homens de amostra de participantes com transtorno de humor exclusivo ou sem diagnóstico psiquiátrico do Estudo São Paulo Megacity, realizado na Grande São Paulo - 2005 a 2007

\begin{tabular}{|c|c|c|c|}
\hline & \multicolumn{2}{|c|}{ TRANSTORNO PSIQUIÁTRICO } & \multirow[t]{2}{*}{$\mathbf{P}$} \\
\hline & Transtorno de humor & Ausente & \\
\hline Homens & $\mathbf{N}=\mathbf{3 1}$ & $N=140$ & \\
\hline Índice de massa corporal $\left(\mathrm{kg} / \mathrm{m}^{2}\right)^{1}$ & $26,7(3,5)$ & $27,1(4,3)$ & 0,60 \\
\hline Estado nutricional(\%) ${ }^{2}$ & & & 0,42 \\
\hline Normal & $10(32,3)$ & $45(32,1)$ & \\
\hline Sobrepeso & $17(54,8)$ & $63(45,0)$ & \\
\hline Obesidade & $4(12,9)$ & $32(22,9)$ & \\
\hline Circunferência abdominal (cm) (\%) & $92,8(8,5)$ & $94,2(12,1)$ & 0,53 \\
\hline Circunferência abdominal elevada (\%) ${ }^{3}$ & $4(12,9)$ & $34(24,5)$ & 0,23 \\
\hline Pressão arterial sistólica $(\mathrm{mm} \mathrm{Hg})^{1}$ & $126,4(24,0)$ & $128,4(19,4)$ & 0,61 \\
\hline Pressão arterial diastólica $(\mathrm{mm} \mathrm{Hg})^{1}$ & $83,2(16,9)$ & $85,7(13,0)$ & 0,37 \\
\hline Hipertensão arterial (\%) ${ }^{4}$ & $12(38,7)$ & $60(42,9)$ & 0,69 \\
\hline \multicolumn{4}{|l|}{${ }^{1}$ Média (desvio-padrão) } \\
\hline \multicolumn{4}{|c|}{$\begin{array}{l}2 \text { Estado nutricional definido por índice de massa corporal (IMC): normal - IMC }<25 \mathrm{~kg} / \mathrm{m}^{2} \text {, sobrepeso - IMC } \\
25 \text { a } 29,9 \mathrm{~kg} / \mathrm{m}^{2} \text { e obesos - IMC } \geq 30 \mathrm{~kg} / \mathrm{m}^{2} \text {. }\end{array}$} \\
\hline \multicolumn{4}{|c|}{${ }^{3}$ Definido como circunferência abdominal acima de $102 \mathrm{~cm}$ em homens. } \\
\hline \multicolumn{4}{|c|}{${ }^{4}$ Hipertensão arterial definida como história médica de hipertensão arterial, uso de medicamentos para } \\
\hline
\end{tabular}




\section{TABELA 8}

Dados antropométricos e medida de pressão arterial em 195 mulheres de amostra de participantes com transtorno de humor exclusivo ou sem diagnóstico psiquiátrico do Estudo São Paulo Megacity, realizado na Grande São Paulo - 2005 a 2007

\begin{tabular}{|c|c|c|c|}
\hline & \multicolumn{2}{|c|}{ TRANSTORNO PSIQUIÁTRICO } & \multirow[t]{2}{*}{$\mathbf{P}$} \\
\hline & Transtorno de humor & Ausente & \\
\hline Mulheres & $\mathbf{N}=59$ & $N=136$ & \\
\hline Índice de massa corporal $\left(\mathrm{kg} / \mathrm{m}^{2}\right)^{1}$ & $26,5(3,8)$ & $27,0(5,5)$ & 0,55 \\
\hline Estado nutricional(\%) ${ }^{2}$ & & & 0,19 \\
\hline Normal & $24(40,7)$ & $56(41,2)$ & \\
\hline Sobrepeso & $26(44,1)$ & $45(33,1)$ & \\
\hline Obesidade & $9(15,3)$ & $35(25,7)$ & \\
\hline Circunferência abdominal (cm) (\%) & $90,3(10,3)$ & $90,6(12,9)$ & 0,91 \\
\hline Circunferência abdominal elevada(\%) ${ }^{3}$ & $32(54,2)$ & $70(51,9)$ & 0,76 \\
\hline Pressão arterial sistólica $(\mathrm{mm} \mathrm{Hg})^{1}$ & $117,3(23,5)$ & $118,1(18,7)$ & 0,81 \\
\hline Pressão arterial diastólica $(\mathrm{mm} \mathrm{Hg})^{1}$ & $77,6(14,5)$ & $78,4(12,3)$ & 0,68 \\
\hline Hipertensão arterial(\%) ${ }^{4}$ & $20(33,9)$ & $42(30,9)$ & 0,74 \\
\hline \multicolumn{4}{|l|}{${ }^{1}$ Média (desvio padrão) } \\
\hline \multirow{2}{*}{\multicolumn{4}{|c|}{$\begin{array}{l}2 \text { Estado nutricional definido por índice de massa corporal (IMC): normal - IMC }<25 \mathrm{~kg} / \mathrm{m}^{2} \text {, sobrepeso - IMC } \\
25 \text { a } 29,9 \mathrm{~kg} / \mathrm{m}^{2} \text { e obesos }-\mathrm{IMC} \geq 30 \mathrm{~kg} / \mathrm{m}^{2} \text {. } \\
{ }^{3} \text { Definido como circunferência abdominal acima de } 88 \mathrm{~cm} \text { em mulheres. }\end{array}$}} \\
\hline & & & \\
\hline \multicolumn{4}{|c|}{$\begin{array}{l}{ }^{4} \text { Hipertensão arterial definida como história médica de hipertensão arterial, uso de medicamentos para } \\
\text { hipertensão arterial ou pressão arterial sistólica } \geq 140 \mathrm{~mm} \mathrm{Hg} \text { ou pressão arterial diastólica } \geq 90 \mathrm{~mm} \mathrm{Hg} \text {. }\end{array}$} \\
\hline
\end{tabular}


* TABELA 9

Perfil metabólico e de risco cardiovascular em 171 homens de amostra de participantes com transtorno de humor exclusivo ou sem diagnóstico psiquiátrico do Estudo São Paulo Megacity, realizado na Grande São Paulo - 2005 a 2007

\begin{tabular}{|c|c|c|c|}
\hline & \multicolumn{2}{|c|}{ TRANSTORNO PSIQUIÁTRICO } & \multirow[t]{2}{*}{$\mathbf{P}$} \\
\hline & Transtorno de humor & Ausente & \\
\hline Homens & $\mathbf{N}=\mathbf{3 1}$ & $N=140$ & \\
\hline Glicemia (mg/dl) ${ }^{1}$ & $88,5(10,4)$ & $95,6(21,9)$ & 0,12 \\
\hline Diabetes mellitus(\%) ${ }^{2}$ & $3(9,7)$ & $10(7,1)$ & 0,71 \\
\hline Colesterol total $(\mathrm{mg} / \mathrm{dl})^{1}$ & $183,0(39,6)$ & $197,3(57,7)$ & 0,19 \\
\hline LDL-colesterol (mg/dl) ${ }^{1}$ & $119,6(35,0)$ & $125,4(33,6)$ & 0,39 \\
\hline HDL-colesterol (mg/dl) ${ }^{1}$ & $40,8(8,3)$ & $42,2(9,8)$ & 0,48 \\
\hline Triglicérides (mg/dl) $^{1}$ & $111,6(37,4)$ & $173,6(381,2)$ & 0,37 \\
\hline LDL-colesterol elevado (\%) ${ }^{3}$ & $9(29,0)$ & $37(27,6)$ & 1,0 \\
\hline HDL-colesterol < 40 mg/dl (\%) & $15(48,4)$ & $61(45,2)$ & 0,84 \\
\hline Triglicérides >150 mg/dl (\%) & $4(12,9)$ & $45(32,1)$ & 0,046 \\
\hline Proteína $C$ reativa ultra-sensível $(\mathrm{mg} / \mathrm{dll})^{1}$ & $1,9(2,0)$ & $2,0(1,8)$ & 0,86 \\
\hline Proteína $\mathrm{C}$ reativa > 3,0 mg/dl (\%) & $7(22,6)$ & $25(19,4)$ & 0,56 \\
\hline $\begin{array}{l}\text { Hormônio tireo-estimulante (TSH) } \\
(\mathrm{mcUl} / \mathrm{ml})^{1}\end{array}$ & $2,5(2,0)$ & $2,2(1,5)$ & 0,27 \\
\hline Síndrome metabólica (\%) & $6(19,4)$ & $40(28,6)$ & 0,30 \\
\hline Escore de risco de Framingham (\%) & & & 0,54 \\
\hline Menor $10 \%$ & $24(77,4)$ & $97(69,3)$ & \\
\hline $10-20 \%$ & $7(22,6)$ & $40(28,6)$ & \\
\hline Maior $20 \%$ & - & $3(2,1)$ & \\
\hline
\end{tabular}

${ }^{1}$ Média (desvio padrão)

${ }^{2}$ Diabetes mellitus definido como história médica de diabetes, uso de medicamentos para tratamento de diabetes mellitus ou glicemia de jejum $\geq 126 \mathrm{mg} / \mathrm{dl}$

${ }^{3}$ Para indivíduos com doença cardiovascular aterosclerótica estabelecida ou diabetes mellitus ou Escore de Risco de Framingham (ERF) $>20 \%$ a meta de LDL-c é $<100$ mg/dl. Para indivíduos com ERF de 10 a 20\%, a meta de LDL-c é $<130 \mathrm{mg} / \mathrm{dl}$ e para aqueles com ERF $<10 \%$, a meta é de LDL-c é $<160 \mathrm{mg} / \mathrm{dl}$. 


\section{TABELA 10}

Perfil metabólico e de risco cardiovascular em 195 mulheres de amostra de participantes com transtorno de humor exclusivo ou sem diagnóstico psiquiátrico do Estudo São Paulo Megacity, realizado na Grande São Paulo - 2005 a 2007

\begin{tabular}{|c|c|c|c|}
\hline & \multicolumn{2}{|c|}{ TRANSTORNO PSIQUIÁTRICO } & \multirow[t]{2}{*}{$\mathbf{P}$} \\
\hline & $\begin{array}{l}\text { Transtorno de } \\
\text { humor }\end{array}$ & $\begin{array}{l}\text { Sem diagnóstico } \\
\text { psiquiátrico }\end{array}$ & \\
\hline Mulheres & $\mathrm{N}=59$ & $N=136$ & \\
\hline Glicemia $(\mathrm{mg} / \mathrm{dl})^{1}$ & $89,6(20,3)$ & $89,8(22,1)$ & 0,95 \\
\hline Diabetes mellitus(\%) ${ }^{2}$ & $5(8,5)$ & $7(5,1)$ & 0,52 \\
\hline Colesterol total $(\mathrm{mg} / \mathrm{dl})^{1}$ & $201,8(46,1)$ & $188,1(39,2)$ & 0,035 \\
\hline LDL-colesterol (mg/dl) ${ }^{1}$ & $129,4(38,4)$ & $119,4(32,8)$ & 0,06 \\
\hline HDL-colesterol (mg/dl) ${ }^{1}$ & $48,6(10,3)$ & $48,8(12,0)$ & 0,93 \\
\hline Triglicérides $(\mathrm{mg} / \mathrm{dl})^{1}$ & $118,0(82,4)$ & $99,0(55,7)$ & 0,06 \\
\hline LDL-colesterol elevado $(\%)^{3}$ & $14(23,7)$ & $17(12,5)$ & 0,057 \\
\hline HDL-colesterol < 40 mg/dl (\%) & $10(16,9)$ & $30(22,1)$ & 0,45 \\
\hline Triglicérides >150 mg/dl (\%) & $11(18,6)$ & $22(16,2)$ & 0,68 \\
\hline Proteína $C$ reativa ultra-sensível $(\mathrm{mg} / \mathrm{dl})^{1}$ & $2,4(2,4)$ & $3,3(2,8)$ & 0,038 \\
\hline Proteína C reativa > 3,0 mg/dl (\%) & $15(26,8)$ & $58(47,9)$ & 0,007 \\
\hline $\begin{array}{l}\text { Hormônio tireo-estimulante (TSH) } \\
(\mathrm{mcUl} / \mathrm{ml})^{1}\end{array}$ & $2,2(2,0)$ & $2,6(1,9)$ & 0,18 \\
\hline Síndrome metabólica (\%) & $17(28,8)$ & $41(30,1)$ & 0,85 \\
\hline Escore de risco de Framingham (\%) & & & 0,63 \\
\hline Menor $10 \%$ & $57(96,6)$ & $133(97,8)$ & \\
\hline $10-20 \%$ & $2(3,4)$ & $3(2,2)$ & \\
\hline Maior $20 \%$ & - & - & \\
\hline \multicolumn{4}{|l|}{${ }^{1}$ Média (desvio padrão) } \\
\hline \multicolumn{4}{|c|}{$\begin{array}{l}\text { Diabetes mellitus definido como história médica de diabetes, uso de medicamentos para tratamento de } \\
\text { diabetes mellitus ou glicemia de jejum } \geq 126 \mathrm{mg} / \mathrm{dl}\end{array}$} \\
\hline \multicolumn{4}{|c|}{$\begin{array}{l}{ }^{3} \text { Para indivíduos com doença cardiovascular aterosclerótica estabelecida ou diabetes mellitus ou Escore de } \\
\text { Risco de Framingham (ERF) }>20 \% \text { a meta de LDL-c é }<100 \mathrm{mg} / \text { dl. Para indivíduos com ERF de } 10 \text { a 20\%, a } \\
\text { meta de LDL-c é }<130 \mathrm{mg} / \text { dl e para aqueles com ERF }<10 \% \text {, a meta é de LDL-c é }<160 \mathrm{mg} / \mathrm{dll} \text {. }\end{array}$} \\
\hline
\end{tabular}

Foi realizada regressão logística com os indivíduos com transtornos de humor exclusivo e comparando com indivíduos sem nenhuma doença psiquiátrica e foram observadas algumas diferenças em ambos os gêneros (tabela 11). Os homens portadores de transtorno de humor exclusivo apresentaram menor freqüência de hipertrigliceridemia, com odds ratio (OR) de 0,31 (IC 95\% 0,10-0,95). No entanto, esta diferença desaparece após ajuste para idade. 
As mulheres com transtornos de humor apresentam maior chance de serem tabagistas, com odds ratio de 2,30 (IC 95\% 1,03-5,15) quando comparadas as mulheres sem transtorno psiquiátrico. Foi observado ainda maior freqüência de LDL-colesterol elevado entre as mulheres com transtorno de humor, porém esta diferença desaparece após ajuste para idade (tabela 11).

Não foi observada associação entre diagnóstico de transtorno de humor exclusivo e a presença de excesso de peso, hipertensão arterial, diabetes mellitus, síndrome metabólica, ou presença de escore de risco de Framingham elevado.

Além disso, na regressão logística, quando são agrupadas as mulheres classificadas como alto (> 3,0 mg/dl) e moderado risco cardiovascular ( de 1,0 a 3,0 mg/dl) por meio do PCR ultra-sensível e comparadas com as mulheres classificadas como baixo risco $(<1,0$ $\mathrm{mg} / \mathrm{dl}$ ), a diferença observada na tabela 10 , deixa de ocorrer.

\section{* TABELA 11}

Fatores associados à presença de transtorno de humor exclusivo no Estudo São Paulo Megacity realizado na Grande São Paulo - 2005 a 2007

\begin{tabular}{|c|c|c|c|c|c|c|}
\hline & \multicolumn{6}{|c|}{ GÊNERO } \\
\hline & \multicolumn{3}{|c|}{ Masculino } & \multicolumn{3}{|c|}{ Feminino } \\
\hline & OR & IC95\% & $\mathbf{P}$ & OR & IC95\% & $\mathbf{P}$ \\
\hline \multicolumn{7}{|l|}{ Inatividade física } \\
\hline Sem ajuste & 0,73 & $0,20-2,64$ & 0,63 & 1,12 & $0,49-2,55$ & 0,79 \\
\hline Ajuste por idade & 0,67 & $0,18-2,47$ & 0,55 & 1,13 & $0,50-2,58$ & 0,77 \\
\hline \multicolumn{7}{|c|}{$\begin{array}{l}\text { Presença de tabagismo } \\
\text { atual }\end{array}$} \\
\hline Sem ajuste & 1,87 & $0,74-4,70$ & 0,19 & 2,33 & $1,05-5,17$ & 0,04 \\
\hline Ajuste por idade & 2,09 & $0,81-5,38$ & 0,13 & 2,30 & $1,03-5,15$ & 0,04 \\
\hline \multicolumn{7}{|c|}{$\begin{array}{l}\text { Presença de excesso } \\
\text { de peso }^{1}\end{array}$} \\
\hline Sem ajuste & 1,0 & $0,43-2,29$ & 0,99 & 1,02 & $0,55-1,90$ & 0,95 \\
\hline Ajuste por idade & 1,11 & $0,47-2,62$ & 0,81 & 0,96 & $0,50-1,86$ & 0,91 \\
\hline \multicolumn{7}{|c|}{ Hipertensão arterial } \\
\hline Sem ajuste & 0,84 & $0,38-1,87$ & 0,67 & 1,15 & $0,60-2,20$ & 0,68 \\
\hline Ajuste por idade & 0,99 & $0,42-2,40$ & 1,0 & 1,09 & $0,55-2,18$ & 0,80 \\
\hline \multicolumn{7}{|c|}{ Diabetes mellitus } \\
\hline Sem ajuste & 1,39 & $0,36-5,39$ & 0,63 & 1,71 & $0,52-5,61$ & 0,38 \\
\hline Ajuste por idade & 1,62 & $0,41-6,48$ & 0,49 & 1,65 & $0,50-5,48$ & 0,42 \\
\hline
\end{tabular}




\begin{tabular}{|c|c|c|c|c|c|c|}
\hline & \multicolumn{6}{|c|}{ GÊNERO } \\
\hline & \multicolumn{3}{|c|}{ Masculino } & \multicolumn{3}{|c|}{ Feminino } \\
\hline & OR & IC95\% & $\mathbf{P}$ & OR & IC95\% & $\mathbf{P}$ \\
\hline \multicolumn{7}{|c|}{ Colesterol total elevado } \\
\hline Sem ajuste & 0,48 & $0,20-1,14$ & 0,10 & 1,16 & $0,63-2,15$ & 0,64 \\
\hline Ajuste por idade & 0,52 & $0,20-1,30$ & 0,16 & 1,11 & $0,58-2,14$ & 0,75 \\
\hline \multicolumn{7}{|c|}{ LDL colesterol elevado } \\
\hline Sem ajuste & 1,07 & $0,45-2,54$ & 0,87 & 2,18 & $0,99-4,78$ & 0,052 \\
\hline Ajuste por idade & 1,33 & $0,52-3,45$ & 0,55 & 2,22 & $0,96-5,15$ & 0,06 \\
\hline \multicolumn{7}{|c|}{ HDL- colesterol reduzido } \\
\hline Sem ajuste & 1,14 & $0,52-2,49$ & 0,75 & 0,72 & $0,33-1,59$ & 0,42 \\
\hline Ajuste por idade & 1,19 & $0,54-2,62$ & 0,67 & 0,71 & $0,32-1,57$ & 0,40 \\
\hline \multicolumn{7}{|c|}{$\begin{array}{l}\text { Presença de } \\
\text { hipertrigliceridemia }\end{array}$} \\
\hline Sem ajuste & 0,31 & $0,10-0,95$ & 0,04 & 1,19 & $0,53-2,64$ & 0,67 \\
\hline Ajuste por idade & 0,33 & $0,11-1,04$ & 0,06 & 1,14 & $0,51-2,58$ & 0,75 \\
\hline \multicolumn{7}{|c|}{$\begin{array}{l}\text { Presença de síndrome } \\
\text { metabólica }\end{array}$} \\
\hline Sem ajuste & 0,60 & $0,23-1,57$ & 0,30 & 0,94 & $0,48-1,84$ & 0,85 \\
\hline Ajuste por idade & 0,67 & $0,25-1,83$ & 0,43 & 0,87 & $0,43-1,78$ & 0,71 \\
\hline \multicolumn{7}{|c|}{ Presença de PCR elevado² } \\
\hline Sem ajuste & 0,74 & $0,34-1,63$ & 0,46 & 1,02 & $0,51-2,05$ & 0,96 \\
\hline Ajuste por idade & 0,79 & $0,35-1,78$ & 0,58 & 1,02 & $0,51-2,05$ & 0,96 \\
\hline \multicolumn{7}{|c|}{ Presença de ERF elevado ${ }^{3}$} \\
\hline Sem ajuste & 0,66 & $0,26-1,64$ & 0,37 & 1,56 & $0,25-9,56$ & 0,63 \\
\hline
\end{tabular}

Os homens com diagnóstico de depressão maior exclusiva (sem presença de comorbidade psiquiátrica) e sem nenhum diagnóstico psiquiátrico apresentam características sócio-demográficas, antecedentes pessoais de doenças e hábitos de vida semelhantes (tabela 12).

Dentre as mulheres com diagnóstico exclusivo de depressão maior, a renda mensal familiar referida é 30\% menor do que nas mulheres sem diagnóstico psiquiátrico ( $\mathrm{p}=0,04)$. Para as demais características sócio-demográficas, antecedentes pessoais de doenças e hábitos de vida, não houve diferença entre os grupos de mulheres (tabela 12). 
* TABELA 12

Características gerais, antecedentes pessoais e hábitos de vida em indivíduos com transtorno depressivo maior exclusivo ou sem diagnóstico psiquiátrico do Estudo São Paulo Megacity, realizado na Grande São Paulo - 2005 a 2007

\begin{tabular}{|c|c|c|c|}
\hline & \multicolumn{2}{|c|}{ TRANSTORNO PSIQUIÁTRICO } & \multirow[t]{2}{*}{$\mathbf{P}$} \\
\hline & Depressão maior & Ausente & \\
\hline Homens & $\mathbf{N}=\mathbf{2 1}$ & $N=140$ & \\
\hline Idade (anos) ${ }^{1}$ & $40,3(11,1)$ & $41,6(10,6)$ & 0,59 \\
\hline Escolaridade (anos) ${ }^{1}$ & $9,9(4,1)$ & $8,9(4,0)$ & 0,30 \\
\hline Renda mensal domiciliar (reais) ${ }^{1}$ & $1.879(1.570)$ & $1.394(1.395)$ & 0,15 \\
\hline Estado civil (\%) & & & 0,21 \\
\hline Casado & $13(68,4)$ & $104(77,0)$ & \\
\hline Viúvo/Separado/ Divorciado & $3(15,8)$ & $7(5,2)$ & \\
\hline Solteiro & $3(15,8)$ & $24(17,8)$ & \\
\hline Emprego (\%) & & & 0,53 \\
\hline Trabalhador & $15(78,9)$ & $115(85,2)$ & \\
\hline Estudante & - & $2(1,5)$ & \\
\hline Do lar & $1(5,3)$ & $1(0,7)$ & \\
\hline Aposentado & $1(5,3)$ & $7(5,2)$ & \\
\hline Outros & $2(10,5)$ & $10(7,4)$ & \\
\hline Tabagismo (\%) & & & 0,35 \\
\hline Nunca fumante & $11(52,4)$ & $84(60,0)$ & \\
\hline Ex-fumante & $4(19,0)$ & $34(24,3)$ & \\
\hline Fumante ativo & $6(28,6)$ & $22(15,7)$ & \\
\hline Consumo de álcool (\%) ${ }^{2}$ & $6(28,6)$ & $37(26,4)$ & 0,85 \\
\hline Atividade física regular (\%) ${ }^{3}$ & $19(90,5)$ & $122(87,1)$ & 1,0 \\
\hline Diagnóstico prévio de hipertensão arterial (\%) & $6(28,6)$ & $38(27,1)$ & 1,0 \\
\hline Diagnóstico prévio de diabetes mellitus (\%) & $3(14,3)$ & $8(5,7)$ & 0,16 \\
\hline Diagnóstico prévio de doença cardiovascular ${ }^{4}$ & $1(4,8)$ & $4(2,9)$ & 0,51 \\
\hline Mulheres & $\mathbf{N}=47$ & $N=136$ & \\
\hline Idade $(\text { anos })^{1}$ & $42,1(10,4)$ & $41,0(10,6)$ & 0,60 \\
\hline Escolaridade (anos) $^{1}$ & $8,2(3,9)$ & $9,2(4,2)$ & 0,15 \\
\hline Renda mensal domiciliar (reais) ${ }^{1}$ & $966(1.057)$ & $1.391(1.278)$ & 0,04 \\
\hline Estado civil (\%) & & & 0,89 \\
\hline Casado & $24(51,1)$ & $73(54,5)$ & \\
\hline Viúvo/Separado/ Divorciado & $12(25,5)$ & $30(22,4)$ & \\
\hline Solteiro & $11(23,4)$ & $31(23,1)$ & \\
\hline
\end{tabular}




\begin{tabular}{|c|c|c|c|}
\hline & \multicolumn{2}{|c|}{ TRANSTORNO PSIQUIÁTRICO } & \multirow[t]{2}{*}{$\mathbf{P}$} \\
\hline & Depressão maior & Ausente & \\
\hline Mulheres & $\mathrm{N}=47$ & $N=136$ & \\
\hline Emprego (\%) & & & 0,61 \\
\hline Trabalhador & $28(59,6)$ & $79(59,0)$ & \\
\hline Estudante & $2(4,3)$ & $2(1,5)$ & \\
\hline Do lar & $10(21,3)$ & $30(22,4)$ & \\
\hline Aposentado & $1(2,1)$ & $9(6,7)$ & \\
\hline Outros & $6(12,8)$ & $14(10,4)$ & \\
\hline Tabagismo atual (\%) & & & 0,23 \\
\hline Nunca fumante & $24(51,1)$ & $84(61,8)$ & \\
\hline Ex-fumante & $13(27,7)$ & $36(26,5)$ & \\
\hline Fumante ativo & $10(21,3)$ & $16(11,8)$ & \\
\hline Consumo de álcool (\%) ${ }^{2}$ & $3(6,4)$ & $13(9,6)$ & 0,26 \\
\hline Atividade física regular (\%) ${ }^{3}$ & $40(85,1)$ & $115(84,6)$ & 1,0 \\
\hline Diagnóstico prévio de hipertensão arterial (\%) & $13(27,7)$ & $30(22,1)$ & 0,43 \\
\hline Diagnóstico prévio de diabetes mellitus (\%) & $5(10,6)$ & $5(3,7)$ & 0,13 \\
\hline Diagnóstico prévio de doença cardiovascular ${ }^{4}$ & $2(4,3)$ & $5(3,7)$ & 1,0 \\
\hline \multicolumn{4}{|l|}{${ }^{1}$ Média (desvio-padrão) } \\
\hline \multicolumn{4}{|c|}{${ }^{2}$ Definido como consumo regular de bebidas alcoólicas pelo menos uma vez por semana } \\
\hline \multicolumn{4}{|c|}{${ }^{3}$ Definido por meio do IPAQ, somando indivíduos ativos e muito ativos. } \\
\hline \multicolumn{4}{|c|}{$\begin{array}{l}{ }^{4} \text { Definido como diagnóstico prévio de acidente vascular cerebral, infarto agudo do miocárdio ou } \\
\text { coronariopatias. }\end{array}$} \\
\hline
\end{tabular}

Não houve diferença entre homens com depressão maior exclusiva e sem diagnóstico psiquiátrico quanto a frequência de sobrepeso e de obesidade, quanto a média da medida de circunferência abdominal, freqüência de circunferência abdominal elevada, nem quanto a diagnóstico de hipertensão arterial (tabela 13).

No entanto, entre as mulheres com depressão há mais portadoras de sobrepeso e menos portadoras de obesidade do que nas mulheres sem diagnóstico psiquiátrico $(\mathrm{p}=0,035)$. Não há diferença entre os grupos de mulheres com depressão maior e sem diagnóstico psiquiátrico quanto a frequência de circunferência abdominal elevada e diagnóstico de hipertensão arterial (tabela 14).

Não foi observada nenhuma diferença entre os grupos de homens com depressão maior exclusiva e sem diagnóstico psiquiátrico relacionada ao perfil metabólico e de risco cardiovascular (tabela 15). 
No entanto, entre as mulheres, há nível médio maior de colesterol total entre as portadoras de depressão maior $(\mathrm{p}=0,047)$. Também foi observado que as mulheres portadoras de depressão apresentam menos frequentemente níveis elevados de proteína $\mathrm{C}$ reativa $(\mathrm{p}=0,005)$. Não foram observadas diferenças entre as demais variáveis do perfil metabólico e de risco cardiovascular para os grupos (tabela 16).

Foi realizada regressão logística para os participantes com transtorno depressivo maior exclusivo, comparando-os com indivíduos sem diagnóstico psiquiátrico e foi observado que os homens com depressão não apresentam diferenças nas variáveis de perfil de risco cardiovascular quando comparados aos indivíduos sem transtorno psiquiátrico (tabela 17).

As mulheres com depressão maior apresentam LDL-colesterol mais elevado do que mulheres sem transtorno psiquiátrico, com OR 2,43 (IC 95\% 1,01-5,87) ajustado para idade. Porém, não apresentam nenhuma outra diferença no perfil metabólico e de risco cardiovascular quando comparadas as mulheres sem diagnóstico psiquiátrico.

\section{* TABELA 13}

Dados antropométricos e medida de pressão arterial em 161 homens com transtorno depressivo maior exclusivo ou sem diagnóstico psiquiátrico do Estudo São Paulo Megacity, realizado na Grande São Paulo - 2005 a 2007

\begin{tabular}{|c|c|c|c|}
\hline & \multicolumn{2}{|c|}{ TRANSTORNO PSIQUIÁTRICO } & \multirow[t]{2}{*}{$\mathbf{P}$} \\
\hline & Depressão maior & Ausente & \\
\hline Homens & $\mathbf{N}=\mathbf{2 1}$ & $N=140$ & \\
\hline Índice de massa corporal $\left(\mathrm{kg} / \mathrm{m}^{2}\right)^{1}$ & $26,5(2,7)$ & $27,1(4,3)$ & 0,51 \\
\hline Estado nutricional (\%) ${ }^{2}$ & & & 0,35 \\
\hline Normal & $7(33,3)$ & $45(32,1)$ & \\
\hline Sobrepeso & $12(57,1)$ & $63(45,0)$ & \\
\hline Obesidade & $2(9,5)$ & $32(22,9)$ & \\
\hline Circunferência abdominal (cm) (\%) & $92,8(8,0)$ & $94,2(12,1)$ & 0,59 \\
\hline Circunferência abdominal elevada (\%) ${ }^{3}$ & $2(9,5)$ & $34(24,5)$ & 0,17 \\
\hline Pressão arterial sistólica $(\mathrm{mm} \mathrm{Hg})^{1}$ & $125,9(22,8)$ & $128,5(19,4)$ & 0,58 \\
\hline Pressão arterial diastólica $(\mathrm{mm} \mathrm{Hg})^{1}$ & $83,5(16,9)$ & $85,7(13,0)$ & 0,49 \\
\hline Hipertensão arterial (\%) ${ }^{4}$ & $7(33,3)$ & $60(42,9)$ & 0,48 \\
\hline \multicolumn{4}{|l|}{${ }^{1}$ Média (desvio-padrão) } \\
\hline \multirow{2}{*}{\multicolumn{4}{|c|}{$\begin{array}{l}{ }^{2} \text { Estado nutricional definido por índice de massa corporal (IMC): normal - IMC }<25 \mathrm{~kg} / \mathrm{m}^{2} \text {, sobrepeso - IMC } \\
25 \text { a } 29,9 \mathrm{~kg} / \mathrm{m}^{2} \text { e obesos - IMC } \geq 30 \mathrm{~kg} / \mathrm{m}^{2} \text {. } \\
{ }^{3} \text { Definido como circunferência abdominal acima de } 102 \mathrm{~cm} \text { em homens. }\end{array}$}} \\
\hline & & & \\
\hline \multicolumn{4}{|c|}{$\begin{array}{l}{ }^{4} \text { Hipertensão arterial definida como história médica de hipertensão arterial, ou uso de medicamentos para } \\
\text { hipertensão arterial ou pressão arterial sistólica } \geq 140 \mathrm{~mm} \mathrm{Hg} \text { ou pressão arterial diastólica } \geq 90 \mathrm{~mm} \mathrm{Hq} \text {. }\end{array}$} \\
\hline
\end{tabular}




\section{TABELA 14}

Dados antropométricos e medida de pressão arterial em 183 mulheres de amostra de participantes com transtorno depressivo maior exclusivo ou sem diagnóstico psiquiátrico do Estudo São Paulo Megacity, realizado na Grande São Paulo - 2005 a 2007

\begin{tabular}{|c|c|c|c|}
\hline & \multicolumn{2}{|c|}{ TRANSTORNO PSIQUIÁTRICO } & \multirow[t]{2}{*}{$\mathbf{P}$} \\
\hline & Depressão maior & Ausente & \\
\hline Mulheres & $\mathrm{N}=47$ & $N=136$ & \\
\hline Índice de massa corporal $\left(\mathrm{kg} / \mathrm{m}^{2}\right)^{1}$ & $26,4(3,4)$ & $27,0(5,5)$ & 0,50 \\
\hline Estado nutricional (\%) ${ }^{2}$ & & & 0,035 \\
\hline Normal & $18(38,3)$ & $56(41,2)$ & \\
\hline Sobrepeso & $24(51,1)$ & $45(33,1)$ & \\
\hline Obesidade & $5(10,6)$ & $35(25,7)$ & \\
\hline Circunferência abdominal (cm) (\%) & $90,0(9,7)$ & $90,6(12,9)$ & 0,77 \\
\hline Circunferência abdominal elevada (\%) ${ }^{3}$ & $26(55,3)$ & $70(51,9)$ & 0,74 \\
\hline Pressão arterial sistólica $(\mathrm{mm} \mathrm{Hg})^{1}$ & $116,6(23,6)$ & $118,1(18,7)$ & 0,65 \\
\hline Pressão arterial diastólica $(\mathrm{mm} \mathrm{Hg})^{1}$ & $77,0(14,3)$ & $78,4(12,3)$ & 0,52 \\
\hline Hipertensão arterial (\%) ${ }^{4}$ & $14(29,8)$ & $42(30,9)$ & 1,0 \\
\hline \multicolumn{4}{|l|}{${ }^{1}$ Média (desvio-padrão) } \\
\hline \multicolumn{4}{|c|}{$\begin{array}{l}{ }^{2} \text { Estado nutricional definido por índice de massa corporal (IMC): normal - IMC }<25 \mathrm{~kg} / \mathrm{m}^{2} \text {, sobrepeso - IMC } \\
25 \text { a } 29,9 \mathrm{~kg} / \mathrm{m}^{2} \text { e obesos }-I M C \geq 30 \mathrm{~kg} / \mathrm{m}^{2} \text {. }\end{array}$} \\
\hline \multicolumn{4}{|c|}{${ }^{3}$ Definido como circunferência abdominal acima de $88 \mathrm{~cm}$ em mulheres. } \\
\hline \multicolumn{4}{|c|}{$\begin{array}{l}{ }^{4} \text { Hipertensão arterial definida como história médica de hipertensão arterial, ou uso de medicamentos } \\
\text { para hipertensão arterial ou pressão arterial sistólica } \geq 140 \mathrm{~mm} \mathrm{Hg} \text { ou pressão arterial diastólica } \geq 90 \\
\text { mm Hg. }\end{array}$} \\
\hline
\end{tabular}


* TABELA 15

Perfil metabólico e de risco cardiovascular em 161 homens de amostra de participantes com transtorno depressivo maior exclusivo ou sem diagnóstico psiquiátrico do Estudo São Paulo Megacity, realizado na Grande São Paulo - 2005 a 2007

\begin{tabular}{|c|c|c|c|}
\hline & \multicolumn{2}{|c|}{ TRANSTORNO PSIQUIÁTRICO } & \multirow[t]{2}{*}{$\mathbf{P}$} \\
\hline & Depressão maior & Ausente & \\
\hline Homens & $\mathbf{N}=\mathbf{2 1}$ & $\mathrm{N}=\mathbf{1 4 0}$ & \\
\hline Glicemia (mg/dl) ${ }^{1}$ & $87,0(9,0)$ & $95,6(21,9)$ & 0,12 \\
\hline Diabetes mellitus(\%) ${ }^{2}$ & $3(14,3)$ & $10(7,1)$ & 0,38 \\
\hline Colesterol total $(\mathrm{mg} / \mathrm{dl})^{1}$ & $189,8(45,9)$ & $197,3(57,7)$ & 0,57 \\
\hline${\text { LDL-colesterol }(\mathrm{mg} / \mathrm{dl})^{1}}^{1}$ & $127,3(39,3)$ & $125,4(33,6)$ & 0,82 \\
\hline HDL-colesterol (mg/dl) ${ }^{1}$ & $38,8(7,8)$ & $42,2(9,8)$ & 0,14 \\
\hline Triglicérides (mg/dl) ${ }^{1}$ & $118,1(34,7)$ & $173,6(381,2)$ & 0,51 \\
\hline LDL-colesterol elevado (\%) ${ }^{3}$ & $9(42,9)$ & $37(27,6)$ & 0,20 \\
\hline HDL-colesterol < 40 mg/dl (\%) & $13(61,9)$ & $61(45,2)$ & 0,17 \\
\hline Triglicérides >150 mg/dl (\%) & $3(14,3)$ & $45(32,1)$ & 0,13 \\
\hline Proteína $C$ reativa ultra-sensível $(\mathrm{mg} / \mathrm{dl})^{1}$ & $2,2(2,1)$ & $2,0(1,8)$ & 0,63 \\
\hline Proteína C reativa > 3,0 mg/dl (\%) & $6(28,6)$ & $25(19,4)$ & 0,52 \\
\hline Hormônio tireo-estimulante (TSH) (mcUl/ml) ${ }^{1}$ & $2,3(1,0)$ & $2,2(1,5)$ & 0,85 \\
\hline Síndrome metabólica (\%) & $4(19,0)$ & $40(28,6)$ & 0,44 \\
\hline Escore de risco de Framingham (\%) & & & 0,79 \\
\hline Menor $10 \%$ & $15(71,4)$ & $97(69,3)$ & \\
\hline $10-20 \%$ & $6(28,6)$ & $40(28,6)$ & \\
\hline Maior $20 \%$ & - & $3(2,1)$ & \\
\hline \multicolumn{4}{|l|}{${ }^{1}$ Média (desvio padrão) } \\
\hline \multicolumn{4}{|c|}{$\begin{array}{l}{ }^{2} \text { Diabetes mellitus definido como história médica de diabetes, uso de medicamentos para tratamento de } \\
\text { diabetes mellitus ou glicemia de jejum } \geq 126 \mathrm{mg} / \mathrm{dl}\end{array}$} \\
\hline \multicolumn{4}{|c|}{$\begin{array}{l}3 \text { Para indivíduos com doença cardiovascular aterosclerótica estabelecida ou diabetes mellitus ou Escore de } \\
\text { Risco de Framingham (ERF) }>20 \% \text { a meta de LDL-c é }<100 \mathrm{mg} / \text { dl. Para indivíduos com ERF de } 10 \text { a 20\%, a } \\
\text { meta de LDL-c é }<130 \mathrm{mg} / \mathrm{dl} \text { e para aqueles com ERF }<10 \% \text {, a meta é de LDL-c é }<160 \mathrm{mg} / \mathrm{dl} \text {. }\end{array}$} \\
\hline
\end{tabular}


* TABELA 17

Perfil de fatores de risco cardiovascular em participantes do Estudo São Paulo Megacity de acordo com a presença de transtorno depressivo maior exclusivo, realizado na Grande São Paulo - 2005 a 2007

\begin{tabular}{|c|c|c|c|c|c|c|}
\hline & \multicolumn{6}{|c|}{ GÊNERO } \\
\hline & \multicolumn{3}{|c|}{ Masculino } & \multicolumn{3}{|c|}{ Feminino } \\
\hline & OR & IC95\% & $\mathbf{P}$ & OR & IC95\% & $\mathbf{P}$ \\
\hline \multicolumn{7}{|l|}{ Inatividade física } \\
\hline Sem ajuste & 0,71 & $0,15-3,32$ & 0,67 & 0,96 & $0,38-2,42$ & 0,93 \\
\hline Ajuste para idade & 0,69 & $0,14-3,22$ & 0,63 & 0,97 & $0,38-2,46$ & 0,95 \\
\hline \multicolumn{7}{|c|}{$\begin{array}{l}\text { Presença de tabagismo } \\
\text { atual }\end{array}$} \\
\hline Sem ajuste & 2,15 & $0,75-6,13$ & 0,15 & 2,03 & $0,85-4,85$ & 0,11 \\
\hline Ajuste para idade & 2,34 & $0,80-6,89$ & 0,12 & 1,97 & $0,81-4,79$ & 0,14 \\
\hline \multicolumn{7}{|c|}{$\begin{array}{l}\text { Presença de excesso } \\
\text { de peso }^{1}\end{array}$} \\
\hline Sem ajuste & 0,95 & $0,36-2,51$ & 0,91 & 1,13 & $0,57-2,23$ & 0,73 \\
\hline Ajuste para idade & 1,01 & $0,37-2,76$ & 0,97 & 1,04 & $0,53-2,17$ & 0,85 \\
\hline \multicolumn{7}{|c|}{ Hipertensão arterial } \\
\hline Sem ajuste & 0,67 & $0,25-1,75$ & 0,41 & 0,95 & $0,46-1,96$ & 0,89 \\
\hline Ajuste para idade & 0,70 & $0,25-1,97$ & 0,50 & 0,88 & $0,41-1,87$ & 0,74 \\
\hline \multicolumn{7}{|l|}{ Diabetes mellitus } \\
\hline Sem ajuste & 2,17 & $0,54-8,62$ & 0,27 & 2,19 & $0,66-7,28$ & 0,20 \\
\hline Ajuste para idade & 2,43 & $0,59-10,0$ & 0,22 & 2,11 & $0,63-7,09$ & 0,23 \\
\hline \multicolumn{7}{|c|}{ Colesterol total elevado } \\
\hline Sem ajuste & 0,85 & $0,33-2,17$ & 0,73 & 1,19 & $0,61-2,32$ & 0,61 \\
\hline Ajuste para idade & 0,92 & $0,33-2,53$ & 0,87 & 1,13 & $0,56-2,28$ & 0,73 \\
\hline \multicolumn{7}{|c|}{ LDL colesterol elevado } \\
\hline Sem ajuste & 1,97 & $0,77-5,05$ & 0,16 & 2,40 & $1,05-5,50$ & 0,04 \\
\hline Ajuste para idade & 2,59 & $0,89-7,60$ & 0,08 & 2,43 & $1,01-5,87$ & 0,05 \\
\hline \multicolumn{7}{|c|}{ HDL- colesterol reduzido } \\
\hline Sem ajuste & 1,97 & $0,77-5,07$ & 0,16 & 0,52 & $0,20-1,33$ & 0,17 \\
\hline Ajuste para idade & 2,02 & $0,79-5,24$ & 0,14 & 0,50 & 0,19-1,30 & 0,16 \\
\hline \multicolumn{7}{|c|}{$\begin{array}{l}\text { Presença de } \\
\text { hipertrigliceridemia }\end{array}$} \\
\hline Sem ajuste & 0,35 & $0,10-1,26$ & 0,11 & 1,06 & $0,44-2,58$ & 0,89 \\
\hline Ajuste para idade & 0,36 & $0,10-1,31$ & 0,12 & 1,01 & $0,41-2,49$ & 0,99 \\
\hline
\end{tabular}




\begin{tabular}{|c|c|c|c|c|c|c|}
\hline & \multicolumn{6}{|c|}{ GÊNERO } \\
\hline & \multicolumn{3}{|c|}{ Masculino } & \multicolumn{3}{|c|}{ Feminino } \\
\hline & OR & IC95\% & $\mathbf{P}$ & OR & IC95\% & $\mathbf{P}$ \\
\hline \multicolumn{7}{|c|}{$\begin{array}{l}\text { Presença de síndrome } \\
\text { metabólica }\end{array}$} \\
\hline Sem ajuste & 0,59 & $0,19-1,86$ & 0,37 & 0,79 & $0,38-1,68$ & 0,55 \\
\hline Ajuste para idade & 0,62 & $0,19-1,04$ & 0,43 & 0,73 & $0,33-1,59$ & 0,42 \\
\hline \multicolumn{7}{|c|}{ Presença de PCR elevado² } \\
\hline Sem ajuste & 0,93 & $0,37-2,36$ & 0,88 & 1,15 & $0,54-2,48$ & 0,72 \\
\hline Ajuste para idade & 0,96 & $0,37-2,50$ & 0,94 & 1,16 & $0,54-2,50$ & 0,71 \\
\hline \multicolumn{7}{|c|}{ Presença de ERF elevado ${ }^{3}$} \\
\hline Sem ajuste & 0,90 & $0,33-2,48$ & 0,84 & 0,96 & $0,10-9,50$ & 0,98 \\
\hline
\end{tabular}

${ }^{1}$ Incluídos indivíduos com sobrepeso ou obesidade.

${ }^{2}$ Indivíduos classificados como moderado ou alto risco para eventos cardiovasculares.

${ }^{3}$ Indivíduos classificados como ERF moderado ou alto risco para eventos cardiovasculares.

Os portadores de transtorno de ansiedade exclusivo (sem co-morbidade de transtorno de humor) foram comparados com indivíduos sem nenhum diagnóstico psiquiátrico e foi observado que não há diferenças em relação às características sócio-demográficas, antecedentes pessoais de doenças e hábitos de vida, em ambos os gêneros (tabela 18).

Também foi observado que entre o grupo de indivíduos portadores de transtorno de ansiedade exclusivo não há diferenças quanto aos dados antropométricos e presença de fatores de risco cardiovascular quando comparados aos indivíduos sem transtornos psiquiátricos (tabela 19, 20, 21 e 22). Somente há uma exceção: as mulheres com transtornos de ansiedade apresentam níveis menores de PCR do que as mulheres que não apresentam nenhum diagnóstico psiquiátrico (tabela 22). 
* TABELA 18

Características gerais, antecedentes pessoais de doenças e hábitos de vida em amostra de participantes com transtornos de ansiedade exclusivo ou sem diagnóstico psiquiátrico do Estudo São Paulo Megacity, realizado na Grande São Paulo - 2005 a 2007

\begin{tabular}{|c|c|c|c|}
\hline & \multicolumn{2}{|c|}{ TRANSTORNO PSIQUIÁTRICO } & \multirow[t]{2}{*}{$\mathbf{P}$} \\
\hline & Transtorno de ansiedade & Ausente & \\
\hline Homens & $\mathrm{N}=42$ & $N=140$ & \\
\hline Idade (anos) ${ }^{1}$ & $40,1(10,9)$ & $41,6(10,6)$ & 0,41 \\
\hline Escolaridade (anos) ${ }^{1}$ & $9,2(3,4)$ & $8,9(4,0)$ & 0,75 \\
\hline Renda mensal domiciliar (reais) ${ }^{1}$ & $1.411(1.470)$ & $1.394(1.395)$ & 0,95 \\
\hline Estado civil (\%) & & & 0,32 \\
\hline Casado & $27(65,9)$ & $104(77,0)$ & \\
\hline Viúvo/Separado/ Divorciado & $4(9,8)$ & $7(5,2)$ & \\
\hline Solteiro & $10(24,4)$ & $24(17,8)$ & \\
\hline Emprego (\%) & & & 0,59 \\
\hline Trabalhador & $33(80,5)$ & $115(85,2)$ & \\
\hline Estudante & - & $2(1,5)$ & \\
\hline Do lar & - & $1(0,7)$ & \\
\hline Aposentado & $2(4,9)$ & $7(5,2)$ & \\
\hline Outros & $6(14,6)$ & $10(7,4)$ & \\
\hline Tabagismo (\%) & & & 0,19 \\
\hline Nunca fumante & $27(65,9)$ & $84(60,0)$ & \\
\hline Ex-fumante & $12(29,3)$ & $34(24,3)$ & \\
\hline Fumante ativo & $2(4,9)$ & $22(15,7)$ & \\
\hline Consumo de álcool (\%) ${ }^{2}$ & $9(22,0)$ & $37(26,4)$ & 0,72 \\
\hline Atividade física regular (\%) ${ }^{3}$ & $33(78,6)$ & $122(87,1)$ & 0,22 \\
\hline $\begin{array}{l}\text { Diagnóstico prévio de } \\
\text { hipertensão arterial (\%) }\end{array}$ & $15(35,7)$ & $38(27,1)$ & 0,33 \\
\hline $\begin{array}{l}\text { Diagnóstico prévio de } \\
\text { diabetes mellitus (\%) }\end{array}$ & $5(11,9)$ & $8(5,7)$ & 0,18 \\
\hline $\begin{array}{l}\text { Diagnóstico prévio de } \\
\text { doença cardiovascular }{ }^{4}\end{array}$ & $1(2,4)$ & $4(2,9)$ & 1,0 \\
\hline Mulheres & $N=69$ & $N=136$ & \\
\hline Idade (anos) ${ }^{1}$ & $37,9(12,6)$ & $41,0(10,6)$ & 0,07 \\
\hline Escolaridade (anos) ${ }^{1}$ & $8,9(3,8)$ & $9,2(4,2)$ & 0,61 \\
\hline Renda mensal domiciliar (reais) ${ }^{1}$ & $1.369(1.822)$ & $1.391(1.278)$ & 0,92 \\
\hline Estado civil (\%) & & & 0,98 \\
\hline
\end{tabular}




\begin{tabular}{|c|c|c|c|}
\hline & \multicolumn{2}{|c|}{ TRANSTORNO PSIQUIÁTRICO } & \multirow[t]{2}{*}{$\mathbf{P}$} \\
\hline & Transtorno de ansiedade & Ausente & \\
\hline Mulheres & $N=69$ & $N=136$ & \\
\hline Casado & $38(55,9)$ & $73(54,5)$ & \\
\hline Viúvo/Separado/ Divorciado & $15(22,1)$ & $30(22,4)$ & \\
\hline Solteiro & $15(22,1)$ & $31(23,1)$ & \\
\hline Emprego (\%) & & & 0,80 \\
\hline Trabalhador & $42(61,8)$ & $79(59,0)$ & \\
\hline Estudante & - & $2(1,5)$ & \\
\hline Do lar & $13(19,1)$ & $30(22,4)$ & \\
\hline Aposentado & $4(5,9)$ & $9(6,7)$ & \\
\hline Outros & $9(13,2)$ & $14(10,4)$ & \\
\hline Tabagismo (\%) & & & 0,94 \\
\hline Nunca fumante & $41(59,4)$ & $84(61,8)$ & \\
\hline Ex-fumante & $19(27,5)$ & $36(26,5)$ & \\
\hline Fumante ativo & $9(13,0)$ & $16(11,8)$ & \\
\hline Consumo de álcool (\%) ${ }^{2}$ & $8(11,6)$ & $13(9,6)$ & 0,90 \\
\hline Atividade física regular (\%) ${ }^{3}$ & $58(84,1)$ & $115(84,6)$ & 1,0 \\
\hline $\begin{array}{l}\text { Diagnóstico prévio de } \\
\text { hipertensão arterial (\%) }\end{array}$ & $21(30,4)$ & $30(22,1)$ & 0,23 \\
\hline $\begin{array}{l}\text { Diagnóstico prévio de } \\
\text { diabetes mellitus (\%) }\end{array}$ & $1(1,4)$ & $5(3,7)$ & 0,67 \\
\hline $\begin{array}{l}\text { Diagnóstico prévio de } \\
\text { doença cardiovascular }{ }^{4}\end{array}$ & $4(5,8)$ & $5(3,7)$ & 0,49 \\
\hline
\end{tabular}

${ }^{1}$ Média (desvio-padrão)

2 Definido como consumo regular de bebidas alcoólicas pelo menos uma vez por semana

${ }^{3}$ Definido por meio do IPAQ, somando indivíduos ativos e muito ativos.

${ }^{4}$ Definido como diagnóstico prévio de acidente vascular cerebral, infarto agudo do miocárdio ou coronariopatias. 
* TABELA 19

Dados antropométricos e medida de pressão arterial em homens de amostra de participantes com transtorno de ansiedade exclusivo ou sem diagnóstico psiquiátrico do Estudo São Paulo Megacity, realizado na Grande São Paulo - 2005 a 2007

\begin{tabular}{|c|c|c|c|}
\hline & \multicolumn{2}{|c|}{ TRANSTORNO PSIQUIÁTRICO } & \multirow[t]{2}{*}{$\mathbf{P}$} \\
\hline & Transtorno de ansiedade & Ausente & \\
\hline Homens & $\mathrm{N}=42$ & $N=140$ & \\
\hline Índice de massa corporal $\left(\mathrm{kg} / \mathrm{m}^{2}\right)^{1}$ & $26,1(4,7)$ & $27,1(4,3)$ & 0,17 \\
\hline Estado nutricional(\%) ${ }^{2}$ & & & 0,77 \\
\hline Normal & $16(38,1)$ & $45(32,1)$ & \\
\hline Sobrepeso & $17(40,5)$ & $63(45,0)$ & \\
\hline Obesidade & $9(21,4)$ & $32(22,9)$ & \\
\hline Circunferência abdominal (cm) (\%) & $91,5(13,0)$ & $94,2(12,1)$ & 0,21 \\
\hline Circunferência abdominal elevada $(\%)^{3}$ & $10(24,4)$ & $34(24,5)$ & 0,99 \\
\hline Pressão arterial sistólica $(\mathrm{mm} \mathrm{Hg})^{1}$ & $123,2(21,3)$ & $128,5(19,4)$ & 0,14 \\
\hline Pressão arterial diastólica $(\mathrm{mm} \mathrm{Hg})^{1}$ & $82,0(13,3)$ & $85,7(13,0)$ & 0,11 \\
\hline Hipertensão arterial (\%) ${ }^{4}$ & $17(40,5)$ & $60(42,9)$ & 0,78 \\
\hline \multicolumn{4}{|l|}{1 Média (desvio-padrão) } \\
\hline \multirow{2}{*}{\multicolumn{4}{|c|}{$\begin{array}{l}{ }^{2} \text { Estado nutricional definido por índice de massa corporal (IMC): normal - IMC }<25 \mathrm{~kg} / \mathrm{m}^{2} \text {, sobrepeso - IMC } \\
25 \text { a } 29,9 \mathrm{~kg} / \mathrm{m}^{2} \text { e obesos - IMC } \geq 30 \mathrm{~kg} / \mathrm{m}^{2} \text {. } \\
{ }^{3} \text { Definido como circunferência abdominal acima de } 102 \mathrm{~cm} \text { em homens. }\end{array}$}} \\
\hline & & & \\
\hline \multicolumn{4}{|c|}{$\begin{array}{l}{ }^{4} \text { Hipertensão arterial definida como história médica de hipertensão arterial, uso de medicamentos para } \\
\text { hipertensão arterial ou pressão arterial sistólica } \geq 140 \mathrm{~mm} \mathrm{Hg} \text { ou pressão arterial diastólica } \geq 90 \mathrm{~mm} \mathrm{Hg}\end{array}$} \\
\hline
\end{tabular}


TABELA 20

Dados antropométricos e medida de pressão arterial em mulheres de amostra de participantes com transtorno de ansiedade exclusivo ou sem diagnóstico psiquiátrico do Estudo São Paulo Megacity, realizado na Grande São Paulo - 2005 a 2007

\begin{tabular}{|c|c|c|c|}
\hline & \multicolumn{2}{|c|}{ TRANSTORNO PSIQUIÁTRICO } & \multirow[t]{2}{*}{ P } \\
\hline & Transtorno de ansiedade & Ausente & \\
\hline Mulheres & $N=69$ & $N=136$ & \\
\hline Índice de massa corporal $\left(\mathrm{kg} / \mathrm{m}^{2}\right)^{1}$ & $27,5(5,4)$ & $27,0(5,5)$ & 0,49 \\
\hline Estado nutricional(\%) ${ }^{2}$ & & & 0,23 \\
\hline Normal & $20(29,0)$ & $56(41,2)$ & \\
\hline Sobrepeso & $28(40,6)$ & $45(33,1)$ & \\
\hline Obesidade & $21(30,4)$ & $35(25,7)$ & \\
\hline Circunferência abdominal (cm) (\%) & $89,9(13,8)$ & $90,6(12,9)$ & 0,73 \\
\hline Circunferência abdominal elevada (\%) ${ }^{3}$ & $37(53,6)$ & $70(51,9)$ & 0,88 \\
\hline Pressão arterial sistólica $(\mathrm{mm} \mathrm{Hg})^{1}$ & $118,4(20,9)$ & $118,1(18,7)$ & 0,93 \\
\hline Pressão arterial diastólica $(\mathrm{mm} \mathrm{Hg})^{1}$ & $76,2(12,9)$ & $78,4(12,3)$ & 0,23 \\
\hline Hipertensão arterial $(\%)^{4}$ & $25(36,2)$ & $42(30,9)$ & 0,53 \\
\hline \multicolumn{4}{|l|}{${ }^{1}$ Média (desvio-padrão) } \\
\hline \multirow{2}{*}{\multicolumn{4}{|c|}{$\begin{array}{l}{ }^{2} \text { Estado nutricional definido por índice de massa corporal (IMC): normal - IMC }<25 \mathrm{~kg} / \mathrm{m}^{2} \text {, sobrepeso - IMC } \\
25 \text { a } 29,9 \mathrm{~kg} / \mathrm{m}^{2} \text { e obesos }-I M C \geq 30 \mathrm{~kg} / \mathrm{m}^{2} \text {. } \\
{ }^{3} \text { Definido como circunferência abdominal acima de } 88 \mathrm{~cm} \text { em mulheres. }\end{array}$}} \\
\hline & & & \\
\hline \multicolumn{4}{|c|}{$\begin{array}{l}{ }^{4} \text { Hipertensão arterial definida como história médica de hipertensão arterial, uso de medicamentos para } \\
\text { hipertensão arterial ou pressão arterial sistólica } \geq 140 \mathrm{~mm} \mathrm{Hg} \text { ou pressão arterial diastólica } \geq 90 \mathrm{~mm} \mathrm{Hg}\end{array}$} \\
\hline
\end{tabular}


* TABELA 21

Perfil metabólico e de risco cardiovascular em homens de amostra de participantes com transtorno de ansiedade exclusivo ou sem diagnóstico psiquiátrico do Estudo São Paulo Megacity, realizado na Grande São Paulo - 2005 a 2007

\begin{tabular}{|c|c|c|c|}
\hline & \multicolumn{2}{|c|}{ TRANSTORNO PSIQUIÁTRICO } & \multirow[t]{2}{*}{$\mathbf{P}$} \\
\hline & Transtorno de ansiedade & Ausente & \\
\hline Homens & $N=42$ & $N=140$ & \\
\hline Glicemia (mg/dl) ${ }^{1}$ & $98,8(34,3)$ & $95,6(21,9)$ & 0,53 \\
\hline Diabetes mellitus(\%) ${ }^{2}$ & $5(11,9)$ & $10(7,1)$ & 0,34 \\
\hline Colesterol total $(\mathrm{mg} / \mathrm{dl})^{1}$ & $186,4(35,9)$ & $197,3(57,7)$ & 0,25 \\
\hline LDL-colesterol (mg/dl) ${ }^{1}$ & $119,4(27,5)$ & $125,4(33,6)$ & 0,30 \\
\hline HDL-colesterol (mg/dl) ${ }^{1}$ & $45,0(11,4)$ & $42,2(9,8)$ & 0,13 \\
\hline Triglicérides $(\mathrm{mg} / \mathrm{dl})^{1}$ & $120,4(88,9)$ & $173,6(381,2)$ & 0,37 \\
\hline LDL-colesterol elevado (\%) ${ }^{3}$ & $9(22,0)$ & $37(27,6)$ & 0,55 \\
\hline HDL-colesterol < 40 mg/dl (\%) & $14(34,1)$ & $61(45,2)$ & 0,28 \\
\hline Triglicérides >150 mg/dl (\%) & $12(28,6)$ & $45(32,1)$ & 0,71 \\
\hline $\begin{array}{l}\text { Proteína } C \text { reativa ultra-sensível } \\
(\mathrm{mg} / \mathrm{dl})^{1}\end{array}$ & $2,0(2,1)$ & $2,0(1,8)$ & 0,82 \\
\hline Proteína $C$ reativa > 3,0 mg/dl (\%) & $7(17,5)$ & $25(19,4)$ & 0,83 \\
\hline $\begin{array}{l}\text { Hormônio tireoestimulante (TSH) } \\
(\mathrm{mcUl} / \mathrm{ml})^{1}\end{array}$ & $2,9(5,9)$ & $2,2(1,5)$ & 0,17 \\
\hline Síndrome metabólica (\%) & $14(33,3)$ & $40(28,6)$ & 0,57 \\
\hline Escore de risco de Framingham (\%) & & & 0,17 \\
\hline Menor $10 \%$ & $35(83,3)$ & $97(69,3)$ & \\
\hline $10-20 \%$ & $6(14,3)$ & $40(28,6)$ & \\
\hline Maior 20\% & $1(2,4)$ & $3(2,1)$ & \\
\hline
\end{tabular}

${ }^{1}$ Média (desvio padrão)

${ }^{2}$ Diabetes mellitus definido como história médica de diabetes, uso de medicamentos para tratamento de diabetes mellitus ou glicemia de jejum $\geq 126 \mathrm{mg} / \mathrm{dl}$

${ }^{3}$ Para indivíduos com doença cardiovascular aterosclerótica estabelecida ou diabetes mellitus ou Escore de Risco de Framingham (ERF) > 20\% a meta de LDL-c é < 100 mg/dl. Para indivíduos com ERF de 10 a 20\%, a meta de LDL-c é $<130 \mathrm{mg} / \mathrm{dl}$ e para aqueles com ERF $<10 \%$, a meta é de LDL-c é $<160 \mathrm{mg} / \mathrm{dl}$. 


\section{TABELA 22}

Perfil metabólico e de risco cardiovascular em mulheres de amostra de participantes com transtorno de ansiedade exclusivo ou sem diagnóstico psiquiátrico do Estudo São Paulo Megacity, realizado na Grande São Paulo - 2005 a 2007

\begin{tabular}{|c|c|c|c|}
\hline & \multicolumn{2}{|c|}{ TRANSTORNO PSIQUIÁTRICO } & \multirow[t]{2}{*}{$\mathbf{P}$} \\
\hline & Transtorno de ansiedade & Ausente & \\
\hline Mulheres & $N=69$ & $N=136$ & \\
\hline Glicemia (mg/dl) ${ }^{1}$ & $87,0(9,8)$ & $89,8(22,1)$ & 0,37 \\
\hline Diabetes mellitus(\%) ${ }^{2}$ & $1(1,4)$ & $7(5,1)$ & 0,27 \\
\hline Colesterol total $(\mathrm{mg} / \mathrm{dl})^{1}$ & $194,9(42,5)$ & $188,1(39,2)$ & 0,26 \\
\hline LDL-colesterol (mg/dl) ${ }^{1}$ & $123,3(36,2)$ & $119,4(32,8)$ & 0,43 \\
\hline HDL-colesterol $(\mathrm{mg} / \mathrm{dl})^{1}$ & $50,0(11,3)$ & $48,8(12,0)$ & 0,48 \\
\hline Triglicérides (mg/dl) ${ }^{1}$ & $107,2(76,5)$ & $99,0(55,7)$ & 0,39 \\
\hline LDL-colesterol elevado (\%) ${ }^{3}$ & $13(19,1)$ & $17(12,5)$ & 0,22 \\
\hline HDL-colesterol < 40 mg/dl (\%) & $11(16,2)$ & $30(22,1)$ & 0,36 \\
\hline Triglicérides >150 mg/dl (\%) & $12(17,6)$ & $22(16,2)$ & 0,84 \\
\hline $\begin{array}{l}\text { Proteína C reativa ultra-sensível } \\
(\mathrm{mg} / \mathrm{dl})^{1}\end{array}$ & $2,3(2,4)$ & $3,3(2,8)$ & 0,02 \\
\hline Proteína C reativa > 3,0 mg/dl (\%) & $16(25,4)$ & $58(47,9)$ & 0,01 \\
\hline $\begin{array}{l}\text { Hormônio tireo-estimulante (TSH) } \\
(\mathrm{mcUl} / \mathrm{ml})^{1}\end{array}$ & $2,1(1,6)$ & $2,6(1,9)$ & 0,08 \\
\hline Síndrome metabólica (\%) & $19(27,5)$ & $41(30,1)$ & 0,70 \\
\hline Escore de risco de Framingham (\%) & & & 0,12 \\
\hline Menor $10 \%$ & $64(92,8)$ & $133(97,8)$ & \\
\hline $10-20 \%$ & $5(7,2)$ & $3(2,2)$ & \\
\hline Maior 20\% & - & - & \\
\hline \multicolumn{4}{|l|}{${ }^{1}$ Média (desvio padrão) } \\
\hline \multicolumn{4}{|c|}{$\begin{array}{l}\text { Diabetes mellitus definido como história médica de diabetes, uso de medicamentos para tratamento de } \\
\text { diabetes mellitus ou glicemia de jejum } \geq 126 \mathrm{mg} / \mathrm{dl}\end{array}$} \\
\hline \multicolumn{4}{|c|}{$\begin{array}{l}3 \text { Para indivíduos com doença cardiovascular aterosclerótica estabelecida ou diabetes mellitus ou Escore de } \\
\text { Risco de Framingham (ERF) }>20 \% \text { a meta de LDL-c é }<100 \mathrm{mg} / \mathrm{dl} \text {. Para indivíduos com ERF de } 10 \text { a 20\%, a } \\
\text { meta de LDL-c é }<130 \mathrm{mg} / \mathrm{dl} \text { e para aqueles com ERF }<10 \% \text {, a meta é de LDL-c é }<160 \mathrm{mg} / \mathrm{dl} \text {. }\end{array}$} \\
\hline
\end{tabular}

Foi realizada regressão logística comparando os portadores de transtornos ansiosos e os indivíduos normais e não foi observada diferenças no gênero masculino para nenhuma característica do perfil de fatores de risco cardiovascular (tabela 23).

No entanto, após ajuste para idade, as mulheres com transtornos de ansiedade apresentam maior frequência de excesso de peso (definido pela soma de indivíduos 
com sobrepeso e com obesidade), com OR de 2,26 (IC 95\% 1,15-4,44). Também não foi observada nenhuma outra diferença entre as mulheres com transtorno de ansiedade e sem diagnóstico psiquiátrico (tabela 23).

\section{* TABELA 23}

Perfil de fatores de risco cardiovascular em participantes do Estudo São Paulo Megacity de acordo com a presença de transtorno de ansiedade exclusivo, realizado na Grande São Paulo -2005 a 2007

\begin{tabular}{|c|c|c|c|c|c|c|}
\hline & \multicolumn{6}{|c|}{ GÊNERO } \\
\hline & \multicolumn{3}{|c|}{ Masculino } & \multicolumn{3}{|c|}{ Feminino } \\
\hline & OR & IC95\% & $\mathbf{P}$ & OR & IC95\% & $\mathbf{P}$ \\
\hline \multicolumn{7}{|l|}{ Inatividade física } \\
\hline Sem ajuste & 1,85 & $0,76-4,49$ & 0,18 & 1,04 & $0,47-2,30$ & 0,93 \\
\hline Ajuste para idade & 1,77 & $0,72-4,35$ & 0,21 & 1,03 & $0,46-2,29$ & 0,95 \\
\hline \multicolumn{7}{|c|}{ Presença de tabagismo atual } \\
\hline Sem ajuste & 0,28 & $0,06-1,22$ & 0,09 & 1,13 & $0,47-2,70$ & 0,79 \\
\hline Ajuste para idade & 0,29 & $0,06-1,29$ & 0,10 & 1,22 & $0,51-2,97$ & 0,65 \\
\hline \multicolumn{7}{|c|}{ Presença de excesso de peso ${ }^{1}$} \\
\hline Sem ajuste & 0,77 & $0,38-1,58$ & 0,47 & 1,72 & $0,92-3,20$ & 0,09 \\
\hline Ajuste para idade & 0,82 & $0,39-1,71$ & 0,59 & 2,26 & $1,15-4,44$ & 0,02 \\
\hline \multicolumn{7}{|c|}{ Hipertensão arterial } \\
\hline Sem ajuste & 0,91 & $0,45-1,83$ & 0,78 & 1,27 & $0,69-2,34$ & 0,44 \\
\hline Ajuste para idade & 1,02 & $0,48-2,19$ & 0,96 & 1,80 & $0,90-3,58$ & 0,10 \\
\hline \multicolumn{7}{|l|}{ Diabetes mellitus } \\
\hline Sem ajuste & 1,76 & $0,57-5,46$ & 0,33 & 0,27 & $0,03-2,25$ & 0,23 \\
\hline Ajuste para idade & 2,11 & $0,64-6,89$ & 0,22 & 0,33 & $0,04-2,78$ & 0,31 \\
\hline \multicolumn{7}{|c|}{ Colesterol total elevado } \\
\hline Sem ajuste & 0,62 & $0,30-1,28$ & 0,20 & 0,97 & $0,54-1,76$ & 0,92 \\
\hline Ajuste para idade & 0,65 & $0,30-1,42$ & 0,28 & 1,15 & $0,62-2,15$ & 0,66 \\
\hline \multicolumn{7}{|c|}{ LDL colesterol elevado } \\
\hline Sem ajuste & 0,74 & $0,32-1,69$ & 0,47 & 1,66 & $0,75-3,64$ & 0,21 \\
\hline Ajuste para idade & 0,84 & $0,34-2,07$ & 0,70 & 2,26 & $0,97-5,27$ & 0,06 \\
\hline \multicolumn{7}{|c|}{ HDL- colesterol reduzido } \\
\hline Sem ajuste & 0,63 & $0,30-1,30$ & 0,21 & 0,68 & $0,32-1,46$ & 0,33 \\
\hline Ajuste para idade & 0,64 & $0,31-1,34$ & 0,24 & 0,73 & $0,34-1,58$ & 0,43 \\
\hline
\end{tabular}




\begin{tabular}{|c|c|c|c|c|c|c|}
\hline & \multicolumn{6}{|c|}{ GÊNERO } \\
\hline & \multicolumn{3}{|c|}{ Masculino } & \multicolumn{3}{|c|}{ Feminino } \\
\hline & OR & IC95\% & $\mathbf{P}$ & OR & IC95\% & $\mathbf{P}$ \\
\hline \multicolumn{7}{|c|}{$\begin{array}{l}\text { Presença de } \\
\text { hipertrigliceridemia }\end{array}$} \\
\hline Sem ajuste & 0,84 & $0,40-1,80$ & 0,66 & 1,11 & $0,51-2,41$ & 0,79 \\
\hline Ajuste para idade & 0,91 & $0,42-2,00$ & 0,81 & 1,30 & $0,59-2,88$ & 0,52 \\
\hline \multicolumn{7}{|c|}{$\begin{array}{l}\text { Presença de } \\
\text { síndrome metabólica }\end{array}$} \\
\hline Sem ajuste & 1,25 & $0,60-2,62$ & 0,55 & 0,88 & $0,46-1,67$ & 0,70 \\
\hline Ajuste para idade & 1,42 & $0,65-3,10$ & 0,38 & 1,07 & $0,54-2,13$ & 0,84 \\
\hline \multicolumn{7}{|c|}{ Presença de PCR elevado } \\
\hline Sem ajuste & 1,16 & $0,56-2,41$ & 0,69 & 0,58 & $0,31-1,10$ & 0,09 \\
\hline Ajuste para idade & 1,22 & $0,58-2,58$ & 0,60 & 0,60 & $0,32-1,15$ & 0,12 \\
\hline \multicolumn{7}{|c|}{ Presença de ERF elevado ${ }^{3}$} \\
\hline Sem ajuste & 0,45 & $0,19-1,10$ & 0,08 & 3,46 & $0,80-14,95$ & 0,10 \\
\hline
\end{tabular}

Foram realizadas análises comparando os indivíduos com e sem transtornos de humor, transtorno depressivo maior e transtornos de ansiedade. Porém nas tabelas subseqüentes não foi excluída a presença de co-morbidade entre transtornos de ansiedade e transtorno de humor.

Os portadores de transtornos de humor (podendo ou não existir co-morbidade de ansiedade) e os indivíduos sem transtorno do humor apresentam características sóciodemográficas semelhantes, sendo um grupo de pessoas relativamente jovens, com idade média de 40 anos. Quanto a hábitos de vida, embora não haja diferença entre os grupos, a maioria dos indivíduos é de não-fumantes e que são ativos ou muito ativos (tabela 24).

As mulheres portadoras de transtornos de humor apresentam diagnóstico prévio de diabetes mellitus mais frequentemente do que as mulheres sem este diagnóstico, sendo que este diagnóstico foi referido por 9,6\% das mulheres com transtornos de humor e por $2,9 \%$ das mulheres sem transtorno de humor $(\mathrm{p}=0,009)$. No entanto, o mesmo não foi observado entre os grupos de homens (tabela 24).

Não há diferença entre os participantes com e sem transtornos de humor quanto aos dados antropométricos, sendo que a maioria das pessoas apresenta excesso de peso, tanto entre homens quanto entre as mulheres (tabelas 25 e 26). Embora haja um frequência elevada de hipertensão arterial (cerca de $40 \%$ em homens e $32 \%$ entre as mulheres), não há diferença entre os grupos. 
* TABELA 24

Características gerais, antecedentes pessoais de doenças e hábitos de vida em amostra de participantes de acordo com a presença de transtorno de humor do Estudo São Paulo Megacity, realizado na Grande de São Paulo - 2005 a 2007

\begin{tabular}{|c|c|c|c|}
\hline & \multicolumn{2}{|c|}{ TRANSTORNO DE HUMOR } & \multirow[t]{2}{*}{$\mathbf{P}$} \\
\hline & Presente & Ausente & \\
\hline Homens & $\mathrm{N}=61$ & $N=182$ & \\
\hline Idade (anos) ${ }^{1}$ & $40,5(10,4)$ & $41,3(10,7)$ & 0,61 \\
\hline Escolaridade (anos) ${ }^{1}$ & $9,7(3,9)$ & $9,0(3,8)$ & 0,24 \\
\hline Renda mensal domiciliar (reais) $^{1}$ & $1.547(1.197)$ & $1.398(1.408)$ & 0,46 \\
\hline Estado civil (\%) & & & 0,19 \\
\hline Casado & $40(69,0)$ & $131(74,4)$ & \\
\hline Viúvo/Separado/ Divorciado & $8(13,8)$ & $11(6,2)$ & \\
\hline Solteiro & $10(17,2)$ & $34(19,3)$ & \\
\hline Emprego (\%) & & & 0,85 \\
\hline Trabalhador & $49(84,5)$ & $148(84,1)$ & \\
\hline Estudante & - & $2(1,1)$ & \\
\hline Do lar & $1(1,7)$ & $1(0,6)$ & \\
\hline Aposentado & $3(5,2)$ & $9(5,1)$ & \\
\hline Outros & $5(8,6)$ & $16(9,1)$ & \\
\hline Tabagismo (\%) & & & 0,49 \\
\hline Nunca fumante & $32(53,3)$ & $111(61,3)$ & \\
\hline Ex-fumante & $17(28,3)$ & $46(25,4)$ & \\
\hline Fumante ativo & $11(18,3)$ & $24(13,3)$ & \\
\hline Consumo de álcool (\%) ${ }^{2}$ & $19(31,7)$ & $46(25,4)$ & 0,41 \\
\hline Atividade física regular (\%) ${ }^{3}$ & $53(86,9)$ & $155(85,2)$ & 0,84 \\
\hline Diagnóstico prévio de hipertensão arterial (\%) & $20(33,3)$ & $53(29,1)$ & 0,63 \\
\hline Diagnóstico prévio de diabetes mellitus (\%) & $5(8,2)$ & $13(7,1)$ & 0,78 \\
\hline Diagnóstico prévio de doença cardiovascular ${ }^{4}$ & $3(4,9)$ & $5(2,7)$ & 0,42 \\
\hline Mulheres & $\mathrm{N}=\mathbf{1 7 8}$ & $\mathrm{N}=\mathbf{2 0 5}$ & \\
\hline Idade (anos) ${ }^{1}$ & $41,4(10,8)$ & $40,0(11,4)$ & 0,20 \\
\hline Escolaridade (anos) ${ }^{1}$ & $8,9(4,4)$ & $9,1(4,1)$ & 0,70 \\
\hline Renda mensal domiciliar (reais) $^{1}$ & $1.190(1.448)$ & $1.384(1.475)$ & 0,20 \\
\hline Estado civil (\%) & & & 0,70 \\
\hline Casado & $102(58,0)$ & $111(55,0)$ & \\
\hline Viúvo/Separado/ Divorciado & $33(18,8)$ & $45(22,3)$ & \\
\hline Solteiro & $41(23,3)$ & $46(22,8)$ & \\
\hline
\end{tabular}




\begin{tabular}{|c|c|c|c|}
\hline & \multicolumn{2}{|c|}{ TRANSTORNO DE HUMOR } & \multirow[t]{2}{*}{$\mathbf{P}$} \\
\hline & Presente & Ausente & \\
\hline Mulheres & $\mathrm{N}=\mathbf{1 7 8}$ & $\mathbf{N}=\mathbf{2 0 5}$ & \\
\hline Emprego (\%) & & & 0,20 \\
\hline Trabalhador & $103(58,5)$ & $121(59,9)$ & \\
\hline Estudante & $2(1,1)$ & $2(1,0)$ & \\
\hline Do lar & $45(25,6)$ & $43(21,3)$ & \\
\hline Aposentado & $3(1,7)$ & $13(6,4)$ & \\
\hline Outros & $23(13,1)$ & $23(11,4)$ & \\
\hline Tabagismo (\%) & & & 0,07 \\
\hline Nunca fumante & $105(59,0)$ & $125(61,0)$ & \\
\hline Ex-fumante & $37(20,8)$ & $55(26,8)$ & \\
\hline Fumante ativo & $36(20,2)$ & $25(12,2)$ & \\
\hline Consumo de álcool (\%) ${ }^{2}$ & $21(11,8)$ & $21(10,2)$ & 0,87 \\
\hline Atividade física regular (\%) ${ }^{3}$ & $150(84,3)$ & $173(84,4)$ & 1,0 \\
\hline Diagnóstico prévio de hipertensão arterial (\%) & $55(30,9)$ & $51(24,9)$ & 0,21 \\
\hline Diagnóstico prévio de diabetes mellitus (\%) & $17(9,6)$ & $6(2,9)$ & 0,009 \\
\hline Diagnóstico prévio de doença cardiovascular ${ }^{4}$ & $5(2,8)$ & $9(4,4)$ & 0,59 \\
\hline \multicolumn{4}{|l|}{ Média (desvio-padrão) } \\
\hline \multicolumn{4}{|c|}{2 Definido como consumo regular de bebidas alcoólicas pelo menos uma vez por semana } \\
\hline \multicolumn{4}{|c|}{${ }^{3}$ Definido por meio do IPAQ, somando indivíduos ativos e muito ativos. } \\
\hline \multicolumn{4}{|c|}{$\begin{array}{l}{ }^{4} \text { Definido como diagnóstico prévio de acidente vascular cerebral, infarto agudo do miocárdio ou } \\
\text { coronariopatias. }\end{array}$} \\
\hline
\end{tabular}


* TABELA 25

Dados antropométricos e medida de pressão arterial em homens de amostra de participantes de acordo com a presença de transtorno de humor do Estudo São Paulo Megacity, realizado na Grande São Paulo - 2005 a 2007

\begin{tabular}{|c|c|c|c|}
\hline & \multicolumn{2}{|c|}{ TRANSTORNO DE HUMOR } & \multirow[t]{2}{*}{$\mathbf{P}$} \\
\hline & Presente & Ausente & \\
\hline Homens & $\mathrm{N}=61$ & $N=182$ & \\
\hline Índice de massa corporal $\left(\mathrm{kg} / \mathrm{m}^{2}\right)^{1}$ & $26,7(4,0)$ & $26,9(4,4)$ & 0,78 \\
\hline Estado nutricional (\%) ${ }^{2}$ & & & 0,43 \\
\hline Normal & $22(36,1)$ & $61(33,5)$ & \\
\hline Sobrepeso & $30(49,2)$ & $80(44,0)$ & \\
\hline Obesidade & $9(14,8)$ & $41(22,5)$ & \\
\hline Circunferência abdominal (cm) (\%) & $92,5(10,0)$ & $93,6(12,3)$ & 0,53 \\
\hline Circunferência abdominal elevada $(\%)^{3}$ & $8(13,1)$ & $44(24,4)$ & 0,07 \\
\hline Pressão arterial sistólica $(\mathrm{mm} \mathrm{Hg})^{1}$ & $124,7(21,4)$ & $127,3(19,9)$ & 0,41 \\
\hline Pressão arterial diastólica $(\mathrm{mm} \mathrm{Hg})^{1}$ & $83,6(14,8)$ & $84,8(13,1)$ & 0,55 \\
\hline Hipertensão arterial (\%) ${ }^{4}$ & $24(40,0)$ & $77(42,3)$ & 0,77 \\
\hline \multicolumn{4}{|l|}{${ }^{1}$ Média (desvio-padrão) } \\
\hline \multirow{2}{*}{\multicolumn{4}{|c|}{$\begin{array}{l}{ }^{2} \text { Estado nutricional definido por índice de massa corporal (IMC): normal - IMC }<25 \mathrm{~kg} / \mathrm{m}^{2} \text {, sobrepeso - IMC } \\
25 \text { a } 29,9 \mathrm{~kg} / \mathrm{m}^{2} \text { e obesos - IMC } \geq 30 \mathrm{~kg} / \mathrm{m}^{2} \text {. } \\
{ }^{3} \text { Definido como circunferência abdominal acima de } 102 \mathrm{~cm} \text { em homens. }\end{array}$}} \\
\hline & & & \\
\hline \multicolumn{4}{|c|}{$\begin{array}{l}{ }^{4} \text { Hipertensão arterial definida como história médica de hipertensão arterial, ou uso de medicamentos } \\
\text { para hipertensão arterial ou pressão arterial sistólica } \geq 140 \mathrm{~mm} \mathrm{Hg} \text { ou pressão arterial diastólica } \geq 90 \\
\mathrm{~mm} \mathrm{Hg}\end{array}$} \\
\hline
\end{tabular}




\section{TABELA 26}

Dados antropométricos e medida de pressão arterial em mulheres de amostra de participantes de acordo com a presença de transtorno de humor do Estudo São Paulo Megacity, realizado na Grande São Paulo - 2005 a 2007

\begin{tabular}{|c|c|c|c|}
\hline & \multicolumn{2}{|c|}{ TRANSTORNO DE HUMOR } & \multirow[t]{2}{*}{$\mathbf{P}$} \\
\hline & Presente & Ausente & \\
\hline Mulheres & $\mathrm{N}=178$ & $\mathrm{~N}=\mathbf{2 0 5}$ & \\
\hline Índice de massa corporal $\left(\mathrm{kg} / \mathrm{m}^{2}\right)^{1}$ & $26,8(5,0)$ & $27,2(5,5)$ & 0,47 \\
\hline Estado nutricional $(\%)^{2}$ & & & 0,39 \\
\hline Normal & $73(41,0)$ & $76(37,1)$ & \\
\hline Sobrepeso & $67(37,6)$ & $73(35,6)$ & \\
\hline Obesidade & $38(21,3)$ & $56(27,3)$ & \\
\hline Circunferência abdominal (cm) (\%) & $90,5(12,4)$ & $90,3(13,2)$ & 0,91 \\
\hline Circunferência abdominal elevada (\%) ${ }^{3}$ & $102(57,3)$ & $107(52,5)$ & 0,36 \\
\hline Pressão arterial sistólica $(\mathrm{mm} \mathrm{Hg})^{1}$ & $117,7(21,2)$ & $118,2(19,4)$ & 0,82 \\
\hline Pressão arterial diastólica $(\mathrm{mm} \mathrm{Hg})^{1}$ & $77,4(13,0)$ & $77,7(12,5)$ & 0,82 \\
\hline Hipertensão arterial (\%) ${ }^{4}$ & $65(36,5)$ & $67(32,7)$ & 0,45 \\
\hline \multicolumn{4}{|l|}{${ }^{1}$ Média (desvio-padrão) } \\
\hline \multirow{2}{*}{\multicolumn{4}{|c|}{$\begin{array}{l}2 \text { Estado nutricional definido por índice de massa corporal (IMC): normal - IMC }<25 \mathrm{~kg} / \mathrm{m}^{2} \text {, sobrepeso - IMC } \\
25 \text { a } 29,9 \mathrm{~kg} / \mathrm{m}^{2} \text { e obesos - IMC } \geq 30 \mathrm{~kg} / \mathrm{m}^{2} \text {. } \\
{ }^{3} \text { Definido como circunferência abdominal acima de } 88 \mathrm{~cm} \text { em mulheres. }\end{array}$}} \\
\hline & & & \\
\hline \multicolumn{4}{|c|}{$\begin{array}{l}{ }^{4} \text { Hipertensão arterial definida como história médica de hipertensão arterial, ou uso de medicamentos } \\
\text { para hipertensão arterial ou pressão arterial sistólica } \geq 140 \mathrm{~mm} \mathrm{Hg} \text { ou pressão arterial diastólica } \geq 90 \\
\mathrm{~mm} \mathrm{Hg}\end{array}$} \\
\hline
\end{tabular}

Também não foi observado perfil metabólico e de risco cardiovascular diferente entre homens com e sem transtornos de humor para nenhum dos parâmetros estudados (tabela 27).

No entanto, entre as mulheres portadoras de transtornos de humor foi observada maior frequência de diagnóstico de diabetes mellitus (tabela 28), sendo que 9,6\% das mulheres portadoras de transtorno de humor apresentaram este diagnóstico e 3,9\% das mulheres sem transtorno de humor $(\mathrm{p}=0,04)$.

Também foi observado que as mulheres com transtorno de humor apresentam com maior freqüência os níveis de LDL-colesterol elevado (23\% das mulheres com transtornos de humor e $14,7 \%$ das mulheres sem transtorno de humor, $\mathrm{p}=0,048$ ). Outro achado importante é que as mulheres sem transtorno de humor apresentam maior frequência de PCR elevado $(\mathrm{p}=0,04)$ quando comparadas as mulheres com transtorno de humor (tabela 28).

Foi realizada regressão logística em relação a frequência de fatores de risco para 
eventos cardiovasculares em portadores de transtornos de humor (com ou sem comorbidade de ansiedade) e foi observado que não há diferenças entre homens com ou sem a doença (tabela 29), mesmo após ajuste para idade.

As mulheres portadoras de transtorno de humor apresentam maior freqüência de tabagismo, com OR de 1,79 (IC95\% 1,03-3,13) ajustado para idade e maior freqüência de diabetes mellitus, com OR de 2,46 (IC95\% 1,03-5,88) ajustado para idade. Também foi observada uma maior freqüência de dislipidemia por LDL-colesterol elevado, porém esta diferença deixa de existir após o ajuste para faixa etária. Não houve diferença para os demais fatores de risco (tabela 29).

* TABELA 27

Perfil metabólico e de risco cardiovascular em homens de amostra de participantes de acordo com a presença de transtorno de humor do Estudo São Paulo Megacity, realizado na Grande São Paulo - 2005 a 2007

\begin{tabular}{|c|c|c|c|}
\hline & \multicolumn{2}{|c|}{ TRANSTORNO DE HUMOR } & \multirow[t]{2}{*}{$\mathbf{P}$} \\
\hline & Presente & Ausente & \\
\hline Homens & $\mathrm{N}=61$ & $\mathrm{~N}=182$ & \\
\hline Glicemia (mg/dl) ${ }^{1}$ & $93,4(29,5)$ & $96,2(24,7)$ & 0,52 \\
\hline Diabetes mellitus $(\%)^{2}$ & $5(8,2)$ & $15(8,2)$ & 1,0 \\
\hline Colesterol total $(\mathrm{mg} / \mathrm{dl})^{1}$ & $188,4(43,1)$ & $194,8(53,5)$ & 0,40 \\
\hline LDL-colesterol (mg/dl) ${ }^{1}$ & $120,3(36,6)$ & $124,0(32,3)$ & 0,46 \\
\hline HDL-colesterol (mg/dl) ${ }^{1}$ & $42,0(10,5)$ & $42,8(10,2)$ & 0,61 \\
\hline Triglicérides (mg/dl) ${ }^{1}$ & $129,7(75,2)$ & $161,4(337,5)$ & 0,47 \\
\hline LDL-colesterol elevado (\%) ${ }^{2}$ & $18(29,5)$ & $46(26,3)$ & 0,62 \\
\hline HDL-colesterol < 40 mg/dl (\%) & $27(44,3)$ & $75(42,6)$ & 0,88 \\
\hline Triglicérides >150 mg/dl (\%) & $17(27,9)$ & $57(31,3)$ & 0,75 \\
\hline Proteína C reativa ultra-sensível $(\mathrm{mg} / \mathrm{dl})^{1}$ & $2,1(2,0)$ & $2,0(1,9)$ & 0,77 \\
\hline Proteína C reativa > 3,0 mg/dl (\%) & $13(22,4)$ & $32(18,9)$ & 0,78 \\
\hline $\begin{array}{l}\text { Hormônio tireo-estimulante (TSH) } \\
(\mathrm{mcUl} / \mathrm{ml})^{1}\end{array}$ & $2,9(3,3)$ & $2,4(3,1)$ & 0,22 \\
\hline Síndrome metabólica (\%) & $17(27,9)$ & $54(29,7)$ & 0,87 \\
\hline Escore de risco de Framingham (\%) ${ }^{3}$ & & & 0,64 \\
\hline Menor 10\% & $48(78,7)$ & $132(72,5)$ & \\
\hline $10-20 \%$ & $12(19,7)$ & $46(25,3)$ & \\
\hline Maior 20\% & $1(1,6)$ & $4(2,2)$ & \\
\hline
\end{tabular}


${ }^{1}$ Média (desvio padrão)

${ }^{2}$ Diabetes mellitus definido como história médica de diabetes, uso de medicamentos para tratamento de diabetes mellitus ou glicemia de jejum $\geq 126 \mathrm{mg} / \mathrm{dl}$

${ }^{3}$ Para indivíduos com doença cardiovascular aterosclerótica estabelecida ou diabetes mellitus ou Escore de Risco de Framingham (ERF) > 20\% a meta de LDL-c é < $100 \mathrm{mg} / \mathrm{dl}$. Para indivíduos com ERF de 10 a 20\%, a meta de LDL-c é $<130 \mathrm{mg} / \mathrm{dl}$ e para aqueles com ERF $<10 \%$, a meta é de LDL-c é $<160 \mathrm{mg} / \mathrm{dl}$.

\section{* TABELA 28}

Perfil metabólico e de risco cardiovascular em mulheres de amostra de participantes de acordo com a presença de transtorno de humor do Estudo São Paulo Megacity, realizado na Grande São Paulo - 2005 a 2007

\begin{tabular}{|c|c|c|c|}
\hline & \multicolumn{2}{|c|}{ TRANSTORNO DE HUMOR } & \multirow[t]{2}{*}{$\mathbf{P}$} \\
\hline & Presente & Ausente & \\
\hline Mulheres & $\mathrm{N}=\mathbf{1 7 8}$ & $\mathrm{N}=\mathbf{2 0 5}$ & \multirow[b]{2}{*}{0,85} \\
\hline Glicemia $(\mathrm{mg} / \mathrm{dl})^{1}$ & $89,4(24,3)$ & $88,9(19,2)$ & \\
\hline Diabetes mellitus (\%) ${ }^{2}$ & $17(9,6)$ & $8(3,9)$ & 0,04 \\
\hline Colesterol total $(\mathrm{mg} / \mathrm{dl})^{1}$ & $196,7(45,1)$ & $190,4(40,3)$ & 0,15 \\
\hline LDL-colesterol (mg/dl) $^{1}$ & $124,7(37,8)$ & $120,7(33,9)$ & 0,28 \\
\hline HDL-colesterol (mg/dl) ${ }^{1}$ & $49,8(12,5)$ & $49,2(11,7)$ & 0,61 \\
\hline Triglicérides $(\mathrm{mg} / \mathrm{dl})^{1}$ & $110,2(66,5)$ & $101,7(63,3)$ & 0,20 \\
\hline LDL-colesterol elevado (\%) ${ }^{3}$ & $41(23,0)$ & $30(14,7)$ & 0,048 \\
\hline HDL-colesterol < 40 mg/dl (\%) & $34(19,1)$ & $41(20,1)$ & 0,90 \\
\hline Triglicérides >150 mg/dl (\%) & $32(18,0)$ & $34(16,7)$ & 0,79 \\
\hline Proteína $\mathrm{C}$ reativa ultra-sensível $(\mathrm{mg} / \mathrm{dl})^{1}$ & $2,5(2,4)$ & $3,0(2,7)$ & 0,06 \\
\hline Proteína C reativa > 3,0 mg/dl (\%) & $49(29,5)$ & $74(40,2)$ & 0,04 \\
\hline Hormônio tireoestimulante $(\mathrm{TSH})(\mathrm{mcUl} / \mathrm{ml})^{1}$ & $2,4(1,8)$ & $2,4(1,8)$ & 0,60 \\
\hline Síndrome metabólica (\%) & $57(32,0)$ & $60(29,3)$ & 0,58 \\
\hline Escore de risco de Framingham (\%) & & & 0,23 \\
\hline Menor $10 \%$ & $175(98,3)$ & $197(96,1)$ & \\
\hline $10-20 \%$ & $3(1,7)$ & $8(3,9)$ & \\
\hline Maior $20 \%$ & - & - & \\
\hline \multicolumn{4}{|l|}{${ }^{1}$ Média (desvio padrão) } \\
\hline \multicolumn{4}{|c|}{$\begin{array}{l}{ }^{2} \text { Diabetes mellitus definido como história médica de diabetes, uso de medicamentos para tratamento de } \\
\text { diabetes mellitus ou glicemia de jejum } \geq 126 \mathrm{mg} / \mathrm{dl}\end{array}$} \\
\hline \multicolumn{4}{|c|}{${ }^{3}$ Para indivíduos com doença cardiovascular aterosclerótica estabelecida ou diabetes mellitus ou Escore de } \\
\hline \multicolumn{4}{|c|}{$\begin{array}{l}\text { Risco de Framingham (ERF) }>20 \% \text { a meta de } L D L-c \text { é }<100 \text { mg/dl. Para indivíduos com ERF de } 10 \text { a 20\%, a } \\
\text { meta de } L D L-c \text { é }<130 \mathrm{mg} / \mathrm{dl} \text { e para aqueles com ERF }<10 \% \text {, a meta é de } L D L-c \text { é }<160 \mathrm{mg} / \mathrm{dl} \text {. }\end{array}$} \\
\hline
\end{tabular}


* TABELA 29

Perfil de fatores de risco cardiovascular em indivíduos de amostra de participantes do Estudo São Paulo Megacity de acordo com a presença de transtorno de humor (com ou sem comorbidade psiquiátrica), Grande São Paulo - 2005 a 2007

\begin{tabular}{|c|c|c|c|c|c|c|}
\hline & \multicolumn{6}{|c|}{ GÊNERO } \\
\hline & \multicolumn{3}{|c|}{ Masculino } & \multicolumn{3}{|c|}{ Feminino } \\
\hline & OR & IC95\% & $\mathbf{P}$ & OR & IC95\% & $\mathbf{P}$ \\
\hline \multicolumn{7}{|l|}{ Inatividade física } \\
\hline Sem ajuste & 0,87 & $0,37-2,02$ & 0,74 & 1,01 & $0,58-1,75$ & 0,97 \\
\hline Ajuste para idade & 0,84 & $0,36-1,98$ & 0,69 & 1,03 & $0,59-1,79$ & 0,92 \\
\hline \multicolumn{7}{|l|}{$\begin{array}{l}\text { Presença de } \\
\text { tabagismo atual }\end{array}$} \\
\hline Sem ajuste & 1,47 & $0,67-3,21$ & 0,34 & 1,83 & $1,05-3,18$ & 0,03 \\
\hline Ajuste para idade & 1,55 & $0,70-3,44$ & 0,28 & 1,79 & $1,03-3,13$ & 0,04 \\
\hline \multicolumn{7}{|c|}{ Presença de excesso de peso $^{1}$} \\
\hline Sem ajuste & 0,89 & $0,49-1,64$ & 0,72 & 0,85 & $0,56-1,28$ & 0,43 \\
\hline Ajuste para idade & 0,92 & $0,50-1,70$ & 0,79 & 0,77 & $0,50-1,19$ & 0,23 \\
\hline \multicolumn{7}{|c|}{ Hipertensão arterial } \\
\hline Sem ajuste & 0,91 & $0,50-1,65$ & 0,75 & 1,19 & $0,78-1,81$ & 0,43 \\
\hline Ajuste para idade & 0,97 & $0,51-1,85$ & 0,93 & 1,08 & $0,69-1,70$ & 0,73 \\
\hline \multicolumn{7}{|l|}{ Diabetes mellitus } \\
\hline Sem ajuste & 0,99 & $0,35-2,86$ & 0,99 & 2,60 & $1,09-6,18$ & 0,03 \\
\hline Ajuste para idade & 1,05 & $0,36-3,06$ & 0,94 & 2,46 & $1,03-5,88$ & 0,04 \\
\hline \multicolumn{7}{|c|}{ Colesterol total elevado } \\
\hline Sem ajuste & 0,86 & $0,47-1,57$ & 0,63 & 0,99 & $0,66-1,49$ & 0,95 \\
\hline Ajuste para idade & 0,90 & $0,47-1,71$ & 0,75 & 0,90 & $0,59-1,39$ & 0,64 \\
\hline \multicolumn{7}{|c|}{ LDL colesterol elevado } \\
\hline Sem ajuste & 1,17 & $0,62-2,24$ & 0,63 & 1,74 & $1,03-2,92$ & 0,04 \\
\hline Ajuste para idade & 1,27 & $0,63-2,54$ & 0,50 & 1,63 & $0,94-2,83$ & 0,08 \\
\hline \multicolumn{7}{|c|}{ HDL- colesterol reduzido } \\
\hline Sem ajuste & 1,07 & $0,60-1,92$ & 0,82 & 0,94 & $0,57-1,56$ & 0,81 \\
\hline Ajuste para idade & 1,08 & $0,60-1,95$ & 0,79 & 0,92 & $0,55-1,53$ & 0,75 \\
\hline \multicolumn{7}{|c|}{$\begin{array}{l}\text { Presença de } \\
\text { hipertrigliceridemia }\end{array}$} \\
\hline Sem ajuste & 0,85 & $0,45-1,61$ & 0,61 & 1,10 & $0,64-1,86$ & 0,74 \\
\hline Ajuste para idade & 0,88 & $0,45-1,71$ & 0,70 & 1,04 & $0,61-1,78$ & 0,89 \\
\hline
\end{tabular}




\begin{tabular}{|c|c|c|c|c|c|c|}
\hline & \multicolumn{6}{|c|}{ GÊNERO } \\
\hline & \multicolumn{3}{|c|}{ Masculino } & \multicolumn{3}{|c|}{ Feminino } \\
\hline & OR & IC95\% & $\mathbf{P}$ & OR & IC95\% & $\mathbf{P}$ \\
\hline \multicolumn{7}{|c|}{$\begin{array}{l}\text { Presença de } \\
\text { síndrome metabólica }\end{array}$} \\
\hline Sem ajuste & 0,92 & $0,48-1,74$ & 0,79 & 1,14 & $0,74-1,76$ & 0,56 \\
\hline Ajuste para idade & 0,96 & $0,49-1,87$ & 0,90 & 1,06 & $0,67-1,67$ & 0,81 \\
\hline \multicolumn{7}{|c|}{ Presença de PCR elevado² } \\
\hline Sem ajuste & 0,95 & $0,52-1,75$ & 0,88 & 1,06 & $0,68-1,66$ & 0,81 \\
\hline Ajuste para idade & 0,95 & $0,51-1,76$ & 0,87 & 1,03 & $0,66-1,62$ & 0,89 \\
\hline \multicolumn{7}{|c|}{ Presença de ERF elevado ${ }^{3}$} \\
\hline Sem ajuste & 0,72 & $0,36-1,43$ & 0,34 & 0,42 & $0,11-1,62$ & 0,21 \\
\hline
\end{tabular}

Quanto aos portadores de transtorno depressivo maior (podendo ou não haver comorbidade de transtornos ansiosos), não há diferenças quanto às características sóciodemográficas e hábitos de vida comparados aos indivíduos sem o mesmo diagnóstico, tanto em homens, quanto em mulheres (tabela 30).

No entanto, há diferença entre as mulheres no tocante a antecedentes pessoais de doenças. As mulheres portadoras de depressão maior apresentam com maior frequência diagnóstico prévio de diabetes mellitus do que as mulheres sem tal diagnóstico $(11 \% \mathrm{em}$ mulheres com depressão maior e 2,6\% em mulheres sem depressão, $p=0,002$ ), embora não tenha sido observada esta diferença entre homens. Também não há diferenças quanto a diagnóstico prévio de hipertensão arterial e doença cardiovascular estabelecida em ambos os gêneros (tabela 30).

Os homens portadores de depressão maior não apresentam níveis diferentes de sobrepeso, nem de obesidade quando comparados aos homens sem diagnóstico psiquiátrico (tabela 31). No entanto, os homens sem depressão maior apresentam com maior frequência a circunferência abdominal elevada do que os homens com depressão maior, sendo que 24,9\% dos homens sem transtorno depressivo apresentam circunferência abdominal alterada e somente $8,3 \%$ dos homens portadores de depressão maior apresentam a cintura alterada $(\mathrm{p}=0,01)$.

Entre as mulheres com e sem depressão maior não foi observada diferença quanto aos dados antropométricos (tabela 32). Não foram observadas diferenças entre a frequência de hipertensão arterial para indivíduos com e sem diagnóstico de transtorno depressivo maior, em ambos os gêneros (tabelas 31 e 32). 
* TABELA 30

Características gerais, antecedentes pessoais de doenças e hábitos de vida em amostra de participantes de acordo com a presença de transtorno depressivo maior do Estudo São Paulo Megacity, realizado na Grande São Paulo - 2005 a 2007

\begin{tabular}{|c|c|c|c|}
\hline & \multicolumn{2}{|c|}{$\begin{array}{c}\text { TRANSTORNO } \\
\text { DEPRESSIVO MAIOR }\end{array}$} & \\
\hline & Presente & Ausente & \\
\hline Homens & $\mathrm{N}=48$ & $\mathrm{~N}=195$ & \\
\hline Idade (anos) ${ }^{1}$ & $41,3(10,2)$ & $41,0(10,7)$ & 0,85 \\
\hline Escolaridade (anos) $^{1}$ & $9,5(4,1)$ & $9,1(3,8)$ & 0,48 \\
\hline Renda mensal domiciliar (reais) ${ }^{1}$ & $1.544(1.239)$ & $1.408(1.387)$ & 0,54 \\
\hline Estado civil (\%) & & & 0,13 \\
\hline Casado & $30(65,2)$ & $141(75,0)$ & \\
\hline Viúvo/Separado/ Divorciado & $7(15,2)$ & $12(6,4)$ & \\
\hline Solteiro & $9(19,6)$ & $35(18,6)$ & \\
\hline Emprego (\%) & & & 0,71 \\
\hline Trabalhador & $40(87,0)$ & $157(83,5)$ & \\
\hline Estudante & - & $2(1,1)$ & \\
\hline Do lar & $1(2,2)$ & $1(0,5)$ & \\
\hline Aposentado & $2(4,3)$ & $10(5,3)$ & \\
\hline Outros & $3(6,5)$ & $18(9,6)$ & \\
\hline Tabagismo (\%) & & & 0,60 \\
\hline Nunca fumante & $26(55,3)$ & $117(60,3)$ & \\
\hline Ex-fumante & $12(25,5)$ & $51(26,3)$ & \\
\hline Fumante ativo & $9(19,1)$ & $26(13,4)$ & \\
\hline Consumo de álcool (\%) ${ }^{2}$ & $14(29,8)$ & $51(26,3)$ & 0,87 \\
\hline Atividade física regular (\%) ${ }^{3}$ & $41(85,4)$ & $167(85,6)$ & 1,0 \\
\hline Diagnóstico prévio de hipertensão arterial (\%) & $15(31,9)$ & $58(29,7)$ & 0,86 \\
\hline Diagnóstico prévio de diabetes mellitus (\%) & $5(10,4)$ & $13(6,7)$ & 0,36 \\
\hline Diagnóstico prévio de doença cardiovascular ${ }^{4}$ & $2(4,2)$ & $6(3,1)$ & 0,66 \\
\hline Mulheres & $\mathrm{N}=155$ & $\mathbf{N}=\mathbf{2 2 8}$ & \\
\hline Idade $(\operatorname{anos})^{1}$ & $41,6(10,7)$ & $40,0(11,4)$ & 0,16 \\
\hline Escolaridade (anos) $^{1}$ & $8,7(4,5)$ & $9,2(4,0)$ & 0,34 \\
\hline Renda anual domiciliar (reais) ${ }^{1}$ & $1.127(1.472)$ & $1.407(1.451)$ & 0,07 \\
\hline Estado civil (\%) & & & 0,61 \\
\hline Casado & $90(58,4)$ & $123(54,9)$ & \\
\hline Viúvo/Separado/ Divorciado & $28(18,2)$ & $50(22,3)$ & \\
\hline
\end{tabular}




\section{TRANSTORNO \\ DEPRESSIVO MAIOR}

\begin{tabular}{|c|c|c|c|}
\hline & Presente & Ausente & \\
\hline Mulheres & $\mathrm{N}=155$ & $N=228$ & \\
\hline Solteiro & $36(23,4)$ & $51(22,8)$ & \\
\hline Emprego (\%) & & & 0,38 \\
\hline Trabalhador & $90(58,4)$ & $134(59,8)$ & \\
\hline Estudante & $2(1,3)$ & $2(0,9)$ & \\
\hline Do lar & $40(26,0)$ & $48(21,4)$ & \\
\hline Aposentado & $3(1,9)$ & $13(5,8)$ & \\
\hline Outros & $19(12,3)$ & $27(12,1)$ & \\
\hline Tabagismo (\%) & & & 0,10 \\
\hline Nunca fumante & $90(58,1)$ & $140(61,4)$ & \\
\hline Ex-fumante & $33(21,3)$ & $59(25,9)$ & \\
\hline Fumante ativo & $32(20,6)$ & $29(12,7)$ & \\
\hline Consumo de álcool (\%) ${ }^{2}$ & $18(11,6)$ & $24(10,5)$ & 0,92 \\
\hline Atividade física regular (\%) ${ }^{3}$ & $129(83,2)$ & $194(85,1)$ & 0,67 \\
\hline Diagnóstico prévio de hipertensão arterial (\%) & $49(31,6)$ & $57(25,0)$ & 0,16 \\
\hline Diagnóstico prévio de diabetes mellitus (\%) & $17(11,0)$ & $6(2,6)$ & 0,002 \\
\hline Diagnóstico prévio de doença cardiovascular ${ }^{4}$ & $4(2,6)$ & $10(4,4)$ & 0,42 \\
\hline
\end{tabular}

${ }^{1}$ Média (desvio-padrão)

${ }^{2}$ Definido como consumo regular de bebidas alcoólicas pelo menos uma vez por semana

${ }^{3}$ Definido por meio do IPAQ, somando indivíduos ativos e muito ativos.

${ }^{4}$ Definido como diagnóstico prévio de acidente vascular cerebral, infarto agudo do miocárdio ou coronariopatias. 
* TABELA 31

Dados antropométricos e medida de pressão arterial em homens de amostra de participantes de acordo com a presença de transtorno depressivo maior do Estudo São Paulo Megacity, realizado na Grande São Paulo - 2005 a 2007

\begin{tabular}{|c|c|c|c|}
\hline & \multicolumn{2}{|c|}{ TRANSTORNO DEPRESSIVO MAIOR } & \multirow[t]{2}{*}{$\mathbf{P}$} \\
\hline & Presente & Ausente & \\
\hline Homens & $\mathrm{N}=48$ & $\mathrm{~N}=195$ & \\
\hline Índice de massa corporal $\left(\mathrm{kg} / \mathrm{m}^{2}\right)^{1}$ & $26,3(3,5)$ & $27,0(4,5)$ & 0,31 \\
\hline Estado nutricional(\%) ${ }^{2}$ & & & 0,15 \\
\hline Normal & $19(39,6)$ & $64(32,8)$ & \\
\hline Sobrepeso & $24(50,0)$ & $86(44,1)$ & \\
\hline Obesidade & $5(10,4)$ & $45(23,1)$ & \\
\hline Circunferência abdominal (cm) (\%) & $91,7(9,3)$ & $93,7(12,3)$ & 0,28 \\
\hline Circunferência abdominal elevada (\%) ${ }^{3}$ & $4(8,3)$ & $48(24,9)$ & 0,01 \\
\hline Pressão arterial sistólica $(\mathrm{mm} \mathrm{Hg})^{1}$ & $124,2(20,6)$ & $127,2(20,2)$ & 0,37 \\
\hline Pressão arterial diastólica $(\mathrm{mm} \mathrm{Hg})^{1}$ & $84,4(14,6)$ & $84,6(13,3)$ & 0,94 \\
\hline Hipertensão arterial (\%) ${ }^{4}$ & $18(38,3)$ & $83(42,6)$ & 0,63 \\
\hline \multicolumn{4}{|l|}{1 Média (desvio-padrão) } \\
\hline \multirow{2}{*}{\multicolumn{4}{|c|}{$\begin{array}{l}{ }^{2} \text { Estado nutricional definido por índice de massa corporal (IMC): normal - IMC }<25 \mathrm{~kg} / \mathrm{m}^{2} \text {, sobrepeso - IMC } \\
25 \text { a } 29,9 \mathrm{~kg} / \mathrm{m}^{2} \text { e obesos - IMC } \geq 30 \mathrm{~kg} / \mathrm{m}^{2} \text {. } \\
{ }^{3} \text { Definido como circunferência abdominal acima de } 102 \mathrm{~cm} \text { em homens. }\end{array}$}} \\
\hline & & & \\
\hline \multicolumn{4}{|c|}{$\begin{array}{l}{ }^{4} \text { Hipertensão arterial definida como história médica de hipertensão arterial, ou uso de medicamentos } \\
\text { para hipertensão arterial ou pressão arterial sistólica } \geq 140 \mathrm{~mm} \mathrm{Hg} \text { ou pressão arterial diastólica } \geq 90 \\
\text { mm Hg. }\end{array}$} \\
\hline
\end{tabular}




\section{TABELA 32}

Dados antropométricos e medida de pressão arterial em mulheres de amostra de participantes de acordo com a presença de transtorno depressivo maior no Estudo São Paulo Megacity, realizado na Grande São Paulo - 2005 a 2007

\begin{tabular}{|c|c|c|c|}
\hline & \multicolumn{2}{|c|}{ TRANSTORNO DEPRESSIVO MAIOR } & \multirow[t]{2}{*}{$\mathbf{P}$} \\
\hline & Presente & Ausente & \\
\hline Mulheres & $\mathrm{N}=155$ & $N=228$ & \\
\hline Índice de massa corporal $\left(\mathrm{kg} / \mathrm{m}^{2}\right)^{1}$ & $26,8(5,0)$ & $27,1(5,4)$ & 0,48 \\
\hline Estado nutricional(\%) ${ }^{2}$ & & & 0,29 \\
\hline Normal & $61(39,4)$ & $88(38,6)$ & \\
\hline Sobrepeso & $62(40,0)$ & $78(34,2)$ & \\
\hline Obesidade & $32(20,6)$ & $62(27,2)$ & \\
\hline Circunferência abdominal (cm) (\%) & $90,2(12,5)$ & $90,5(13,1)$ & 0,81 \\
\hline Circunferência abdominal elevada $(\%)^{3}$ & $88(56,8)$ & $121(53,3)$ & 0,53 \\
\hline Pressão arterial sistólica $(\mathrm{mm} \mathrm{Hg})^{1}$ & $117,7(21,2)$ & $118,2(19,6)$ & 0,81 \\
\hline Pressão arterial diastólica $(\mathrm{mm} \mathrm{Hg})^{1}$ & $77,2(13,0)$ & $77,8(12,5)$ & 0,67 \\
\hline Hipertensão arterial (\%) ${ }^{4}$ & $57(36,8)$ & $75(32,9)$ & 0,45 \\
\hline \multicolumn{4}{|l|}{${ }^{1}$ Média (desvio-padrão) } \\
\hline \multirow{2}{*}{\multicolumn{4}{|c|}{$\begin{array}{l}{ }^{2} \text { Estado nutricional definido por índice de massa corporal (IMC): normal - IMC }<25 \mathrm{~kg} / \mathrm{m}^{2} \text {, sobrepeso - IMC } \\
25 \text { a } 29,9 \mathrm{~kg} / \mathrm{m}^{2} \text { e obesos }-I M C \geq 30 \mathrm{~kg} / \mathrm{m}^{2} \text {. } \\
{ }^{3} \text { Definido como circunferência abdominal acima de } 88 \mathrm{~cm} \text { em mulheres. }\end{array}$}} \\
\hline \multicolumn{2}{|c|}{${ }^{3}$ Definido como circunferência abdominal acima de $88 \mathrm{~cm}$ em mulheres. } & & \\
\hline \multicolumn{4}{|c|}{$\begin{array}{l}{ }^{4} \text { Hipertensão arterial definida como história médica de hipertensão arterial, ou uso de medicamentos para } \\
\text { hipertensão arterial ou pressão arterial sistólica } \geq 140 \mathrm{~mm} \mathrm{Hg} \text { ou pressão arterial diastólica } \geq 90 \mathrm{~mm} \mathrm{Hg} \text {. }\end{array}$} \\
\hline
\end{tabular}

No grupo de homens com transtorno depressivo maior, não foi observada frequência diferente de nenhum dos fatores de risco para doença cardiovascular estudados (tabela 33).

No entanto, entre as mulheres, a frequência de diabetes mellitus é maior entre as portadoras de depressão maior, com $11 \%$ entre as mulheres com depressão e 3,5\% entre as mulheres sem depressão $(\mathrm{p}=0,005)$. Também foi observado que há maior freqüência de LDL-colesterol elevado entre as portadoras de depressão, sendo que $24,5 \%$ das mulheres deprimidas e $14,5 \%$ das mulheres sem depressão $(\mathrm{p}=0,02)$ apresentam este diagnóstico (tabela 34).

Além disso, foi observado que as mulheres com depressão apresentam níveis menores de PCR do que as mulheres sem depressão e também apresentam menor frequência de PCR elevado do que as mulheres sem diagnóstico psiquiátrico (27,6\% nas mulheres com depressão e 40,5\% das mulheres sem depressão apresentam PCR elevado, p=0,005).

$\mathrm{O}$ perfil de fatores de risco cardiovascular entre homens com ou sem transtorno depressivo maior é semelhante, quando analisado através da regressão logística (tabela 
35). Porém, entre as mulheres, foi observada uma maior freqüência de tabagismo, com odds ratio de 1,75 (IC95\% 1,01-3,04), de diabetes mellitus, com odds ratio de 3,19 (IC95\% 1,33-7,66) e de LDL-colesterol elevado, com odds ratio de 1,80 (IC95\% 1,04-3,11), todos ajustados para faixa etária (tabela 35).

Novamente, as diferenças observadas quanto a classificação do risco cardiovascular por meio do PCR ultra-sensível entre mulheres com depressão maior (observadas na tabela 34) deixa de aparecer na regressão logística (tabela 35).

\section{* TABELA 33}

Perfil metabólico e de risco cardiovascular em homens de amostra de participantes de acordo com a presença de transtorno depressivo maior do Estudo São Paulo Megacity, realizado na Grande São Paulo - 2005 a 2007

\begin{tabular}{|c|c|c|c|}
\hline & \multicolumn{2}{|c|}{$\begin{array}{c}\text { TRANSTORNO } \\
\text { DEPRESSIVO MAIOR }\end{array}$} & \multirow[t]{2}{*}{$\mathbf{P}$} \\
\hline & Presente & Ausente & \\
\hline Homens & $\mathrm{N}=48$ & $\mathrm{~N}=195$ & \\
\hline Glicemia (mg/dl) $)^{1}$ & $93,5(32,0)$ & $96,0(24,2)$ & 0,58 \\
\hline Diabetes mellitus (\%) ${ }^{2}$ & $5(10,4)$ & $15(7,7)$ & 0,56 \\
\hline Colesterol total $(\mathrm{mg} / \mathrm{dl})^{1}$ & $195,1(42,0)$ & $192,7(53,2)$ & 0,77 \\
\hline LDL-colesterol (mg/dl) ${ }^{1}$ & $127,6(34,4)$ & $121,9(33,2)$ & 0,29 \\
\hline HDL-colesterol (mg/dl) ${ }^{1}$ & $41,8(11,0)$ & $42,8(10,1)$ & 0,55 \\
\hline Triglicérides (mg/dl) ${ }^{1}$ & $127,9(69,5)$ & $159,7(326,9)$ & 0,50 \\
\hline LDL-colesterol elevado (\%) ${ }^{3}$ & $17(35,4)$ & $47(25,0)$ & 0,15 \\
\hline HDL-colesterol < 40 mg/dl (\%) & $23(47,9)$ & $79(41,8)$ & 0,51 \\
\hline Triglicérides >150 mg/dl (\%) & $13(27,1)$ & $61(31,3)$ & 0,61 \\
\hline Proteína $\mathrm{C}$ reativa ultra-sensível $(\mathrm{mg} / \mathrm{dl})^{1}$ & $2,1(2,1)$ & $2,0(1,9)$ & 0,57 \\
\hline Proteína C reativa > 3,0 mg/dl (\%) & $11(24,4)$ & $34(18,7)$ & 0,55 \\
\hline Hormônio tireo-estimulante (TSH) (mcUl/ml) ${ }^{1}$ & $2,9(3,5)$ & $2,4(3,1)$ & 0,33 \\
\hline Síndrome metabólica (\%) & $13(27,1)$ & $58(29,7)$ & 0,86 \\
\hline Escore de risco de Framingham (\%) & & & 0,99 \\
\hline Menor 10\% & $36(75,0)$ & $144(73,8)$ & \\
\hline $10-20 \%$ & $11(22,9)$ & $47(24,1)$ & \\
\hline Maior $20 \%$ & $1(2,1)$ & $4(2,1)$ & \\
\hline
\end{tabular}


3 Para indivíduos com doença cardiovascular aterosclerótica estabelecida ou diabetes mellitus ou Escore de Risco de Framingham (ERF) > 20\% a meta de LDL-c é < 100 mg/dl. Para indivíduos com ERF de 10 a 20\%, a meta de LDL-c é $<130 \mathrm{mg} / \mathrm{dl}$ e para aqueles com ERF < 10\%, a meta é de LDL-c é $<160 \mathrm{mg} / \mathrm{dl}$.

\section{* TABELA 34}

Perfil metabólico e de risco cardiovascular em mulheres de amostra de participantes de acordo com a presença de transtorno depressivo maior do Estudo São Paulo Megacity, realizado na Grande São Paulo - 2005 a 2007

\begin{tabular}{|c|c|c|c|}
\hline & \multicolumn{2}{|c|}{$\begin{array}{c}\text { TRANSTORNO } \\
\text { DEPRESSIVO MAIOR }\end{array}$} & \multirow[t]{2}{*}{$\mathbf{P}$} \\
\hline & Presente & Ausente & \\
\hline Mulheres & $N=155$ & $N=228$ & \\
\hline Glicemia $(\mathrm{mg} / \mathrm{dl})^{1}$ & $89,9(25,7)$ & $88,7(18,5)$ & 0,62 \\
\hline Diabetes mellitus (\%) ${ }^{2}$ & $17(11,0)$ & $8(3,5)$ & 0,005 \\
\hline Colesterol total $(\mathrm{mg} / \mathrm{dl})^{1}$ & $197,3(44,4)$ & $190,6(41,4)$ & 0,14 \\
\hline LDL-colesterol (mg/dl) ${ }^{1}$ & $124,5(37,4)$ & $121,2(34,7)$ & 0,39 \\
\hline HDL-colesterol (mg/dl) ${ }^{1}$ & $50,5(12,6)$ & $48,8(11,7)$ & 0,19 \\
\hline Triglicérides (mg/dl) ${ }^{1}$ & $110,9(66,8)$ & $102,1(63,4)$ & 0,19 \\
\hline LDL-colesterol elevado (\%) ${ }^{3}$ & $38(24,5)$ & $33(14,5)$ & 0,02 \\
\hline HDL-colesterol < 40 mg/dl (\%) & $26(16,8)$ & $49(21,6)$ & 0,29 \\
\hline Triglicérides >150 mg/dl (\%) & $29(18,7)$ & $37(16,3)$ & 0,58 \\
\hline Proteína $C$ reativa ultra-sensível $(\mathrm{mg} / \mathrm{dl})^{1}$ & $2,4(2,4)$ & $3,0(2,7)$ & 0,049 \\
\hline Proteína C reativa > 3,0 mg/dl (\%) & $40(27,6)$ & $83(40,5)$ & 0,005 \\
\hline Hormônio tireoestimulante (TSH) $(\mathrm{mcUl} / \mathrm{ml})^{1}$ & $2,4(1,8)$ & $2,4(1,8)$ & 0,86 \\
\hline Síndrome metabólica (\%) & $50(32,3)$ & $67(29,4)$ & 0,57 \\
\hline Escore de risco de Framingham (\%) & & & 0,21 \\
\hline Menor $10 \%$ & $153(98,7)$ & $219(96,1)$ & \\
\hline $10-20 \%$ & $2(1,3)$ & $9(3,9)$ & \\
\hline Maior $20 \%$ & - & - & \\
\hline
\end{tabular}

\footnotetext{
${ }^{1}$ Média (desvio padrão)

2 Diabetes mellitus definido como história médica de diabetes, uso de medicamentos para tratamento de diabetes mellitus ou glicemia de jejum $\geq 126 \mathrm{mg} / \mathrm{dl}$

3 Para indivíduos com doença cardiovascular aterosclerótica estabelecida ou diabetes mellitus ou Escore de Risco de Framingham (ERF) $>20 \%$ a meta de LDL-c é $<100$ mg/dl. Para indivíduos com ERF de 10 a 20\%, a meta de LDL-c é $<130 \mathrm{mg} / \mathrm{dl}$ e para aqueles com ERF $<10 \%$, a meta é de LDL-c é $<160 \mathrm{mg} / \mathrm{dl}$.
} 
TABELA 35

Perfil de fatores de risco cardiovascular em indivíduos de amostra de participantes do Estudo São Paulo Megacity de acordo com a presença de transtorno depressivo maior (com ou sem co-morbidade psiquiátrica), realizado na Grande São Paulo - 2005 a 2007

\begin{tabular}{|c|c|c|c|c|c|c|}
\hline & \multicolumn{6}{|c|}{ GÊNERO } \\
\hline & \multicolumn{3}{|c|}{ Masculino } & \multicolumn{3}{|c|}{ Feminino } \\
\hline & OR & IC95\% & $\mathbf{P}$ & OR & IC95\% & $\mathbf{P}$ \\
\hline \multicolumn{7}{|l|}{ Inatividade física } \\
\hline Sem ajuste & 1,02 & $0,42-2,49$ & 0,97 & 1,15 & $0,66-2,01$ & 0,62 \\
\hline Ajuste para idade & 1,03 & $0,42-2,54$ & 0,95 & 1,18 & $0,67-2,06$ & 0,57 \\
\hline \multicolumn{7}{|c|}{ Presença de tabagismo atual } \\
\hline Sem ajuste & 1,53 & $0,66-3,53$ & 0,32 & 1,79 & $1,03-3,10$ & 0,04 \\
\hline Ajuste para idade & 1,54 & $0,66-3,60$ & 0,32 & 1,75 & $1,01-3,04$ & 0,047 \\
\hline \multicolumn{7}{|c|}{ Presença de excesso de peso ${ }^{1}$} \\
\hline Sem ajuste & 0,75 & $0,39-1,43$ & 0,38 & 0,97 & $0,64-1,47$ & 0,88 \\
\hline Ajuste para idade & 0,73 & $0,38-1,41$ & 0,35 & 0,88 & $0,57-1,37$ & 0,58 \\
\hline \multicolumn{7}{|c|}{ Hipertensão arterial } \\
\hline Sem ajuste & 0,84 & $0,44-1,61$ & 0,60 & 1,19 & $0,77-1,82$ & 0,43 \\
\hline Ajuste para idade & 0,80 & $0,40-1,62$ & 0,54 & 1,07 & $0,68-1,70$ & 0,76 \\
\hline \multicolumn{7}{|l|}{ Diabetes mellitus } \\
\hline Sem ajuste & 1,40 & $0,48-4,05$ & 0,54 & 3,39 & $1,42-8,06$ & 0,006 \\
\hline Ajuste para idade & 1,38 & $0,47-4,09$ & 0,56 & 3,19 & $1,33-7,66$ & 0,009 \\
\hline \multicolumn{7}{|c|}{ Colesterol total elevado } \\
\hline Sem ajuste & 1,17 & $0,61-2,22$ & 0,64 & 0,95 & $0,63-1,45$ & 0,82 \\
\hline Ajuste para idade & 1,16 & $0,59-2,31$ & 0,67 & 0,86 & $0,55-1,33$ & 0,49 \\
\hline \multicolumn{7}{|c|}{ LDL colesterol elevado } \\
\hline Sem ajuste & 1,65 & $0,84-3,24$ & 0,15 & 1,91 & $1,14-3,21$ & 0,015 \\
\hline Ajuste para idade & 1,70 & $0,82-3,53$ & 0,16 & 1,80 & $1,04-3,11$ & 0,04 \\
\hline \multicolumn{7}{|c|}{ HDL- colesterol reduzido } \\
\hline Sem ajuste & 1,28 & $0,68-2,42$ & 0,45 & 0,73 & $0,43-1,24$ & 0,25 \\
\hline Ajuste para idade & 1,27 & $0,67-2,41$ & 0,47 & 0,71 & $0,42-1,21$ & 0,21 \\
\hline \multicolumn{7}{|c|}{$\begin{array}{l}\text { Presença de } \\
\text { hipertrigliceridemia }\end{array}$} \\
\hline Sem ajuste & 0,82 & $0,40-1,65$ & 0,57 & 1,18 & $0,69-2,02$ & 0,54 \\
\hline Ajuste para idade & 0,79 & $0,38-1,63$ & 0,52 & 1,12 & $0,65-1,92$ & 0,69 \\
\hline
\end{tabular}




\begin{tabular}{|c|c|c|c|c|c|c|}
\hline & \multicolumn{6}{|c|}{ GÊNERO } \\
\hline & \multicolumn{3}{|c|}{ Masculino } & \multicolumn{3}{|c|}{ Feminino } \\
\hline & OR & IC95\% & $\mathbf{P}$ & OR & IC95\% & $\mathbf{P}$ \\
\hline \multicolumn{7}{|c|}{$\begin{array}{l}\text { Presença de } \\
\text { síndrome metabólica }\end{array}$} \\
\hline Sem ajuste & 0,88 & $0,43-1,78$ & 0,72 & 1,14 & $0,74-1,78$ & 0,55 \\
\hline Ajuste para idade & 0,85 & $0,41-1,77$ & 0,67 & 1,06 & $0,67-1,67$ & 0,82 \\
\hline \multicolumn{7}{|c|}{ Presença de PCR elevado² } \\
\hline Sem ajuste & 0,92 & $0,47-1,78$ & 0,80 & 1,13 & $0,72-1,78$ & 0,61 \\
\hline Ajuste para idade & 0,87 & $0,44-1,71$ & 0,69 & 1,10 & $0,69-1,73$ & 0,70 \\
\hline \multicolumn{7}{|c|}{ Presença de ERF elevado 3} \\
\hline Sem ajuste & 0,94 & $0,46-1,95$ & 0,87 & 0,32 & $0,07-1,49$ & 0,15 \\
\hline
\end{tabular}

Os indivíduos portadores de transtornos de ansiedade (com ou sem co-morbidade de transtorno de humor) não apresentam diferenças quanto as características sóciodemográficas, antecedentes pessoais e de hábitos de vida, quando comparados aos indivíduos sem transtornos de ansiedade, em ambos os gêneros (tabela 36).

Também não foram encontradas diferenças entre os grupos de homens com e sem transtornos de ansiedade quanto aos dados antropométricos, sendo que a maioria dos homens se encontra em sobrepeso $(\mathrm{p}=0,60)$ e cerca de um quinto destes apresenta circunferência abdominal elevada $(\mathrm{p}=0,73)$. Também não há diferença entre os grupos quanto aos níveis pressóricos e ao diagnóstico de hipertensão arterial, embora haja uma freqüência bastante elevada desde diagnóstico (tabela 37).

Entre as mulheres, também não há diferenças de dados antropométricos entre os grupos com e sem transtorno de ansiedade (tabela 38). Porém, existe uma grande frequência de circunferência abdominal elevada, sem diferença entre os grupos, pois $56,9 \%$ das mulheres com transtorno de ansiedade e 52,6\% das mulheres sem transtornos de ansiedade apresentam tal característica $(\mathrm{p}=0,41)$. Também não houve diferença entre os grupos quanto ao diagnóstico de hipertensão arterial. 
* TABELA 36

Características gerais, antecedentes pessoais de doenças e hábitos de vida em amostra de participantes de acordo com a presença de transtorno de ansiedade do Estudo São Paulo Megacity, realizado na Grande São Paulo - 2005 a 2007

\begin{tabular}{|c|c|c|c|}
\hline & \multicolumn{2}{|c|}{ TRANSTORNO DE ANSIEDADE } & \multirow[t]{2}{*}{$\mathbf{P}$} \\
\hline & Presente & Ausente & \\
\hline Homens & $\mathrm{N}=72$ & $N=171$ & \\
\hline Idade (anos) ${ }^{1}$ & $40,7(10,5)$ & $41,2(10,7)$ & 0,72 \\
\hline Escolaridade (anos) ${ }^{1}$ & $9,2(3,6)$ & $9,1(4,0)$ & 0,95 \\
\hline Renda mensal domiciliar (reais) $^{1}$ & $1.381(1.238)$ & $1.497(1.408)$ & 0,69 \\
\hline Estado civil (\%) & & & 0,12 \\
\hline Casado & $46(64,8)$ & $125(76,7)$ & \\
\hline Viúvo/Separado/ Divorciado & $9(12,7)$ & $10(6,1)$ & \\
\hline Solteiro & $16(22,5)$ & $28(17,2)$ & \\
\hline Emprego (\%) & & & 0,73 \\
\hline Trabalhador & $61(85,9)$ & $136(83,4)$ & \\
\hline Estudante & - & $2(1,2)$ & \\
\hline Do lar & - & $2(1,2)$ & \\
\hline Aposentado & $3(4,2)$ & $9(5,5)$ & \\
\hline Outros & $7(9,9)$ & $14(8,6)$ & \\
\hline Tabagismo (\%) & & & 0,07 \\
\hline Nunca fumante & $42(60,0)$ & $101(59,1)$ & \\
\hline Ex-fumante & $23(32,9)$ & $40(23,4)$ & \\
\hline Fumante ativo & $5(7,1)$ & $30(17,5)$ & \\
\hline Consumo de álcool (\%) ${ }^{2}$ & $20(28,6)$ & $45(26,3)$ & 0,92 \\
\hline Atividade física regular (\%) ${ }^{3}$ & $58(80,6)$ & $150(87,7)$ & 0,16 \\
\hline Diagnóstico prévio de hipertensão arterial (\%) & $25(35,2)$ & $48(28,1)$ & 0,29 \\
\hline Diagnóstico prévio de diabetes mellitus (\%) & $7(9,7)$ & $11(6,4)$ & 0,42 \\
\hline Diagnóstico prévio de doença cardiovascular ${ }^{4}$ & $2(2,8)$ & $6(3,5)$ & 1,0 \\
\hline Mulheres & $N=188$ & $\mathrm{~N}=195$ & \\
\hline Idade (anos) ${ }^{1}$ & $40,0(11,6)$ & $41,3(10,7)$ & 0,27 \\
\hline Escolaridade (anos) ${ }^{1}$ & $9,0(4,3)$ & $9,0(4,1)$ & 0,83 \\
\hline Renda mensal domiciliar (reais) $^{1}$ & $1.293(1.681)$ & $1.296(1.230)$ & 0,99 \\
\hline Estado civil (\%) & & & 0,40 \\
\hline Casado & $111(59,7)$ & $102(53,1)$ & \\
\hline Viúvo/Separado/ Divorciado & $34(18,3)$ & $44(22,9)$ & \\
\hline Solteiro & $41(22,0)$ & $46(24,0)$ & \\
\hline
\end{tabular}




\begin{tabular}{|c|c|c|c|}
\hline & \multicolumn{2}{|c|}{ TRANSTORNO DE ANSIEDADE } & \multirow[t]{2}{*}{$\mathbf{P}$} \\
\hline & Presente & Ausente & \\
\hline Mulheres & $N=188$ & $\mathbf{N}=195$ & \\
\hline Emprego (\%) & & & 0,28 \\
\hline Trabalhador & $111(59,7)$ & $113(58,9)$ & \\
\hline Estudante & - & $4(2,1)$ & \\
\hline Do lar & $46(24,7)$ & $42(21,9)$ & \\
\hline Aposentado & $6(3,2)$ & $10(5,2)$ & \\
\hline Outros & $23(12,4)$ & $23(12,0)$ & \\
\hline Tabagismo (\%) & & & 0,86 \\
\hline Nunca fumante & $114(60,6)$ & $116(59,5)$ & \\
\hline Ex-tabagista & $43(22,9)$ & $49(25,1)$ & \\
\hline Fumante ativo & $31(16,5)$ & $30(15,4)$ & \\
\hline Consumo de álcool (\%) ${ }^{2}$ & $24(12,8)$ & $18(9,2)$ & 0,27 \\
\hline Atividade física regular (\%) ${ }^{3}$ & $159(84,6)$ & $164(84,1)$ & 1,0 \\
\hline Diagnóstico prévio de hipertensão arterial (\%) & $59(31,4)$ & $47(24,1)$ & 0,14 \\
\hline Diagnóstico prévio de diabetes mellitus (\%) & $13(6,9)$ & $10(5,1)$ & 0,52 \\
\hline Diagnóstico prévio de doença cardiovascular ${ }^{4}$ & $6(3,2)$ & $8(4,1)$ & 0,79 \\
\hline
\end{tabular}

${ }^{1}$ Média (desvio-padrão)

${ }^{2}$ Definido como consumo regular de bebidas alcoólicas pelo menos uma vez por semana

${ }^{3}$ Definido por meio do IPAQ, somando indivíduos ativos e muito ativos.

${ }^{4}$ Definido como diagnóstico prévio de acidente vascular cerebral, infarto agudo do miocárdio ou coronariopatias. 
* TABELA 37

Dados antropométricos e medida de pressão arterial em homens de amostra de participantes de acordo com a presença de transtorno de ansiedade do Estudo São Paulo Megacity, realizado na Grande São Paulo - 2005 a 2007

\begin{tabular}{|c|c|c|c|}
\hline & \multicolumn{2}{|c|}{ TRANSTORNO DE ANSIEDADE } & \multirow[t]{2}{*}{$\mathbf{P}$} \\
\hline & Presente & Ausente & \\
\hline Homens & $\mathrm{N}=72$ & $\mathrm{~N}=171$ & \\
\hline Índice de massa corporal $\left(\mathrm{kg} / \mathrm{m}^{2}\right)^{1}$ & $26,3(4,6)$ & $27,0(4,1)$ & 0,24 \\
\hline Estado nutricional (\%) ${ }^{2}$ & & & 0,60 \\
\hline Normal & $28(38,9)$ & $55(32,2)$ & \\
\hline Sobrepeso & $30(41,7)$ & $80(46,8)$ & \\
\hline Obesidade & $14(19,4)$ & $36(21,1)$ & \\
\hline Circunferência abdominal (cm) (\%) & $91,8(12,3)$ & $94,0(11,5)$ & 0,19 \\
\hline Circunferência abdominal elevada (\%) ${ }^{3}$ & $14(19,7)$ & $38(22,4)$ & 0,73 \\
\hline Pressão arterial sistólica $(\mathrm{mm} \mathrm{Hg})^{1}$ & $123,1(20,0)$ & $128,1(20,3)$ & 0,08 \\
\hline Pressão arterial diastólica $(\mathrm{mm} \mathrm{Hg})^{1}$ & $82,9(13,0)$ & $85,2(13,8)$ & 0,21 \\
\hline Hipertensão arterial (\%) ${ }^{4}$ & $29(40,8)$ & $72(42,1)$ & 0,89 \\
\hline \multicolumn{4}{|l|}{1 Média (desvio-padrão) } \\
\hline \multirow{2}{*}{\multicolumn{4}{|c|}{$\begin{array}{l}{ }^{2} \text { Estado nutricional definido por índice de massa corporal (IMC): normal - IMC }<25 \mathrm{~kg} / \mathrm{m}^{2} \text {, sobrepeso - IMC } \\
25 \text { a } 29,9 \mathrm{~kg} / \mathrm{m}^{2} \text { e obesos - IMC } \geq 30 \mathrm{~kg} / \mathrm{m}^{2} \text {. } \\
{ }^{3} \text { Definido como circunferência abdominal acima de } 102 \mathrm{~cm} \text { em homens. }\end{array}$}} \\
\hline & & & \\
\hline \multicolumn{4}{|c|}{$\begin{array}{l}{ }^{4} \text { Hipertensão arterial definida como história médica de hipertensão arterial, ou uso de medicamentos } \\
\text { para hipertensão arterial ou pressão arterial sistólica } \geq 140 \mathrm{~mm} \mathrm{Hg} \text { ou pressão arterial diastólica } \geq 90 \\
\mathrm{~mm} \mathrm{Hg}\end{array}$} \\
\hline
\end{tabular}




\section{TABELA 38}

Dados antropométricos e medida de pressão arterial em mulheres de amostra de participantes de acordo com a presença de transtorno de ansiedade do Estudo São Paulo Megacity, realizado na Grande São Paulo - 2005 a 2007

\begin{tabular}{|c|c|c|c|}
\hline & \multicolumn{2}{|c|}{ TRANSTORNO DE ANSIEDADE } & \multirow[t]{2}{*}{$\mathbf{P}$} \\
\hline & Presente & Ausente & \\
\hline Mulheres & $N=188$ & $\mathrm{~N}=195$ & \\
\hline Índice de massa corporal $\left(\mathrm{kg} / \mathrm{m}^{2}\right)^{1}$ & $27,1(5,5)$ & $26,8(5,1)$ & 0,56 \\
\hline Estado nutricional (\%) ${ }^{2}$ & & & 0,58 \\
\hline Normal & $69(36,7)$ & $80(41,0)$ & \\
\hline Sobrepeso & $69(36,7)$ & $71(36,4)$ & \\
\hline Obesidade & $50(26,6)$ & $44(22,6)$ & \\
\hline Circunferência abdominal (cm) (\%) & $90,3(13,5)$ & $90,5(12,2)$ & 0,89 \\
\hline Circunferência abdominal elevada (\%) & $107(56,9)$ & $102(52,6)$ & 0,41 \\
\hline Pressão arterial sistólica $(\mathrm{mm} \mathrm{Hg})^{1}$ & $118,1(20,3)$ & $117,9(20,2)$ & 0,93 \\
\hline Pressão arterial diastólica $(\mathrm{mm} \mathrm{Hg})^{1}$ & $76,9(12,5)$ & $78,2(12,9)$ & 0,33 \\
\hline Hipertensão arterial (\%) ${ }^{4}$ & $70(37,2)$ & $62(31,8)$ & 0,28 \\
\hline \multicolumn{4}{|l|}{${ }^{1}$ Média (desvio-padrão) } \\
\hline \multirow{2}{*}{\multicolumn{4}{|c|}{$\begin{array}{l}2 \text { Estado nutricional definido por índice de massa corporal (IMC): normal - IMC }<25 \mathrm{~kg} / \mathrm{m}^{2} \text {, sobrepeso - IMC } \\
25 \text { a } 29,9 \mathrm{~kg} / \mathrm{m}^{2} \text { e obesos - IMC } \geq 30 \mathrm{~kg} / \mathrm{m}^{2} . \\
{ }^{3} \text { Definido como circunferência abdominal acima de } 88 \mathrm{~cm} \text { em mulheres. }\end{array}$}} \\
\hline & & & \\
\hline \multicolumn{4}{|c|}{$\begin{array}{l}{ }^{4} \text { Hipertensão arterial definida como história médica de hipertensão arterial, ou uso de medicamentos } \\
\text { para hipertensão arterial ou pressão arterial sistólica } \geq 140 \mathrm{~mm} \mathrm{Hg} \text { ou pressão arterial diastólica } \geq 90 \\
\mathrm{~mm} \mathrm{Hg}\end{array}$} \\
\hline
\end{tabular}

Os homens portadores de transtorno de ansiedade apresentam diferença limítrofe dos homens sem diagnóstico de transtornos de ansiedade, com maiores níveis de hormônio tireoestimulante $(p=0,054)$. No entanto, não apresentam diferenças quanto aos outros parâmetros de perfil de risco cardiovascular entre os grupos (tabela 39).

As mulheres portadoras de transtornos ansiosos apresentam menores níveis médios de PCR ultra-sensível $(\mathrm{P}=0,03)$ e menor frequência de níveis elevados de PCR $(\mathrm{p}=0,051)$. Também não apresentam diferenças quanto ao restante do perfil metabólico e de risco cardiovascular (tabela 40).

Quanto aos portadores de transtornos de ansiedade (com ou sem co-morbidade psiquiátrica), foi observado que não há diferença no perfil de fatores de risco cardiovascular em mulheres com e sem transtorno ansioso na análise de regressão logística (tabela 41).

Os homens portadores de transtornos de ansiedade apresentam menor freqüência de tabagismo do que os homens sem ansiedade, com odds ratio de 0,36 (IC95\% 0,13-0,99) 
* TABELA 41

Perfil de fatores de risco cardiovascular em indivíduos de amostra de participantes do Estudo São Paulo Megacity de acordo com a presença de transtorno de ansiedade (com ou sem comorbidade psiquiátrica), realizado na Grande São Paulo - 2005 a 2007

\begin{tabular}{|c|c|c|c|c|c|c|}
\hline & \multicolumn{6}{|c|}{ GÊNERO } \\
\hline & \multicolumn{3}{|c|}{ Masculino } & \multicolumn{3}{|c|}{ Feminino } \\
\hline & OR & IC95\% & $\mathbf{P}$ & OR & IC95\% & $\mathbf{P}$ \\
\hline \multicolumn{7}{|l|}{ Inatividade física } \\
\hline Sem ajuste & 1,72 & $0,82-3,62$ & 0,15 & 0,97 & $0,56-1,68$ & 0,90 \\
\hline Ajuste para idade & 1,71 & $0,81-3,61$ & 0,16 & 0,95 & $0,55-1,65$ & 0,85 \\
\hline \multicolumn{7}{|c|}{ Presença de tabagismo atual } \\
\hline Sem ajuste & 0,36 & $0,13-0,97$ & 0,044 & 1,09 & $0,63-1,88$ & 0,77 \\
\hline Ajuste para idade & 0,36 & $0,13-0,99$ & 0,047 & 1,11 & $0,64-1,92$ & 0,72 \\
\hline \multicolumn{7}{|c|}{ Presença de excesso de peso ${ }^{1}$} \\
\hline Sem ajuste & 0,75 & $0,42-1,32$ & 0,31 & 1,20 & $0,80-1,81$ & 0,39 \\
\hline Ajuste para idade & 0,75 & $0,42-1,35$ & 0,34 & 1,31 & $0,85-2,01$ & 0,22 \\
\hline \multicolumn{7}{|c|}{ Hipertensão arterial } \\
\hline Sem ajuste & 0,95 & $0,54-1,67$ & 0,86 & 1,27 & $0,83-1,94$ & 0,26 \\
\hline Ajuste para idade & 1,00 & $0,54-1,83$ & 0,99 & 1,46 & $0,92-2,30$ & 0,11 \\
\hline \multicolumn{7}{|l|}{ Diabetes mellitus } \\
\hline Sem ajuste & 1,31 & $0,50-3,43$ & 0,58 & 1,13 & $0,50-2,55$ & 0,76 \\
\hline Ajuste para idade & 1,37 & $0,51-3,64$ & 0,53 & 1,21 & $0,53-2,76$ & 0,64 \\
\hline \multicolumn{7}{|c|}{ Colesterol total elevado } \\
\hline Sem ajuste & 0,93 & $0,53-1,64$ & 0,81 & 0,88 & $0,59-1,33$ & 0,55 \\
\hline Ajuste para idade & 0,96 & $0,52-1,76$ & 0,90 & 0,94 & $0,61-1,44$ & 0,78 \\
\hline \multicolumn{7}{|c|}{ LDL colesterol elevado } \\
\hline Sem ajuste & 0,88 & $0,47-1,66$ & 0,69 & 1,44 & $0,86-2,42$ & 0,17 \\
\hline Ajuste para idade & 0,91 & $0,46-1,79$ & 0,78 & 1,69 & $0,97-2,93$ & 0,06 \\
\hline \multicolumn{7}{|c|}{ HDL- colesterol reduzido } \\
\hline Sem ajuste & 0,68 & $0,39-1,21$ & 0,19 & 0,89 & $0,54-1,48$ & 0,66 \\
\hline Ajuste para idade & 0,70 & $0,39-1,22$ & 0,20 & 0,91 & $0,55-1,51$ & 0,71 \\
\hline \multicolumn{7}{|c|}{$\begin{array}{l}\text { Presença de } \\
\text { hipertrigliceridemia }\end{array}$} \\
\hline Sem ajuste & 1,32 & $0,74-2,38$ & 0,35 & 1,05 & $0,62-1,79$ & 0,85 \\
\hline Ajuste para idade & 1,40 & $0,76-2,59$ & 0,28 & 1,11 & $0,65-1,89$ & 0,72 \\
\hline
\end{tabular}




\begin{tabular}{|c|c|c|c|c|c|c|}
\hline & \multicolumn{6}{|c|}{ GÊNERO } \\
\hline & \multicolumn{3}{|c|}{ Masculino } & \multicolumn{3}{|c|}{ Feminino } \\
\hline & OR & IC95\% & $\mathbf{P}$ & OR & IC95\% & $\mathbf{P}$ \\
\hline \multicolumn{7}{|c|}{$\begin{array}{l}\text { Presença de } \\
\text { síndrome metabólica }\end{array}$} \\
\hline Sem ajuste & 1,45 & $0,80-2,61$ & 0,22 & 1,08 & $0,70-1,67$ & 0,73 \\
\hline Ajuste para idade & 1,54 & $0,83-2,87$ & 0,17 & 1,17 & $0,74-1,84$ & 0,50 \\
\hline \multicolumn{7}{|c|}{ Presença de PCR elevado ${ }^{2}$} \\
\hline Sem ajuste & 1,32 & $0,73-2,39$ & 0,35 & 0,71 & $0,45-1,11$ & 0,13 \\
\hline Ajuste para idade & 1,32 & $0,73-2,41$ & 0,36 & 0,72 & $0,46-1,13$ & 0,15 \\
\hline \multicolumn{7}{|c|}{ Presença de ERF elevado ${ }^{3}$} \\
\hline Sem ajuste & 0,53 & $0,27-1,06$ & 0,07 & 1,25 & $0,38-4,18$ & 0,71 \\
\hline
\end{tabular}

${ }^{1}$ Incluídos indivíduos com sobrepeso ou obesidade.

2 Indivíduos classificados como moderado ou alto risco para eventos cardiovasculares.

${ }^{3}$ Indivíduos classificados como ERF moderado ou alto risco para eventos cardiovasculares.

Foram analisados os componentes da atividade física entre os participantes de acordo com a presença ou ausência de cada diagnóstico psiquiátrico e foi observado que os níveis de atividade física no lazer são bastante reduzidos (tabela 42). No entanto, mais da metade dos indivíduos é ativo em atividades praticadas em casa. Cerca de um terço a um quarto dos participantes são ativos nas suas atividades laborais e durante o transporte para o trabalho, sem diferença entre os grupos com ou sem transtorno psiquiátrico, somente com uma exceção: os homens portadores de transtornos de humor (com ou sem comorbidade) apresentam maior atividade física no transporte entre a casa e o trabalho do que os homens sem transtorno de humor $(\mathrm{p}=0,03)$. 
* TABELA 42

Perfil de realização de atividade física de acordo com transtorno psiquiátrico e gênero em participantes do Estudo São Paulo Megacity, realizado na Grande São Paulo - 2005 a 2007.

\begin{tabular}{lcccc}
\hline & \multicolumn{4}{c}{ ATIVIDADE FísICA } \\
\hline & $\begin{array}{c}\text { Ativo no } \\
\text { trabalho }\end{array}$ & $\begin{array}{c}\text { Ativo no } \\
\text { transporte }\end{array}$ & $\begin{array}{c}\text { Ativo em } \\
\text { casa }\end{array}$ & $\begin{array}{c}\text { Ativo no } \\
\text { lazer }\end{array}$ \\
\cline { 2 - 5 } Masculino & $\mathbf{N}(\%)$ & $\mathbf{N}(\%)$ & $\mathbf{N}(\%)$ & $\mathbf{N}(\%)$ \\
\cline { 2 - 5 } Sem diagnóstico psiquiátrico & $41(29,3)$ & $35(25,0)$ & $77(55,0)$ & $25(17,9)$ \\
Transtorno de humor exclusivo & $8(25,8)$ & $10(32,3)$ & $19(61,3)$ & $3(9,7)$ \\
Depressão maior exclusiva & $5(23,8)$ & $6(28,6)$ & $14(66,7)$ & $2(9,5)$ \\
Transtorno de ansiedade exclusivo & $16(38,1)$ & $9(21,4)$ & $22(52,4)$ & $5(11,9)$ \\
Transtorno de humor & $18(29,5)$ & $24(35,3) *$ & $35(57,4)$ & $10(16,4)$ \\
Depressão maior & $16(33,3)$ & $18(37,5)$ & $26(54,2)$ & $7(17,5)$ \\
Transtorno de ansiedade & $26(36,1)$ & $23(31,9)$ & $38(52,8)$ & $12(16,7)$ \\
\cline { 2 - 5 } Feminino & $\mathbf{N}(\%)$ & $\mathbf{N}(\%)$ & $\mathbf{N}(\%)$ & $\mathbf{N}(\%)$ \\
\cline { 2 - 5 } Sem diagnóstico psiquiátrico & $47(34,6)$ & $34(25,0)$ & $73(53,7)$ & $22(16,2)$ \\
Transtorno de humor exclusivo & $17(28,8)$ & $9(15,3)$ & $38(64,4)$ & $6(10,2)$ \\
Depressão maior exclusiva & $15(31,9)$ & $7(14,9)$ & $30(63,8)$ & $4(8,5)$ \\
Transtorno de ansiedade exclusivo & $21(30,4)$ & $21(30,4)$ & $42(60,9)$ & $13(18,8)$ \\
Transtorno de humor & $59(33,1)$ & $39(41,5)$ & $95(53,4)$ & $28(15,7)$ \\
Depressão maior & $54(34,8)$ & $33(21,3)$ & $80(51,6)$ & $21(33,3)$ \\
Transtorno de ansiedade & $63(33,5)$ & $51(27,1)$ & $99(52,7)$ & $35(18,6)$ \\
\hline
\end{tabular}

* $p=0,03$ 



\section{DISCUSSÃO}

\subsection{PANORAMA GERAL}

Os transtornos psiquiátricos são prevalentes em indivíduos de todo o mundo. A Organização Mundial da Saúde (OMS) realizou um inquérito World Health Organization's World Mental Health Survey Iniciative conduzido em 17 países pertencentes às regiões da África, Américas, Ásia, Europa e Oriente Médio, entre 2005 e 2007, com 85.052 participantes e observaram que, na maioria dos países, os diagnósticos psiquiátricos mais prevalentes, na maioria dos países, são os transtornos de humor e ansiedade ${ }^{142}$.

Nos Estados Unidos da América, 31,0\% dos indivíduos avaliados apresentaram transtornos de ansiedade durante a vida, 25,0\% transtornos de controle de impulsos, $21,4 \%$ transtornos de humor e 14,6\% transtornos por uso de substâncias. Na Bélgica, 14,1\% dos entrevistados apresentaram durante a vida transtornos de humor, 13,1\% apresentaram transtornos de ansiedade, 8,3\% transtornos por uso de substâncias e 5,2\% transtornos de controle de impulsos. Na Colômbia, 25,3\% dos participantes apresentaram transtorno de ansiedade durante a vida, 14,6\% transtornos de humor, 9,6\% transtornos de controle de impulsos e 9,6\% transtornos de uso de substâncias. No México, 14,3\% de prevalência de transtorno de ansiedade, 9,2\% de transtorno de humor, 7,8\% de transtorno por uso de substâncias e 5,7\% de transtorno de controle de impulsos ${ }^{142}$.

No Brasil, não há pesquisas recentes de prevalência nacional de transtornos psiquiátricos. Porém, há dados regionais: Almeida Filho et al. avaliaram 2303 indivíduos da cidade de Salvador (Bahia) em 2001 e observaram que 12,2\% da população estudada apresentava sintomas depressivos, com maior prevalência em mulheres (OR 2,65; IC 95\% 1,99-3,56), entre divorciados e viúvos (OR 1,69; IC 95\% 1,06-2,69), em mulatos (OR 1,78; IC 95\% 1,09-2,90) e nas faixas etárias entre 35 e 44 anos (OR 2,08; IC 95\% 1,21-3,56) e entre 45 e 54 anos (OR 2,43; IC 95\% 1,39-4,26) ${ }^{143}$.

Andrade et al. avaliaram 1.464 indivíduos de 2 bairros da região centro-oeste do município de São Paulo (Jardim América e Vila Madalena) e observaram que 33,1\% dos participantes apresentaram algum transtorno psiquiátrico durante a vida (sendo que a dependência a nicotina não foi incluída no estudo). Nesse estudo $24, \%$ dos entrevistados apresentaram transtorno de humor e/ou de ansiedade durante a vida, 18,4\% dos participantes relataram transtornos de humor ( dentre este grupo, 16,8\% de transtornos depressivos) e 12,5\% dos participantes relataram transtorno de ansiedade. Além disso, 27,3\% dos participantes relataram transtornos relacionados ao uso de substâncias durante a vida ${ }^{144}$. 
O perfil de morbidade psiquiátrica observado na segunda fase do Inquérito de Saúde Mental São Paulo Megacity demonstra um padrão semelhante ao encontrado no World Health Organization's World Mental Health Survey Iniciative ${ }^{142}$. Nosso estudo observou que o grupo de transtornos psiquiátricos mais frequente dentre os participantes é o de transtornos de ansiedade (43,7\% da população estudada), seguido por transtornos de humor (40,2\% da população estudada) e em seguida os transtornos por uso de substâncias $(13,9 \%)$.

No entanto, as frequências não são similares às encontradas em estudos internacionais e brasileiros, devido ao fato da população estudada ter sido selecionada para amostrar um maior número de portadores de transtornos de psiquiátricos (35\% de indivíduos sem transtornos psiquiátricos e $65 \%$ de indivíduos com transtorno psiquiátrico) a partir de um inquérito populacional e, desta maneira, possibilitar a avaliação da frequência dos fatores de risco para doença cardiovascular.

\subsection{ESTILO DE VIDA \& TRANSTORNOS DE HUMOR EI OU ANSIEDADE}

\subsubsection{Tabagismo}

As características do estilo de vida tem grande impacto na determinação do risco para eventos cardiovasculares. O tabagismo é relatado por 30\% dos indivíduos do mundo ocidental e é considerado a primeira causa de mortes passíveis de prevenção ${ }^{145}$. Segundo a OMS:

O tabaco é um fator de risco para seis das oito principais causas de morte no mundo e mata uma pessoa a cada seis segundos. O tabaco mata de um terço a metade de todas as pessoas que o usam, em média 15 anos prematuramente. (...) O tabagismo responde atualmente por 40 a 45\% de todas as mortes por câncer, 90 a 95\% das mortes por câncer de pulmão, 75\% das mortes por DPOC, cerca de 20\% das mortes por doenças vasculares, 35\% das mortes por doenças cardiovasculares, entre homens de 35 a 69 anos de idade, nos países desenvolvidos.

O tabagismo foi associado a diversos transtornos psiquiátricos e há relatos de que indivíduos portadores de tais transtornos apresentam o dobro do risco de serem tabagistas comparados a população geral ${ }^{106}$ e consomem mais cigarros do que os indivíduos sem diagnóstico psiquiátrico ${ }^{146}$. Em nosso estudo foi observado que, entre as mulheres 
portadoras de transtornos de humor ou depressão maior, há uma freqüência maior de tabagistas, porém esta característica não foi observada entre mulheres portadoras de transtornos ansiosos.

A maior frequência de tabagismo não aparece quando o tabagismo é classificado em três grupos: fumantes atuais, ex-fumantes e nunca fumantes. As mulheres portadoras de transtorno de humor exclusivo apresentaram frequência de $23,7 \%$ de tabagismo atual, enquanto as mulheres sem diagnóstico psiquiátrico apresentaram 11,8\% de tabagismo $(\mathrm{P}=0,10)$. As mulheres com depressão maior exclusiva apresentaram frequência de $21,3 \%$ e as mulheres sem transtorno psiquiátrico $11,8 \%(\mathrm{p}=0,23)$. As mulheres com transtorno de humor (com ou sem co-morbidade) apresentaram 20,2\% de tabagismo e as mulheres sem transtorno de humor apresentaram $12,2 \%$ de tabagismo $(\mathrm{P}=0,07)$. As mulheres com depressão maior (com ou sem co-morbidade) apresentaram 20,6\% de tabagismo e as mulheres sem depressão apresentaram $12,7 \%$ de tabagismo $(\mathrm{p}=0,10)$.

No entanto, ao agrupar as ex-fumantes com as mulheres que nunca fumaram, ou seja, o grupo de menor risco cardiovascular, as diferenças passam a ser evidentes. Em mulheres com transtorno de humor exclusivo, o OR é de 2,30 (IC 95\% 1,03-5,15) para tabagismo atual quando ajustado para idade. Em mulheres com transtorno de humor com ou sem co-morbidade de transtornos ansiosos, o OR é de 1,79 (IC 95\% 1,03-3,13), quando ajustado pela idade. As mulheres portadoras de depressão exclusiva não apresentaram maior frequência (OR 1,97; IC 95\% 0,81-4,79), porém as portadoras de depressão maior com ou sem co-morbidade de ansiedade apresentaram maior chance de serem tabagistas (OR 1,75; IC 95\% 1,01-3,04).

Possivelmente, não foi observada diferença no grupo de mulheres com depressão exclusiva pelo menor número de portadoras de tal diagnóstico, já que quando associada as mulheres com associação de ansiedade a diferença de torna evidente.

Outra explicação possível, é que a depressão por si só não esteja associada a maior frequência de tabagismo e somente quando associado a transtornos de ansiedade a associação com tabagismo ocorra. Strine et al. e Mykletun et al. observaram que a associação entre depressão e ansiedade apresentam maior impacto na carga tabágica e na associação com tabagismo ${ }^{109,110}$.

Não foi observada maior frequência de tabagismo nos grupos de homens com transtorno de humor (OR 1,55; IC 95\% 0,70-3,44) e/ou depressão maior (OR 1,54; IC 95\% 0,66-3,60). No entanto, foi observado menor freqüência de tabagismo atual entre homens portadores de transtornos ansiosos com ou sem co-morbidade de transtorno de humor (OR 0,36; IC 95\% 0,13-0,99).

Bonnet et al. também encontraram maior freqüência de tabagismo entre mulheres com depressão e ausência de associação com ansiedade. No entanto, Bonnet et al. também observaram maior freqüência de tabagismo em homens com sintomas depressivos ou com 
sintomas ansiosos, ao contrário do observado em nosso estudo ${ }^{108}$. Strine et al. observaram que existe associação em ambos os gêneros entre maior freqüência de tabagismo e diagnóstico de depressão e/ou de ansiedade. Os autores observaram ainda associação entre maior carga tabágica com maior gravidade da doença ${ }^{109}$.

Nosso estudo observou uma diferença de gênero importante na associação entre tabagismo e transtornos de humor e/ou de ansiedade. Enquanto nas mulheres com transtornos de humor há uma associação positiva, como já discutido na literatura ${ }^{108,109}$, não foi observada associação com o diagnóstico de transtornos de ansiedade. O estudo de Bonnet et al. também não encontrou associação entre sintomas ansiosos e maior freqüência de tabagismo ${ }^{108}$. Desta maneira, outra hipótese é que haja influências culturais nesta associação, devido aos achados que variam de acordo com os diferentes países estudados.

No entanto, o resultado observado entre homens é interessante e inesperado: os homens portadores de transtornos de humor e/ou depressão maior não apresentam maior freqüência de tabagismo. Este resultado pode ser explicado por uma ausência de poder estatístico para demonstrar uma diferença existente pois há menor número de homens com tal diagnóstico neste estudo, quando comparados às mulheres. São 61 homens com transtornos de humor e 48 homens com depressão maior, enquanto há 178 mulheres com transtornos de humor e 155 mulheres com depressão maior.

Outro resultado inesperado se trata da menor frequência de tabagismo entre homens com transtornos de ansiedade. Apesar de não haver nenhum dado na literatura corroborando este resultado, o achado pode ser explicado por se tratar de um estudo em comunidade, que em geral realiza diagnóstico em casos menos graves do que os estudos em ambiente hospitalar ou de serviços de saúde. O instrumento utilizado (SCID-I NP) realiza diagnóstico de transtorno psiquiátrico na vida, podendo também se tratar de diagnóstico prévio já remitido.

Cougle et al. avaliaram 5.692 indivíduos participantes do National Comorbidity Survey Replication e observaram que não há associação entre presença de fobia social e tabagismo diário (OR 1,12; IC 95\% 0,90-1,39), entre tabagismo pesado (definido como fumar 20 ou mais cigarros por dia) e fobia social (OR 1,08; IC 95\% 0,84-1,39), nem entre tabagismo pesado e transtorno do pânico (OR 1,29; IC 95\% 0,84-1,96) ${ }^{147}$.

A heterogeneidade dos transtornos presentes dentro do grupo de transtornos ansiosos do nosso estudo pode levar a diferentes associação com o uso de tabaco. Na população estudada, a maior parte dos transtornos presentes no grupo de transtornos ansiosos são de indivíduos portadores de fobia social e fobia específica, o que pode explicar os resultados obtidos.

Comparando as frequências de tabagismo encontradas nesta tese com as taxas de prevalência do estudo Vigitel 2007, podemos observar que os homens participantes deste estudo apresentaram menor freqüência de tabagismo (14\%). O estudo Vigitel encontrou 
uma taxa de prevalência de 26,2\% (IC 95\% 21,8-30,6) em homens adultos no município de São Paulo. Já entre as mulheres, as freqüências são similares: 15,9\% em nosso estudo e no Vigitel 14,6\% (IC 95\% 12,0-17,1). Os dados também são similares em relação a freqüência de ex-fumantes em ambos sexos ${ }^{148}$.

Comparando nossos dados com o estudo de Lawrence et al. apresentamos uma freqüência bastante reduzida de tabagistas (15,4\% da população total do estudo, com 18,3\% dos homens e $20,2 \%$ das mulheres entre portadores de transtornos de humor e $7,1 \%$ dos homens e $16,5 \%$ das mulheres portadores de transtorno de ansiedade), pois os autores observaram uma prevalência de tabagismo na população australiana com transtornos psiquiátricos de 36,2\% (IC 95\% 32,9-39,6) e na população americana com transtornos psiquiátricos de 40,1\% (IC 95\% 37,6-42,7), ${ }^{105}$.

\subsubsection{Atividade física}

A atividade física realizada por indivíduos em seu dia-a-dia também apresenta grande impacto na sua morbi-mortalidade, com uma associação inversa ${ }^{149}$. O sedentarismo está implicado como fator de risco para mortalidade por todas as causas e para mortalidade por doenças cardiovasculares, além de aumentar a incidência de diversos tipos de doenças, entre elas: neoplasias, osteoporose, doença cardiovascular e seus fatores de risco, como dislipidemia, hipertensão arterial, diabetes mellitus e obesidade ${ }^{150,151}$.

A atividade física também apresenta associação com transtornos de humor e, menos consistentemente, com transtornos de ansiedade ${ }^{152}$. Há estudos demonstrando que indivíduos que apresentam maiores níveis de atividade física apresentam menos sintomas depressivos do que aqueles sedentários ${ }^{152,153}$. Existem ainda evidências de que atividade física é um tratamento eficaz para transtornos de humor e ansiedade ${ }^{154}$.

Wise et al. avaliaram 35.224 mulheres americanas negras participantes de coorte do Black Women's Health Study e observaram que as mulheres que apresentavam atividade física vigorosa no lazer apresentavam menos sintomas depressivos, com benefício a partir de uma hora por semana (OR 0,85; IC 95\% 0,78-0,92), e com benefício crescente até a prática de 3 a 4 horas por semana (OR 0,72; IC 95\% 0,66-0,80). Não foi observado menor frequência de sintomas em quem pratica caminhada no lazer (OR 0,94; IC 95\% 0,84-1,05, para 3 a 4 horas por semana). As praticantes de atividade física vigorosa no lazer apresentavam menor idade, maior escolaridade, menos tabagismo e ausência de co-morbidades. $\mathrm{E}$ as mulheres que praticavam caminhada no lazer apresentavam maior escolaridade e menos tabagismo do que as sedentárias ${ }^{153}$.

Foi observado em nosso estudo uma freqüência inesperadamente alta de indivíduos ativos ou muito ativos (avaliados pelo IPAQ). Entre os participantes, 85,9\% dos homens e 
$84,0 \%$ das mulheres foram considerados ativos ou muito ativos segundo o instrumento, sem diferença de gênero $(\mathrm{p}=0,58)$. No entanto, a maior parte da atividade física relatada ocorre por atividades realizadas no cuidado de casa, no trabalho ou ainda no transporte entre a casa e o trabalho. A frequência de atividade física praticada no lazer é bastante reduzida.

O fato de nossa amostra apresentar, em grande parte, indivíduos de menor nível sócio-econômico pode ser responsável pelos maiores níveis de atividade física. Reis et al. avaliaram 150 indivíduos moradores do Estado da Bahia com o IPAQ (versão curta), e compararam grupos de maior e menor nível sócio-econômico. Os autores observaram que indivíduos com maior nível sócio-econômico apresentavam menores níveis de atividade física, sendo que 57,6\% destes eram insuficientemente ativos (e 42,9\% dos indivíduos de baixo nível sócio-econômicos eram insuficientemente ativos). Nesta amostra, foram considerados ativos ou muito ativos: $57,2 \%$ dos indivíduos de baixo nível sócio-econômico e 42,4\% dos indivíduos de alto nível sócio-econômico $(\mathrm{p}=0,006){ }^{155}$.

$\mathrm{O}$ fato de que indivíduos de menor nível sócio-econômico apresentarem atividades laborais mais ativas e realizadas através de esforço físico (trabalhadores da construção civil, empregadas domésticas, por exemplo) resulta em maiores níveis de atividade física. Além disso, indivíduos que cuidam de seus lares e realizam atividade de limpeza doméstica são ativos devido a estas atividades. As pessoas de maior nível sócio-econômico apresentam maior atividade física no lazer, porém na somatória de atividade física praticada durante o dia, em média, costumam a apresentar menores níveis do que os indivíduos de menor nível sócio-econômico.

Existem outros estudos que encontraram altos níveis de atividade física em população do município e do estado de São Paulo. Viebig et al. avaliaram 123 mulheres e 77 homens livres de doença cardiovascular que procuraram realizar exames de rastreamento no município de São Paulo e observaram que somente 4,5\% dos homens e 6,5\% das mulheres foram considerados sedentários pela avaliação do IPAQ (versão curta). Nesta amostra a idade média era similar ao do nosso estudo (41 anos) ${ }^{156}$.

Zaitune et al. avaliaram 1.950 idosos no Inquérito de Saúde no Estado de São Paulo (ISA-SP) com utilização do IPAQ (versão curta) e observaram que 78,5\% (IC 95\% 74,582,0 ) das mulheres e $67,7 \%$ (IC 95\% 63,5-71,6) dos homens foram considerados ativos ou muito ativos ${ }^{157}$.

Zanchetta et al. avaliaram 2.050 adultos do Estado de São Paulo (em diversas cidades diferentes) e observaram que $76,6 \%$ dos homens e $89,3 \%$ das mulheres eram ativas ou muito ativas, segundo o IPAQ (versão curta) ${ }^{158}$. Esses autores também observaram que os níveis de sedentarismo aumentam com a posse de carro e com a maior escolaridade, além observar que pessoas que se consideram negras ou pardas apresentam menores níveis de sedentarismo ${ }^{158}$. 
Em nosso estudo, não foi observada associação entre inatividade física (considerado como a soma de indivíduos considerados inativos e irregularmente ativos) e diagnóstico de transtorno de humor, depressão e/ou ansiedade. Ambos grupos com e sem transtornos psiquiátricos apresentam frequência elevada de atividade física. Diversos estudos demonstram a associação entre transtornos psiquiátricos e níveis maiores de sedentarismo, principalmente em deprimidos 54,108,109. No entanto, outros demonstram ausência de associação tanto em portadores de depressão como em portadores de ansiedade ${ }^{107,} 109$.

Porém, este estudo utilizou amostra de origem comunitária, proveniente de inquérito populacional, o que geralmente engloba indivíduos com transtornos menos graves e que nem sempre procuram os serviços de saúde. Bonnet et al. avaliaram amostra de conveniência em centro de atenção secundária, de indivíduos encaminhados por seus médicos de família ${ }^{108}$. Desta maneira, os indivíduos encaminhados apresentam um perfil de maior gravidade (tanto de risco cardiovascular, como de saúde mental) quando comparado a amostra deste estudo.

Em nossa amostra foi realizado rastreamento em domicílio para transtornos psiquiátricos, com instrumento sensível (CIDI) e posteriormente, foi realizada reavaliação com psiquiatras treinados, com entrevista semi-estruturada (SCID-I NP), e portanto, o diagnóstico psiquiátrico foi realizado de maneira bastante sensível. Desta maneira, pode haver um grande percentual de transtornos leves neste estudo, devido a sensibilidade alta dos instrumentos utilizados.

Além disso, o SCID-I NP realiza diagnósticos psiquiátricos que o indivíduo apresentou durante a vida, podendo diagnosticar episódios prévios. É conhecido que o efeito dos transtornos psiquiátricos sobre o estilo de vida, com impacto deletério, é maior na vigência do episódio ${ }^{109}$. Isto pode explicar a ausência de associação entre sedentarismo e presença de transtornos de humor e/ou de ansiedade.

No entanto, Strine et al. avaliaram 217.379 indivíduos de 38 estados americanos por meio de inquérito telefônico e observaram que há maior frequência de inatividade física entre em indivíduos com antecedente de depressão (OR 1,3; IC 95\% 1,2-1,4) ou antecedente de depressão associado a ansiedade (OR 1,3; IC 95\% 1,2-1,4) ${ }^{109}$. No entanto, não houve associação entre inatividade física e diagnóstico prévio de ansiedade (sem depressão associada). Também não encontramos associação entre diagnóstico de ansiedade e sedentarismo.

Outra hipótese que pode explicar a ausência de associação entre diagnóstico de transtornos de humor e/ou de ansiedade e inatividade física é o fato dos indivíduos participantes deste estudo apresentarem maiores níveis de atividade física relacionada a maior atividade no lar, no trabalho e no deslocamento. Pode haver também uma questão cultural entre latinos na resposta à depressão relacionada a atividade física. Pagoto et al. avaliaram 210 latinos residentes nos EUA com risco aumentado de desenvolver diabetes 
mellitus (classificados através de fórmula de Stern) e observaram que aqueles com depressão maior não apresentavam níveis diferentes de atividade física comparados a indivíduos sem transtorno depressivo ${ }^{159}$.

No estudo Vigitel 2007 foi observado que 33,2\% (IC 95\% 28,7-37,7) dos homens e 25,0\% (IC 95\% 21,7-28,2) das mulheres são fisicamente inativos no município de São Paulo 148. Os dados referentes à população brasileira entre 35 e 44 anos demonstram que 27,5\% (IC 95\% 24,9-30,1) dos homens e 18,8\% (IC 95\% 17,0-20,6) das mulheres são fisicamente inativos. Apesar destas freqüências de sedentarismo serem mais elevadas do que as encontradas neste estudo, cabe ressaltar que o instrumento utilizado na obtenção dos dados sobre atividade física no estudo Vigitel é diferente do utilizado no presente estudo (IPAQ), levando portanto a resultados pouco comparáveis.

\subsection{MEDIDAS ANTROPOMÉTRICAS \& TRANSTORNOS DE HUMOR EIOU ANSIEDADE}

O excesso de peso está relacionado a maior mortalidade por todas as causas e a maior mortalidade por doença cardiovascular, tanto em homens quanto em mulheres ${ }^{151}$. Além disso, o excesso de peso se associa a maior incidência de neoplasias (de mama, endometrial, ovariana, colo-retal, renal, pancreática) e de eventos cardiovasculares, assim como seus fatores de risco, como diabetes mellitus e hipertensão arterial ${ }^{64}$.

Foi observada elevada frequência de excesso de peso na população estudada na presente tese, com 20,5\% dos homens e $24,5 \%$ das mulheres com obesidade e com $45,1 \%$ dos homens e $36,6 \%$ das mulheres com sobrepeso. Desta maneira, se observa que a maioria da população estudada (62,9\%) apresentava-se com excesso de peso e somente $37,1 \%$ dos participantes encontravam-se com IMC dentro dos limites da normalidade.

No entanto, apesar desta frequência elevada de excesso de peso, não foi observada maior frequência de obesidade em mulheres portadoras de transtornos de humor, como o descrito previamente na literatura ${ }^{56,60,109}$.

Entre mulheres com transtorno depressivo maior exclusivo foi observado que há menos obesas (10,6\% em mulheres com depressão e 25,7\% em mulheres sem diagnóstico psiquiátrico) e mais portadoras de sobrepeso (51,1\% em deprimidas e 33,1\% em mulheres sem transtorno psiquiátrico) do que as mulheres sem diagnóstico psiquiátrico (tabela 14).

Segundo os critérios diagnósticos do transtorno depressivo maior, o indivíduo pode apresentar aumento ou redução do apetite e/ou ganho ou redução do peso ${ }^{141}$. Caso as mulheres com depressão maior da população estudada apresentem maior freqüência de anorexia (ou redução de peso) isto pode explicar o achado quanto a menor freqüência de 
obesidade neste grupo. Porém, não há dados disponíveis sobre a freqüência de sintomas nesta população para que se comprove ou rejeite esta hipótese.

No entanto, quando as mulheres com depressão maior foram agrupadas na categoria excesso de peso (somando mulheres com obesidade e sobrepeso) utilizada para realização da análise de regressão logística, esta diferença deixa de aparecer, com OR de 1,04 (IC 95\% 0,51-2,13) quando ajustado para idade. Isto significa que, apesar de haver menos obesas, há mais portadoras de sobrepeso entre as mulheres com depressão exclusiva, pois não há diferença de excesso de peso entre mulheres com depressão exclusiva e mulheres sem transtorno psiquiátrico.

A menor freqüência de obesidade entre as mulheres com depressão maior só ocorre nas portadoras que não apresentaram co-morbidade de ansiedade, pois quando foram analisadas mulheres com depressão maior e com ou sem co-morbidade de transtorno ansioso, a diferença não foi demonstrada (20,6\% das mulheres com depressão com ou sem co-morbidade psiquiátrica apresentavam obesidade e $27,2 \%$ das mulheres sem este diagnóstico; $\mathrm{p}=0,29)$.

É possível que a presença de ansiedade se associe a aumento de peso, mudando o perfil de mulheres com co-morbidade depressão e ansiedade em relação às mulheres com depressão exclusiva, pois foi observado neste estudo associação entre ansiedade e excesso de peso em mulheres, como será discutido posteriormente.

Outro resultado interessante a ser discutido é que, apesar de haver menos obesas entre as mulheres com depressão maior exclusiva, a circunferência abdominal média é semelhante entre os grupos (90,0 cm entre as portadoras de depressão e 90,6 cm entre as mulheres sem diagnóstico psiquiátrico, $\mathrm{p}=0,77$ ). A freqüência de circunferência abdominal elevada também é similar entre os grupos $(55,3 \%$ das mulheres com depressão maior e 51,9\% das mulheres sem diagnóstico psiquiátrico, $\mathrm{p}=0,77)$. Desta maneira, é possível observar que o grupo de mulheres com depressão exclusiva apresenta menor percentual de obesas, porém a mesma freqüência de mulheres com circunferência abdominal elevada, demonstrando uma maior gordura abdominal neste grupo.

Isto corrobora dados já observados em estudos prévios. Há descrição de maior deposição de gordura central em mulheres portadoras de depressão maior, levando a maior atividade inflamatória e desta maneira, maior risco cardiovascular ${ }^{160,161}$.

Neste estudo não foi observada maior frequência de obesidade ou excesso de peso entre mulheres com e sem antecedente de transtornos de humor, tanto nas portadoras de transtorno de humor exclusivo, como entre as portadoras de transtorno de humor com ou sem co-morbidade de transtorno ansioso. Este achado é compatível com dados de estudos prévios. Jacka et al. avaliaram 755 mulheres australianas e não encontraram associação entre história de depressão durante a vida e obesidade, com OR de 1,09 (IC 95\% $0,69-1,70)^{107}$. 
Aparentemente, há diferenças entre os diferentes países e as suas culturasinfluenciando a associação entre obesidade e transtornos de humor. Luppino et al. discutem em sua metaanálise que as associações entre obesidade e transtornos de humor são mais frequentes em estudos americanos do que em europeus ${ }^{60}$.

Wiltink et al. avaliaram 4.753 indivíduos alemães entre 35 e 74 anos e observaram que não havia associação entre depressão e obesidade (OR 1,17; IC 95\% 0,87-1,58). Em relação a transtorno de ansiedade generalizada, houve associação com obesidade (OR 1,65; IC 95\% 1,11-2,44). Tais resultados são próximos aos encontrados nesta tese, embora Wiltink et al. não tenha encontrado diferença entre gêneros ${ }^{78}$.

Konttinen et al. discutem a mediação de atividade física e alimentação para a associação entre obesidade e transtorno depressivo ${ }^{162}$. Estes autores observaram que, após o ajuste para estes mediadores, a associação entre obesidade e depressão deixou de ocorrer. Isto pode explicar em parte os resultados observados em nosso trabalho. Afinal, os indivíduos avaliados neste estudo apresentam alta freqüência de atividade física, não havendo maior sedentarismo entre os portadores de transtornos psiquiátricos.

Entre mulheres com antecedente de transtorno de ansiedade exclusivo foi observada uma maior frequência de excesso de peso, após ajuste para idade, com OR de 2,06 (IC 95\% 1,04-4,07). Strine et al. também observaram maior frequência de obesidade em mulheres portadoras de transtorno de ansiedade exclusivo, com OR de 1,2 (IC 95\% 1,101,40) ${ }^{109}$. Os autores encontraram a associação com significância limítrofe entre obesidade e diagnóstico exclusivo de ansiedade em homens, com OR de 1,2 (IC 95\% 1,00-1,40).

Em nosso estudo não foi observada associação entre excesso de peso e transtornos de humor, nem em transtornos de ansiedade, entre homens. Entre homens, as evidências quanto a associação entre obesidade e transtornos de humor e/ou ansiedade são contraditórias. Há resultados positivos ${ }^{60,109}$, estudos que demonstram associação inversa 53,57,58 ou ausência de associação $0^{55,56,59}$.

No entanto, foi observado que homens portadores de transtorno depressivo maior (com ou sem co-morbidade de transtorno de ansiedade) apresentam menor frequência de circunferência abdominal elevada (8,3\% entre portadores de depressão e $24,9 \%$ em indivíduos sem depressão maior, $\mathrm{p}=0,01)$, mesmo sem diferença quanto aos índices de sobrepeso e obesidade. Este resultado é novo na literatura e necessita de novas comprovações, pois pode significar que os homens paulistanos com antecedente de depressão maior apresentem um padrão diferente de deposição corporal de gordura.

Podemos observar que foi encontrada uma frequência de obesidade diferente das observadas nesta tese no município de São Paulo: 15,5\% (IC95\% 12,5-18,6\%) dos homens e 10,7\% (8,5-12,9\%) das mulheres apresentavam obesidade. Segundo dados da população brasileira entre 35-44 anos, 18,5\% (IC95\% 16,0-20,9) dos homens e 11,5\% (IC95\% 9,6$13,3)$ das mulheres apresentam obesidade ${ }^{148}$. Desta maneira, se observa que embora as 
frequências em nosso estudo sejam mais elevadas do que a observada no município, os homens apresentam freqüência esperada para a população brasileira de faixa etária semelhante. No entanto, as mulheres de nossa amostra apresentam maior frequência de obesidade do que os dados populacionais brasileiros. Isto pode ser explicado pelo fato de que o perfil da população estudada é de nível sócio-econômico reduzido, e existem estudos que demonstram uma maior prevalência de obesidade em mulheres em condições de desvantagem sócio-econômica ${ }^{163,164}$.

\subsection{FATORES DE RISCO PARA DOENÇA CARDIOVASCULAR \& TRANSTORNOS DE HUMOR EIOU ANSIEDADE}

\subsubsection{Hipertensão arterial}

A hipertensão arterial é um dos fatores de risco para eventos cardiovasculares mais prevalentes no Brasil e no mundo, com prevalência de acima de $30 \%$ entre adultos ${ }^{165}$.

Foi observada uma freqüência elevada de relato de diagnóstico prévio de hipertensão arterial na população estudada, pois 30\% dos homens e $27,7 \%$ das mulheres afirmaram possuir este diagnóstico, apesar da idade média de 41 anos de nossa amostra e da escassez de participantes idosos. Quando somados os indivíduos com diagnóstico prévio de hipertensão arterial, aqueles que realizavam tratamento para hipertensão e os indivíduos que apresentaram medidas de pressão arterial elevadas no estudo, foram somados $41,6 \%$ dos homens e 34,5\% das mulheres com hipertensão arterial.

Não foi observada associação entre diagnóstico de hipertensão arterial e transtornos de humor e/ou de ansiedade neste estudo. Os resultados de estudos prévios são contraditórios 70-75,107. Nossos resultados corroboram os resultados negativos encontrados. Jacka et al. avaliaram 755 mulheres australianas em estudo de corte transversal e observaram OR ajustado para idade de 1,00 (IC 95\% 0,64-1,54), para associação entre história prévia de depressão e hipertensão arterial ${ }^{107}$. Meyer et al., Shinn et al. e Yan et al. realizaram estudos de coorte prospectiva, com indivíduos sem hipertensão arterial no início do estudo e observaram que não há maior incidência de hipertensão arterial nos portadores de depressão ${ }^{70-72}$.

Segundo os dados do Vigitel 2007, os brasileiros com faixa etária entre 35 e 44 anos apresenta uma freqüência menor de hipertensão arterial do que o observado nesta tese, sendo que 18,1\% (IC 95\% 15,9-20,3\%) dos homens e 20,6\% (IC 95\% 18,4-22,8\%) das mulheres relatavam diagnóstico de hipertensão arterial no Brasil ${ }^{148}$. No entanto, a freqüência de 
hipertensão no município de São Paulo é maior, sendo 21,9\% (IC 95\% 18,4-25,5) em homens e $25,0 \%$ (IC 95\% 22,0-28,0) em mulheres adultas que residem no município (incluindo dados de todas as faixas etárias).

\subsubsection{Diabetes mellitus}

A presença de diabetes mellitus é o fator de risco com maior impacto na incidência de doença cardiovascular, afinal somente a sua presença em um indivíduo já o classifica como de alto risco cardiovascular ${ }^{114}$.

A prevalência de diabetes mellitus tem aumentado no Brasil: 5,2\% da população relatava diagnóstico de diabetes mellitus em 2006 e este percentual subiu para 5,8\% em 2009 ( $p=0,046)$, com aumento significativo entre homens $(p=0,038){ }^{50}$. Esta elevação se deve em parte ao aumento das prevalências de obesidade e excesso de peso observadas no mesmo período (em 2006, a prevalência de obesidade foi de $11,4 \%$ e de excesso de peso de $42,7 \%$, enquanto, em 2009, a prevalência de obesidade foi de $13,9 \%$ e a de excesso de peso de 46,6\%, p<0,001, em ambas comparações).

Foi observado neste estudo que as mulheres portadoras de transtornos de humor ou de depressão maior (quando associadas as mulheres com e sem co-morbidade de transtorno ansioso) apresentam maior freqüência de diabetes mellitus do que as mulheres sem tais diagnósticos. As mulheres portadoras de transtornos de humor apresentam um OR ajustado para idade de 2,46 (IC 95\% 1,03-5,88) quando comparadas a mulheres sem transtorno de humor. Mulheres com depressão maior apresentam OR ajustado para idade de 3,19 (IC 95\% 1,33-7,66) quando comparadas as mulheres sem depressão maior.

As evidências prévias já descreviam a associação entre diabetes mellitus e diagnóstico de transtornos de humor ou depressão maior ${ }^{66-68,166}$, demonstrando que a presença de transtorno depressivo maior aumenta a incidência de diabetes mellitus e que os portadores de diabetes apresentam maior incidência de depressão maior.

Porém, nas análises em que avaliamos as mulheres com transtorno de humor exclusivo e transtorno depressivo exclusivo, não houve diferença entre os grupos com e sem transtorno psiquiátrico. Isto pode ter ocorrido pelo menor número de mulheres, reduzindo o poder para detectar a possível diferença entre os grupos.

Ou ainda, a associação pode ocorrer na população paulista, somente em associação com transtorno de ansiedade, conforme observado no estudo de Engum ${ }^{166}$. Em coorte norueguesa, Engum avaliou 37.291 participantes, com seguimento de 10 anos, e observou que nos indivíduos com co-morbidade entre depressão e ansiedade havia maior incidência de diabetes em ambos os gêneros (OR 1,59; IC 95\% 1,24-2,04 em mulheres e OR 1,42; IC 95\% 1,11-1,84 em homens, com ajuste para idade, nível educacional e estado civil). Porém, 
não observou associação com diabetes em portadores de sintomas ansiosos ou depressivos em separado ${ }^{166}$.

A associação entre diabetes mellitus e transtornos de humor ou depressão (com ou sem co-morbidade de transtorno de ansiedade) em nosso estudo ocorre, mas não se associa a uma maior frequência de obesidade nos grupos com transtorno psiquiátrico, uma vez que não há maior freqüência de obesas no momento do estudo no grupo com diagnóstico psiquiátrico. Isto levanta a questão se a obesidade é ou não um mediador na associação entre diabetes e transtornos de humor ou transtorno depressivo maior.

Andersohn et al. realizaram estudo caso-controle aninhado em coorte no Reino Unido e avaliaram 2.243 casos e 8.963 controles pareados. Os autores observaram que indivíduos que utilizaram antidepressivo em doses moderadas a altas por período prolongado (maior de 24 meses) apresentaram maior risco de diabetes incidente com OR de 1,84 (IC 95\% 1,35-2,52), com associação tanto para uso de antidepressivos tricíclicos, como para antidepressivos inibidores de recaptação de serotonina ${ }^{167}$. Não houve associação entre diabetes e uso de antidepressivos em tratamentos por períodos mais curtos.

Não há como realizar análise semelhante neste estudo, pois não há dados sobre o uso de antidepressivos, nem sobre sua duração. Porém, o uso de medicamentos antidepressivos pode ser uma explicação possível para a associação entre diabetes e transtornos de humor neste estudo.

Timonen et al. avaliaram 2.609 homens finlandeses e observaram que os portadores de sintomas depressivos apresentavam maiores taxas de resistência insulínica, apesar de apresentarem mesmo IMC, mesmos níveis de glicemia, colesterol total e proteína $\mathrm{C}$ reativa ultra-sensível ${ }^{168}$. Portanto, a depressão pode estar associada a estados de maior resistência insulínica, levando a maior desenvolvimento posterior de diabetes mellitus em indivíduos predispostos.

Não foi observado em nosso estudo a associação entre diabetes mellitus e transtornos de humor ou depressão entre os homens, contrariando as evidências prévias ${ }^{66-68}$. Tal resultado pode ser explicado pela menor amostra de homens com diagnóstico de depressão maior e/ou transtornos de humor, reduzindo assim o poder de nosso estudo para detectar uma possível diferença.

Outra explicação pode ser relacionada às diferenças de gênero na associação entre diabetes e depressão e transtornos de humor na população brasileira, afinal os homens com depressão maior neste estudo apresentaram menor freqüência de circunferência abdominal elevada, o que se associa a menor resistência insulínica e, conseqüentemente, a menores freqüências de diabetes mellitus.

Ao contrário do esperado (devido a média de idade relativamente jovem desta amostra), a freqüência de diagnóstico prévio de diabetes mellitus é elevada na população estudada. Foram encontrados 7,4\% de homens diabéticos e 6,0\% de mulheres diabéticas 
em nosso estudo. Quando somados os indivíduos com diagnóstico prévio de diabetes mellitus, aqueles que realizam tratamento para diabetes e os indivíduos que apresentaram medida de glicemia elevada no estudo, foram somados $8,2 \%$ dos homens e $6,5 \%$ das mulheres com diabetes mellitus.

No município de São Paulo, as taxas de prevalência são de 5,0\% (IC 95\% 3,5-6,5) para homens e 6,7\% (IC 95\% 5,1-8,2) das mulheres, incluídos indivíduos de todas as faixas etárias. A freqüência encontrada na população brasileira entre 35-44 anos foi de 2,7\% (IC 95\% 1,9-3,4) nos homens e 3,1\% (IC 95\% 2,1-4,0) nas mulheres ${ }^{148}$. Desta maneira podemos observar que a população estudada apresenta uma freqüência mais elevada de diabetes mellitus do que a população geral da mesma faixa etária.

\subsubsection{Dislipidemia}

As dislipidemias são desordens metabólicas associadas ao aumento do risco de eventos cardiovasculares e que, em parte, estão relacionadas com o aumento da prevalência de obesidade e com maior consumo de gorduras saturadas e colesterol na dieta habitual ${ }^{64,77}$.

Nos homens não foi observada associação entre dislipidemia e diagnóstico de transtorno de humor e/ou de ansiedade. Somente nos portadores de transtorno de humor exclusivo, foi observado que entre homens havia menor percentual de indivíduos com hipertrigliceridemia do que entre os indivíduos sem transtornos psiquiátricos (12,9\% entre portadores de transtornos de humor e 32,1\% entre indivíduos sem diagnóstico psiquiátrico, $\mathrm{p}=0,046)$. No entanto, ao realizar a regressão logística esta diferença desaparece após o ajuste por idade, com OR de 0,33 (IC 95\% 0,11-1,04).

Entre as mulheres portadoras de transtorno de humor exclusivo, foi observada uma média de colesterol total maior do que entre as mulheres sem transtorno psiquiátrico (201,8 mg/dl entre mulheres com transtorno de humor e 188,1 mg/dl entre mulheres sem diagnóstico psiquiátrico, $\mathrm{p}=0,035)$. No entanto, ao serem criadas as categorias binárias para regressão logística, sendo considerado como alterado colesterol total acima de 200 $\mathrm{mg} / \mathrm{dl}$ e comparado com os valores normais, esta diferença deixa de existir, com OR ajustado para idade de 1,11 (IC 95\% 0,58-2,14).

Também foi observado entre as mulheres com transtornos de humor exclusivo, uma maior frequência de LDL-colesterol alterado (com significância limítrofe), porém este resultado também deixa de existir após ajuste para idade (OR 2,22; IC 95\% 0,96-5,15). O mesmo ocorre entre as mulheres portadoras de transtornos de humor com ou sem comorbidade de transtorno ansioso, sendo observada maior frequência de LDL-colesterol elevado, que desaparece após ajuste para idade (OR 1,63; IC 95\% 0,94-2,83).

No entanto, entre mulheres portadoras de depressão maior exclusiva foi observada 
maior frequência de portadoras de LDL-colesterol elevado (OR 2,40; IC 95\% 1,05-5,50), com diferença que permanece após ajuste para idade, com OR de 2,43 (IC 95\% 1,01-5,87). O mesmo é observado entre as mulheres com depressão maior com ou sem co-morbidades de ansiedade, com OR de 1,80 (IC 95\% 1,04-3,11).

Há diversas controvérsias na literatura quanto a associação entre dislipidemia e transtornos de humor, com resultados discrepantes ${ }^{78-80,82-87}$. Porém, Wiltink et al. avaliaram 4.753 indivíduos alemães e observaram associação entre depressão e dislipidemia (OR 1,35; IC 95\% 1,02-1,79). Em relação a transtorno de ansiedade generalizada, não houve associação com dislipidemia (OR 1,02; IC 95\% 0,69-1,51) ${ }^{78}$. Estes resultados são bastante próximos aos encontrados nesta tese.

Há possibilidade que a associação entre LDL-colesterol elevado e depressão maior seja uma peculiaridade da população brasileira. Há ainda relatos de que elevações nos níveis de LDL-colesterol possam ser causadas pelo uso de alguns antidepressivos, em especial a paroxetina e a sertralina, e que estes níveis se normalizem após a retirada do medicamento ${ }^{169}$. Como não há dados sobre uso de medicação antidepressiva neste estudo, não podemos analisar se esta explicação se associa com o aumento de LDL-colesterol encontrado em mulheres com depressão.

Não foi observada associação entre dislipidemias e transtornos de ansiedade entre as mulheres estudadas, nem entre mulheres com transtorno de ansiedade exclusivo, nem entre as mulheres com co-morbidade de ansiedade e transtorno de humor. Estes achados corroboram os resultados de alguns estudos ${ }^{78,86,87}$.

Foi observada uma frequência elevada de dislipidemias na população estudada, pois foi observado que 21,8\% dos participantes apresentavam LDL-colesterol elevado, 28,6\% apresentavam HDL-colesterol reduzido e 22,4\% apresentavam níveis de triglicérides aumentados. Isto pode estar associado ao fato de haver mais indivíduos com excesso de peso em nossa amostra do que o esperado para população geral ( $23 \%$ da população estudada apresentava-se em níveis de IMC de obesidade, 39,9\% com níveis de sobrepeso e 41,9\% apresentava circunferência abdominal alterada).

Gigante et al. avaliaram dados provenientes de 49.395 indivíduos participantes do estudo Vigitel 2006 e observaram uma prevalência de dislipidemia auto-referida de 11\% em indivíduos com IMC normal $\left(<25 \mathrm{~kg} / \mathrm{m}^{2}\right), 22,1 \%$ em indivíduos com sobrepeso (IMC de 25 a 29,9 kg/m²), 28,6\% em indivíduos portadores de obesidade grau 1 (IMC de 30 a $34,9 \mathrm{~kg} / \mathrm{m}^{2}$ ) e $29,7 \%$ em obesos grau 2 ou mais (IMC a partir de $35 \mathrm{~kg} / \mathrm{m}^{2}$ ) ${ }^{163}$. A razão de prevalência ajustada (utilizando indivíduos com IMC normal como referência) foi de 1,69 (IC 95\% 1,54-1,85) para portadores de sobrepeso, de 2,09 (IC 95\% 1,86-2,35) para portadores de obesidade grau 1 e de 2,14 (IC95\% 1,68-2,73) para portadores de obesidade grau 2 ou 3. 


\subsubsection{Síndrome metabólica}

A síndrome metabólica é uma entidade relativamente recente, descrita por Heaven em 1985, que agrega diversos fatores de risco cardiovascular e que apresentam a obesidade abdominal e a hiperinsulinemia como substrato fisiopatológico comum. Porém, há discussão se o reconhecimento da síndrome agrega um risco maior de eventos cardiovasculares ao risco associado aos fatores isoladamente ${ }^{170}$.

Não foi observada maior freqüência de síndrome metabólica entre indivíduos portadores de transtornos de humor e/ou de ansiedade em ambos os gêneros. Tal achado é surpreendente entre as mulheres, pois há vasta literatura demonstrando associação entre depressão e síndrome metabólica neste gênero ${ }^{95-98}$, principalmente, tendo em vista o achado de maior frequência de diabetes mellitus entre portadoras de transtornos de humor e de depressão maior nesta tese.

No entanto, a ausência de associação entre depressão e síndrome metabólica em homens é amplamente comprovada ${ }^{96,97,99,171,172}$, embora a associação com ansiedade seja controversa ${ }^{99,171,172}$.

Herva et al. avaliaram 5.698 indivíduos provenientes de coorte finlandesa de indivíduos nascidos em 1966 e, em avaliação transversal, não foi observada associação entre síndrome metabólica e sintomas ansiosos e depressivos ${ }^{171}$. Hildrum et al. avaliaram em estudo transversal 9.571 indivíduos noruegueses e também não observaram nenhuma associação entre síndrome metabólica e sintomas depressivos e/ou ansiosos ${ }^{172}$.

Dortland et al. avaliaram 1.217 indivíduos portadores de depressão e/ou ansiedade e observaram que não há associação entre ansiedade e síndrome metabólica (OR 1,04; IC 95\% 0,71-1,54), nem entre depressão e síndrome metabólica (OR 1,12; IC 95\% 0,76-1,66). No entanto, quando avaliada a gravidade da depressão, os portadores de casos muito graves apresentaram maior freqüência de síndrome metabólica (OR 2,21; IC 95\% 1,06-4,64). Porém esta associação não foi observada entre casos leves, moderados ou graves. Também foi observada associação entre síndrome metabólica e uso de antidepressivos tricíclicos (OR 2,30; IC 95\% 1,21-4,36) ${ }^{173}$.

A maior parte dos estudos que discutem a associação entre síndrome metabólica e transtornos de humor e/ou de ansiedade, não descreve a gravidade de seus casos. Isto pode explicar a heterogeneidade de resultados encontrados.

Porém, há poucos estudos que avaliaram associação entre síndrome metabólica e transtornos ansiosos, tanto em homens quanto em mulheres, com a maior parte destes com resultados negativos ${ }^{95,171,172}$. Carroll et al. avaliaram 4.256 homens militares veteranos da Guerra do Vietnã e observaram associação positiva entre transtorno de ansiedade generalizada e síndrome metabólica (OR 1,39; IC 95\%: 1,02-1,89). Neste mesmo estudo foi observado ausência de associação entre depressão maior e síndrome metabólica ${ }^{99}$. 
Entre mulheres, Raikkonen et al. avaliaram 432 mulheres na pré-menopausa em coorte prospectiva com seguimento de 15 anos e observaram ausência de associação entre sintomas ansiosos e síndrome metabólica ${ }^{95}$.

A presença de tamanha controvérsia nas evidências demonstra que a associação entre síndrome metabólica e transtornos de humor e/ou ansiedade possivelmente apresentam peculiaridades sócio-demográficas e/ou culturais na sua determinação, que resultam em variabilidade entre as diversas populações estudadas, de diferentes países.

Vogelzangs et al. avaliaram 867 participantes idosos do InChianti Study e observaram associação entre depressão e síndrome metabólica, somente naqueles indivíduos que apresentavam maiores níveis de cortisol (OR 1,84; IC 95\% 1,02-3,34) ${ }^{103}$. Isto demonstra que há certa heterogeneidade entre os indivíduos com depressão, que pode estar associado com a síndrome metabólica ou não.

Na população estudada neste estudo houve uma freqüência próxima a outros estudos de síndrome metabólica: 29,2\% dos homens e 30,5\% das mulheres ( $\mathrm{P}=0,79)$. Apesar de não haver estudos sobre a prevalência nacional de síndrome metabólica, um estudo da área metropolitana de São Paulo observou prevalência de 36,6\% (Silva et al.) ${ }^{92}$. Barbosa et al. avaliaram 1424 indivíduos moradores de Salvador - BA e observou uma frequência de síndrome metabólica de $23 \%$ nesta população ${ }^{94}$.

\subsubsection{Proteína C reativa ultra-sensível}

A dosagem de proteína C reativa (PCR) ultra-sensível demonstra o nível de inflamação sistêmica dos indivíduos e tem sido debatida como estratégia adicional na estratificação de risco cardiovascular ${ }^{116,122}$.

Foi observado em nosso estudo que as mulheres portadoras de transtornos de humor e/ou de ansiedade apresentam menores níveis de PCR do que as mulheres sem tais diagnósticos. As mulheres portadoras de transtornos de humor apresentam tanto menores níveis médios de PCR (2,4 mg/dl entre portadoras de transtornos de humor e 3,3 $\mathrm{mg} / \mathrm{dl}$ entre mulheres sem diagnóstico psiquiátrico, $\mathrm{p}=0,038$ ), quanto a menor frequência de mulheres classificadas como alto risco cardiovascular $(26,8 \%$ entre mulheres com transtornos de humor e 47,9\% entre mulheres sem diagnóstico psiquiátrico, $\mathrm{p}=0,007$ ).

O mesmo é observado entre mulheres com depressão maior (26,1\% entre mulheres com depressão e 47,9\% entre mulheres sem diagnóstico psiquiátrico, $\mathrm{p}=0,005$ ) e portadoras de transtornos de ansiedade (25,4\% entre mulheres com transtornos de ansiedade e $47,9 \%$ entre mulheres sem diagnóstico psiquiátrico, $\mathrm{p}=0,01$ ).

Quando foi realizada a regressão logística binária, foi optado por categorizar a classificação pelo PCR em baixo risco $(<1 \mathrm{mg} / \mathrm{dl}$ ) e risco elevado (maior ou igual a $1 \mathrm{mg}$ / 
dl). Em todas as análises, desaparece a diferença. Mulheres com transtorno de humor apresentam OR ajustado para idade de 1,02 (IC 95\% 0,51-2,05) para PCR elevado, portadoras de depressão maior apresentam OR ajustado para idade de 1,16 (IC 95\% 0,542,50) e portadoras de transtorno de ansiedade apresentam OR ajustado para idade de 0,60 (IC 95\% 0,32-1,15). Portanto, se a diferença desaparece com esta maneira de agrupar as categorias, isto significa que as diferenças se baseavam entre a maior frequência de portadores de alto risco em comparação com os portadores de médio e baixo risco.

Não foi observada associação entre níveis de PCR e transtornos de ansiedade e/ou humor entre homens, em nenhuma das análises realizadas, o que contradiz a literatura prévia ${ }^{125-127}$. Há diversos estudos que demonstram um maior nível de PCR em homens portadores de depressão maior, porém o mesmo não é observado entre mulheres ${ }^{125-127}$. Os estudos também evidenciam que esta associação ocorre quando o episódio depressivo é recente (menos de um ano), porém desaparece em indivíduos com quadro de depressão mais antigo ${ }^{126,127}$. Talvez isto explique a ausência de associação observada em nossa população masculina. O instrumento utilizado para o estudo (o SCID-I NP) é um instrumento para diagnóstico de transtornos psiquiátricos durante a vida, podendo diagnosticar episódios antigos.

Além disso, a amostra masculina de portadores de transtornos de humor e de depressão maior foi menor (61 homens com transtornos de humor e 48 homens com depressão maior) do que entre as mulheres, podendo reduzir o poder do estudo para detectar uma diferença que possa existir.

Outra explicação possível é a alta frequência de atividade física entre os participantes deste estudo. Há estudos que evidenciam que maiores níveis de atividade física se associam a menores níveis de PCR ${ }^{124}$. Portanto, o fato de que 85,9\% dos homens e $84,0 \%$ das mulheres (sem diferença entre os grupos de indivíduos com e sem transtorno psiquiátrico) são fisicamente ativos pode estar associado a menores níveis de PCR do que o esperado.

No entanto, o resultado encontrado entre as mulheres não apresenta nenhuma confirmação em evidências anteriores. Nenhum estudo foi encontrado com associação de menores níveis de PCR entre mulheres com transtornos de humor e/ou ansiedade.

Uma explicação possível para tal achado seja que as mulheres sem diagnóstico psiquiátrico que aceitaram participar deste estudo apresentem outras co-morbidades que apresentem inflamação sistêmica e elevem o PCR. Almeida et al. avaliaram 5.438 idosos homens e observaram que a associação entre depressão e níveis de PCR deixam de existir após ajuste para co-morbidades e avaliação ruim do estado de saúde ${ }^{130}$.

Há dois estudos que apresentam resultados próximos ao encontrado, mas não totalmente semelhantes, pois avaliam outros marcadores inflamatórios, porém não o PCR. Baune et al. avaliaram 4.181 indivíduos alemães e encontraram em homens com depressão maior menores níveis de marcadores inflamatórios como ferritina, 
transferrina e fibrinogênio do que entre homens sem depressão maior. No entanto, não houve diferença entre as mulheres ${ }^{174}$. Podlipny et al. avaliaram 43 participantes tchecos em estudo caso-controle, sendo que 27 indivíduos apresentavam muitos sintomas depressivos e 16 indivíduos apresentavam poucos sintomas depressivos ${ }^{175}$. Foi observado que apesar do IMC e da circunferência abdominal serem similares nos grupos, havia menores níveis de interleucina-6 no grupo com maiores níveis de sintomas depressivos $(\mathrm{p}=0,049)$.

No entanto, há necessidade de confirmação destes resultados com estudos prospectivos na população brasileira.

\subsubsection{Escore de risco de Framingham}

O escore de risco de Framingham (ERF) é um instrumento de estratificação de risco baseado nos principais fatores de risco associado às doenças cardiovasculares: idade, nível de colesterol total, nível de HDL-colesterol, níveis de pressão arterial, presença de tabagismo e de diabetes mellitus. O escore de risco de Framingham evidencia a agregação de fatores de risco cardiovascular, além de predizer eventos cardiovasculares ${ }^{111,112,115}$.

Não foi observado diferenças na classificação de risco de Framingham entre indivíduos com e sem transtornos de humor e/ou de ansiedade na população estudada, em ambos os gêneros. Como no modelo do ERF a variável de maior peso é a idade, há possibilidade de que a média de idade jovem de nosso estudo seja em parte responsável pela ausência de associação.

Apesar da idade média da população deste estudo, foi observada uma alta frequência de fatores de risco cardiovascular, como hipertensão arterial, diabetes mellitus, dislipidemias e obesidade. Mesmo com esta frequência elevada de fatores de risco, não foi observada uma maior agregação destes em portadores de transtornos psiquiátricos.

Existem poucos estudos sobre a utilização do ERF em pacientes com transtornos psiquiátricos. Jin et al. avaliaram 179 pacientes com sintomas psicóticos provenientes de serviços de psiquiatria e observaram um risco mais elevado, com um aumento de $79 \%$ (IC 95\% 50-107\%) em portadores de esquizofrenia, 72\% (IC 95\% 34-109\%) nos portadores de transtorno de estresse pós-traumático, 61\% (IC 95\% 36-86\%) em portadores de transtornos de humor, porém sem aumento de risco em portadores de demência ${ }^{176}$.

Goff et al. avaliaram 1.493 indivíduos portadores de esquizofrenia, comparandoos com os achados do NHANES III, e observaram risco cardiovascular elevado entre os portadores de esquizofrenia (estes apresentavam maiores frequências de tabagismo, hipertensão, diabetes, além de menores níveis de HDL-colesterol). O risco estimado foi $34 \%$ maior entre homens e 50\% maior em mulheres com esquizofrenia ${ }^{177}$. 
No entanto, vale ressaltar que os resultados encontrados em amostra de população com esquizofrenia apresentam perfil cardiovascular mais grave do que a população deste estudo, que abrange transtornos de humor e de ansiedade.

Koponen et al. avaliaram 923 indivíduos de meia idade em estudo de corte transversal e observaram associação entre sintomas depressivos e maior escore de risco de Framingham em homens (OR 2,2; IC 95\% 1,1-4,2), porém sem associação em mulheres (OR 1,3; IC 95\% 0,7-2,6) ${ }^{178}$. Estes resultados são conflitantes com os achados deste estudo, no entanto, a idade média dos participantes do estudo de Koponen et al. era maior, além de ser um estudo realizado em outro país.

As frequências encontradas de homens de alto, médio e baixo risco cardiovascular são bastante diferentes de outros estudos brasileiros ou mesmo internacionais ${ }^{116}$. Foi observado que, entre os homens, 74,1\% apresentavam baixo risco, 23,9\% médio risco e $2,0 \%$ alto risco classificados pelo ERF. Entre as mulheres, $97,1 \%$ apresentavam baixo risco e 2,9\% médio risco, sem que nenhuma participante tenha sido classificada como alto risco cardiovascular pelo ERF.

Embora a idade média desta amostra seja razoavelmente jovem, nossos achados entre os homens são de pior perfil de risco cardiovascular do que em estudos prévios brasileiros ${ }^{117,118,120}$. Este achado pode ser explicado pelo fato de 5,7\% dos homens e 4,7\% das mulheres da população estudada (sem diferença entre os gêneros, $\mathrm{p}=1,0$ ) nesta tese terem relatado evento cardiovascular prévio.

$\mathrm{O}$ único estudo brasileiro com perfil pior do que o encontrado nesta tese foi o estudo de Matos e Ladela et al., que estudaram a população rural do Estado da Bahia ${ }^{119}$, com características bastante diferentes da nossa população.

\subsection{PERFIL SÓCIO-DEMOGRÁFICO \& TRANSTORNOS DE HUMOR E/OU ANSIEDADE}

A população estudada na segunda fase do Inquérito de Saúde Mental São Paulo Megacity é de adultos residentes na região da Grande São Paulo, sendo que 243 (38,8\%) indivíduos do sexo masculino e 383 (61,2\%) indivíduos do sexo feminino foram analisados neste estudo. O percentual de homens é menor devido à reduzida aceitação em participar do estudo, o que reflete a diferença de gênero na procura por serviços preventivos (pois é conhecido que as mulheres utilizam mais os serviços de saúde quando não há queixas agudas) ${ }^{181,182}$.

A população adulta estudada nesta tese apresenta uma representação das faixas etárias diferente da observada no município de São Paulo, pois existe uma representação 
reduzida dos extremos etários (indivíduos entre 18-24 anos e indivíduos com 65 anos ou mais). Tal diferença pode estar relacionada ao fato da amostra ter avaliado moradores dos municípios do entorno, que apresentam pirâmide etária diferente da encontrada no município de São Paulo (tabela 43). Porém, outros fatores que influenciam a faixa etária ser diferente da população é efeito da seleção da amostra e da taxa de participação ter sido reduzida, afinal, somente 52,2\% (1471/2820) dos indivíduos selecionados foram efetivamente contatados para oferecimento para segunda fase do estudo e dentre os contatados, somente 53\% (780/1471) aceitaram participar.

A população estudada apresenta perfil semelhante de escolaridade ao descrito para o município de São Paulo, com discreta frequência maior de indivíduos que tem nove a onze anos de estudo, em detrimento de pessoas com zero a oito anos de estudo (tabela 43). Desta maneira podemos observar que o perfil de escolaridade de nossa amostra é próximo ao perfil da população do município.

De acordo com a média da renda familiar mensal referida, podemos ressaltar que o perfil dos indivíduos participantes é de nível sócio-econômico reduzido, pois, em 2007, o valor do salário mínimo era de $\mathrm{R} \$ 380,00{ }^{183}$ e a renda média familiar referida foi de R\$1.349,00, o que corresponde a 3,5 salários mínimos. Segundo a Pesquisa Nacional por Amostra de Domicílios (PNAD), com dados referentes a pesquisa realizada em 2008, cerca de $54 \%$ da população urbana brasileira recebe 3 salários mínimos ou menos por pessoa empregada ${ }^{179}$. Logo, se em nossa amostra apresenta média de 3,5 salários mínimos de renda familiar, e não per capita como o avaliado no PNAD, podemos afirmar que se trata de uma população de nível sócio-econômico reduzido. Segundo a mesma pesquisa, a média de indivíduos que habitam o mesmo domicílio chega a 3,5.

Entre as mulheres portadoras de transtorno depressivo maior exclusivo, apesar da mesma idade média e mesma escolaridade, foi encontrada uma menor renda mensal familiar do que entre as mulheres sem diagnóstico psiquiátrico. Tal achado pode ser explicado tanto pelo impacto da doença na função laborativa do indivíduo ${ }^{141} \mathrm{e}$, desta maneira, coma redução da renda mensal familiar, como também pode ser explicado de maneira inversa: piores condições de vida podem ser um gatilho para a depressão maior. Há estudos prévios na literatura que evidenciam associação entre transtornos depressivos e menor nível sócio-econômico ${ }^{180}$. Foi realizado inquérito de saúde mental em Ontario (Canadá), com um total de 12.376 participantes e observado que o aumento da renda se associa inversamente com a frequência de transtornos depressivos. Indivíduos com renda familiar anual maior do $\$ 30.000$ apresentam OR 0,82 (IC 95\% 0,74-0,90) quando comparados com indivíduos com renda menor ${ }^{180}$.

A população estudada apresenta diferenças no estado civil entre os gêneros. Os homens são casados mais freqüentemente que as mulheres (73,9\% vs. 57,0\%) e as mulheres são mais freqüentemente viúvas, separadas ou divorciadas ( $21,1 \%$ vs. $8,7 \%)$. No entanto, 
apesar de haver evidências prévias de que indivíduos separados ou divorciados apresentam maior risco de transtornos depressivos ${ }^{180}$, isto não foi observado neste estudo. Não houve diferenças de estado civil entre os grupos com e sem transtornos psiquiátricos.

\section{* TABELA 43}

Características sócio-demográficas da população de estudo e da população do município

\begin{tabular}{lcc}
\hline $\begin{array}{l}\text { Faixa etária } \\
\text { (anos) }\end{array}$ & $\begin{array}{c}\text { População do } \\
\text { município de SP }\end{array}$ & $\begin{array}{c}\text { População do } \\
\text { estudo }\end{array}$ \\
\hline $18-24$ & $19,8 \%$ & $8,9 \%$ \\
$25-34$ & $25,1 \%$ & $20,6 \%$ \\
$35-44$ & $21,4 \%$ & $31,2 \%$ \\
$45-54$ & $15,3 \%$ & $29,3 \%$ \\
$55-64$ & $9,2 \%$ & $10,0 \%$ \\
65 ou mais & $9,2 \%$ & $0 \%$ \\
Gênero & & \\
Feminino & $53,5 \%$ & $57,1 \%$ \\
Masculino & $46,5 \%$ & $42,9 \%$ \\
Anos de escolaridade (anos) & & $46,0 \%$ \\
$0-8$ & $54,5 \%$ & $35,1 \%$ \\
$9-11$ & $27,4 \%$ & $17,9 \%$ \\
12 ou mais & $18,1 \%$ & \\
\hline
\end{tabular}

Fonte: VIGITEL $2007^{148}$, retirado do CENSO 2000

\subsection{FORÇAS E LIMITAÇÕES DO ESTUDO}

Este estudo é o único estudo brasileiro que avalia os fatores de risco cardiovascular em amostra comunitária de indivíduos, selecionados a partir de um inquérito de saúde mental. Não há nenhum estudo na população brasileira, nem no município de São Paulo, sobre fatores de risco para doenças cardiovasculares em portadores ambulatoriais de transtorno depressivo e/ ou de ansiedade, havendo somente estudos utilizando amostras de conveniência (usuários de ambulatórios, hospitais ou ainda pacientes internados).

Além disso, não foi utilizado somente o relato de diagnósticos prévios dos fatores de risco como instrumento de avaliação. Foram realizadas medidas antropométricas padronizadas e medidas laboratoriais para avaliação dos diagnósticos dos fatores de risco, 
além do relato dos participantes. Dessa maneira, não há sub-estimativa dos fatores de risco para doença cardiovascular, nem a possibilidade da influência da falta de acesso a serviços de saúde para realização do diagnóstico desses fatores de risco cardiovascular.

O diagnóstico psiquiátrico foi realizado por psiquiatras treinados utilizando o SCID-I NP, que atualmente é considerado o padrão-ouro dos instrumentos de avaliação psiquiátrica. A maior parte dos estudos prévios que avaliam a associação entre transtornos de humor ou de ansiedade utiliza questionários auto-aplicados ou entrevistas aplicadas por profissionais que não pertencem à área da saúde. Desta maneira, a acurácia do diagnóstico psiquiátrico na segunda fase do Inquérito de Saúde Mental São Paulo Megacity é muito elevada.

Por se tratar de um estudo em duas etapas, sendo que a primeira foi realizada no domicílio dos participantes e a segunda etapa em ambiente hospitalar, no Instituto de Psiquiatria do Hospital das Clínicas da Faculdade de Medicina da Universidade de São Paulo, as taxas de participação são menores na segunda fase do que na primeira.

O objeto desta tese é a segunda fase do estudo e, por se tratar de avaliação em ambiente hospitalar, é necessário deslocamento do participante. Na primeira fase do estudo, 81,3\% dos indivíduos convidados aceitaram participar ${ }^{132}$. Porém, na segunda fase, somente 53\% dos que foram convidados a participar aceitaram (ou seja, 780 indivíduos dos 1.471 convidados contatados). Portanto, devido a taxa de recusa ser maior, esta amostra não tem as características de ser uma amostra populacional representativa da população da região da Grande São Paulo, sendo uma das limitações deste estudo.

Não há estudos que avaliem a população da região da Grande São Paulo como um todo e que tenha como enfoque principal o diagnóstico de transtornos psiquiátricos e fatores de risco cardiovascular. Por isso, as comparações feitas na discussão dos resultados foram realizadas com dados do município de São Paulo, o que é uma das limitações deste estudo.

Outra limitação do presente estudo é o delineamento de corte transversal. Isto implica no fato de que não há determinação da causalidade entre as associações.

Quanto a avaliação de fatores de risco para doença cardiovascular, foi optado por não realizar avaliação de todos os fatores de risco existentes, pois se trata de um número muito extenso e de maior dificuldade na avaliação (por exemplo, síndrome da apnéia obstrutiva do sono, avaliação de escore de cálcio coronariano). Portanto foi optado por focar nos fatores de risco clássicos, com maior suporte na literatura. Uma limitação deste estudo foi não avaliar a alimentação dos participantes, devido a importância deste fator de risco na determinação da doença cardiovascular.

Outra limitação do estudo se trata da ausência de confirmação dos resultados dos exames laboratoriais. Nem todos participantes que apresentaram resultados alterados aceitaram realizar uma nova medida laboratorial, portanto, devido ao fenômeno de regressão à média, pode haver uma discreta superestimativa das alterações laboratoriais. Também não houve a possibilidade de realizar nova medida de pressão arterial dos 
participantes em um dia diferente, conforme preconizado pelas diretrizes ${ }^{69}$, pois cada participante realizou somente uma visita ao Instituto de Psiquiatria do Hospital das Clínicas da Faculdade de Medicina da USP.

\subsection{CONSIDERAÇÕES FINAIS}

Há um provável excesso de mortalidade cardiovascular em pacientes portadores de transtornos de humor e de ansiedade quando comparados à população geral. Os transtornos de humor e de ansiedade possivelmente aumentam a incidência de eventos cardiovasculares, no entanto, esta associação é mediada por diversos fatores: pobreza e desigualdade social, dificuldades de acesso a cuidados de saúde, alterações neurohumorais e sistêmicas (inflamação aumentada, hipercortisolismo, hiperatividade simpática, disfunção endotelial), influência genética e maior freqüência de alguns fatores de risco cardiovascular nos portadores de transtornos psiquiátricos.

A parcela desta associação que pode ser mediada por fatores de risco cardiovasculares (diabetes mellitus, hipertensão arterial, obesidade, nível de atividade física, entre outros) apresenta-se em frequências diversas nas diferentes populações, devido à influência cultural nos hábitos de vida, na produção laboral e na vida social. Portanto, estudos americanos ou europeus não refletem os hábitos e modus operandi de vida da população brasileira, o que provavelmente sucederão a padrões diferentes de morbi-mortalidade.

Como observado neste estudo, nos indivíduos estudados provenientes da população da Grande São Paulo, os transtornos de humor e/ou de ansiedade não se associam a maior inatividade física, nem a maiores frequências de obesidade, o que contrasta com o observado na literatura internacional. Além disso, esta amostra apresentou também altos níveis de atividade física, porém também altos níveis de hipertensão arterial.

Seriam necessários mais estudos com enfoque nas associações entre transtornos de humor e de ansiedade com doença cardiovascular no Brasil, tanto para confirmar o excesso de mortalidade no Brasil (pois o único estudo brasileiro é entre psicóticos ${ }^{18}$, que demonstra maior razão de mortalidade padronizada), como para confirmar as associações encontradas neste estudo. A realização de uma coorte prospectiva possibilitaria as respostas, desde que avaliados todos os diversos fatores que mediam a possível associação entre doença cardiovascular e transtornos de ansiedade e de humor: nível sócio-econômico, condições de vida na infância, acesso e uso de serviços de saúde (incluindo a qualidade da atenção à saúde prestada), hábitos de vida, adesão a tratamentos medicamentosos e nãomedicamentosos, além do surgimento dos fatores de risco cardiovasculares e dos eventos cardiovasculares. 
No entanto, embora seja se extrema importância avaliar todos os fatores que interferem na associação entre doença cardiovascular e transtornos de humor e de ansiedade, há uma necessidade mais premente. É freqüente o preconceito do profissional de saúde frente aos portadores de transtornos mentais, levando a um julgamento de que ações de prevenção ou de tratamento às doenças clínicas nestes usuários sejam de menor importância. Há que se investir na educação dos profissionais de saúde focando na atenção integral ao portador de transtorno de humor e de ansiedade, principalmente no rastreamento e no manejo das co-morbidades entre doenças psiquiátricas e doenças sistêmicas, principalmente das doenças cardiovasculares. 



\section{CONCLUSÕES}

\subsection{CONCLUSÃO PRINCIPAL}

Há associação entre a presença de alguns fatores de risco para doença cardiovascular e transtornos de humor (inclusive depressão maior) e transtornos de ansiedade em participantes do Inquérito de Saúde Mental São Paulo Megacity.

\subsection{CONCLUSÕES SECUNDÁRIAS}

\section{Estilo de vida \& transtorno de humor e/ou transtorno de ansiedade.}

Há diferenças quanto ao estilo de vida, com uma maior freqüência de tabagismo entre mulheres portadoras de transtorno de humor e de depressão maior e menor freqüência de tabagismo entre homens portadores de transtornos de ansiedade. No entanto, não foi observado diferentes níveis de atividade física entre portadores de transtornos de humor e/ou de ansiedade quando comparados a população sem tais diagnósticos.

\section{Alterações em medidas antropométricas \& transtorno de humor e/ou transtorno de ansiedade}

Foram observadas algumas diferenças quanto as medidas antropométricas em portadores de transtornos de humor e/ou ansiedade. Foi observado que as mulheres com depressão maior apresentam menor freqüência de obesidade e maior freqüência de sobrepeso do que as mulheres sem depressão. Houve maior freqüência de excesso de peso em mulheres portadoras de transtornos de ansiedade. Foi encontrada menor frequência de circunferência abdominal alterada em homens com depressão maior. 


\section{Fatores de risco para doença cardiovascular \& transtorno de humor e/ou transtorno de ansiedade.}

Foi observada associação entre alguns fatores de risco cardiovascular e diagnóstico de transtornos de humor e/ou ansiedade. As mulheres portadoras de transtorno de humor ou depressão apresentam maior freqüência de diabetes mellitus. As mulheres com depressão maior apresentam maior freqüência de LDL-colesterol elevado. E foi observado ainda menores níveis de PCR entre mulheres com transtornos de humor e/ou de ansiedade.

Não foi observada associação com transtornos de humor e/ou ansiedade com hipertensão arterial, síndrome metabólica e maior risco avaliado pelo escore de risco de Framingham. 
ANEXOS 



\section{ANEXO A}

\section{HOSPITAL DAS CLÍNICAS}

DA

FACULDADE DE MEDICINA DA UNIVERSIDADE DE SÃO PAULO

TERMO DE CONSENTIMENTO LIVRE E ESCLARECIDO

(Instruções para preenchimento no verso)

\section{I- DADOS DE IDENTIFICAÇÃO DO SUJEITO DA PESQUISA OU RESPONSÁVEL LEGAL}

1. NOME DO PACIENTE:

DOCUMENTO DE IDENTIDADE No:

SEXO: $M \square \quad F \square$

DATA NASCIMENTO:

ENDEREÇO: No APTO:

BAIRRO: CIDADE:

CEP: TELEFONE: DDD ( )

2. RESPONSÁVEL LEGAL:

NATUREZA (grau de parentesco, tutor, curador etc.)

DOCUMENTO DE IDENTIDADE No:

SEXO: $M \square \quad F \square$

DATA NASCIMENTO: I I I

ENDEREÇO: No APTO:

BAIRRO: CIDADE:

CEP: TELEFONE: DDD ( )

\section{II - DADOS SOBRE A PESQUISA CIENTÍFICA}

TÍTULO DO PROTOCOLO DE PESQUISA:

Avaliação de medidas antropométricas em população geral

PESQUISADOR: Isabela M. Benseñor

CARGO/FUNÇÃO: Médica

INSCRIÇÃO CONSELHO REGIONAL N UNIDADE DO HCFMUSP: 45167

3. AVALIAÇÃO DO RISCO DA PESQUISA:

$\begin{array}{llll}\text { SEM RISCO } & \text { RISCO MÍNIMO } \\ \text { RISCO BAIXO } & \text { RISCO MAIOR } & \text { RISCO MÉDIO }\end{array}$

(probabilidade de que o indivíduo sofra algum dano como consequência imediata ou tardia do estudo)

4. DURAÇÃO DA PESQUISA: 1 ano 


\section{III- REGISTRO DAS EXPLICAÇÕES DO PESQUISADOR AO PACIENTE OU SEU REPRESENTANTE LEGAL SOBRE A PESQUISA, CONSIGNANDO:}

1. justificativa e os objetivos da pesquisa; 2. procedimentos que serão utilizados e propósitos, incluindo a identificação dos procedimentos que são experimentais; 3. desconfortos e riscos esperados; 4. benefícios que poderão ser obtidos; 5. procedimentos alternativos que possam ser vantajosos para o indivíduo.

1. Essa pesquisa quer saber as medidas de peso altura, cintura e quadril e pressão arterial do paciente e associar com os valores de glicose e colesterol no sangue para saber se só através das medidas externas podemos prever a chance de um paciente ter diabetes ou colesterol aumentado; 2. Só serão pedidos os exames que forem necessários para a pesquisa que serão dosagem de glicose e colesterol total e frações no sangue. Não será colhido nenhum outro exame por causa da pesquisa.. Os Sr (Sra) passará por uma consulta de rotina de promoção a saúde (check-up) com avaliação de outros fatores de risco para doença do coração. 3. Colher sangue pode causar dor no local onde a agulha entrou na pele. Pode formar alguns caroços no local (coágulos de sangue), podendo doer por um ou dois dias. Qualquer complicação causada pela coleta de sangue, será resolvida no próprio hospital. Só será colhido sangue se a queixa do Sr (Sra) indicar a coleta. Não será colhido nenhum exame específico somente por causa da pesquisa. A mesma coisa vale para os outros exames que forem necessários. 4. O Sr (Sra) será tratado em todas as queixas que motivaram a sua procura ao hospital, só sendo dispensado após a resolução das queixas. 5. Se o Sr (Sra) não quiser participar da pesquisa, será atendido normalmente no mesmo local, da mesma maneira que se tivesse consentido em participar da pesquisa.

\section{IV - ESCLARECIMENTOS DADOS PELO PESQUISADOR SOBRE GARANTIAS DO SUJEITO DA PESQUISA:}

1. acesso, a qualquer tempo, às informações sobre procedimentos, riscos e benefícios relacionados à pesquisa, inclusive para dirimir eventuais dúvidas. Todos os pacientes terão acesso o tempo todo aos resultados da pesquisa e dos exames feitos como em qualquer consulta normal.

2. liberdade de retirar seu consentimento a qualquer momento e de deixar de participar do estudo, sem que isto traga prejuízo à continuidade da assistência. $\underline{\mathrm{O}} \mathrm{Sr}(\mathrm{a})$ pode retirar o seu consentimento para participar da pesquisa em qualquer momento.

3. salvaguarda da confidencialidade, sigilo e privacidade. Todos os resultados da pesquisa serão sigilosos jamais identificando nominalmente um paciente.

4. disponibilidade de assistência no HCFMUSP, por eventuais danos à saúde, decorrentes da pesquisa. Todas as complicações decorrentes da pesquisa serão resolvidas no próprio Hospital das Clínicas.

5. viabilidade de indenização por eventuais danos à saúde decorrentes da pesquisa. Todos os danos decorrentes da pesquisa serào devidamente indenizados. 
V - INFORMAÇÕES DE NOMES, ENDEREÇOS E TELEFONES DOS RESPONSÁVEIS PELO ACOMPANHAMENTO DA PESQUISA, PARA CONTATO EM CASO DE INTERCORRÊNCIAS CLÍNICAS E REAÇÕES ADVERSAS.

Dra Isabela- fone $3069-7690$

\section{VI - OBSERVAÇõES COMPLEMENTARES:}

Trata-se de pesquisa que simplesmente observará as etapas necessárias para o médico fazer o diagnóstico da doença. Nenhum exame ou procedimento será realizado só por causa da pesquisa

\section{VII - CONSENTIMENTO PÓS-ESCLARECIDO}

Declaro que, após convenientemente esclarecido pelo pesquisador e ter entendido o que me foi explicado, consinto em participar do presente Protocolo de Pesquisa

São Paulo, de de

assinatura do sujeito da pesquisa ou responsável legal assinatura do pesquisador

(carimbo ou nome Legível) 


\section{ANEXO B}

Nome:

Número no estudo: Sexo: masculino (0) feminino (1)

Data de nascimento (dia/mês/ano):

1. MEDIDAS ANTROPOMÉTRICAS E EXAMES LABORATORIAIS

\begin{tabular}{|l|l|l|}
\hline MEDIDAS ANTROPOMÉTRICAS & VALOR & AVALIAÇÃO \\
\hline Altura (em cm) & & \\
\hline Peso (em Kg) & & \\
\hline Medida da Cintura & & \\
\hline Medida do Quadril & & \\
\hline Índice de Massa Corporal & & \\
\hline Razão Cintura/Quadril & & \\
\hline
\end{tabular}

\begin{tabular}{|l|l|l|}
\hline DOSAGENS SÉRICAS & VALOR & AVALIAÇÃO \\
\hline Glicemia & & \\
\hline Colesterol Total & & \\
\hline HDL Colesterol & & \\
\hline Triglicérides & & \\
\hline TSH & & \\
\hline T4-livre & & \\
\hline Proteína C ultra-sensível & & \\
\hline
\end{tabular}

COMENTÁRIOS: 


\section{ANEXO C}

Algum médico já lhe disse que você tem ou já teve:

[ASSINALAR COM UM X A(S) COLUNA(S) ADEQUADA(S)]

\begin{tabular}{|l|l|l|l|}
\hline DIAGNÓSTICO & TEM & JÁ TEVE & NÃO \\
\hline Diabetes? & & & \\
\hline Pressão alta (hipertensão arterial)? & & & \\
\hline Derrame (Acidente Vascular Cerebral)? & & & \\
\hline Ataque cardíaco (Infarto Agudo do Miocárdio)? & & & \\
\hline Doença coronariana? & & & \\
\hline Outra doença do coração? & & \\
\hline $\begin{array}{l}\text { Problema de tireóide? } \\
\text { Se sim: Hiper ( ) Hipo ( ) Ca ( ) Outros ( ) }\end{array}$ & & & \\
\hline
\end{tabular}

Alguém da sua família (seu pai, mãe, irmãos ou filhos) tem ou já teve:

[ASSINALAR COM UM X A(S) COLUNA(S) ADEQUADA(S)]

\begin{tabular}{|l|l|l|l|}
\hline DIAGNÓSTICO & TEM & JÁ TEVE & NÃO \\
\hline Diabetes? & & & \\
\hline Pressão alta (hipertensão arterial)? & & & \\
\hline Derrame (Acidente Vascular Cerebral)? & & & \\
\hline Ataque cardíaco (Infarto Agudo do Miocárdio)? & & & \\
\hline Colesterol alto? & & & \\
\hline Doença coronariana? & & & \\
\hline Outra doença do coração? & & & \\
\hline $\begin{array}{l}\text { Problema de tireóide? } \\
\text { Se sim: Hiper ( ) Hipo ( ) Ca ( ) Outros ( ) }\end{array}$ & & \\
\hline Outros problemas de saúde: quais? [ANOTAR] & & \\
\hline
\end{tabular}

Você:

[ASSINALAR COM UM X A COLUNA ADEQUADA]

\begin{tabular}{|l|l|l|l|}
\hline \multirow{2}{*}{} & \multicolumn{2}{|c|}{ SIM } & \multirow{2}{*}{ NÃO } \\
\cline { 2 - 3 } & Atual & Passado & \\
\hline Faz (ou fazia) exercício físico regularmente? & & & \\
\hline Fuma (ou fumou) diariamente? & & & \\
\hline $\begin{array}{l}\text { Consome (ou já consumiu) bebidas alcoólicas } \\
\text { regularmente (pelo menos uma x/semana)? }\end{array}$ & & & \\
\hline Toma (ou já tomou) remédio para a pressão? & & & \\
\hline Toma (ou já tomou) remédio para diabetes? & & & \\
\hline Toma (ou já tomou) remédio para o coração? & & & \\
\hline Toma (ou já tomou) remédio para a tireóide? & & & \\
\hline $\begin{array}{l}\text { Toma (ou já tomou) remédio para abaixar o } \\
\text { colesterol? }\end{array}$ & & & \\
\hline \multicolumn{2}{|l|}{ Outros remédios atualmente: quais? [ANOTAR OS NOMES] } & & \\
\hline
\end{tabular}




\section{INTERNATIONAL PHYSICAL ACTIVITY QUESTIONNAIRE (IPAQ)}

\section{SEÇÃO 1 - ATIVIDADES FÍSICA NO TRABALHO}

Esta seção inclui as atividades que você faz no seu serviço, que incluem trabalho remunerado ou voluntário, as atividades na escola ou faculdade e outro tipo de trabalho não remunerado fora da sua casa. NÃO incluir trabalho não remunerado que você faz na sua casa como tarefas domésticas, cuidar do jardim e da casa ou tomar conta da sua família. Estas serão incluídas na seção 3.

1a. Atualmente você trabalha voluntário fora de sua casa?

( ) Sim ( ) Não - Caso você responda não Vá para seção: Transporte.

As próximas questões são em relação a toda a atividade

Física que você faz em uma semana USUAL ou NORMAL como parte do seu trabalho remunerado ou não remunerado. NÃO inclua o transporte para o trabalho. Pense unicamente nas atividades que você faz por pelo menos 10 minutos contínuos:

1b. Em quantos dias de uma semana normal você gasta fazendo atividades vigorosas, por pelo menos 10 minutos contínuos, como trabalho de construção pesada, carregar grandes pesos, trabalhar com enxada, escavar ou subir escadas como parte do seu trabalho:

dias por SEMANA ( ) nenhum - Vá para a questão 1d.

1c. Quanto tempo no total você usualmente gasta POR DIA fazendo atividades físicas vigorosas como parte do seu trabalho?

horas minutos

1d. Em quantos dias de uma semana normal você faz atividades moderadas, por pelo menos 10 minutos contínuos, como carregar pesos leves como parte do seu trabalho? dias por SEMANA ( ) nenhum - Vá para a questão 1f.

1e. Quanto tempo no total você usualmente gasta POR DIA fazendo atividades moderadas como parte do seu trabalho? horas minutos

1f. Em quantos dias de uma semana normal você anda, durante pelo menos 10 minutos contínuos, como parte do seu trabalho? Por favor NÃO inclua o andar como forma de transporte para ir ou voltar do trabalho. dias por SEMANA ( ) nenhum - Vá para a questão 2 - transporte. 
1g. Quanto tempo no total você usualmente gasta POR DIA caminhando como parte do seu trabalho? horas minutos

\section{SEÇÃO 2 - ATIVIDADE FÍSICA COMO MEIO DE TRANSPORTE}

Estas questões se referem a forma típica como você se desloca de um lugar para outro, incluindo seu trabalho, escola, cinema, lojas e outros.

2a. Em quantos dias de uma semana normal você anda de carro, ônibus, metrô ou trem? dias por SEMANA ( ) nenhum - Vá para a questão $2 c$.

2b. Quanto tempo no total você usualmente gasta POR DIA andando de carro, ônibus, metrô ou trem?

horas minutos

Agora pense somente em relação a caminhar ou pedalar para ir de um lugar a outro em uma semana normal.

2c. Em quantos dais de uma semana normal você anda de bicicleta por pelo menos 10 minutos contínuos para ir de um lugar para outro? (NÃO inclua o pedalar por lazer ou exercício) dias por SEMANA ( ) nenhum - Vá para a questão $2 \mathbf{e}$.

2d. Nos dias que você pedala quanto tempo no total você pedala POR DIA para ir de um lugar para outro? horas minutos

2e. Em quantos dias de uma semana normal você caminha por pelo menos 10 minutos contínuos para ir de um lugar para outro?(NÃO inclua as caminhadas por lazer ou exercícios). dias por SEMANA ( ) nenhum - Vá para Seção.

2f. Quando você caminha para ir de um lugar pra outro quanto tempo POR DIA você gasta? (NÃO inclua caminhadas por lazer ou exercício) horas minutos

\section{SEÇÃO 3 - ATIVIDADE FÍSICA EM CASA: TRABALHO, TAREFAS DOMÉSTICAS E CUIDAR DA FAMÍLIA}

Esta parte inclui as atividades físicas que você faz em uma semana NORMAL na sua casa e ao redor da sua casa, por exemplo trabalho em casa, cuidar do jardim, cuidar do quintal, trabalho de manutenção da casa ou para cuidar da sua família. Novamente pense somente naquelas atividades físicas que você faz por pelo menos 10 minutos contínuos. 
3a. Em quantos dias de uma semana normal você faz físicas vigorosas no jardim ou quintal por pelo menos 10 minutos como carpir, lavar o quintal, esfregar o chão: dias por SEMANA ( ) nenhum - Vá para a questão 3c.

3b. Nos dias que você faz este tipo de atividades vigorosas no quintal ou jardim quanto tempo no total você gasta POR DIA? horas minutos

3c. Em quantos dias de uma semana normal você faz atividades moderadas por pelo menos 10 minutos como carregar pesos leves, limpar vidros, varrer, rastelar com no jardim ou quintal. dias por SEMANA ( ) nenhum - Vá para a questão 3c.

3d.Nos dias que você faz este tipo de atividades quanto tempo no total você gasta POR DIA fazendo essas atividades moderadas no jardim ou no quintal? horas minutos

3e. Em quantos dias de uma semana normal você faz atividades moderadas por pelo menos 10 minutos como carregar pesos leves, limpar vidros, varrer ou limpar o chão dentro da sua casa. dias por SEMANA ( ) nenhum - Vá para Seção 4.

3f. Nos dias que você faz este tipo de atividades moderadas dentro da sua casa quanto tempo no total você gasta POR DIA? horas minutos

\section{SEÇÃO 4 - ATIVIDADE FÍSICAS DE RECREAÇÃO, ESPORTE, EXERCÍCIO E DE LAZER}

Esta seção se refere às atividades físicas que você faz em uma semana NORMAL unicamente por recreação, esporte, exercício ou lazer. Novamente pense somente nas atividades físicas que faz por pelo menos 10 minutos contínuos. Por favor NÃO inclua atividades que você já tenha citado.

4a. Sem contar qualquer caminhada que você tenha citado anteriormente, em quantos dias de uma semana normal, você caminha por pelo menos 10 minutos contínuos no seu tempo livre? dias por SEMANA ( ) nenhum - Vá para Seção 4d.

4b.Nos dias em que você caminha no seu tempo livre, quanto tempo no total você gasta POR DIA?

horas minutos 
4c. Em quantos dias de uma semana normal, você faz atividades vigorosas no seu tempo livre por pelo menos 10 minutos, como correr, fazer aeróbicos, nadar rápido ou fazer jogging: dias por SEMANA ( ) nenhum - Vá para Seção 4f.

4d.Nos dias em que você faz estas atividades vigorosas no seu tempo livre quanto tempo no total você gasta POR DIA? horas minutos

4e.Em quantos dias de uma semana normal, você faz atividades moderadas no seu tempo livre por pelo menos 10 minutos, como pedalar ou nadar a velocidade regular jogar bola, vôlei, baquete, tênis: dias por SEMANA ( ) nenhum - Vá para Seção 5.

4f. Nos dias em que você faz estas atividades moderadas no seu tempo livre quanto tempo no total você gasta POR DIA? horas minutos

\section{SEÇÃO 5 - TEMPO GASTO SENTADO}

Estas últimas questões são sobre o tempo que você permanece sentado todo dia, no trabalho, na escola ou faculdade, em casa e durante seu tempo livre. Isto inclui o tempo sentado estudando, sentado enquanto descansa, fazendo lição de casa visitando um amigo, lendo, sentado ou deitado assistindo TV. Não inclua o tempo gasto sentando durante o transporte em ônibus, trem, metrô ou carro.

5a. Quanto tempo no total você gasta sentado durante um dia de semana? horas minutos

5b. Quanto tempo no total você gasta sentado durante em um dia de final de semana? horas minutos 


\section{ANEXO E}

EXEMPLOS DE CARTAS COM RESULTADOS DE EXAMES LABORATORIAIS

\section{CARTA PARA INDIVÍDUOS COM RESULTADOS NORMAIS}

Sr.

Resultados dos exames do Projeto Megacity

\begin{tabular}{|l|l|l|l|}
\hline & & & Valores normais \\
\hline Glicemia & & $\mathrm{mg} / \mathrm{dl}$ & Abaixo de $110 \mathrm{mg} / \mathrm{dl}$ \\
\hline Colesterol total & & $\mathrm{mg} / \mathrm{dl}$ & Abaixo de $200 \mathrm{mg} / \mathrm{dl}$ \\
\hline LDL-colesterol & & $\mathrm{mg} / \mathrm{dl}$ & Abaixo de $130 \mathrm{mg} / \mathrm{dl}$ \\
\hline HDL-colesterol & & $\mathrm{mg} / \mathrm{dl}$ & Acima de $40 \mathrm{mg} / \mathrm{dl}$ \\
\hline Triglicérides & & $\mathrm{mg} / \mathrm{dl}$ & Abaixo de $150 \mathrm{mg} / \mathrm{dl}$ \\
\hline TSH & & $\mathrm{mcUl} / \mathrm{ml}$ & Entre 0,4 e $5,5 \mathrm{mcUl} / \mathrm{ml}$ \\
\hline T4-livre & & $\mathrm{ng} / \mathrm{dl}$ & Entre 0,8 e $1,8 \mathrm{ng} / \mathrm{dl}$ \\
\hline
\end{tabular}

O TSH e o T4 livre medem a função da glândula tireóide. Os resultados dos seus exames estão normais. Agradecemos a sua participação no projeto.

\section{CARTA PARA INDIVÍDUOS COM DOSAGEM DE HDL-COLESTEROL REDUZIDO}

Sr.

Resultados dos exames do Projeto Megacity

\begin{tabular}{|l|l|l|l|}
\hline & & & Valores normais \\
\hline Glicemia & & $\mathrm{mg} / \mathrm{dl}$ & Abaixo de $110 \mathrm{mg} / \mathrm{dl}$ \\
\hline Colesterol total & & $\mathrm{mg} / \mathrm{dl}$ & Abaixo de $200 \mathrm{mg} / \mathrm{dl}$ \\
\hline LDL-colesterol & & $\mathrm{mg} / \mathrm{dl}$ & Abaixo de $130 \mathrm{mg} / \mathrm{dl}$ \\
\hline HDL-colesterol & & $\mathrm{mg} / \mathrm{dl}$ & Acima de $40 \mathrm{mg} / \mathrm{dl}$ \\
\hline Triglicérides & & $\mathrm{mg} / \mathrm{dl}$ & Abaixo de $150 \mathrm{mg} / \mathrm{dl}$ \\
\hline TSH & & $\mathrm{mcUl} / \mathrm{ml}$ & Entre 0,4 e $4,0 \mathrm{mcUl} / \mathrm{ml}$ \\
\hline T4-livre & & $\mathrm{ng} / \mathrm{dl}$ & Ente 0,7 e $1,8 \mathrm{ng} / \mathrm{dl}$ \\
\hline
\end{tabular}

O TSH e o T4 livre medem a função da glândula tireóide. O seu colesterol protetor HDLcolesterol veio abaixo do adequado. Para aumentar o seu colesterol protetor é importante caminhar meia hora por dia todos os dias.

Tente manter o peso que o sr(a) tinha aos 20 anos. O ganho de peso aumenta o riso de ficar hipertenso ou diabético.

Se o sr(a) fuma, pare imediatamente de fumar.

Procure atendimento médico de rotina para controlar os fatores de risco para as doenças cardiovasculares.

Agradecemos a sua participação no projeto. 
CARTA PARA INDIVÍDUOS COM DOSAGEM DE COLESTEROL TOTAL E LDL-COLESTEROL

\section{ELEVADOS}

Sr.

Resultados dos exames do Projeto Megacity

\begin{tabular}{|l|l|l|l|}
\hline & & & Valores normais \\
\hline Glicemia & & $\mathrm{mg} / \mathrm{dl}$ & Abaixo de $110 \mathrm{mg} / \mathrm{dl}$ \\
\hline Colesterol total & & $\mathrm{mg} / \mathrm{dl}$ & Abaixo de $200 \mathrm{mg} / \mathrm{dl}$ \\
\hline LDL-colesterol & & $\mathrm{mg} / \mathrm{dl}$ & Abaixo de $130 \mathrm{mg} / \mathrm{dl}$ \\
\hline HDL-colesterol & & $\mathrm{mg} / \mathrm{dl}$ & Acima de $40 \mathrm{mg} / \mathrm{dl}$ \\
\hline Triglicérides & & $\mathrm{mg} / \mathrm{dl}$ & Abaixo de $150 \mathrm{mg} / \mathrm{dl}$ \\
\hline TSH & & $\mathrm{mcUl} / \mathrm{ml}$ & Entre 0,4 e $4,0 \mathrm{mcUl} / \mathrm{ml}$ \\
\hline T4-livre & & $\mathrm{ng} / \mathrm{dl}$ & Entre 0,7 e $1,8 \mathrm{ng} / \mathrm{dl}$ \\
\hline
\end{tabular}

O TSH e o T4 livre medem a função da glândula tireóide. Os exames mostraram que o seu colesterol total e o LDL-colesterol estão aumentados.

É importante que o senhor mude a sua dieta evitando gorduras. Coma menos carne e quando comer, tire toda a gordura visível.

Coma mais frango, sempre tirando a pele. A carne do peito de frango tem muito pouca gordura.

Evite o leite integral e a manteiga. Prefira as margarinas cremosas.

Coma frutas e verduras que tem grande quantidade de fibras.

Os cereais integrais como o farelo de trigo e o farelo de aveia também contêm muitas fibras. As fibras diminuem a absorção do colesterol.

Tente manter o peso que o $\mathrm{Sr}(\mathrm{a})$ tinha aos 20 anos. O ganho de peso aumenta o risco de ficar com pressão alta ou diabetes.

Caminhe meia hora por dia todos os dias.

Se o sr(a) fuma, pare imediatamente de fumar.

Procure atendimento médico de rotina para controle dos fatores de risco para as doenças do coração.

Agradecemos sua participação no projeto. 
Sr.

Resultados dos exames do Projeto Megacity

\begin{tabular}{|l|l|l|l|}
\hline & & & Valores normais \\
\hline Glicemia & & $\mathrm{mg} / \mathrm{dl}$ & Abaixo de $110 \mathrm{mg} / \mathrm{dl}$ \\
\hline Colesterol total & & $\mathrm{mg} / \mathrm{dl}$ & Abaixo de $200 \mathrm{mg} / \mathrm{dl}$ \\
\hline LDL-colesterol & & $\mathrm{mg} / \mathrm{dl}$ & Abaixo de $130 \mathrm{mg} / \mathrm{dl}$ \\
\hline HDL-colesterol & & $\mathrm{mg} / \mathrm{dl}$ & Acima de $40 \mathrm{mg} / \mathrm{dl}$ \\
\hline Triglicérides & & $\mathrm{mg} / \mathrm{dl}$ & Abaixo de $150 \mathrm{mg} / \mathrm{dl}$ \\
\hline TSH & $\mathrm{mcUl} / \mathrm{ml}$ & Entre 0,4 e $4,0 \mathrm{mcUl} / \mathrm{ml}$ \\
\hline T4-livre & & $\mathrm{ng} / \mathrm{dl}$ & Ente 0,7 e $1,8 \mathrm{ng} / \mathrm{dl}$ \\
\hline
\end{tabular}

O TSH e o T4 livre medem a função da glândula tireóide. O seu colesterol protetor HDLcolesterol veio abaixo do adequado. Para aumentar o seu colesterol protetor é importante caminhar meia hora por dia todos os dias.

A dosagem de triglicérides está um pouco acima do normal. Tente comer menos açúcares e outras calorias.

A sua glicemia também está aumentada.

É importante diminuir a quantidade de açúcares e outras calorias e doces na dieta.

É importante que o senhor também mude a sua dieta evitando gorduras. Coma menos carne e quando comer, tire toda a gordura visível.

Coma mais frango, sempre tirando a pele. A carne do peito de frango tem muito pouca gordura.

Evite o leite integral e a manteiga. Prefira as margarinas cremosas.

Coma frutas e verduras que tem grande quantidade de fibras.

Os cereais integrais como o farelo de trigo e o farelo de aveia também contêm muitas fibras. As fibras diminuem a absorção do colesterol.

Perca peso e tente manter o peso que o sr(a) tinha aos 20 anos. $O$ ganho de peso aumenta o risco de ficar hipertenso ou diabético.

Se o $\operatorname{sr}(a)$ fuma, pare imediatamente de fumar.

Procure atendimento médico de rotina para controlar os fatores de risco para as doenças cardiovasculares.

Agradecemos a sua participação no projeto. 


\section{ANEXO F}

\section{ESCORE DE RISCO DE FRAMINGHAM}

Retirado de: Sociedade Brasileira de Cardiologia. Departamento de Aterosclerose da Sociedade Brasileira de Cardiologia. VI Diretriz Brasileira sobre Dislipidemia e Prevenção de Aterosclerose. Arq Bras Cardiol. 2007;88(supl 1):S1-19.

\begin{tabular}{|c|c|c|c|c|c|c|c|c|c|c|c|}
\hline \multicolumn{6}{|c|}{ HOMENS } & \multicolumn{6}{|c|}{ MULHERES } \\
\hline \multicolumn{2}{|l|}{ Idade } & \multicolumn{4}{|c|}{ Pontos } & \multicolumn{2}{|c|}{ Idade } & \multicolumn{4}{|c|}{ Pontos } \\
\hline $20-34$ & & \multicolumn{4}{|c|}{-9} & \multicolumn{2}{|c|}{$20-34$} & \multicolumn{4}{|c|}{-7} \\
\hline $35-39$ & & \multicolumn{4}{|c|}{-4} & \multicolumn{2}{|c|}{$35-39$} & \multicolumn{4}{|c|}{-3} \\
\hline $40-44$ & & \multicolumn{4}{|c|}{0} & \multicolumn{2}{|c|}{$40-44$} & \multicolumn{4}{|c|}{0} \\
\hline $45-49$ & & \multicolumn{4}{|c|}{3} & \multicolumn{2}{|c|}{$45-49$} & \multicolumn{4}{|c|}{3} \\
\hline $50-54$ & & \multicolumn{4}{|c|}{6} & \multicolumn{2}{|c|}{$50-54$} & \multicolumn{4}{|c|}{6} \\
\hline $55-59$ & & \multicolumn{4}{|c|}{8} & \multicolumn{2}{|c|}{$55-59$} & \multicolumn{4}{|c|}{8} \\
\hline $60-64$ & & \multicolumn{4}{|c|}{10} & \multicolumn{2}{|c|}{$60-64$} & & 1 & & \\
\hline $65-69$ & & & & & & $65-6$ & & & 1 & & \\
\hline $70-74$ & & & & & & $70-7$ & & & 1 & & \\
\hline $75-79$ & & & & & & $75-7$ & & & 1 & & \\
\hline Colesterol & idade & idade & idade & idade & idlade & Colesterol & idade & idade & idade & idade & idade \\
\hline $\begin{array}{l}\text { Total, } \\
\mathrm{mg} / \mathrm{dL}\end{array}$ & $20-39$ & $40-49$ & $50-59$ & $60-69$ & $70-79$ & $\begin{array}{l}\text { Total, } \\
\mathbf{m g} / \mathbf{d L}\end{array}$ & $20-39$ & $40-49$ & $50-59$ & $60-69$ & $70-79$ \\
\hline$<160$ & 0 & 0 & 0 & 0 & 0 & $<160$ & 0 & 0 & 0 & 0 & 0 \\
\hline $160-199$ & 4 & 3 & 2 & 1 & 0 & $160-199$ & 4 & 3 & 2 & 1 & 1 \\
\hline $200-239$ & 7 & 5 & 3 & 1 & 0 & $200-239$ & 8 & 6 & 4 & 2 & 1 \\
\hline $240-279$ & 9 & 6 & 4 & 2 & 1 & $240-279$ & 11 & 8 & 5 & 3 & 2 \\
\hline$\geq 280$ & 11 & 8 & 5 & 3 & 1 & $\geq 280$ & 13 & 10 & 7 & 4 & 2 \\
\hline Fumo & idade & idade & idade & idade & idlade & Fumo & idade & idade & idade & idade & idade \\
\hline & $20-39$ & $40-49$ & $50-59$ & $60-69$ & $70-79$ & & $20-39$ & $40-49$ & $50-59$ & $60-69$ & $70-79$ \\
\hline Nāo & 0 & 0 & 0 & 0 & 0 & Nāo & 0 & 0 & 0 & 0 & 0 \\
\hline Sim & 8 & 5 & 3 & 1 & 1 & Sim & 9 & 7 & 4 & 2 & 1 \\
\hline HDL-colest & $(\mathrm{mg} / \mathrm{dL})$ & & & Pontos & & HDL-co & esterol (n & $/(d L)$ & & Pontos & \\
\hline$\geq 60$ & & & & -1 & & & $\geq 60$ & & & -1 & \\
\hline $50-59$ & & & & 0 & & & $50-59$ & & & 0 & \\
\hline $40-49$ & & & & 1 & & & $40-49$ & & & 1 & \\
\hline$<40$ & & & & 2 & & & $<40$ & & & 2 & \\
\hline PA (sistólic: & $\mathrm{m} \mathrm{Hg}$ ) & & io tratad & & tratada & PA (sist & lica, $\mathrm{mm}$ & & nāo tratada & & ada \\
\hline$<120$ & & & 0 & & 0 & & 120 & & 0 & & \\
\hline $120-129$ & & & 0 & & 1 & & $0-129$ & & 1 & & \\
\hline $130-139$ & & & 1 & & 2 & & $0-139$ & & 2 & & \\
\hline $140-159$ & & & 1 & & 2 & & $0-159$ & & 3 & & \\
\hline$\geq 160$ & & & 2 & & 3 & & $=160$ & & 4 & & \\
\hline
\end{tabular}




\begin{tabular}{|c|c|c|c|}
\hline \multirow[b]{2}{*}{ Total de pontos } & \multicolumn{3}{|c|}{$\begin{array}{l}\text { risco de Framingham (ERF) para cálculo do risco absoluto de infarto e morte em } 10 \text { anos } \\
\text { para homens e mulheres (Fase 2) - Continuaçäo. }\end{array}$} \\
\hline & Risco absoluto em 10 anos $(\%)$ & Total de pontos & Risco absoluto em 10 anos $(\%)$ \\
\hline$<0$ & $<1$ & $<9$ & $<1$ \\
\hline 0 & 1 & 9 & 1 \\
\hline 1 & 1 & 10 & 1 \\
\hline 2 & 1 & 11 & 1 \\
\hline 3 & 1 & 12 & 1 \\
\hline 4 & 1 & 13 & 2 \\
\hline 5 & 2 & 14 & 2 \\
\hline 6 & 2 & 15 & 3 \\
\hline 7 & 3 & 16 & 4 \\
\hline 8 & 4 & 17 & 5 \\
\hline 9 & 5 & 18 & 6 \\
\hline 10 & 6 & 19 & 8 \\
\hline 11 & 8 & 20 & 11 \\
\hline 12 & 10 & 21 & 14 \\
\hline 13 & 12 & 22 & 17 \\
\hline 14 & 16 & 23 & 22 \\
\hline 15 & 20 & 24 & 27 \\
\hline 16 & 25 & $\geq 25$ & $\geq 30$ \\
\hline$\geq 17$ & $\geq 30$ & & \\
\hline
\end{tabular}




\section{REFERÊNCIAS}

1. Castro MG, Andrade TMR, Muller MC. Conceito mente e corpo através da história. Psicologia em Estudo. 2006;11(1):39-43.

2. Vieira MJ F. As funções orgânicas diante do estresse. In: Arantes MAAC \& Vieira MJF. Estresse - Coleção Clínica Psicanalítica. São Paulo: Casa do Psicólogo; 2002.

3. Osler W. Lectures on angina pectoris and allied states. New York: D'Appleton and Company; 1892.

4. Ballester DA, Filippon AP, Braga C, Andreoli SB. The general practitioner and mental health problems: challenges and strategies for medical education. Sao Paulo Med J. 2005;123(2):72-6.

5. De Hert M, Dekker JM, Wood D, Kahl KG, Holt RIG, Moller HJ. Cardiovascular disease and diabetes in people with severe mental illness position statement from the European Psychiatric Association (EPA), supported by the European Association for the Study of Diabetes (EASD) and the European Society of Cardiology (ESC). European Psychiatry. $2009 ; 24 ; 412-24$.

6. Brown S. Excess mortality in schizophrenia: a meta-analysis. $\mathrm{Br} J$ Psychiatry. 1997;171:502-8.

7. Sampaio ALP, Caetano D. Mortalidade em pacientes psiquiátricos: revisão bibliográfica. J Bras Psiquiatr. 2006;55(3):226-31.

8. Angst F, Stassen HH, Clayton PJ, Angst J. Mortality of patients with mood disorders: follow-up over 34-38 years. J Affect Disorders. 2002;68:167-81.

9. Lawrence DM, Holman CDJ, Jablensky AV, Hobbs MST. Death rate from ischaemic heart disease in Western Australian psychiatric patients 1980-1998. Br J Psychiatry. 2003;182:31-36.

10. Zheng D, Macera CA, Croft JB, Giles WH, Davis D, Scott WK. Major depression and all-cause mortality among White adults in the United States. Ann Epidemiol. 1997;7:213-18. 
11. Druss BG, Bradford D, Rosenheck RA, Radford MJ, Krumholz HM. Quality of medical care and excess mortality in older patients with mental disorders. Arch Gen Psychiatry. 2001;58: 565-72.

12. Kisely S, Smith M, Lawrence D, Cox M, Campbell LA, Maaten S. Inequitable access for mentally ill patients to some medically necessary procedures. CMAJ. 2007; 176(6):779-84.

13. Hirdes, A. A reforma psiquiátrica no Brasil: uma (re)visão. Ciência \& Saúde Coletiva. 2009;14(1):297-305.

14. Brown S, Inskip H, Barraclough B. Causes of the excess mortality of schizophrenia. $\mathrm{Br}$ J Psychiatry. 2000;177:212-17.

15. Saha S, Chant D, McGrath J. A systematic review of the mortality in schizophrenia: is the differential mortality gap worsening over time? Arch Gen Psychiatry. 2007;64(10):11231131.

16. Osborn DPJ, Levy G, Nazareth I, Petersen I, Islam A, King MB. Relative risk of cardiovascular and cancer mortality in people with severe mental illness from the United Kingdom's General Practice Research Database. Arch Gen Psychiatry. 2007;64:242-49.

17. Laursen TM, Munk-Olsen T, Agerbo E, Gasse C, Mortensen PB. Somatic hospital contacts, invasive cardiac procedures and mortality from heart disease in patients with severe mental disorder. Arch Gen Psychiatry. 2009;66(7):713-20.

18. Menezes PR; Mann AH. Mortality among patients with non-affective functional psychoses in a metropolitan area of South Eastern Brazil. Rev. Saúde Pública. 1996;30 (4):304-9.

19. Colton CW; Manderscheid RW. Congruencies in increased mortality rates, years of potential life lost, and causes of death among public mental health clients in eight states. Prev Chronic Dis. 2006;3(2):1-14.

20. Grigoletti L, Perini G, Rossi A, Biggeri A, Barbui C, Tansella M, Amaddeo F. Mortality and cause of death among psychiatric patients: a 20-year case-register study in an area with a community-based system of care. Psychological Medicine. 2009;39:1875-84. 
21. Almeida OP, Affonso H, Hankey GJ, Flicker L. Depression, antidepressant use and mortality in later life: the Health in Men Study. PLos ONE. 2010;5(6):el1266.

22. Chang CK, Hayes RD, Broadbent M, Fernandes AC, Lee W, Hotopf M, Stewart R. All-cause mortality among people with serious mental illness (SMI), substance use disorders, and depressive disorders in southeast London: a cohort study. BMC Psychiatry. 2010;10:77-84.

23. Ostir GV, Goodwin JS. High anxiety is associated with an increased risk of death in a older tri-ethnic population. J Clin Epidemiol. 2006;59(5):534-40.

24. Lin EHB, Heckbert SR, Rutter CM, Katon WJ, Ciechanowski P, Ludman EJ, Oliver M, Young BA, McCulloch DK, Von Korff M. Depression and increased mortality in diabetes: unexpected causes of death. Ann Fam Med. 2009;7:414-21.

25. Whooley MA, Browner WS. Association between depressive symptoms and mortality in older women. Arch Intern Med. 1998;158(19):2129-35.

26. Leon CFM, Krumholz HM, Seeman TS, Vaccarino V, Williams CS, Kasl SV, Berkman LF. Depression and risk of coronary heart disease in elderly men and women: New Haven EPESE, 1982-1991. Arch Intern Med. 1998;158(21):2341-48.

27. Pratt LA, Ford DE, Crum RM, Armenian HK, Gallo JJ, Eaton WW. Depression, psychotropic medication and risk of myocardial infarction. Circulation. 1996;94:3123-29.

28. Ferketich AK, Schwartzbaum JA, Frid DJ, Moeschberger ML. Depression as an antecedent to heart disease among women and men in the NHANES I Study. Arch Intern Med. 2000;160:1261-8.

29. Hippisley-Cox J, Fielding K, Pringle M. Depression as a risk factor for ischaemic heart disease in men: population based case-control study. BMJ. 1998;316:1714-1719.

30. Ariyo AA, Haan M, Tangen CM, Rutledge JC, Cushman M, Dobs A, Furberg CD. Depressive symptoms and risks of coronary heart disease and mortality in elderly americans. Circulation. 2000; 102:1773-9.

31. Wulsin LR, Singal BM. Do depressive symptoms increase the risk for the onset of coronary disease? A systematic quantitative review. Psychosom Med. 2003; 65(2): 201-10. 
32. Hemingway $\mathrm{H}$, Marmot $\mathrm{M}$. Psychosocial factors in the aetiology and prognosis of coronary heart disease: systematic review of prospective cohort studies. BMJ. 1999; 318:1460-7.

33. Penninx BWJH, Beekman ATF, Honig A, Deeg DJH, Schoevers RA, van Eijk JTM, van Tilburg W. Depression and cardiac mortality: results from a community-based longitudinal study. Arch Gen Psychiatry. 2001;58:221-7.

34. Surtees PG, Wainwright NWJ, Luben RN, Wareham NJ, Bingham SA, Khaw KT. Depression and ischemic heart disease mortality: evidence from the EPIC-Norfolk United Kingdom Prospective Cohort Study. Am J Psychiatry. 2008;165:515-23.

35. Wassertheil-Smoller S, Applegate WB, Berge K, Chang CJ, Davis BR, Grimm R, Kostis J, Pressel SMS, Schron ERN. Change in depression as a precursor of cardiovascular events. Arch Intern Med. 1996;156(5):553-61.

36. Aromaa $A$, Raitasalo R, Reunanen $A$, Impivaara $O$, Heliovaara $M$, Knekt $P$, Lehtinen V, Joukamaa M, Maatela J. Depression and cardiovascular diseases. Acta Psychiatr Scand. 1994;77(suppl3):77-82.

37. Whang W, Kubzansky LD, Kawachi I, Rexrode KM, Kroenke CH, Glynn RJ, Garan H, Albert CM. Depression and risk of sudden cardiac death and coronary heart disease in women: results from the Nurses' Health Study. J Am Coll Cardiol. 2009;53(11):950-8.

38. Nabi H, Hall M, Koskenvuo M, Singh-Manoux A, Oksanen T, Suominen S, Kivimaki M, Vahtera J. Psychological and somatic symptoms of anxiety and risk of coronary heart disease: the health and social support prospective cohort study. Biol Psychiatry. 2010;67(4):378-85.

39. Lund C, Breen A, Flisher AJ, Kakuna R, Corrigal J, Joska JA, Swartz L, Patel V. Poverty and common mental disorders in low and middle income countries: a systematic review. Social Science \& Medicine. 2010;71:517-28.

40. Joynt KE, Whellan DJ, O'Connor CM. Depression and cardiovascular disease: mechanisms. Biol Psychiatry. 2003;54:248-61. 
41. Khawaja IS, Westermeyer JJ, Gajwani P, Feinstein RE. Depression and coronary artery disease: the association, mechanisms, and therapeutic implications. Psychiatry (Edgemont). 2009;6(1):38-51.

42. Vreeburg SA, Hoogendijk WJG, Van Pelt J, DeRijk RH, Verhagen JCM, Van Dyck R, Smit JH, Zitman FG, Penninx BWJH. Major depressive disorder and hypothalamicpituitary-adrenal axis activity. Arch Gen Psychiatry. 2009;66(6):617-26.

43. Grippo AJ, Johnson AK. Stress, depression, and cardiovascular dysregulation: a review of neurobiological mechanisms and the integration of research from preclinical disease models. Stress. 2009;12(1):1-21.

44. Howren MB, Lamkin DM, Suls J. Associations of depression with C-reactive protein, IL-1 and IL-6: a meta-analysis. Psychosom Med. 2009;71:171-86.

45. Tomfohr LM, Martin TM, Miller GE. Symptoms of depression and impaired endothelial function in healthy adolescent women. J Behav Med. 2008;31:137-43.

46. DiMatteo MR, Lepper HS, Croghan TW. Depression is a risk factor for compliance with medical treatment. Arch Intern Med. 2000;160:2101-07.

47. Vaccarino V, Votaw J, Faber T, Veledar E, Murrah NV, Jones LR, Zhao J, Su S, Goldberg J, Raggi P, Quyyumi AA, Sheps DS, Bremner D. Major depression and coronary flow reserve detected by positron emission tomography. Arch Intern Med. 2009;169(18):1668-76.

48. World Health Organization. Action plan for the global strategy for the prevention and control of noncommunicable diseases Disponível em: http://www.who.int/mediacentre/ factsheets/fs311/en/index.htm. Acesso em 20 de junho de 2011.

49. Ogden CL, Carroll MD, Curtin LR, McDowell MA, Tabak CJ, Flegal KM. Prevalence of overweight and obesity in the United States, 1999-2004. JAMA. 2006;295:1549-55.

50. Brasil. Ministério da Saúde. Secretaria de Vigilância em Saúde. Secretaria de Gestão Estratégica e Participativa. Vigitel Brasil 2009: vigilância de fatores de risco e proteção para doenças crônicas por inquérito telefônico. Ministério da Saúde, Secretaria de Vigilância em Saúde, Secretaria de Gestão Estratégica e Participativa. - Brasília: Ministério da Saúde, 2010. 
51. Jacka FN, Pasco JA, McConnell S, Williams LJ, Kotowicz MA, Nicholson GC, Berk M. Self-Reported Depression and Cardiovascular Risk Factors in a Community Sample of Women. Psychosomatics. 2007;48:54-9.

52. Allison DB, Newcomer JW, Dunn AL, Blumenthal JA, Fabricatore AN, Daumit GL, Cope MB, Riley WT, Vreeland B, Hibbeln JR, Alpert JE. Obesity among those mental disorders: a National Institute of Mental Health Meeting Report. Am J Prev Med. 2009;36(4):431-50.

53. Carpenter KM, Hasin DS, Allison DB, Faith MS. Relationships between obesity and DSM-IV major depressive disorder, suicide ideation, and suicide attempts: results from a general population study. Am J Public Health. 2000;90:251-7.

54. Simon GE, Ludman EJ, Linde JA, Operskalski BH, Ichikawa L, Rohde P, Finch EA, Jeffery RW. Association between obesity and depression in middle-aged women. Gen Hosp Psychiatry. 2008;30(1):32-9.

55. Fiedorowicz JG, He J, Merikangas KR. The association between mood and anxiety disorders with vascular diseases and risk factors in a nationally representative sample. $J$ Psychosomatic Research. 2011;70:145-54.

56. Simon GE, Von Korff M, Saunders K, Miglioretti DL, Crane PK, Van Belle G, Kessler RC. Association between obesity and psychiatric disorders in the US adult population. Arch Gen Psychiatry. 2006;63:824-30.

57. Palinkas LA, Wingard DL, Barret-Connor E. Depressive symptoms in overweight and obese older adults: a test of the "jolly fat" hypothesis. J Psychosomatic Research 1996;40(1):59-66.

58. Allison DB, Newcomer JW, Dunn AL, Blumenthal JA, Fabricatore AN, Daumit GL, Cope MB, Riley WT, Vreeland B, Hibbeln JR, Alpert JE. Obesity among those with mental disorders: a National Institute of Mental Health Meeting Report. Am J Prev Med. 2009; 36(4):431-350.

59. Larijani B, Bayat MKS, Gorgani MK, Bandarian F, Akhondzadeh S, Sadjadi SA. Association between depression and diabetes. German J Psychiatry. 2004; 7: 62-5. 
60. Luppino FS, De Wit LM, Bouvy PF, Stijnen T, Cuijpers P, Penninx BWJH, Zitman FG. Overweight, obesity, and depression. Arch Gen Psychiatry. 2010;67(3): 220-9.

61. Fabricatore AN, Wadden TA, Higginbotham AJ, Faulconbridge LF, Nguyen AM, Heymsfield SB, Faith MS. Intentional weight loss and changes in symptoms of depression: a systematic review and meta-analysis. International Journal of Obesity. 2011;1-14.

62. Smits JAJ, Rosenfield D, Mather AA, Tart CD, Henriksen C, Sareen J. Psychotropic medication use mediates the relationship between mood and anxiety disorders and obesity: findings from a nationally representative sample. J Psychiatric Research. 2010;44:1010-1016.

63. American Diabetes Association. Diagnosis and classification of diabetes mellitus. Diabetes Care. 2010; 33(Suppl 1):S2-9.

64. Guh DP, Zhang W, Bansback N, Amarsi Z, Birmingham CL, Anis AH. The incidence of co-morbidities related to obesity and overweight: a systematic review and meta-analysis. BMC Public Health. 2009;9:88.

65. Goldenberg P, Franco LJ, Pagliaro H, Silva RS, Santos CA. Diabetes mellitus autoreferido no município de São Paulo: prevalência e desigualdade. Cad Saúde Publica. 1996;12(1):37-45.

66. Knol MJ, Twisk JWR, Beekman ATF, Heine RJ, Snoek FJ, Pouwer F. Depression as a risk factor for the onset of type 2 diabetes mellitus: a meta-analysis. Diabetologia. 2006;49:837-45.

67. Mezuk B, Eaton WW, Albretch S, Golden SH. Depression and type 2 diabetes over the lifespan: a meta-analysis. Diabetes Care. 2008;31(12):2383-90.

68. Pan A, Lucas M, Sun Q, van Dam RM, Franco OH, Willet WC, Manson JE, Rexrode $\mathrm{KM}$, Ascherio A, Hu FB. Increased mortality risk in women with depression and diabetes mellitus. Arch Gen Psychiatry. 2011;68(1):42-50.

69. Chobanian AV, Bakris GL, Black HR, Cushman WC, Green LA, Izzo JL, Jones DW, Materson BJ, Oparil S, Wright JT, Roccella EJ and the National High Blood Pressure Education Program Coordinating Committee. Seventh Report of the Joint National Committee on Prevention, Detection, Evaluation, and the Treatment of High Blood Pressure. Hypertension. 2003; 42:1206-52. 
70. Yan LL, Liu K, Matthews KA, Daviglus ML, Ferguson TF, Kiefe CI. Psychosocial factors and risk of hypertension. JAMA. 2003;290(16):2138-48.

71. Shinn EH, Poston WSC, Kimball KT, Jeor STS, Foreyt JP. Blood pressure and symptoms of depression and anxiety: a prospective study. American Journal of Hypertension. 2001;14:660-4.

72. Meyer CM, Armenian HK, Eaton WW, Ford DE. Incident hypertension associated with depression in the Baltimore Epidemiologic Catchment area follow-up study. $J$ Affect Disorders. 2004;83:127-33.

73. Jonas BS, Franks P, Ingram DD. Are symptoms of anxiety and depression risk factors for hypertension? Longitudinal evidence from the National Health and Nutrition Examination Survey I Epidemiologic Follow-up Study. Arch Fam Med. 1997;6:43-9.

74. Grimsrud A, Stein DJ, Seedat S, Williams D, Myer L. The association between hypertension and depression and anxiety disorders: results from a nationally-representative sample of South African Adults. PLoS ONE. 2009;4(5):e5552.

75. Stern SL, Dhanda R, Hazuda HP. Helplessness predicts the development of hypertension in older mexican and european americans. J Psychosom Res. 2009;67(4):333-7.

76. Scalco AZ, Scalco MZ, Azul JBS, Lotufo Neto F. Hypertension and depression. Clinics. 2005;60(3):241-50.

77. Fletcher B, Berra K, Ades P, Braun LT, Burke LE, Durstine L, Fair JM, Fletcher GF, Goff D, Hayman LL, Hiatt WR, Miller NH, Krauss R, Kris-Etherton P, Stone N, Wilterdink J, Winston M. Managing abnormal blood lipids: a collaborative approach. Circulation. 2005;112:3184-209.

78. Wiltink J, Beutel ME, Till Y, Ojeda FM, Wild PS, Munzel T, Blankenberg S, Michal M. Prevalence of distress, comorbid conditions and well being in the general population. J Affect Disord. 2010, doi: 10.1016/j.jad.2010.10.041.

79. Glassy CM, Lemus H, Cronan T, Glassy MS, Talavera GA. Relationship between depressive symptoms and cardiovascular risk factors among selected Latino patients at a community clinic. Psychology, Health \& Medicine. 2010;15(2):117-26. 
80. Panagiotakos DB, Kinlaw M, Papaerakleous N, Papoutsou S, Toutouzas P, Polychronopoulos E. Depressive symptomatology and the prevalence of cardiovascular risk factors among older men and women from Cyprus; the MEDIS (Mediterranean Islands Elderly) epidemiological study. Journal of Clinical Nursing. 2008;17:688-95.

81. Shin JY, Suls J, Martin R. Are cholesterol and depression inversely related? A metaanalysis of the association between two cardiac risk factors. Ann Behav Med. 2008; 36(1):33-43.

82. Martinez-Carpio PA, Barba J, Bedoya-Del Campillo A. Relation between cholesterol levels and neuropsychiatric disorders. Rev Neurol. 2009; 48(5):261-4.

83. Kunugi $H$, Takei $N$, Aoki $H$, Nanko S. Low serum cholesterol levels in suicide attempters. Biol Psychiatry. 1997;41(2): 196-200.

84. Colin A, Reggers J, Castronovo V, Ansseau M. Lipids, depression and suicide. Encephale. 2003;29(1):49-58.

85. Maes M, Smith R, Christophe A, Vandoolaeghe E, Van Gastel A, Neels H, Demedts P, Wauters A, Meltzer HY. Lower serum high-density lipoprotein cholesterol (HDL-C) in major depression and in depressed men with serious suicidal attempts: relationship with immune-inflammatory markers. Acta Psychiatr Scand. 1997;95(3):212-21.

86. Dortland AKBR, Giltay EJ, van Veen T, van Pelt J, Ziltman FG, Penninx BWJH. Associations between serum lipids and major depressive disorder: results from the Netherlands Study of Depression and Anxiety (NESDA). J Clin Psychiatry. 2010;71(6):729-36.

87. Ergun UG, Uguz S, Bozdemir N, Guzel R, Burgut R, Saatçi E, Akpinar E. The relationship between cholesterol levels and depression in the elderly. Int J Geriatr Psychiatry. 2004; 19(3):291-296.

88. Huang TL, Wu SC, Chiang YS, Chen JF. Correlation between serum lipid, lipoprotein concentrations and anxious state, depressive state or major depressive disorder. Psychiatry Research. 2003;118:147-53.

89. Igna CV, Julkunen J, Vanhanen $H$, Keskivaara $P$, Verkasalo M. Depressive symptoms and serum lipid fractions in middle-aged men: physiologic and health behavior links. Psychosom Med. 2008;70:960-6. 
90. Grundy SM, Cleeman JI, Daniels SR, Donato KA, Eckel RH, Franklin BA, Gordon DJ, Krauss RM, Savage PJ, Smith SC Jr, Spertus JA, Costa F. Diagnosis and Management of the Metabolic Syndrome: An American Heart Association / National Heart, Lung, and Blood Institute Scientific Statement. Circulation. 2005: 112:2735-52.

91. Sá NNB e Moura EC. Fatores associados a carga de doenças da síndrome metabólica entre adultos brasileiros. Cad Saúde Pública. 2010;26(9):1853-62.

92. Silva EC, Martins IS, Araújo EAC. Síndrome metabólica e baixa estatura em adultos da região metropolitana de São Paulo (SP, Brasil). Ciência \& Saúde Coletiva. 2011;16(2):663-8. 93. Silveira VMF, Horta BL, Gigante DP, Azevedo Junior MR. Metabolic syndrome in the 1982 Pelotas cohort: effect of contemporary lifestyle and socioeconomic status. Arq Bras Endocrinol Metab. 2010;54(4):390-7.

94. Barbosa PJB, Lessa I, Almeida Filho N, Magalhães LBNC, Araújo J. Influence of the self-reported skin color on the prevalence of metabolic syndrome in an urban Brazilian population. Arq Bras Cardiol. 2010;94(1):33-9.

95. Raikkonen K, Matthews KA, Kuller LH. Depressive symptoms and stressful life events predict metabolic syndrome among middle-aged women. Diabetes Care. 2007;30(4):872-7.

96.Kinder LS, Carnethon MR, Palaniappan LP, King AC, Fortmann SP. Depression and the metabolic syndrome in young adults: findings from the third National Health and Nutrition Examination Survey. Psychosomc Med. 2004;66:316-22.

97. Koponen H, Jokelainen J, Keinanen-Kiukaanniemi S, Kumpusalo E, Vanhala M. Metabolic syndrome predisposes to depressive symptoms: a population-based 7-year follow-up study. J Clin Psychiatry. 2008;69(2):178-82.

98. Goldbacher EM, Bromberger J, Matthews KA. Lifetime history of major depression predicts the development of the metabolic syndrome in middle-aged women. Psychosom Med. 2009;71(3):266-72.

99. Carroll D, Phillips AC, Thomas GN, Gale CR, Deary I, Batty GD. Generalized anxiety disorder is associated with metabolic syndrome in the Vietnam Experience Study. Biol Psychiatry. 2009;66:91-3. 
100. Takeuchi T, Nakao M, Nomura K, Inoue M, Tsurugano S, Shinozaki Y, Yano E. association of the metabolic syndrome with depression and anxiety in Japanese men: a 1-year cohort study. Diabetes Metab Res Rev. 2009;25:762-7.

101. Teixeira PJR \& Rocha FL. The prevalence of metabolic syndrome among psychiatric inpatients in Brazil. Rev Bras Psiquiatr. 2007;29(4):330-6.

102. Gomes FA, Magalhães PV, Kunz M, Silveira LE, Weyne F, Andreazza AC, Cereser KM, Furlanetto TW, Kapczinski F. Resistência à insulina e síndrome metabólica em pacientes ambulatoriais com transtorno do humor bipolar. Rev Psiq Clín. 2010;37(2):81-84.

103. Vogelzangs N, Suthers K, Ferrucci L, Simonsick EM, Ble A, Schrager M, Bandinelli S, Lauretani F, Giannelli SV, Penninx BW. Hypercortisolemic depression is associated with the metabolic syndrome in late-life. Psychoneuroendocrinology. 2007;32:151-9.

104. Capuron L, Su S, Miller AH, Bremner JD, Goldberg J, Vogt GJ, Maisano C, Jones L, Murrah NV, Vaccarino V. Depressive symptoms and metabolic syndrome: is inflammation the underlying link? Biol Psychiatry. 2008;64(10):896-900.

105. Lawrence D, Mitrou F, Zubrick SR. Smoking and mental illness: results from population surveys in Australia and the United States. BMC Public Health. 2009;9:285.

106. Lasser K, Boyd JW, Woolhandler S, Himmelstein DU, McCormick D, Bor DH. Smoking and mental illness: a population-based prevalence study. JAMA. 2000;284(20):2606-10.

107. Jacka FN, Pasco JA, McConnell S, Williams LJ, Kotowicz MA, Nicholson GC, Berk M. Self-reportes depression and cardiovascular risk factors in a community sample of men. Psychosomatics. 2007;48:54-9.

108. Bonnet F, Irving K, Terra JL, Nony P, Berthezéne F, Moulin P. Anxiety and depression are associated with unhealthy lifestyle in patients at risk of cardiovascular disease. Atherosclerosis. 2005; 178: 339-44.

109. Strine TW, Mokdad AH, Dube SR, Balluz LS, Gonzalez O, Berry JT, Manderscheid $\mathrm{R}$, Kroenke K. The association of depression and anxiety with obesity and unhealthy behaviors among community-dwelling US adults. Gen Hosp Psychiatry. 2008;30:127-37. 
110. Mykletun A, Overland S, Aaro LE, Liabo HM, Stewart R. Smoking in relation to anxiety and depression: evidence from a large population survey (the HUNT study). European Psychiatry. 2008;23:77-84.

111. Brasil. Ministério da Saúde. Secretaria de Atenção à Saúde. Departamento de Atenção Básica. Cadernos de Atenção Básica: Prevenção clínica de doenças cardiovasculares, cerebrovasculares e renais. Ministério da Saúde, Secretaria de Atenção à Saúde, Departamento de Atenção Básica. - Brasília: Ministério da Saúde, 2006.

112. Wilson PWF, D'Agostino RB, Levy D, Belanger AM, Silbershatz H, Kannel WB. Prediction of coronary heart disease using risk fator categories. Circulation. 1998;97:1837-47.

113. Grundy SM, Cleeman JI, Merz NB, Brewer HB, Clark LT, Hunninghake DB, Pasternak RC, Smith SC, Stone NJ. Implications of recent clinical trials for the National Cholesterol Education Program Adult Treatment Panel III Guidelines. Circulation. 2004;110:227-39.

114. Fletcher B, Berra K, Ades P, Braunn LT, Burke LE, Durstine JL, Fair JM, Fletcher GF, Goff D, Hayman LL, Hiatt WR, Miller NH, Krauss R, Kris-Etherton P, Stone N, Wilterdink J, Winston M. Managing Abnormal Lipids: a collaborative approach. Circulation. 2005;112:3184-3209.

115. Eichler K, Puhan MA, Steurer J, Bachmann LM. Prediction of first coronary events with the Framingham score: a systematic review. Am Heart J. 2007;153:722-31.

116. Dhangana R, Murphy TP, Pencina MJ, Zafar AM. Prevalence of low ankle-brachial index, elevated plasma fibrinogen and C-reactive protein across Framingham risk categories: data from the National Health and Nutrition Examination Survey (NHANES) 1999-2004. Atherosclerosis. 2011; doi:10.1016/j.atherosclerosis. 2010.10.021.

117. Rodrigues TFF e Philippi ST. Avaliação nutricional e risco cardiovascular em executivos submetidos a check up. Rev Assoc Med Bras. 2008;54(4):322-7.

118. Barreto SM, Passos VMA, Cardoso ARA, Lima-Costa MF. Quantifying the risk of coronary artery disease in a community: the Bambuí Project. Arq Bras Cardiol. 2003;81(6):556-61.

119. Matos AC e Ladela AM. Assessment of cardiovascular risk factos in a rural community in the Brazilian state of Bahia. Arq Bras Cardiol. 2003;81(3):297-302. 
120. Landim MBP e Victor EG. Escore de Framingham em motoristas de transportes coletivos urbanos de Teresina-Piauí. Arq Bras Cardiol. 2006;87(3):315-20.

121. Khot UN, Khot MB, Bajzer CT, Sapp SK, Ohman EM, Brener SJ, Ellis SG, Lincoff AM, Topol EJ. Prevalence of conventional risk factors in patients with coronary heart disease. JAMA. 2003;290(7):898-904.

122. US Preventive Services Task Force. Using nontraditional risk factors in coronary heart disease risk assessment: US Preventive Services Task Force Recommendation Statement. Ann Intern Med. 2009; 151:474-82.

123. Ridker PM, Danielson E, Fonseca FAH, Genest J, Gotto AM, Kastelein JJP, Koenig W, Libby P, Lorenzatti AJ, MacFadyen JG, Nordestgaard BG, Shepherd J, Willerson JT, Glynn RJ. Rosuvastatin to prevent vascular events in men and women with elevated C-reactive protein. N Engl Med. 2008; 359: 2195-207.

124. Pitanga $\mathrm{F}$ e Lessa I. Associação entre atividade física no tempo livre e proteína $\mathrm{C}$ reativa em adultos na cidade de Salvador, Brasil. Arq Bras Cardiol. 2009; 92 (4):302-6.

125. Howren MB, Lamkin DM, Suls J. Associations of depression with C-reactive protein, IL-1 and IL-6: a meta-analysis. Psychosom Med. 2009;71:171-86.

126. Danner M, Kasl SV, Abramson JL, Vaccarino V. Association between depression and elevated C-reactive protein. Psychosom Med. 2003; 65:347-56.

127. Ford DE, Erlinger TP. Depression and C-reactive protein in US adults: data from the Third National Health and Nutrition Examination Survey. Arch Intern Med. 2004; 164: 1010-14.

128. Douglas KM, Taylor AJ, O'Malley PG. Relationship between depression and C-reactive protein in a screening population. Psychosom Med. 2004; 66: 679-83.

129. Visser M, Bouter LM, McQuillan GM. Elevated C-reactive protein levels in overweight and obese adults. JAMA. 1999; 282 (22):2131-5.

130. Almeida OP, Norman P, Hankey GJ, Jamrozik K, Flicker L. The association between C-reactive protein concentration and depression in later life is due to poor physical health: results from the Health in Men Study (HIMS). Psychological Medicine. 2007; 37: 1775-86. 
131. Koponen H, Jokelainen J, Keinanen-Kiukaanniemi S, Vanhala M. Depressive symptoms and 10-year risk for cardiovascular morbidity and mortality. World J Biol Psychiatry. 2010;11(6):834-9.

132. Viana MC, Teixeira MG, Beraldi F, Bassani IS, Andrade LH. São Paulo Megacity Mental Health Survey - a population-based epidemiological study of psychiatric morbidity in the São Paulo Metropolitan Area: aims, design and field implementation. Rev Bras Psiquiatr. 2009;31(4):375-86.

133. Centers for Disease Control and Prevention (CDC). National Center for Health Statistics (NCHS). National Health and Nutrition Examination Survey Data. Anthropometry procedures manual. Hyattsville, MD: U.S. Department of Health and Human Services, Centers for Disease Control and Prevention, 2004.

134. Kac G, Sichieri R, Gigante DP (org). Epidemiologia Nutricional. Rio de Janeiro: Editora Fiocruz / Atheneu, 2007.

135. World Health Organization. Physical status: the use and interpretation of anthropometry. Report of a WHO Expert Committee. World Health Organ Tech Rep Ser. 1995; 854:1-452.

136. Matsudo S, Araújo T, Matsudo V, Andrade D, Andrade E, Oliveira LC, Braggion G. Questionário Internacional de Atividade Física (IPAQ): estudo de validade e reprodutibilidade no Brasil. Rev Bras Ativ Fís Saúde. 2001;6:5-18.

137. Barros MVG, Nahas MV. Reprodutibilidade (teste-reteste) do questionário internacional de atividade física (QIAF - versão 6): um estudo piloto com adultos no Brasil. Rev Bras Ciên e Mov Brasília. 2000:8(1):23-6.

138. Zanarini MC, Frankenburg FR. Attainment and maintenance of reliability of axis I and axis II disorders over the course of a longitudinal study. Comprehensive Psych. 2001;42(5):369-74.

139. Shear MK, Greeno C, Kang J. Diagnosis of nonpsychotic patients in community clinics. Am J Psychiatry. 2000;157:581-7.

140. Steiner JL, Tebes JK, Sledge WH. A comparison of the structured clinical interview for DSM-III-R and clinical diagnoses. J Nerv Ment Dis. 1995;183(6):365-9. 
141. American Psychiatric Association: Diagnostic and Statistical Manual of Mental Disorders. 4th ed. Washington, DC: American Psychiatric Association, 1994.

142. Kessler RC, Angermeyer M, Anthony JC, De Graaf R, Demyttenaere K, Gasquet I, Girolamo G, Gluzman S, Gureje O, Haro JM, Kawakami N, Karam A, Levinson D, Mora MEM, Browne MAO, Posada-Villa J, Stein DJ et al. for the WHO World Mental Health Survey Consortium. Lifetime prevalence and age-of-onset distributions of mental disorders in the World Health Organization's World Mental Health Survey Initiative. World Psychiatry. 2007;6:168-76.

143. Almeida Filho N, Lessa I, Magalhães L, Araújo MJ, Aquino E, James AS, Kawachi I. Social inequality and depressive disorders in Bahia, Brazil: interactions of gender, ethnicity, and social class. Social Science \& Medicine. 2004;54:1339-53.

144. Andrade L, Walters EE, Gentil V, Laurenti R. Prevalence of ICD-10 mental disorders in a catchment area in the city of São Paulo, Brazil. Soc Psychiatry Psychiatr Epidemiol. 2002;37:316-25.

145. World Health Organization. The European health report 2002. World Health Organization: 2002.

146. Grant BF, Hasin DS, Chou P, Stinson FS, Dawson DA. Nicotine dependence and psychiatric disorders in the United States. Arch Gen Psychiatry. 2004;61:1107-15.

147. Cougle JR, Zvolensky MJ, Fitch KE, Sachs-Ericsson N. The role of comorbidity in explaining the association between anxiety disorders and smoking. Nicotine \& Tobacco Research. 2010;12(4):355-64.

148. Brasil. Ministério da Saúde. Secretaria de Vigilância em Saúde. Secretaria de Gestão Estratégica e Participativa. Vigitel Brasil 2007: vigilância de fatores de risco e proteção para doenças crônicas por inquérito telefônico. Ministério da Saúde, Secretaria de Vigilância em Saúde, Secretaria de Gestão Estratégica e Participativa. - Brasília: Ministério da Saúde, 2009.

149. Stringhini S, Dugravot A, Shipley M, Goldberg M, Zins M, Kivimaki M, Marmot M, Sabia S, Singh-Manoux A. Health behaviours, socioeconomic status, and mortality: further analyses of the British Whitehall II and the French GAZEL prospective cohorts. PLoS Medicine. 2011;8(2):e10000419. 
150. US Department of Health and Human Services. 2008 Physical activity guidelines for americans. US Department of Health and Human Services. Disponível em http://www. health.gov/paguidelines/. Acesso em 11 de junho de 2011.

151. Pedersen BK. Body mass index-independent effect of fitness and physical activity for all-cause mortality. Scand J Med Sci Sports. 2007;17:196-204.

152. Peluso MAM e Andrade LHSG. Physical activity and mental health: the association between exercise and mood. Clinics. 2005;60 (1):61-70.

153. Wise LA, Adams-Campbell LL, Palmer JR, Rosenberg L. Leisure time physical activity in relation to depressive symptoms in the Black Women's Health Study. Ann Behav Med. 2006;32(1):68-76.

154. Rethrost CD, Wipfli BM, Landres DM. The antidepressive effects of exercise: a metaanalysis of randomized trials. Sports Med. 2009;39(6):491-511.

155. Reis HFC, Ladeia AMT, Passos EC, Santos FGO, Wasconcellos LT, Correia LCL, Menezes MS, Santos RDG, Bonfim VG, Rocha MS. Prevalência e variáveis associadas a inatividade física em indivíduos de alto e baixo nível sócio-econômico. Arq Bras Cardiol. 2009;92(3):203-8.

156. Viebig RF, Valero MP, Araújo F, Yamada AT, Mansur AJ. Perfil de saúde cardiovascular de uma população adulta da região metropolitana de São Paulo. Arq Bras Cardiol. 2006;86 (5): 353-60.

157. Zaitune MPA, Barros MBA, César CLG, Carandina L, Goldbaum M, Alves MCGP. Fatores associados a prática de atividade física global e de lazer em idosos: Inquérito de Saúde no Estado de São Paulo (ISA-SP), Brasil. Cad Saúde Pública. 2010;26(8):1606-18.

158. Zanchetta LM, Barros MBA, César CLG, Carandina L, Goldbaum M, Alves MCGP. Inatividade física e fatores associados em adultos, São Paulo, Brasil. Rev Bras Epidemiol. 2010;13(3):387-99.

159. Pagoto SL, Ma Y, Bodenlos JS, Olendzki B, Rosal MC, Tellez T, Merriam P, Ockene IS. Association of depressive symptoms and lifestyle behaviours among latinos at risk of type 2 diabetes. J Am Diet Assoc. 2009;109(7):1246-50. 
160. Everson-Rose SA, Lewis TT, Karavolos K, Dugan SA, Wesley D Powell LH. Depressive symptoms and increased visceral fat in middle-aged women. Psychosom Med. 2009;71:410-6.

161. Eskandari F, Mistry S, Martinez PE, Torvik S, Kotila C, Sebring N, Drinkard BE, Levy C, Reynolds JC, Csako G, Gold PW, Horne M, Cizza G. Younger, premenopausal women with major depressive disorder have more abdominal fat and increased serum levels of prothrombotic factors: implications for greater cardiovascular risk. Metabolism. 2005;54(7):918-924.

162. Konttinen H, Silventoinen K, Sarlio-Lahteenkorva S, Mannisto S, Haukkala A. Emotional eating and physical activity self-efficacy as pathways in the association between depressive symptoms and adiposity indicators. Am J Clin Nutr. 2010;92:1031-9.

163. Gigante DP, Moura EC, Sardinha LMV. Prevalência de excesso de peso e obesidade e fatores associados, Brasil, 2006. Rev Saúde Pública. 2009;43(supl2):83-89.

164. Goulart AC. Obesidade e fatores associados numa amostra de mulheres em área de exclusão social, na cidade de São Paulo: correlação com índices antropométricos. Tese de doutorado. São Paulo: Faculdade de Medicina, Universidade de São Paulo, 2005.

165. Sociedade Brasileira de Cardiologia/ Sociedade Brasileira de Hipertensão/ Sociedade Brasileira de Nefrologia.. VI Diretrizes Brasileiras de Hipertensão. Arq Bras Cardiol. 2010;95(supl 1):1-51.

166. Engum A. The role of depression and anxiety in onset of diabetes in a large populationbased study. J Psychosom Res. 2007;62:31-8.

167. Andersohn F, Schade R, Suissa S, Garbe E. Long-term use of antidepressants for depressive disorders and the risk of diabetes mellitus. Am J Psychiatry. 2009;166:591-8.

168. Timonen M, Rajala U, Jokelainen J, Keinanen-Kiukaanniemi S, Meyer-Rochow VB, Rasanen P. Depressive symptoms and insulin resistance in young adult males: results from the Morthern Finland 1966 birth cohort. Molecular Psychiatry. 2006;11:929-33.

169. Wei F, Crain AL, Whitebird RR, Godlevsky OV, O'Connor PJ. Effects of paroxetine and sertraline on low-density lipoprotein cholesterol: an observational cohort study. CNS Drugs. 2009;23(10):857-65. 
170. Stern MP, Williams K, González-Villalpando C, Hunt KJ, Haffner SM. Does the metabolic syndrome improve identification of individuals at risk of type 2 diabetes and/or cardiovascular disease? Diabetes Care. 2004;27(11):2676-81.

171. Herva A, Rasanen P, Miettunen J, Timonen M, Laksy K, Veijola J, Laitinen J, Ruokonen A. Co-ocurrence of metabolic syndrome with depression and anxiety in Young adults: the Northern Finland 1966 Birth Cohort Study. Psychosom Med. 2006;68:213-6.

172. Hildrum B, Mykletun A, Midthjell K, Ismail K, Dahl AA. No association of depression and anxiety with the metabolic syndrome: the Norwegian HUNT study. Acta Psychiatr Scand. 2009;120:14-22.

173. van Reedt Dortland AKB, Giltay EJ, van Veen T, Zitman FG, Penninx BWJH. Metabolic syndrome abnormalities are associated with severity of anxiety and depression and with tricyclic antidepressant use. Acta Psychiatr Scand. 2010;122:30-9.

174. Baune BT, Neuhauser H, Ellert U, Berger K. The role of the inflammatory markers ferritin, transferrin and fibrinogen in the relationship between major depression and cardiovascular disorders: the German Health Interview and Examination Survey. Acta Psychiatr Scand. 2010;121:135-42.

175. Podlipny J, Hess Z, Vrzalová J, Rosolová H, Beran J, Petrlová B. Lower serum levels of interleukin-6 in a population sample in symptoms of depression than in a population sample without symptoms of depression. Physiol Res. 2010;59:121-26.

176. Jin H, Folsom D, Sasaki A, Mudaliar S, Henry R, Torres M, Golshan S, Glorioso DK, Jeste D. Increased Framingham 10-year risk of coronary heart disease in middle-aged and older patients with psychotic symptoms. Schizophrenia Research. 2011;125:295-9.

177. Goff DC, Sullivan LM, McEvoy JP, Meyer JM, Nasrallah HA, Daumit GL, Lamberti S, D'Agostino JM, Stroup TS, Davis S, Lieberman JA. A comparison of ten-year cardiac risk estimates in schizophrenia patients from the CATIE study and matched controls. Schizophrenia Research. 2005;80:45-53.

178. Koponen H, Jokelainen J, Keinanen-Kiukaanniemi S, Vanhala M. Depressive symptoms and 10-year risk for cardiovascular morbidity and mortality. World J Biol Psychiatry. 2010;11(6):834-9. 
179. Ministério do Planejamento, Orçamento e Gestão. Intituto Brasileiro de Geografia e Estatística. Pesquisa Nacional por Amostra de Domicílios 2009: síntese de indicadores. Ministério do Planejamento, Orçamento e Gestão, Intituto Brasileiro de Geografia e Estatística. - Brasília, 2009. Disponível em: http://www.ibge.gov.br/home/estatistica/ populacao/trabalhoerendimento/pnad2009/default.shtm. Acesso em 26 de junho de 2011.

180. Akhtar-Danesh N, Landeen J. Relation between depression and sociodemografic factors. International Journal of Mental Health Systems. 2007;1:4 doi:10.1186/1752-4458-1-4.

181. Pinheiro RS, Viacava F, Travassos C, Brito AS. Gênero, morbidade, acesso e utilização de serviços no Brasil. Ciência \& Saúde Coletiva. 2002;7(4): 687-707.

182. Travassos C, Viacava F, Pinheiro R, Brito A. Utilização dos serviços de saúde no Brasil: gênero, características familiares e condição social. Rev Panam Salud Publica. 2002;11(5/6):365-373.

183. Guia trabalhista (site disponível na internet). Disponível em: http://www. guiatrabalhista.com.br/guia/salario minimo.htm. Acesso em 11/junho/2011. 
Impresso em julho de 2011. 